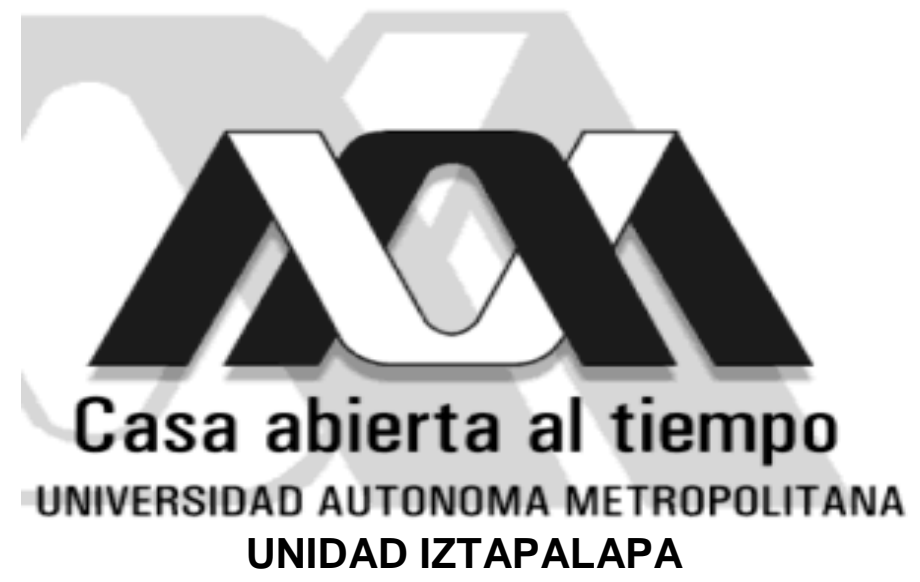

TESIS DE DOCTORADO TITULADA:

"SIMULACION Y CONTROL DEL PROCESO DE CRISTALIZACION DE AZUCAR DE CAÑA POR LOTES A VACIO CON UN ENFOQUE DE DISEÑO DIRECTO"

TESIS QUE PRESENTA

M.C. OSCAR VELAZQUEZ CAMILO

PARA OBTENER EL GRADO DE

DOCTOR EN CIENCIAS EN INGENIERIA QUIMICA

ASESORES:

Dr. JOSE DE JESUS ALVAREZ RAMIREZ Dr. EUSEBIO BOLAÑOS REYNOSO

Departamento de Ingeniería de Procesos e Hidráulica

División de Ciencias Básicas e Ingeniería

Universidad Autónoma Metropolitana - Iztapalapa

Av. Michoacán y Purísima s/n, Col. Vicentina, C.P. 09340

Cd. México, D.F., México

Octubre 2010 


\title{
SIMULACIÓN Y CONTROL DEL PROCESO DE CRISTALIZACIÓN DE AZÚCAR DE CAÑA POR LOTES A VACÍO CON UN ENFOQUE DE DISEÑO DIRECTO
}

\author{
Tesis que presenta \\ Oscar Velázquez Camilo \\ Para obtener el grado de \\ Doctor en Ciencias en Ingeniería Química
}

Asesores: Dr. José de Jesús Álvarez Ramírez

Dr. Eusebio Bolaños Reynoso

\section{Jurado Calificador:}

Presidente: Dr. Mario Gonzalo Vizcarra Mendoza

(UAM-I)

Secretario: Dr. Juan Carlos Echeverría Arjonilla

Vocal: Dr. Eusebio Bolaños Reynoso

(I.T.O.)

Vocal: $\quad$ Dr. Pedro Alberto Quintana Hernández

(I.T.C.)

Vocal:

Dr. Héctor Fernando Puebla Núñez

(UAM-A)

México D. F. a 15 de Octubre de 2010 


\section{Agradecimientos}

$\mathcal{A}$ aquel que ha de venir en breve y según algunos lo tienen por tardanza, porque siempre ha estado conmigo para guiarme con su amor y sabiduría, gracias eternamente mi grande amigo Jesucristo.

$\mathcal{A}$ mis dos preciosas Alondra M. Rosas Díaz y Stephanie Velázquez Rosas, y a mi campeón Oscar Zuriel Velázquez Rosas porque son parte de la fuerza que da sentido a mi vida.

A mis padres $C$. Oscar Velázquez Rincón y Zoila E. Camilo Reyes, y a mi suegra María de los Ángeles Díaz Hernández porque siempre me han apoyado incondicionalmente.

A mis asesores Dr. José de Jesús Álvarez Ramírez y Dr. Eusebio Bolaños Reynoso por la dirección en el presente trabajo y porque muchas veces más que asesores han sido mis amigos.

$\mathcal{A} E$ duardo Rodríguez por compartir conmigo sus conocimientos y por todo el apoyo Grindado y su amistad.

Al Honorable Jurado por su interés y valiosos comentarios que ayudaron a mejorar la calidad del presente trabajo:
Dr. José de Jesús Álvarez Ramírez
Dr. Eusebio Bolaños Reynoso
Dr. Mario Gonzalo Vizcarra Mendoza
Dr. Juan Carlos Echeverría Arjonilla
Dr. Pedro Alberto Quintana Hernández
Dr. Héctor Fernando Puebla Núñez

$\mathcal{A}$ mis amigos del Laboratorio de Plantas Pilotos (área cristalización) con los que he convivido en esta etapa de mi vida y disfrutado del trabajo en equipo (Eder $\mathcal{B}$. Páez G., Luis J. López F., Josué Alvarado S., Antonio Arenas R., Euclides Juárez J., Teresita de Jesús de Debernardi, Diana J. Cruz V., Aldo Guzmán, Miguel Teco X., A6di A. Antonio, Blanca Janet Montieh, Amira Antonio A., Oscar J., Alberto I. , Victor H. Vallejo Roman, Jonathan C.Salcedo Montieh, Arturo Solís, Mariana Molina , Yuridia Solís Galán, Alma G. Villa Victoria y SahadaG. Romero R.). 
A Ia VAMM-Iztapalapa y al I.T. Oriza6a, y a sus profesores que me han apoyado en la formación de esta etapa de mi vida como un futuro investigador.

Al COSACYT por su apoyo económico que hizo posible la realización de este trabajo de investigación y culminación de los estudios doctorales.

Al Fondo Mixto CONACYT - Gobierno del Estado de Veracruz, por el apoyo económico otorgado mediante el proyecto "Estrategias de control de la sobresaturación en cristalizadores 6atch (tachos) para la minimización de sacarosa en mieles de azúcar de caña a través de regulación de vacío", con clave 37571, en el Instituto Tecnológico de Orizaba.

Finalmente pero con la misma importancia a mis amigos y hermanos con los cuales he convivido gran parte de esta etapa de mi vida los cuales he disfrutado mucho. Sería dificil mencionar a todos por lo que omitiré nombres, sabiendo de antemano que mis verdaderos amigos han de sentirse aludidos. 


\section{RESUMEN}

La industria azucarera en México actualmente no cuenta con sistemas de control eficientes en sus procesos para obtener productos con Distribución de Tamaño de Cristal (DTC) especifica, e incluso en algunos ingenios azucareros aún se sigue laborando con personal que mide de forma cualitativa y empírica la DTC en el lote, dando como consecuencia un producto con alta variabilidad. Por ello se ha desarrollado esta investigación para dar solución a una de las problemáticas de la industria azucarera en México: el manejo y control de la sobresaturación en la primera zona metaestable de la cristalización de mieles en el área de refinado. Para lo anterior se ha implementado una estrategia de tipo C-Control con un enfoque de diseño directo el cual está basado en el estudio de las zonas metaestables para la identificación de una región de operación que permita favorecer el crecimiento de cristales (sembrados) y evitar la nucleación espontanea. En la bibliografía existen muchos estudios que aplican un enfoque de primeros principios a partir de modelos matemáticos basados en balances de materia, energía y población, con el objetivo de optimizar algunas variables cuantitativas o cualitativas del proceso (DTC, masa de cristales, densidad, temperatura, presión de vacío, etc.), pero en cristalización el enfoque del diseño directo, ha sido poco estudiado a nivel planta piloto, lo anterior se debe principalmente a la dificultad de tener laboratorios con equipos sofisticados o al costo elevado de realizar experimentos en planta. Con la planta piloto ubicada en la División de Estudios de Posgrado e Investigación del Instituto Tecnológico de Orizaba, fue factible implementar la estrategia C-Control de la sobresaturación con enfoque del diseño directo para evaluar experimentalmente y modelar los límites de las zonas de concentración (zona insaturación, primer y segunda zona metaestable y zona lábil) en la cristalización de azúcar de caña en términos de densidad, encontrándose que el ancho de las zonas aumenta de forma no lineal conforme la temperatura de saturación disminuye en un rango de 70 a $40{ }^{\circ} \mathrm{C}$, lo cual es discordante con lo reportado en la literatura actual en donde se considera que para este mismo rango de enfriamiento el ancho de las zonas metaestables para una solución de azúcar de caña permanecen constantes (lineales). También se estableció la cinética de crecimiento del cristal a través de los límites. 
También se estudió mediante simulación dinámica el comportamiento en estado estático de cristalizadores continuos tipo tanque agitado. A pesar de que la sustancia de trabajo en este estudio fue sulfato de amonio-agua (sistema polar con transferencia de masa rápida) y no azúcar de caña-agua (sistema no polar con transferencia de masa lenta), el ejercicio de simulación fue el primer acercamiento en el estudio de la cristalización, en donde a partir de los resultados obtenidos por simulación dinámica se pudo inferir que si se deseaba controlar la sobresaturación, era necesario obtener las curvas de concentración de equilibrio y/o metaestables. Los sistemas de cristalización en continuo en donde su respuesta transiente se ha estabilizado, no presentan variaciones significativas en la sobresaturación del sistema, lo que origina cristales homogéneos de tamaño aceptable. Sin embargo, la operación en continuo bajo ciertas condiciones de operación (concentración de alimentación, temperatura y tiempo de residencia) y en especial para tiempos de residencia grandes es altamente inestable y difícil de ser controlada.

Otro estudio realizado en este trabajo consistió en el uso de un método de análisis fractal (análisis de fluctuación con remoción de tendencia (DFA) por sus siglas en ingles), para el estudio de patrones en el crecimiento de los cristales fijando como variable de estudio el diámetro promedio relativo al volumen $(\mathrm{D}(4,3))$. El estudio se enfocó en el exponente de escalamiento y la dimensión fractal másica para dar seguimiento a la cristalización, encontrándose que existe una relación entre el $\mathrm{D}(4,3)$ y la dimensión fractal másica. Estos resultados proporcionaron un seguimiento de la evolución de la cristalización, incluyendo los efectos del crecimiento durante el periodo inicial y la posible ocurrencia de enucleación secundaria y mecanismos de atrición debidos a cambios en el modo de operación y densidad alta de cristales formados. Usando este método también es posible definir o visualizar los límites de concentración metaestables. 
Resumen $\quad$ i

Índice iii

Lista de figuras vii

Lista de tablas $\quad$ xii

Capítulo 1. Introducción 1

1.1 Objetivos 5

1.1.1 Objetivo general 5

1.1.2 Objetivos particulares 5

1.2 Justificación 5

$\begin{array}{lll}1.3 & \text { Organización de la tesis } & 7\end{array}$

Capítulo 2. Evaluación experimental de las zonas de concentración en la 9 cristalización de azúcar de caña usando adquisición de datos e imágenes

2.1 Resumen 9

2.2 Introducción 9

2.3 Metodología 11

2.3.1 Infraestructura 11

2.3.2 Sistema de adquisición de datos e imágenes 12

2.3.3 Manipulación de la sobresaturación 13

2.3.4 Obtención de la línea de saturación 15

2.3.5 Obtención de los límites de las zonas metaestable y lábil 16

2.3.6 Obtención de las cinéticas de crecimiento 17

$\begin{array}{lll}2.4 & \text { Resultados } & 19\end{array}$

2.4.1 Línea de saturación o equilibrio 19

2.4.2 Análisis de la concentración promedio en función de temperaturas 20 de enfriamiento

2.4.3 Análisis de la distribución de tamaño de cristal y secuencias 22 micrográficas 
2.4.4 Límites de las zonas metaestable y lábil 29

2.4.5 Modelado de los límites de concentración 30

2.4.6 Cinética de crecimiento 31

2.5 Conclusiones 34

Capítulo 3. Control de la sobresaturación de azúcar de caña en un 36 cristalizador por lotes a vacío

3.1 Resumen 36

3.2 Introducción 36

3.3 Metodología 38

3.3.1 Infraestructura 38

3.3.2 Sistema de adquisición de datos e imágenes 39

3.3.3 Estrategia de control C-control (C-T) 41

3.3.4 Condiciones iniciales del proceso 44

3.4 Resultados 44

3.4.1 Identificación de las variables del proceso 44

3.4.2 Análisis a lazo abierto 46

3.4.3 Obtención del modelo matemático de la concentración en el 50 cristalizador por lotes a vacío

3.4.4 Análisis a lazo cerrado $\quad 53$

3.5 Conclusiones 66

Capítulo 4. Análisis comparativo de la dinámica de un cristalizador continuo 68 tipo tanque agitado: casos isotérmico y por enfriamiento

$\begin{array}{lll}4.1 & \text { Resumen } & 68\end{array}$

4.2 Introducción 69

$\begin{array}{lll}4.3 & \text { Caso isotérmico } & 70\end{array}$

4.3.1 Modelo matemático para la operación isotérmica 70

4.3.2 Análisis dinámico y estático del proceso a lazo abierto para la 71 operación isotérmica 
4.3.3 Control bajo operación isotérmica 75

$\begin{array}{lll}4.4 & \text { Caso por enfriamiento } & 77\end{array}$

4.4.1 Modelo matemático para la operación por enfriamiento 77

4.4.2 Análisis estático del proceso a lazo abierto para la operación por 78 enfriamiento

4.4.3 Control bajo operación por enfriamiento 80

$\begin{array}{lll}4.5 & \text { Conclusiones } & 81\end{array}$

Capítulo 5. Análisis fractal de imágenes adquiridas de la cristalización de 83 azúcar de caña

5.1 Resumen 83

5.2 Introducción 83

5.3 Metodología 86

5.3.1 Infraestructura 86

5.3.2 Sistema de adquisición de imagen 87

5.3.3 Condiciones de operación 87

5.3.4 Concepto de geometría fractal 88

5.3.5 Método de análisis fractal: Análisis de fluctuación con remoción $\quad 89$ de la tendencia (DFA)

5.4 Resultados 92

$\begin{array}{lll}5.5 & \text { Conclusiones } & 102\end{array}$

$\begin{array}{ll}\text { Conclusiones y perspectivas } & 104\end{array}$

$\begin{array}{ll}\text { Bibliografía } & 106\end{array}$

APÉNDICE A 112

A.1 Ejecución del programa IMAQ visión builder 112

A.2 Ejecución del programa DTC aqd-im para el cálculo de la DTC 113 
B.1 Verificación de la ecuación de Moncada y Rodríguez para la línea de saturación en términos de densidad

B.2 Datos experimentales para la obtención de las densidades promedios

B.3 Resultados experimentales para la obtención de la DTC promedio y DTC más representativa

\section{APÉNDICE C}

C.1 Panel de control principal, pestañas secundarias y diagramas de bloques

C.2 Programación de válvulas proporcionales para un proceso con dinámica lenta 
Figura

Nombre de la figura

página

2.1 Cristalizador por lotes de vidrio por enfriamiento de contacto directo.

2.2 Determinación de la línea de saturación en términos de densidad.

2.3 Promedio de los resultados experimentales (densidad vs. Temperatura).

2.4 DTC tipo log-normal en \% volumen para soluciones saturadas a diferentes temperaturas. a) $40^{\circ} \mathrm{C}$, b) $50{ }^{\circ} \mathrm{C}$, c) $60^{\circ} \mathrm{C}$ y d) $70^{\circ} \mathrm{C}$.

2.5 Secuencia micrográfica de la producción y crecimiento de núcleos 25 para una solución saturada a $40^{\circ} \mathrm{C}$. a) primera zona metaestable (40$\left.37^{\circ} \mathrm{C}\right)$, b) segunda zona metaestable $\left(36-33^{\circ} \mathrm{C}\right)$ y c) zona inestable (32 ${ }^{\circ} \mathrm{C}$ o menor).

2.6 Secuencia micrográfica de la producción y crecimiento de núcleos para una solución saturada a $50^{\circ} \mathrm{C}$. a) primera zona metaestable (50$\left.48^{\circ} \mathrm{C}\right)$, b) segunda zona metaestable $\left(47-45^{\circ} \mathrm{C}\right)$ y c) zona inestable (44 ${ }^{\circ} \mathrm{C}$ o menor).

2.7 Secuencia micrográfica de la producción y crecimiento de núcleos para una solución saturada a $60^{\circ} \mathrm{C}$. a) primera zona metaestable (60$\left.59^{\circ} \mathrm{C}\right)$, b) segunda zona metaestable $\left(58-56^{\circ} \mathrm{C}\right)$ y c) zona inestable (55 ${ }^{\circ} \mathrm{C}$ o menor).

2.8 Secuencia micrográfica de la producción y crecimiento de núcleos 28 para una solución saturada a $70^{\circ} \mathrm{C}$. a) primera zona metaestable (70$\left.67^{\circ} \mathrm{C}\right)$, b) segunda zona metaestable $\left(66-65^{\circ} \mathrm{C}\right)$ y c) zona inestable (64 ${ }^{\circ} \mathrm{C}$ o menor).

2.9 Identificación de los puntos críticos en un diagrama de 30 concentración - temperatura.

2.10 Cinética de crecimiento para cada solución saturada.

2.11 Cinética de crecimiento para una solución saturada a $70^{\circ} \mathrm{C}$.

3.1 Cristalizador por lotes a vacío.

3.2 Panel de control principal de un cristalizador por lotes a vacío usando sistema SCADA. 
3.3 Variables relevantes del proceso de cristalización por lotes a vacío. $\quad 45$

3.4 Temperatura de equilibrio con respecto a la presión de vacío. 46

3.5 Respuesta del proceso a lazo abierto. a) densidad, b) presión de vacío y c) temperatura del interior del cristalizador.

3.6 Diagrama concentración-temperatura a lazo abierto. $\quad 48$

3.7 Temperaturas del sistema a lazo abierto. $\quad 49$

3.8 Curva de reacción de la concentración en el cristalizador por lotes a 51 vacío.

3.9 Setpoint de concentración-temperatura. 53

3.10 Respuestas del sistema (corrida 1). a) temperaturas, b) presión de 55 vacío, c) densidad y d) diagrama concentración-temperatura.

3.11 Respuestas del sistema (corrida 2). a) temperaturas, b) presión de 56 vacío, c) densidad y d) diagrama concentración-temperatura.

3.12 Respuestas del sistema (corrida 3). a) temperaturas, b) presión de vacío, c) densidad y d) diagrama concentración-temperatura.

3.13 Comparativa de la densidad en un diagrama concentracióntemperatura.

3.14 Comparativas de respuestas experimentales. a) $\mathrm{D}(4,3)$ y b) $\mathrm{S}(4,3)$. 60

3.15 DTC tipo log-normal en \% volumen de la corrida 1. 61

3.16 Micrografías de la corrida 1. a) $\min 0$, b) $\min 10.4$, c) $\min 67$, d) 62 $\min 128.7$ y e) $\min 149.5$

3.17 DTC tipo log-normal en \% volumen de la corrida 2.

3.18 Micrografías de la corrida 2. a) min 0, b) min 9.4, c) min 63.6, d) 63 $\min 126$ y e) $\min 186$

3.19 DTC tipo log-normal en \% volumen de la corrida 3. 64

3.20 Micrografías de la corrida 3. a) $\min 0$, b) $\min 9.4$, c) $\min 60$, d) $\min \quad 65$ 120.7 y e) $\min 175.6$

3.21 Comparativa de técnicas de enfriamiento y control de la 66 sobresaturación en un diagrama de concentración-temperatura y limites metaestables. 
4.1 Respuesta del proceso (concentración del soluto) a lazo abierto para diferentes tiempos de residencia.

4.2 Respuesta del proceso $(\mathrm{D}(4,3))$ a lazo abierto para diferentes tiempos de residencia.

4.3 Respuesta estática de $\mathrm{D}(4,3)$ sobre la zona de ciclos límites para la operación isotérmica.

4.4 Estudio estático de $\mathrm{D}(4,3)$ sobre las zonas de alta y baja sensibilidad.

4.5 Respuesta del proceso a lazo abierto (operación isotérmica con $\tau=0.3 \mathrm{hr})$.

4.6 Respuesta del proceso a lazo cerrado (operación isotérmica con $\tau=0.3 \mathrm{hr})$.

4.7 Estudio estático de $\mathrm{D}(4,3)$ sobre la zona de ciclos límites para la operación por enfriamiento.

4.8 Respuesta del proceso a lazo abierto (operación por enfriamiento con $\tau=0.2 \mathrm{hr})$.

4.9 Respuesta del proceso a lazo cerrado (operación por enfriamiento con $\tau=0.2 \mathrm{hr})$.

5.1 Secuencia de imágenes tomadas a diferentes tiempos del proceso. a) 10 min, b) 20 min, c) 55 min y d) 83 min.

5.2 Concepto matemático fractal.

5.3 Variables del proceso. a) temperatura interior y presión de vacío, b) densidad experimental en un diagrama concentración-temperatura, c) masa de cristal formado (MCF) y d) $\mathrm{D}(4,3)$ y $\mathrm{S}(4,3)$ obtenida de la DTC de tipo log-normal en \% volumen.

5.4 Exponente de escalamiento $\alpha$ para las imágenes en escala de grises en la Figura 5.1.

5.5 Imágenes binarizadas con valor del umbral de $\gamma=75$ correspondientes a la Figura 5.1.

5.6 Exponente de escalamiento como una función del valor del umbral. 96

5.7 Resultados del DFA para las imágenes de la Figura 5.4. 
5.8 Exponente de escalamiento en función del tiempo de cristalización.

a) $\gamma=50$, b) $\gamma=70$ y c) $\gamma=90$

5.9 Imagen binarizada para el minuto 20. a) $\gamma=50$ y b) $\gamma=70$

5.10 Dimensión fractal másica para los tres valores de umbral 100 presentados en la Figura 5.7.

5.11 Exponente de escalamiento (a) y dimensión fractal másica (b), en 101 función del diámetro promedio relativo al volumen $\mathrm{D}(4,3)$.

A.1 Ventana de inicio del sistema de adquisición de imágenes (IMAQ).

A.2 Ventana para guardar una imagen mediante el sistema de adquisición de imágenes (IMAQ).

A.3 Ventana principal del programa DTC Adq-im (Córdova 2004).

A.4 Ventana de ingreso de datos en el programa DTC Adq-im (Córdova, 2004).

A.5 Ventana de resultados del programa DTC Adq-Im (Córdova, 2004).

B.1 Línea de saturación corregida en el punto de saturación a $40{ }^{\circ} \mathrm{C}$.

B.2 Comparación entre las líneas de saturación corregida en el punto de saturación a $40{ }^{\circ} \mathrm{C}$ y la línea de saturación obtenida por Solís y Villa (2008).

B.3 Resultados experimentales de la densidad con respecto a la temperatura. a) solución saturada a $40^{\circ} \mathrm{C}$, b) solución saturada a $50^{\circ} \mathrm{C}$, c) solución saturada $60^{\circ} \mathrm{C}$ y d) solución saturada a $70^{\circ} \mathrm{C}$.

B.4 DTC en \% Volumen para una solución saturada a $70^{\circ} \mathrm{C}$. a) prueba 1 , b) réplica 1, c) réplica 2 y d) Promedios de las DTC.

B.5 DTC en \% Volumen para una solución saturada a $60^{\circ} \mathrm{C}$. a) prueba 1 , b) réplica 1, c) réplica 2 y d) promedios de las DTC.

B.6 DTC en \% Volumen para una solución saturada a $50^{\circ} \mathrm{C}$. a) prueba 1 , b) réplica 1, c) réplica 2 y d) promedios de las DTC.

B.7 DTC en \% Volumen para una solución saturada a $40^{\circ} \mathrm{C}$. a) prueba 1 , b) réplica 1, c) réplica 2 y d) promedios de las DTC.

C.1 Panel de control principal.

C.2 Pestaña de concentración. 
C.3 Pestaña de la presión de vacío y respuesta de la válvula proporcional de vacío.

C.4 Pestaña de resultados (impresión de datos experimentales).

C.5 Diagrama de bloques para la implementación de los límites de concentración y adquisición la concentración con respecto a la temperatura del sistema.

C.6 Diagrama de bloques para la adquisición de datos del DMA-4500 vía puerto serial RS-232 (Basic Serial Write and Read.vi).

C.7 Diagrama de bloques para la manipulación y control de la velocidad de agitación, temperatura de equilibrio y setpoint de concentracióntemperatura.

C.8 Diagrama de bloques para la implementación de la estrategia CControl retroalimentado PID.

C.9 Diagrama de bloques para el control de la caldera y operación por enfriamiento.

C.10 Diagrama de bloques para la impresión de datos experimentales en un archivo de hoja de cálculo para el análisis de los estados del sistema.

C.11 Válvulas proporcionales con controlador digital electrónico. a) para vacío y b) para vapor.

C.12 Modo de configuración del controlador electrónico digital Burkert tipo 8605. 
Tabla

Nombre de la tabla

página

2.1 Dispositivos electrónicos del cristalizador por lotes de vidrio por enfriamiento de contacto directo.

2.2 Dispositivos electrónicos para el sistema de adquisición de datos e imágenes.

2.3 Preparación de las soluciones a cada temperatura de saturación para la obtención de la línea de equilibrio.

2.4 Preparación de las soluciones a cada temperatura de saturación para la obtención de las zonas metaestables e inestable.

2.5 Identificación de los puntos críticos.

2.6 Parámetros de los modelos cinéticos de crecimiento para las soluciones saturadas a $70,60,50$ and $40^{\circ} \mathrm{C}$.

3.1 Instrumentos y dispositivos electrónicos del cristalizador por lotes a vacío.

3.2 Dispositivos electrónicos para el sistema de adquisición de datos e 41 imágenes.

3.3 Ajuste de parámetros de sintonía usando razón de asentamiento de 54 un cuarto de Ziegler-Nichols.

4.1 Parámetros del proceso (Christofides et al., 2000).

4.2 Valores máximos de $\mathrm{D}(4,3)$ para diferentes tiempos de residencia.

B.1 Preparación de las soluciones en la obtención del punto de 118 saturación a $40{ }^{\circ} \mathrm{C}$.

12 7

\section{3} 5 
CAPÍTULO I

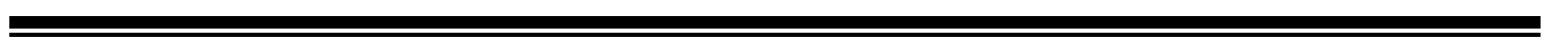




\section{Introducción}

La cristalización es una operación unitaria que consiste en purificar químicos orgánicos e inorgánicos mediante la separación sólido-líquido, en donde un componente de una solución sobresaturada es transferido a una fase sólida en forma de cristales que precipitan, obteniéndose la presencia de una fase continua y una fase dispersa que a su vez dan lugar a la presencia de fenómenos fisicoquímicos como la nucleación, crecimiento, atrición y muerte de los cristales. Los sistemas distribuidos son procesos con parámetros y estados que están variando espacialmente, en la cristalización las propiedades físicas y químicas del producto están distribuidas sobre la población de cristales (tamaño de los cristales, forma, morfología, porosidad y peso molecular), actualmente se sabe que las propiedades fisicoquímicas y mecánicas del producto en los procesos de cristalización son fuertemente dependientes de la Distribución de Tamaño de Cristales (DTC) (Ulrich 2003; Quintana-Hernandez et al., 2004; Shi et al., 2006; Velazquez-Camilo et al., 2009).

El potencial impulsor para que suceda la nucleación y/o el crecimiento del cristal es la sobresaturación la cual es función de la temperatura de enfriamiento, por lo que no habrá lugar para estos fenómenos en una solución saturada o insaturada (Jones, 2002). La cristalización posee gran importancia económica en la industria química, ya que se requiere menos energía para la separación/purificación que de lo que se utiliza en la destilación y otros métodos de purificación; además se puede obtener a partir de soluciones relativamente impuras en un sólo paso de procesamiento a temperaturas relativamente bajas y a una escala que varía desde unos cuantos gramos hasta miles de toneladas con purezas superiores al 99\%. Ésta también mejora la apariencia y hace más fácil su transporte (Perry, 2003; Geankoplis, 1998). La cristalización es ampliamente utilizada en la producción de azúcar, fertilizantes y productos farmacéuticos, entre otras industrias, teniendo como objetivo a nivel industrial que el producto tenga una DTC y pureza específica, en lugar de un producto aleatorio (Ulrich, 2003).

Los cristalizadores por lotes presentan la ventaja de ser simple, flexible y requiere de poca inversión. Sin embargo, comparado con la operación en continuo, el proceso por lotes opera bajo condiciones no controlables, obteniéndose un producto no uniforme 
(Srinivasakannan et al., 2002), por lo tanto, la cristalización por lotes debe ser operada bajo condiciones controlables. La mayoría de las industrias que utilizan el proceso de cristalización, no tienen un control satisfactorio sobre las variables de importancia por lo que el interés por el estudio en la simulación y control de esta operación está creciendo debido a la demanda de productos de mayor calidad con propiedades específicas, la necesidad de disminución del consumo de energía para evitar mermas (Bolaños, 2000). Actualmente la industria azucarera en México no cuenta con sistemas de control eficientes en sus procesos para obtener productos con DTC especifica, e incluso en algunos ingenios azucareros aún se sigue laborando con personal que mide de forma cualitativa y empírica la DTC en el lote, dando como consecuencia un producto con alta variabilidad. Por lo tanto cualquier intento por establecer un control en la DTC, requiere que las especificaciones de los productos, estén orientadas hacia la minimización de la nucleación espontánea y al incremento del tamaño del cristal, ya que la DTC y la Masa de Cristal Formado (MCF) dependerán de la interacción entre los fenómenos de nucleación y crecimiento de cristales.

El nivel de sobresaturación en cristalizadores por lotes a vacío (enfriamiento por evaporación adiabática) es determinado por el porcentaje de energía transferida, si la sobresaturación no es controlada adecuadamente para el crecimiento de los cristales existentes (sembrados), ésta se dirigirá a un punto en el que se origina la nucleación espontánea provocando un incremento indeseable en el número de núcleos. Un modo deseable de operación es aquel que cambia el porcentaje de enfriamiento por evaporación adiabática para llevar a cabo un gradiente de sobresaturación que beneficie el crecimiento de los cristales sembrados y minimice o inhiba la nucleación.

Se puede controlar la DTC en un cristalizador por lotes a vacío, empleando el método de siembra seguido por perfiles controlados de velocidad de enfriamiento o de evaporación adiabática y velocidad de agitación, los cuales están basados en sistemas de tipo T-Control (control mediante funciones indexadas dependientes del tiempo), sin embargo las tendencias tecnológicas en el campo de la cristalización refieren que los sistemas C-Control (control de concentración independiente del tiempo) son superiores a los sistemas tradicionales T-Control, por lo que si se desea obtener un control adecuado sobre la sobresaturación del sistema es 
necesario la implementación de un sistema C-Control (Calderon-De-Anda et al., 2005; Wang et al., 2007). El objetivo de este sistema de control es obtener cristales sólo de las semillas sembradas al inicio de la sobresaturación, cuando ésta se encuentra dentro de la primera zona metaestable, dichas semillas deben ser de un tamaño uniforme (Genck, 2000; Lang et al., 1999). Aunque la mayoría de los lazos operan de forma continua con puntos de control fijos, en procesos por lotes pueden producirse cambios frecuentes de puntos de control. El mecanismo más común para alcanzar ambos objetivos es el control retroalimentado, ya que es el más simple y el más aplicado en los procesos químicos (Stephanopoulos, 1984; Smith y Corripio, 1991).

El principal objetivo del presente trabajo consistió en el desarrollo e implementación de una estrategia de control de la sobresaturación para azúcar de caña refinada, se usó un enfoque de diseño directo, para evaluar experimentalmente y modelar los límites de las zonas de concentración en términos de densidad (zona insaturación, primer y segunda zona metaestable y zona lábil). El diseño del algoritmo de control fue de tipo C-Control para mantener la concentración de sobresaturación dentro de la primera zona metaestable, se aplicó un controlador Proporcional-Integral-Derivativo (PID) retroalimentado servo-regulador y las variables manipulables fueron: la presión de vacío (enfriamiento adiabático) y la temperatura en la chaqueta. Al controlar la sobresaturación dentro de la primera zona metaestable se busca asegurar que crezcan solamente los cristales sembrados para obtener mayor MCF y uniformidad en la DTC. También se implementó un sistema SCADA (Supervisory Control and Data Acquisition), en el que se desarrollaron instrumentos virtuales para adquirir y procesar datos provenientes de la planta (estados del sistema) en tiempo real con una interface gráfica programada con LabView ${ }^{\mathrm{TM}}$ de National Instruments Inc., (Velazquez-Camilo et al., 2010B).

Como trabajos secundarios se realizaron los siguientes estudios dentro del área de la cristalización:

Se caracterizó dinámicamente vía simulación un cristalizador continuo tipo tanque agitado en estado isotérmico y por enfriamiento. En este trabajo se estudiaron 
alternativas de operación y controlabilidad de este proceso. El modelo matemático del proceso se basó en el método de momentos. La metodología consistió en la implementación de un servocontrol SISO (única entrada-única salida) retroalimentado con controlador PID. Los parámetros de sintonía del controlador se obtuvieron con las estrategias de un modelo de control interno (IMC). La variable del proceso a controlar fue el diámetro promedio relativo en $\%$ volumen $\mathrm{D}(4,3)=\mu_{4} / \mu_{3}$, ya que es una variable muy usada en el ámbito comercial e industrial; la variable manipulable en el caso isotérmico ó por enfriamiento fue la concentración del soluto en la alimentación y la temperatura de enfriamiento, respectivamente. Del análisis estático se obtuvieron las zonas donde existe la presencia de ciclos límites y los valores de tiempos de residencia más favorables para operar y controlar la cristalización isotérmica y por enfriamiento. Se concluyó que el controlador PID retroalimentado implementado en los dos casos fue satisfactorio eliminando las desviaciones entre el punto de ajuste y la respuesta de la variable controlable (Velazquez-Camilo et al., 2009).

Debido a que a nivel industrial y científico se ha incrementado el uso y análisis de imágenes en línea/seudolinea para monitoreo de la evolución de la cristalización, se ha desarrollado un estudio basado en análisis fractal para cuantificar el grado de complejidad de la cristalización de azúcar de caña a diferentes tiempos del proceso. El principal objetivo de esta técnica es dar seguimiento al crecimiento del cristal a través de la cuantificación de los cambios de forma. Sin embargo, las imágenes micrográficas obtenidas directamente de la solución (slurry) muestran que los cristales no se encuentran aislados, sino que presentan un patrón complejo de cristales pequeños y grandes superpuestos de manera irregular. Para este fin, se usó el método de análisis de fluctuación con remoción de la tendencia (DFA) el cual provee un índice de exponente de escalamiento, para cuantificar el grado de complejidad ó estructura de similaridad de un patrón bidimensional irregular. Los resultados muestran que el exponente de escalamiento y la dimensión fractal másica de las imágenes proporcionan una visión o tendencia de la evolución del proceso de la cristalización (Velazquez-Camilo et al., 2010A). 


\subsection{Objetivos}

\subsubsection{Objetivo general}

Simular y controlar el proceso de cristalización de azúcar de caña refinada por lotes a vacío estableciendo una estrategia para obtener una DTC específica.

\subsubsection{Objetivos particulares}

1 Simular y caracterizar modelos matemáticos concernientes a la cristalización.

2 Estudiar e identificar los puntos críticos de las zonas insaturada, metaestable y lábil en la cristalización de azúcar de caña.

3 Modelar matemáticamente las zonas de concentración determinadas experimentalmente.

4 Desarrollar y configurar instrumentos virtuales para controlar la concentración dentro de la primera zona metaestable (enfoque de diseño directo) en un cristalizador a nivel planta piloto.

5 Efectuar la adquisición de datos del sistema (manipulación de actuadores, sensores y equipos de medición en línea/seudolinea).

6 Realizar pruebas a lazo abierto para obtención de las señales de estado y análisis de sensibilidad de variables del proceso.

7 Implementar un lazo de control retroalimentado.

\subsection{Justificación}

Actualmente la industria azucarera en México no cuenta con sistemas de control eficientes en sus procesos para obtener productos con DTC específica, e incluso en algunos ingenios azucareros aún se sigue laborando con personal que mide de forma cualitativa y empírica la DTC en el lote, dando como consecuencia un producto con alta variabilidad. 
La mayoría de las industrias que utilizan el proceso de cristalización operan indeseablemente, por no contar con un control satisfactorio sobre las variables de importancia por lo que el interés por el estudio en la simulación y control de esta operación ha crecido debido a la demanda de productos de mayor calidad con propiedades específicas, diminución del consumo de energía, mermas y de deshechos. Por lo tanto cualquier intento por establecer un control en la DTC, requiere que las especificaciones de los productos, estén orientadas hacia la minimización de la nucleación espontánea y al incremento del tamaño del cristal, ya que si la DTC final y la pureza de los cristales no es aceptable, la cristalización por lotes tendrá que pasar por nuevas etapas de procesamiento, como son la molienda o la recristalización, ocasionando un incremento en el costo del producto. Un modo deseable de operación es aquel que cambia el porcentaje de enfriamiento (adiabático) para llevar a cabo un nivel de sobresaturación que favorezca un adecuado porcentaje de crecimiento de los cristales sembrados e inhiba la nucleación.

Otro factor adicional que justifica el estudio de esta operación, es porque, a partir de experimentos previos (Bolaños-Reynoso et al., 2008), se ha observado que los procesos de cristalización por lotes a vacío controlados a partir de funciones indexadas de la presión de vacío, se ha logrado ubicar la concentración del slurry sobre la línea de saturación (equilibrio), sin embargo, por no conocerse los límites metaestables, se ha dejado de aprovechar un gradiente de concentración factible para lograr incrementar la masa de cristal formado y el tamaño de cristal. Los procesos de cristalización sin control, frecuentemente tienen un grado de sobresaturación ubicado en la zona lábil o inestable, lo que produce nucleación excesiva y espontánea, desaprovechándose la sobresaturación existente. Por tal situación, se requiere primeramente determinar experimentalmente las zonas metaestables para la cristalización de azúcar de caña y posteriormente implementar un sistema que controle la concentración (sobresaturación) mediante la manipulación automática de la temperatura y presión de vacío independiente del tiempo (C-Control), ya que se tiene la hipótesis de que se favorece el crecimiento de cristales sembrados; además las tendencias tecnológicas en el campo de la cristalización indican que los sistemas C-Control son superiores a los sistemas tradicionales por lotes con funciones indexadas dependientes del tiempo (T-control) (Braatz et al., 2005). 


\subsection{Organización de la tesis}

En el Capítulo 2 se evalúan experimentalmente los límites de las zonas de concentración (zona de insaturación, primer y segunda zona metaestable, y zona lábil) para azúcar de caña refinada en términos de densidad y se obtienen los modelos matemáticos que las describen, mediante el análisis de la DTC, de secuencias micrográficas y cinéticas de crecimiento.

En el Capítulo 3 se diseñó e implementó una estrategia de control de la sobresaturación de azúcar de caña en un cristalizador por lotes a vacío a nivel planta piloto. El algoritmo de control fue de tipo C-control, obteniéndose un controlador PID retroalimentado servoregulador para el control de la sobresaturación (densidad) en seudolinea, para ello se desarrolló un panel de control en lenguaje gráfico usando el software LabView de National Instruments Inc.

En el Capítulo 4 se caracterizó dinámicamente vía simulación un cristalizador continuo tipo tanque agitado en estado isotérmico y por enfriamiento, y se estudiaron alternativas de operación y controlabilidad del proceso para esta operación. A pesar de que la sustancia de trabajo en este estudio fue sulfato de amonio y no azúcar de caña, la simulación sirvió para inferir que si se deseaba controlar la concentración de sobresaturación en un lote, era necesario obtener las curvas de concentración de equilibrio y/o metaestables. De lo anterior, se observó que la operación en continuo bajo ciertas condiciones de operación (concentración de alimentación, temperatura y tiempo de residencia) es altamente inestable y difícil de ser controlada.

En el Capítulo 5 se desarrolló un estudio basado en análisis fractal para cuantificar el grado de complejidad de la cristalización de azúcar de caña a diferentes tiempos del proceso. Para este fin, se usó el método de análisis de fluctuación con remoción de la tendencia (DFA) para un arreglo bidimensional, el cual provee un índice de exponente de escalamiento, para cuantificar el grado de complejidad de un patrón bidimensional irregular.

En el Capítulo de conclusiones, se presentan las conclusiones generales y perspectivas de investigación desprendidas del presente trabajo. 
En el Apéndice A se presentan los pasos a seguir en la ejecución de programas utilizados en la estimación de la DTC, D(4,3) y S(4,3), IMAQ Vision Builder de National Instruments Inc., y DTC Adq-Im.

En el Apéndice B se presenta primeramente la ecuación de la línea de saturación corregida en el punto de saturación a $40{ }^{\circ} \mathrm{C}$ y resultados experimentales complementarios citados en el capítulo 2.

En el Apéndice C se detalla el panel de control principal y los menús necesarios para dar seguimiento a la evolución de la cristalización. 
CAPÍTULO II

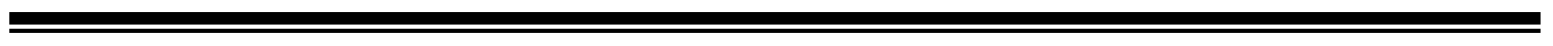




\section{Evaluación experimental de las zonas de concentración en la cristalización de azúcar de caña usando adquisición de datos e imágenes}

\subsection{Resumen}

El propósito de este capítulo es estudiar y evaluar experimentalmente los límites de las zonas de concentración (zona de insaturación, primer y segunda zona metaestable, y zona lábil) para azúcar de caña refinada en términos de densidad y obtener los modelos matemáticos que las describan, mediante el análisis de la Distribución de Tamaño de Cristal (DTC), de secuencias micrográficas y cinéticas de crecimiento. Se encontró que el ancho de las zonas de concentración (metaestable y lábil) aumenta de forma no lineal conforme la temperatura de enfriamiento disminuye en un rango de 70 a $40{ }^{\circ} \mathrm{C}$. Con los resultados obtenidos se contribuyó a tener un mejor conocimiento de los límites de concentración, información que frecuentemente es requerida para tener un control adecuado de la sobresaturación en el proceso industrial de cristalización de azúcar de caña.

\subsection{Introducción}

La cristalización es una operación unitaria que consiste en la separación sólido-líquido de químicos orgánicos e inorgánicos dónde ocurre transferencia de masa de un soluto disuelto en una fase líquida a una fase sólida. A nivel industrial, los productos cristalinos deben tener una alta pureza y DTC específica en lugar de un producto aleatorio. Para lograr una DTC especifica es importante controlar la sobresaturación, ya que es el prerrequisito para que la nucleación y el crecimiento del producto cristalino. Esto se puede lograrse a través de cambios programados en la temperatura de enfriamiento, presión de vacío, velocidad de agitación y 
sembrado de cristales, entre otros (Quintana-Hernández et al., 2004; Sutradhar 2004; Ulrich 2003; Srinivasakannan et al., 2002; Mersmann 1995; Velázquez-Camilo et al., 2009).

La cristalización por enfriamiento se emplea cuando la solubilidad de la sustancia se incrementa con la temperatura, esta operación es ampliamente usada en la industria para producir sólidos cristalinos con una alta pureza a un costo relativamente bajo en comparación a otras operaciones de separación/ purificación (Perry y Green, 2003).

Uno de los atributos importantes en los procesos de cristalización es la presencia de una fase continua y una fase dispersa que llevan a la presencia de fenómenos fisicoquímicos tales como la nucleación, crecimiento, oclusión y atrición de los cristales; lo que genera una condición distribuida de las propiedades físicas y químicas del producto como el tamaño de los cristales, forma, morfología, porosidad y peso molecular. Actualmente se sabe que las propiedades fisicoquímicas y mecánicas del producto en los procesos de cristalización son fuertemente dependientes de la DTC (Salcedo-Estrada et al., 2002; Shi et al., 2006).

La operación de un cristalizador continuo o por lote, debe satisfacer los requerimientos del cliente en cuanto a pureza del producto y distribución del tamaño del cristal. Así como los requerimientos del productor, en cuanto a economía y una adecuada operación del proceso. Los costos de producción y todas las variables que afectan al proceso, deben ser manipulados dentro de un rango aceptable de operación que está normado por la naturaleza química del producto, solvente e impurezas presentes (Rawlings y Miller, 1994). En la bibliografía actual existen muchos estudios que aplican un enfoque de primeros principios a partir de modelos matemáticos basados en balances de materia, energía y población, con el objetivo de optimizar algunas variables cuantitativas o cualitativas del proceso (DTC, masa de cristales, densidad, temperatura, presión de vacío, etc.) y así obtener mejores rendimientos tanto para el productor como para el cliente (Bolaños-Reynoso et al., 2008; Fujiwara et al., 2005; Zhou et al., 2006). En cristalización el enfoque del diseño directo está basado en el estudio de las zonas metaestables para la identificación de una región de operación que permita favorecer el crecimiento de cristales sembrados y evitar la nucleación espontanea (Bolaños-Reynoso et al., 2008; Fujiwara et al., 2005; Zhou et al., 2006; Lang et al., 1999). Sin embargo, el estudio o 
aplicación del enfoque de diseño directo ha sido menos estudiado que el enfoque de primeros principios, principalmente debido a la dificultad de tener laboratorios con equipos sofisticados o al costo elevado de realizar experimentos en planta. Este trabajo tiene la finalidad de emplear el enfoque del diseño directo para evaluar experimentalmente y modelar los límites de las zonas de concentración (zona insaturación, primer y segunda zona metaestable, y zona lábil) en la cristalización de azúcar de caña en términos de densidad y establecer la cinética de crecimiento del cristal a través de los límites metaestables.

\subsection{Metodología}

\subsubsection{Infraestructura}

El equipo empleado para el desarrollo experimental fue un cristalizador por lotes de vidrio tipo tanque agitado con chaqueta de calentamiento - enfriamiento aislado (ver Figura 2.1).

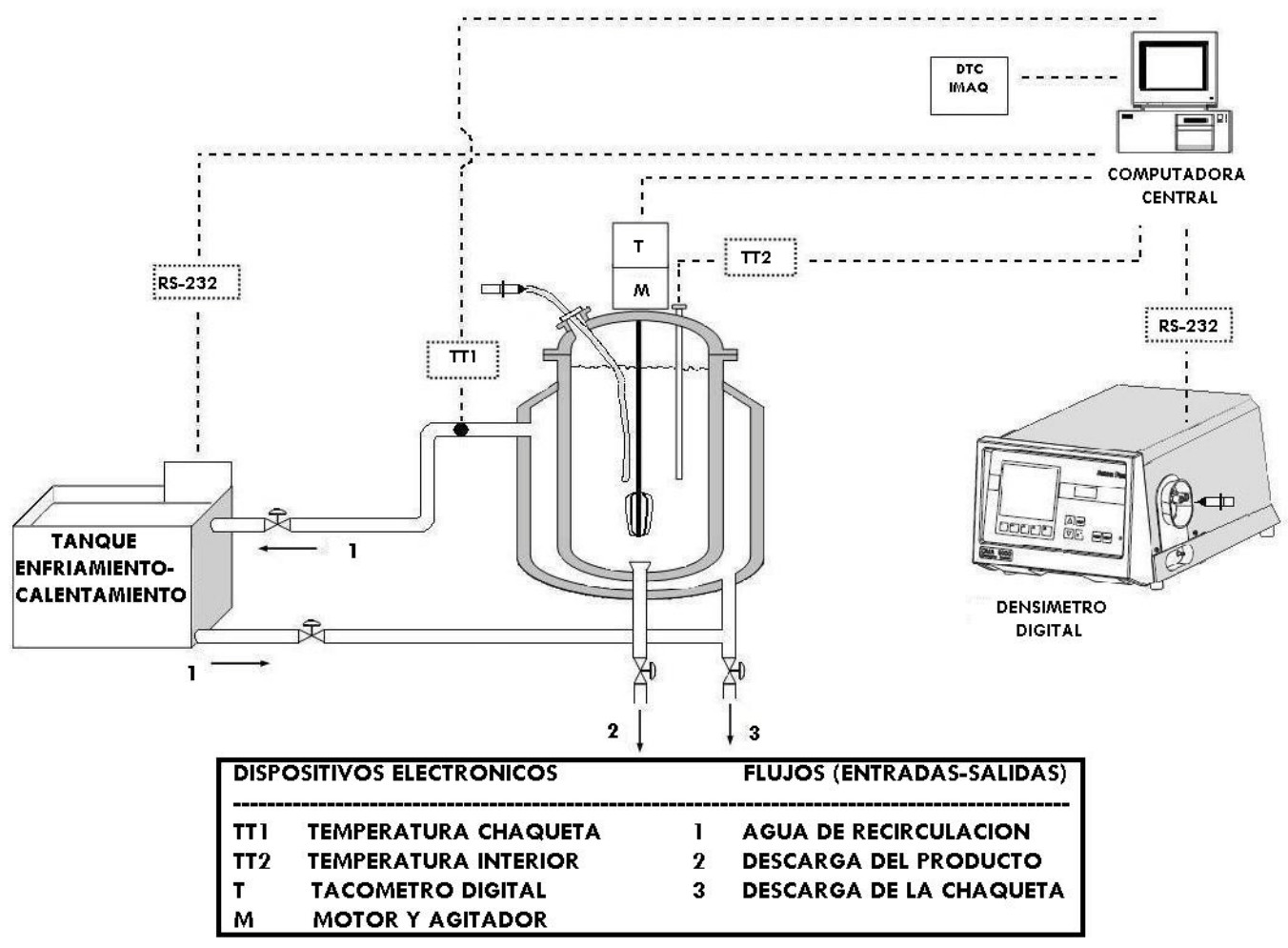

Figura 2.1 Cristalizador por lotes de vidrio por enfriamiento de contacto directo. 
El equipo cuenta con baño de recirculación programable, motor de agitación variable, medidor de concentración (densidad) y un sistema de adquisición de imágenes microscópicas en pseudolinea. Los equipos, dispositivos electrónicos e instrumentación del cristalizador se presentan en la Tabla 2.1.

Tabla 2.1. Dispositivos electrónicos del cristalizador por lotes de vidrio por enfriamiento de contacto directo.

\begin{tabular}{|c|c|}
\hline Cantidad & Dispositivos \\
\hline 1 & $\begin{array}{l}\text { Cristalizador de vidrio de } 6 \mathrm{~L} \text {, chaqueta de calentamiento-enfriamiento de } 2.55 \\
\text { L, dimensiones del cristalizador: altura } 35 \mathrm{~cm} \text { y diámetro interno de } 14.4 \mathrm{~cm} \text {, } \\
\text { altura domo inferior de } 1.8 \mathrm{~cm} \text { y altura domo superior (tapa hermética) de } 5 \mathrm{~cm} \text {. }\end{array}$ \\
\hline 1 & $\begin{array}{l}\text { Motor genérico de velocidad variable, transmisión directa de } 0 \text { a 1,500 rpm, } 60 \\
\text { Herz, } 127 \text { VCA y } 760 \mathrm{~W} \text {, flecha de agitación de } 14 \text { in (longitud) y } 1 / 4 \text { in de } \\
\text { diámetro en acero inoxidable } 316 \text {. }\end{array}$ \\
\hline 1 & $\begin{array}{l}\text { Agitador (impeller) de } 4 \text { anillos rectangulares con separación de } 90^{\circ} \text { entre cada } \\
\text { cruce. Aspas de } 2 \text { x } 1 \text { in de longitud por anchura en acero inoxidable } 316 \text {. }\end{array}$ \\
\hline 2 & Thermocouple $\mathrm{J}$ type. 0 to $760{ }^{\circ} \mathrm{C}$, wire-rope: $3 \mathrm{~m}$ \\
\hline 1 & Termo pozo de cobre de 14 in (longitud) y 1/2 in de diámetro. \\
\hline 1 & $\begin{array}{l}\text { Aislante térmico para alta temperatura de fibra de vidrio con } 1 / 2 \text { in. de espesor } \\
\text { recubierto con papel aluminio foil. }\end{array}$ \\
\hline 1 & $\begin{array}{l}\text { Baño de recirculación programable Julabo F-34, con rango de temperatura de - } \\
34 \text { at } 200{ }^{\circ} \mathrm{C} \text {, con bomba de recirculación de } 15 \mathrm{~L} / \mathrm{min} \text {, volumen del baño de } 14 \\
\text { a } 20 \mathrm{~L}, 120 \mathrm{VCA} / 60 \mathrm{~Hz} \text {. }\end{array}$ \\
\hline 1 & $\begin{array}{l}\text { Densímetro digital DMA-4500 de Anton-Paar, rango de medición de } 0 \text { a } 3 \\
\text { gr/ } \mathrm{cm}^{3} \text {, alimentación de muestra en la celda de } 1 \mathrm{ml} \text { de solución, error de } \\
\text { medición en la temperatura } 0.1{ }^{\circ} \mathrm{C} \mathrm{y} 1^{*} 10^{-5} \mathrm{gr} / \mathrm{cm}^{3} \text { en densidad. Tiempo de } \\
\text { medición por muestreo usualmente } 5 \mathrm{~min} \text {. Interface COM1, COM2 para } \\
\text { conexión por puerto serial RS-232. }\end{array}$ \\
\hline
\end{tabular}

\subsubsection{Sistema de adquisición de datos e imágenes}

El equipo experimental está integrado por un sistema de adquisición de datos usado para registrar la concentración en una computadora central y controlar a lazo abierto la 
temperatura del sistema mediante un baño de recirculación programable. Para monitorear la DTC en pseudolinea se implementó un sistema de adquisición de imágenes que consistió de la captura de imágenes a través de una videocámara digital monocromática RS-170 y $60 \mathrm{~Hz}$ entrelazado (8 bits de resolución) acoplada a un microscopio trinocular y mediante el uso del software IMAQ Vision Builder de National Instruments, Inc., se realizó la toma de la imagen y se midieron las áreas de los cristales usando la técnica del umbral (threshold) que permite obtener imágenes en escala de grises. Para realizar la conversión de las áreas de cristales en pixeles a micras, se realizó una calibración a través del conteo directo usando una cámara o celda de Neubuer, obteniéndose que el lado de 1 pixel es equivalente a $200 \mu \mathrm{m}$ de longitud. Lo anterior es descrito con más detalle por Bolaños-Reynoso et al., (2008). Las características de los dispositivos electrónicos usados se presentan en la Tabla 2.2.

Tabla 2.2. Dispositivos electrónicos para el sistema de adquisición de datos e imágenes.

\begin{tabular}{|c|l|}
\hline Cantidad & \multicolumn{1}{|c|}{ Dispositivos } \\
\hline 1 & Tarjeta de adquisición de datos: PCI-232/485.2CH. National Instruments, Inc. \\
\hline 1 & Tarjeta de adquisición de datos: PCI-6025E. National Instruments, Inc. \\
\hline 1 & Tarjeta de adquisición de imágenes: PCI-1407. National Instruments, Inc. \\
\hline 1 & Modulo portador blindado: SC-2345. National Instruments, Inc. \\
\hline 2 & Modulo de acondicionamiento de señales: SCC-TC02. National Instruments, Inc. \\
\hline 1 & Microscopio profesional: 48923-30; trinocular. Cole Palmer. \\
\hline 1 & $\begin{array}{l}\text { Cámara Monocromática con video RS-170. Lens: 0.19 mm por pixel. National } \\
\text { Instruments, Inc. }\end{array}$ \\
\hline 1 & $\begin{array}{l}\text { Tacometro digital ACT-3. Monarch Instrument. Rango de medición de 5-999 } \\
0.5 \text { ms y sensor óptico infrarrojo con rango de 1-250 000 rpm. }\end{array}$ \\
\hline
\end{tabular}

\subsubsection{Manipulación de la sobresaturación}

La saturación es un estado de equilibrio termodinámico estable. Si una solución se concentra por evaporación, o si se enfría más allá del punto de saturación, los núcleos 
aparecerán de manera espontanea, esto debido a un nivel de sobresaturación que alcanzan los límites en las llamadas segunda zona metaestable y zona lábil. En la práctica industrial es conveniente que haya una sobresaturación considerable, para que los núcleos se formen en el licor concentrado (solución de sacarosa o jugo de caña). La sobresaturación en el licor disminuye en la proporción en que los cristales se forman y crecen. Para que exista la sobresaturación, la solución debe tener una concentración que exceda la concentración de saturación. Esta varía dependiendo de las diferentes zonas de concentración (estable, metaestable y lábil) que pueden ocurrir durante el enfriamiento de una solución (QuintanaHernandez et al., 2004).

La manipulación de la supersaturación en algunos trabajos anteriores (QuintanaHernandez et al., 2004; Bolaños-Reynoso et al., 2008; Quintana-Hernández et al., 2001), se han basado en la ecuación de Moncada y Rodríguez (Quintana-Hernández et al., 2001), la cual describe la línea de saturación o solubilidad para el sistema azúcar de caña comercial-agua en términos de ${ }^{\circ}$ Brix, obtenida mediante un refractómetro de precisión. Quintana-Hernández et al. (2001) definieron los límites de las zonas metaestables a partir de la línea de solubilidad dada por Moncada y Rodríguez, asignando el porcentaje fijado por Meade y Chen, (1977) para definir el ancho de la primera y segunda zona metaestable, y el límite de la zona lábil (Bolaños-Reynoso et al., 2008; Meade y Chen, 1977). Dichos anchos de zonas metaestables de concentración son constantes para cualquier rango de temperatura de enfriamiento dado.

En este trabajo se presenta de forma novedosa mediante experimentación y modelado, la línea de saturación y límites de las zonas metaestable y lábil en términos de densidad; dichas mediciones de densidad se obtuvieron sobre la fase continua de la solución mediante el filtrado de la solución con papel azucarero estándar de $19 \mu \mathrm{m}$ de porosidad, y las mediciones se realizaron a través de un densímetro digital de alta precisión DMA-4500 de Anton-Paar, especifico para muestreos en volumen pequeños (3 ml). Este equipo basa su medición en el método de oscilación harmónica de tubo en U desarrollado por Stabinger et al. (1967) y determina la densidad con un error de $1 * 10^{-5} \mathrm{~g} / \mathrm{cm}^{3}$ (Manual densímetro digital DMA-4500 de Anton- Paar). El densímetro cuenta con un sistema de corrección de temperatura (calentamiento-enfriamiento). 


\subsubsection{Obtención de la línea de saturación}

Para la obtención de la línea de saturación o equilibrio en términos de densidad se desarrolló una estrategia experimental que consistió en preparar soluciones saturadas de azúcar de caña refinada (comercial) a diferentes temperaturas de saturación (40, 50, 60 y 70 $\left.{ }^{\circ} \mathrm{C}\right)$. La preparación de las soluciones se realizó a partir de la curva de solubilidad establecida por Moncada y Rodríguez (Quintana-Hernandez et al., 2001) en términos de ${ }^{\circ}$ Brix (Ec. 2.1), tomándose como base 208 gr de solución (g azúcar / ml agua) para cada temperatura de saturación (ver Tabla 2.3).

${ }^{\circ} \mathrm{Brix}_{\mathrm{Sat}}=60.912+0.264 * \mathrm{~T}-0.0007 * \mathrm{~T}^{2}$

Tabla 2.3. Preparación de las soluciones a cada temperatura de saturación para la obtención de la línea de equilibrio.

\begin{tabular}{|c|c|c|c|}
\hline $\begin{array}{c}\text { Temperatura de } \\
\text { saturación } \\
\left({ }^{\circ} \mathbf{C}\right)\end{array}$ & $\begin{array}{c}\text { Solución } \\
\text { saturada } \\
\left(\mathbf{g}_{\text {azúcar }} / \mathbf{~ m l}_{\text {agua }}\right)\end{array}$ & $\begin{array}{c}\text { Azúcar } \\
\mathbf{( g )}\end{array}$ & $\begin{array}{c}\text { Agua } \\
(\mathbf{m l})\end{array}$ \\
\hline 70 & 208 & 158.0 & 50.0 \\
\hline 60 & 208 & 154.4 & 53.6 \\
\hline 50 & 208 & 150.5 & 57.5 \\
\hline 40 & 208 & 146.3 & 61.7 \\
\hline
\end{tabular}

Las pruebas experimentales se realizaron por triplicado para cada temperatura de saturación, lo anterior se llevó a cabo en matraces Erlenmeyer de $250 \mathrm{ml}$ para mantener un mejor control de la evaporación del agua al momento de manipular la solución. Cada prueba experimental fue calentada a baño maría con una temperatura de $80{ }^{\circ} \mathrm{C}$ hasta obtener una disolución completa y con agitación de 450 rpm, posteriormente la solución fue enfriada a su respectiva temperatura de saturación mediante una rampa de enfriamiento (1 a 2 hrs. dependiendo de la temperatura de saturación). La muestra a cada temperatura de saturación fue de $3 \mathrm{ml}$ de solución, considerándose que este volumen no afecta al sistema. El muestreo se realizó sin filtrar, ya que a cada temperatura de saturación no existe formación de núcleos en 
la solución. Lo anterior se verificó evaluando la concentración en cada punto de saturación y mediante la adquisición de imágenes de la muestra en seudolinea, mediante el software IMAQ Vision Builder de National Instruments, Inc, descrito en la Sección 2.3.2. La muestra puede transportarse hasta el sistema de adquisición de imágenes mediante una bomba peristáltica, sin embargo como el experimento requiere de no desperdiciar solución, se optó por transportar la muestra en cubre objetos. La medición de la densidad en el densímetro digital DMA-4500 requirió de introducir al equipo $3 \mathrm{ml}$ de esta solución (aunque solo $1 \mathrm{ml}$ es requerido en la celda de medición del densímetro), trabajándose a la presión atmosférica de 875.6 a 878.8 mb (875.6 a 878.8 hpa).

\subsubsection{Obtención de los límites de las zonas metaestable y lábil}

Para la obtención de los límites de las zonas metaestable y lábil se desarrolló una estrategia experimental similar a la desarrollada en la Sección 2.3.4, está consistió en preparar soluciones saturadas de azúcar de caña refinada a diferentes temperaturas de saturación (40, 50, 60 y $70^{\circ} \mathrm{C}$ ) basadas en la ecuación de Moncada y Rodríguez (Ec. 2.1), las pruebas se realizaron por triplicado para cada temperatura de saturación en un cristalizador de vidrio (por lote) con chaqueta de enfriamiento, ilustrado en la Figura 2.1. Igual que en la Sección 2.3.4 la disolución se llevó a cabo mediante recirculación de agua de calentamiento en la chaqueta a $80{ }^{\circ} \mathrm{C}$ hasta obtener una disolución completa (esto se verificó a través del microscopio para observar que no existieran cristales en el seno de la solución), posteriormente se aplicó un enfriamiento tipo rampa hasta alcanzar su respectiva temperatura de saturación. En este momento, empieza la corrida experimental en donde la solución fue enfriada lentamente en intervalos de $1{ }^{\circ} \mathrm{C}$ y en cada estado estacionario de temperatura se tomó una muestra de la solución en pseudolinea para medir la concentración y la DTC. Para la medición de la concentración se tomaron $3 \mathrm{ml}$ de solución o slurry (fase continua + cristales) filtrada con papel azucarero estándar con porosidad de $19 \mu \mathrm{m}$ y se introdujo $1 \mathrm{ml}$ en el densímetro digital DMA-4500, trabajándose a la presión atmosférica de 875.6 a 878.8 mb (875.6 a 878.8 hpa). Para la medición y análisis de la DTC se tomaron $5 \mathrm{ml}$ de solución sin filtrar y se adquirieron imágenes de los núcleos y/o cristales existentes con un microscopio trinocular, una cámara 
monocromática de video y el software IMAQ Vision Builder de National Instruments, Inc. (la ejecución de este programa se describe en el Apéndice A, Sección A.1). Posteriormente, se le dio un tratamiento a las imágenes usando el software DTC Adq-Im (Bolaños-Reynoso et al., 2008; Cordova-Pestaña et al., 2004) para obtener los diámetros promedios relativos en \%número, \%longitud, \%área y \%volumen (la ejecución de este programa se describe en el Apéndice A, Sección A.2).

La preparación de las soluciones saturadas a sus correspondientes temperaturas (40, 50, 60 y $70^{\circ} \mathrm{C}$ ) se realizó de forma aleatoria y por triplicado. El peso de cada solución establecido fue de 4500 gr (g azúcar / ml agua), con el fin de que el muestreo no fuera una variable de importancia a considerar y poder manejar el sistema como una solución a volumen constante (se retiraron por muestreo $8 \mathrm{ml}$ equivalente al $0.17 \%$ de la solución total). En la Tabla 2.4, se presentan las relaciones que se tomaron para preparar las soluciones saturadas a su respectiva temperatura de equilibrio. Las soluciones preparadas son una mezcla de azúcar refinada comercial y agua destilada/desionizada, y las medidas y pesos establecidos fueron obtenidos considerando la ecuación de Moncada y Rodríguez (Quintana-Hernandez et al., 2001).

Tabla 2.4. Preparación de las soluciones a cada temperatura de saturación para la obtención de las zonas metaestables e inestable.

\begin{tabular}{|c|c|c|c|}
\hline $\begin{array}{c}\text { Temperatura de } \\
\text { saturación } \\
\left({ }^{\circ} \mathbf{C}\right)\end{array}$ & $\begin{array}{c}\text { Solución } \\
\text { saturada } \\
(\mathbf{g} \text { azúcar } / \mathbf{m l} \\
\text { agua }\end{array}$ & $\begin{array}{c}\text { Azúcar } \\
\mathbf{( g )}\end{array}$ & $\begin{array}{c}\text { Agua } \\
\mathbf{( m l )}\end{array}$ \\
\hline 70 & 4500 & 3418.3 & 1081.7 \\
\hline 60 & 4500 & 3340.4 & 1159.6 \\
\hline 50 & 4500 & 3256.3 & 1243.7 \\
\hline 40 & 4500 & 3165.8 & 1334.2 \\
\hline
\end{tabular}

\subsubsection{Obtención de las cinéticas de crecimiento}

Los modelos matemáticos que describen las cinéticas de crecimiento para cada solución saturada $\left(40,50,60\right.$ y $\left.70^{\circ} \mathrm{C}\right)$, en función de enfriamientos de $1^{\circ} \mathrm{C}$ fueron obtenidos a partir de las mediciones de tamaño de cristal con respecto al tiempo, usando el software IMAQ 
Vision Builder de National Instruments, Inc. La adquisición de imágenes se efectuó por medio de una cámara monocromática con video RS-170 (8 bits de resolución) acoplado a un microscopio trinocular (lente ocular 10x y objetivo de 40x). El análisis de las imágenes se realizó empleando la técnica del umbral, la cual consiste en obtener una imagen en escala de grises con áreas para ser analizadas independientemente, midiéndose los pixeles negros (área de los cristales) considerados como una figura geométrica cuadrada (pixeles en términos de longitud). Para cada temperatura de enfriamiento, los pixeles medidos de las imágenes capturadas de cada solución saturada fueron promediados. Posteriormente, usando la técnica descrita en la sección de adquisición de datos e imágenes (Sección 2.3.2) se convirtieron los pixeles medidos a micras ( $1 \mu \mathrm{m}$ es igual a 0.005 la longitud del lado de un pixel) y de micras a centímetros. Las variables consideradas en la construcción del modelo fueron el tiempo de cristalización, la temperatura de enfriamiento, y la densidad relativa. El modelo propuesto es de tipo exponencial (Ec. 2.2), realizándose el ajuste de los datos experimentales mediante regresión no lineal utilizando el software NCSS (Manual de usuario NCSS, 2004).

$$
\mathrm{G}_{\rho_{\mathrm{Sat}}}=\mathrm{K}_{\mathrm{g}}\left[\left(1-\mathrm{e}^{-\mathrm{t}}\right) / \mathrm{T}\right] \rho_{\mathrm{Sr}}^{\alpha}
$$

Donde:

$\mathrm{G}_{\rho_{\mathrm{Sat}}}$ Cinética de crecimiento $[=](\mathrm{cm} / \mathrm{min})$

$\mathrm{K}_{\mathrm{g}}$ Coeficiente pre-exponencial (constante de velocidad) $[=]\left(\mathrm{cm}^{4} \cdot{ }^{\circ} \mathrm{C} / \mathrm{g} \cdot \mathrm{min}^{2}\right)$

t Tiempo experimental de cristalización [=] (min)

$\mathrm{T}$ Temperatura experimental de cristalización $[=]\left({ }^{\circ} \mathrm{C}\right)$

$\rho_{S r} \quad$ Densidad relativa [=] $\left(\mathrm{g} / \mathrm{cm}^{3}\right)$

$\alpha \quad$ Coeficiente exponencial de la densidad relativa [=] (---) 


\subsection{Resultados}

\subsubsection{Línea de saturación o equilibrio}

La Figura 2.2 presenta los datos experimentales de concentración promedio obtenidos para cada solución a su respectiva temperatura de saturación (como se describió en la Sección 2.3.4) y el ajuste por regresión no lineal de los datos experimentales.

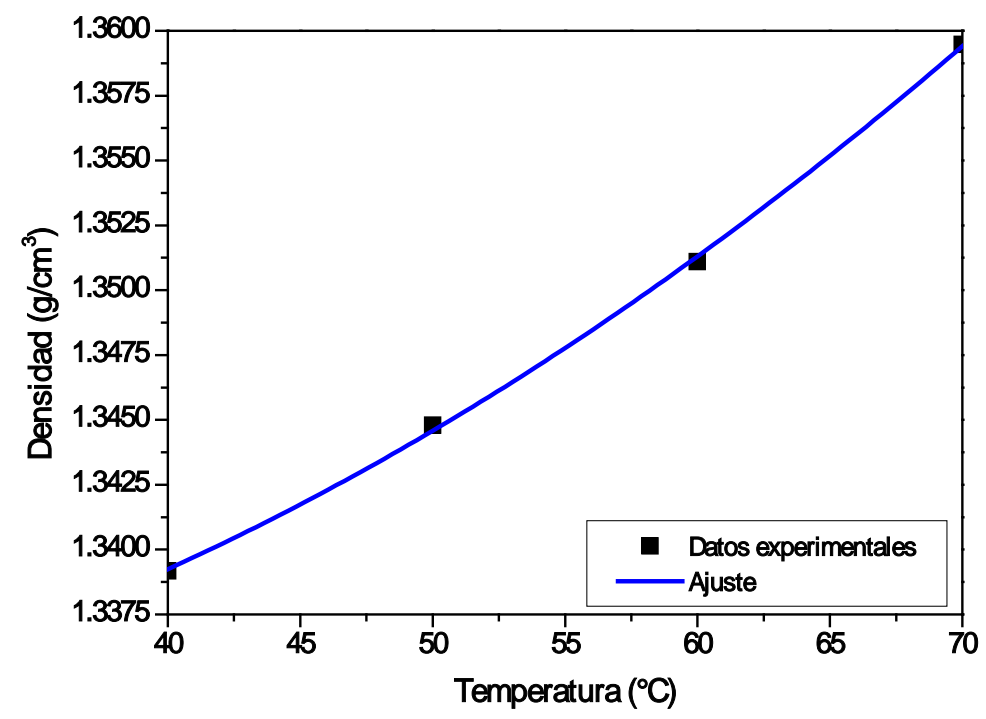

Figura 2.2 Determinación de la línea de saturación en términos de densidad.

La Ec. (2.3) representa la línea de saturación en términos de densidad para el sistema azúcar de caña refinada-agua desionizada obtenida por Solís y Villa, (2008) a partir de la ecuación de Moncada y Rodríguez (Quintana-Hernandez et al., 2001), con $\mathrm{R}^{2}=0.99872$.

$\rho_{\text {sat }}=1.331731-8.893748 \mathrm{E}-05^{*} \mathrm{~T}+6.918750 \mathrm{E}-06 * \mathrm{~T}^{2}$

Donde $\rho_{\text {sat }}$ es la densidad de saturación en $\mathrm{g} / \mathrm{cm}^{3}$ para una temperatura de equilibrio específica $\mathrm{T}$ en ${ }^{\circ} \mathrm{C}$. El intervalo de densidad para un rango de temperatura de 70 a $40{ }^{\circ} \mathrm{C}$ es de 1.3594073 a $1.3392435 \mathrm{~g} / \mathrm{cm}^{3}$, respectivamente. A partir de la densidad de saturación es posible obtener la concentración de supersaturación $\left(\rho_{S s a t}\right)$ y saturación relativa $\left(\rho_{S r}\right)$, dadas por la Ec. (2.4) y Ec. (2.5) respectivamente, donde $\rho_{\text {exp }}$ es la densidad experimental en g/ $\mathrm{cm}^{3}$. 
$\rho_{\text {Ssat }}=\rho_{\text {exp }}-\rho_{\text {sat }}$

$\rho_{S r}=\left(\rho_{\text {exp }}-\rho_{\text {sat }}\right) / \rho_{\text {sat }}$

En el Apéndice B, Sección B.1 se presenta la obtención de una línea de saturación a partir de experimentos posteriores con el fin de verificar una inconsistencia presentada en la ecuación de Moncada y Rodríguez en el punto de saturación a $40{ }^{\circ} \mathrm{C}$ y que repercutió en la obtención de la línea de saturación en términos de densidad de Solís y Villa, (2008).

\subsubsection{Análisis de la concentración promedio en función de temperaturas de enfriamiento}

En la Figura 2.3 se presentan los datos experimentales promediados de las densidades obtenidas de 3 pruebas por cada temperatura de saturación (40, 50, 60 y $70{ }^{\circ} \mathrm{C}$ ). La prueba consistió en aplicar gradientes de enfriamientos de $1{ }^{\circ} \mathrm{C}$ hasta alcanzar un estado estacionario, se realizaron en promedio 10 determinaciones de concentración por cada prueba según la metodología dada en la Sección 2.3.5.

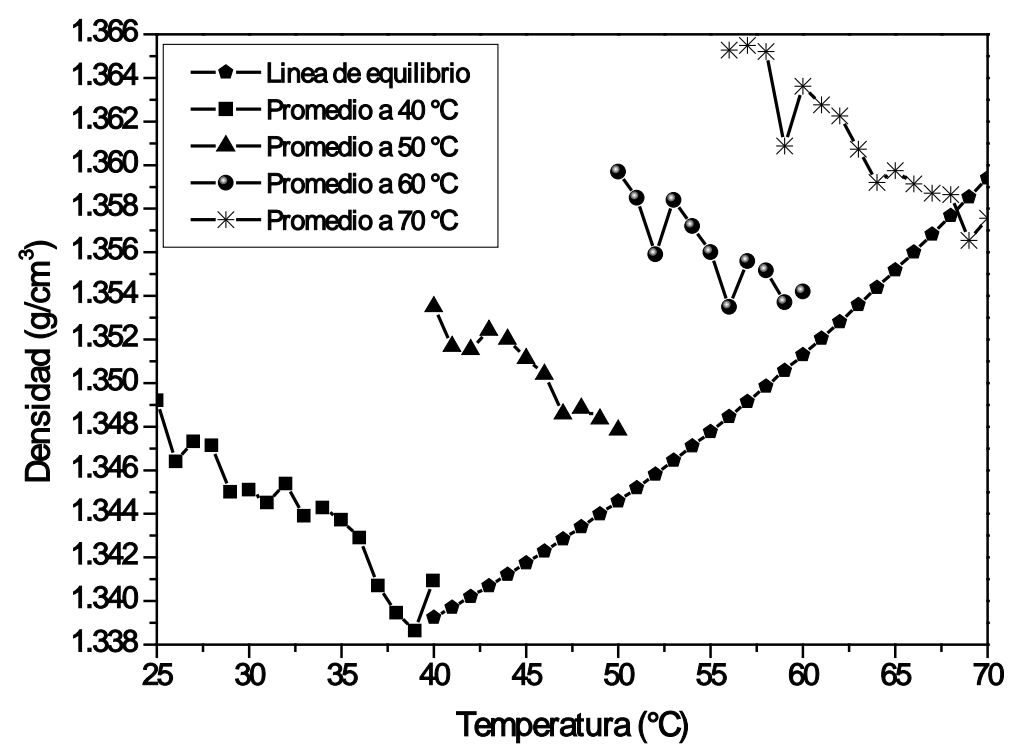

Figura 2.3 Promedio de los resultados experimentales (densidad vs. Temperatura). 
Los resultados experimentales para la obtención de las densidades promedios (Figura 2.3) se presentan en el Apéndice B, Sección B.2. En esta figura se observa que las densidades para cada temperatura de saturación aumentan conforme la temperatura de enfriamiento disminuye. Para cada solución de saturación se obtuvo un rango de temperatura de enfriamiento y concentración: para $40^{\circ} \mathrm{C}$ el rango de temperatura fue de 40 a $25{ }^{\circ} \mathrm{C}$ y concentración de 1.34093 a $1.34921 \mathrm{~g} / \mathrm{cm}^{3}$, para $50{ }^{\circ} \mathrm{C}$ el rango de temperatura de enfriamiento fue de 50 a $40{ }^{\circ} \mathrm{C}$ y concentración de 1.34785 a $1.35351 \mathrm{~g} / \mathrm{cm}^{3}$, para $60{ }^{\circ} \mathrm{C}$ fue de 60 a $50{ }^{\circ} \mathrm{C}$ y concentración de 1.3542 a $1.3597 \mathrm{~g} / \mathrm{cm}^{3}$ y para $70{ }^{\circ} \mathrm{C}$ fue de 70 a $53{ }^{\circ} \mathrm{C}$ y concentración de 1.35769 a $1.36592 \mathrm{~g} / \mathrm{cm}^{3}$. Estos rangos de concentración y temperatura son la base para la determinación de los límites de concentración (puntos críticos) de las zonas metaestable y lábil, complementado con las mediciones y análisis de la DTC con el fin de cuantificar el tamaño de cristal (Sección 2.4.3) y las imágenes adquiridas (Sección 2.4.4) para observar cualitativamente mediante las micrografías la formación y crecimiento del cristal a través de las zonas de concentración.

De la Figura 2.3, se observa que los dos datos iníciales de la solución saturada a $70{ }^{\circ} \mathrm{C}$ están por debajo de la línea de saturación. Sin embargo, estos datos no afectan la determinación de los puntos críticos ya que se encuentran en la zona de insaturación observándose mediante la adquisición de imágenes que no existe formación ni crecimiento de cristales por cuantificar. No obstante, en las pruebas experimentales una vez que la solución alcanzaba su punto de saturación a su correspondiente temperatura (ejemplo solución saturada a $70^{\circ} \mathrm{C}$ ), se utilizó papel azucarero para filtrar la solución y medir su correspondiente densidad en la fase continua.

Otro caso donde podrían presentarse formación de núcleos consistiría en que la fase continua se enfriara por el transporte del cristalizador al densímetro, propiciando la formación de núcleos o pequeños cristales inferiores a $1 \mu \mathrm{m}$. Sin embargo, cuando la solución es alimentada en la celda de medición del equipo este último compensa la temperatura al punto de saturación de la solución, diluyendo así los núcleos y cristales pequeños formados por la interacción del ambiente. 


\subsubsection{Análisis de la distribución de tamaño de cristal y secuencias micrográficas}

La Figura 2.4 presenta la DTC en \% volumen con una distribución de tipo log-normal para cada solución saturada $\left(40,50,60\right.$ y $\left.70{ }^{\circ} \mathrm{C}\right)$, siendo estas las más representativas con respecto al promedio de tres pruebas experimentales por cada temperatura de saturación; los datos experimentales completos se presentan en el Apéndice B, Sección B.3.

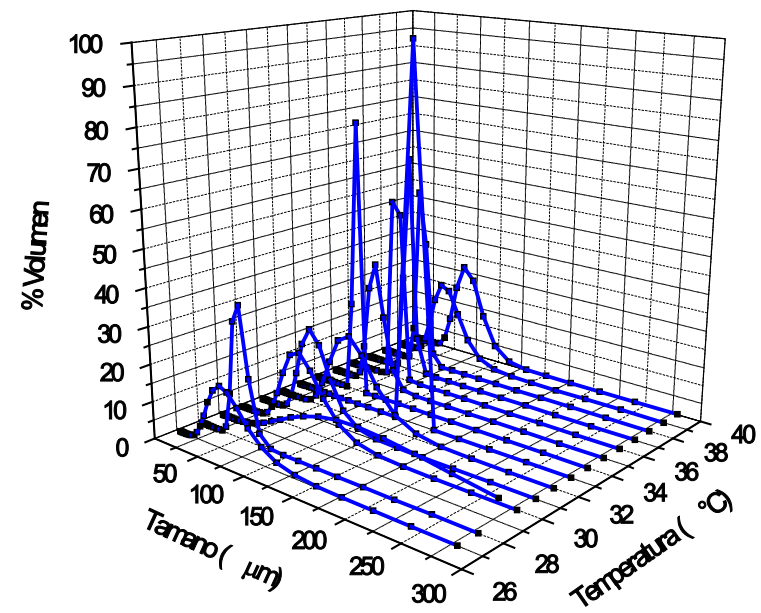

a)

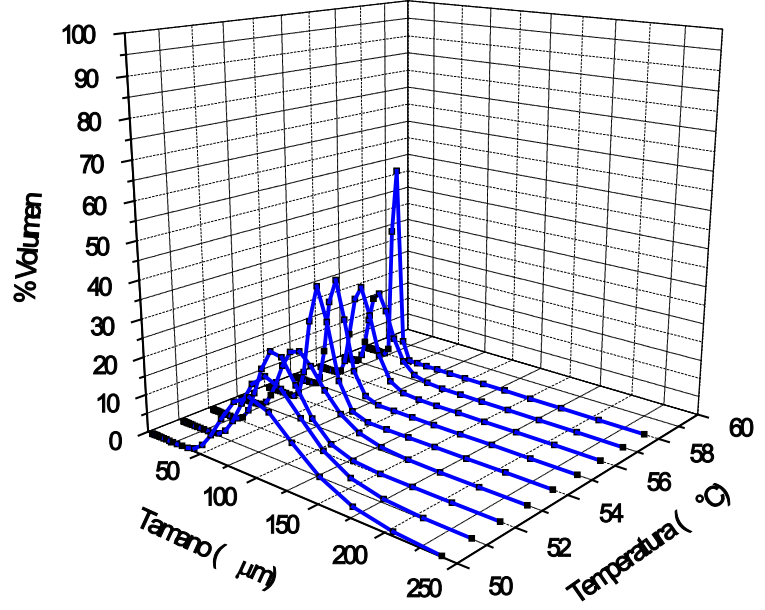

c)

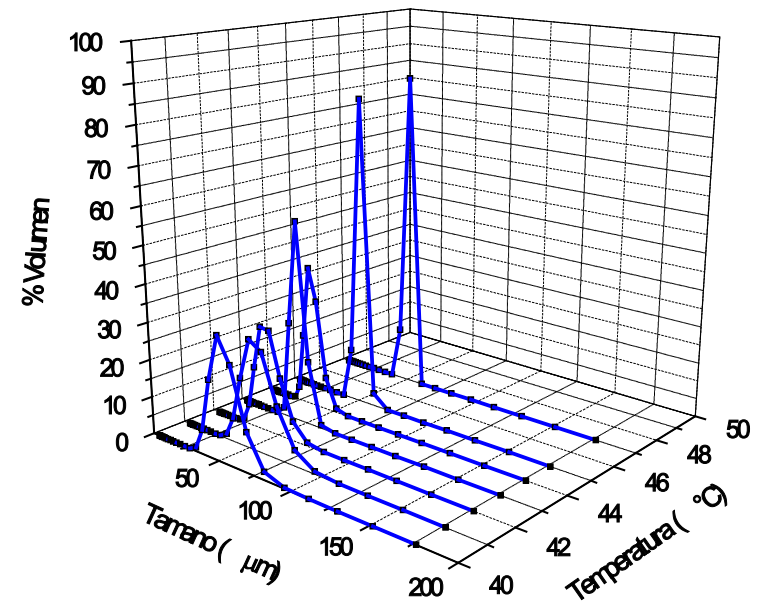

b)

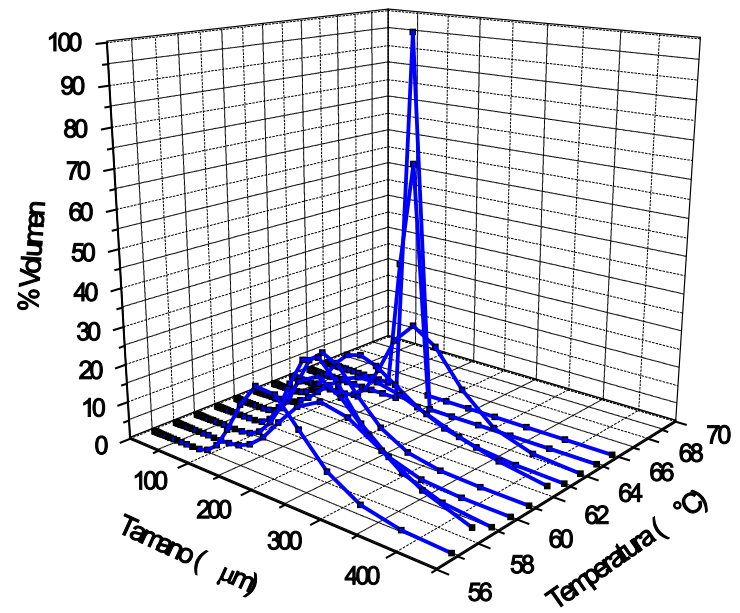

d)

Figura 2.4 DTC tipo log-normal en \% volumen para soluciones saturadas a diferentes temperaturas. a) $40^{\circ} \mathrm{C}$, b) $50{ }^{\circ} \mathrm{C}$, c) $60^{\circ} \mathrm{C}$ y d) $70^{\circ} \mathrm{C}$. 
El análisis se basó en la cuantificación y observación de los patrones en la población de cristales para un rango de temperatura de enfriamiento y densidad. Este patrón se establece de acuerdo a la variación del \% volumen (porcentaje en volumen de partículas de un tamaño específico) y del tamaño de cristales (diámetro promedio relativo al volumen $\mathrm{D}(4,3)$ ) en la cuantificación de la DTC. La Figura 2.4a muestra la DTC para una solución saturada a $40{ }^{\circ} \mathrm{C}$, observándose un patrón de tres zonas de DTC para diferentes rangos de temperatura. De la Figura 2.4a, se observa que de 40 a $37^{\circ} \mathrm{C}$ se tiene de 20 a $25 \%$ volumen $(\mathrm{D}(4,3)$ de 30.4 a $49.9 \mu \mathrm{m})$ y se asume que representa la primera zona metaestable; si bien no debe existir formación de núcleos ni cristales en esta zona (Lang et al., 1999; Meade y Chen, 1977; Hugot, 1963). Las réplicas experimentales presentan las mismas características, obteniéndose en promedio cristales pequeños 30.4 a $49.9 \mu \mathrm{m}$. Lo anterior se atribuye a posibles errores en el ajuste de datos que dan origen a la ecuación de Moncada y Rodríguez (Quintana-Hernandez et al., 2001) para la preparación de las soluciones saturadas a $40^{\circ} \mathrm{C}$ (en términos de ${ }^{\circ}$ Brix). Para una rango de temperatura de 36 a $33{ }^{\circ} \mathrm{C}$, el \% volumen aumenta bruscamente de 50 a $95 \%$ $(\mathrm{D}(4,3)$ de 50.9 a $130.2 \mu \mathrm{m})$ y se considera que representa la segunda zona metaestable (domina el crecimiento de cristales y la nucleación es mínima); cuando la temperatura de enfriamiento disminuye hasta $32{ }^{\circ} \mathrm{C}$, el \% volumen cae drásticamente a $22 \%$ en promedio $(\mathrm{D}(4,3)$ de $82.3 \mu \mathrm{m})$ y se considera que representa la zona lábil (domina la nucleación con respecto al crecimiento del cristal), en esta zona se aprecian algunos aglomerados y aunque a este fenómeno se le ha atribuido en muchas referencias a una mala agitación, también se puede considerar a la producción súbita de núcleos debido a que los aglomerados en su mayoría se componen de núcleos y cristales de tamaños por debajo de las 10 micras. Este patrón también puede observarse cualitativamente mediante las secuencias micrográficas presentadas en la Figura 2.5.

En las Figuras (2.5-2.8) se presentan las secuencias micrográficas que describen cualitativamente el comportamiento de formación de cristales pequeños considerados como núcleos y el crecimiento de los mismos. En base a la cuantificación de la DTC y al análisis cualitativo de las secuencias micrográficas para cada rango de temperatura es posible distinguir los puntos críticos que delimitaran las zonas de concentración (primera y segunda zona metaestable, y región lábil). Estas micrografías se obtuvieron en base al procedimiento 
de la Sección 2.3.5. En las Figuras 2.4.b, 2.4c y 2.4d, se ilustra la DTC para una solución saturada a $50{ }^{\circ} \mathrm{C}, 60^{\circ} \mathrm{C}$ y $70^{\circ} \mathrm{C}$, respectivamente.

Para la temperatura de saturación a $50{ }^{\circ} \mathrm{C}$ (Figura 2.4b), se observa que para un rango de enfriamiento entre 50 y $48{ }^{\circ} \mathrm{C}$ no existe formación de núcleos, por lo que se considera que en este rango de temperatura se encuentra la primera zona metaestable. La segunda zona metaestable se considera para un rango de enfriamiento entre 47 y $45^{\circ} \mathrm{C}$, con 80 a $85 \%$ volumen y $\mathrm{D}(4,3)$ de 51 a $51.3 \mu \mathrm{m}$ respectivamente. La zona lábil se considera para una temperatura menor de $44{ }^{\circ} \mathrm{C}$, con un $25 \%$ volumen en promedio y $\mathrm{D}(4,3)$ menor de $54 \mu \mathrm{m}$.

Para la temperatura de saturación a $60{ }^{\circ} \mathrm{C}$ (Figura 2.4c), se observa que para un rango de enfriamiento entre 60 y $59{ }^{\circ} \mathrm{C}$ no existe formación de núcleos, por lo que se considera que en este rango de temperatura se encuentra la primera zona metaestable. La segunda zona metaestable se considera para un rango de enfriamiento entre 58 y $56{ }^{\circ} \mathrm{C}$, con 55 a $25 \%$ volumen y $\mathrm{D}(4,3)$ de de 31.3 a $44.6 \mu \mathrm{m}$ respectivamente. La zona lábil se considera para una temperatura menor de $55^{\circ} \mathrm{C}$, con un $18 \%$ volumen en promedio y $\mathrm{D}(4,3)$ menor de $101.8 \mu \mathrm{m}$.

Para la temperatura de saturación a $70{ }^{\circ} \mathrm{C}$ (Figura 2.4d), se observa que para un rango de enfriamiento entre 70 y $67^{\circ} \mathrm{C}$ no existe formación de núcleos, por lo que se considera que en este rango de temperatura se encuentra la primera zona metaestable. La segunda zona metaestable se considera para un rango de enfriamiento entre 66 y $65{ }^{\circ} \mathrm{C}$, con 64 a $95 \%$ volumen y $\mathrm{D}(4,3)$ de de 144 a $214.9 \mu \mathrm{m}$ respectivamente. La zona lábil se considera para una temperatura menor de $64{ }^{\circ} \mathrm{C}$, con un $17 \%$ volumen en promedio y $\mathrm{D}(4,3)$ menor de $259 \mu \mathrm{m}$.

En las Figura 2.6, 2.7 y 2.8, se presentan las secuencias micrográficas para la solución saturada a $50{ }^{\circ} \mathrm{C}, 60^{\circ} \mathrm{C}$ y $70{ }^{\circ} \mathrm{C}$, respectivamente. En estas imágenes micrográficas se observa el mismo patrón en la formación de núcleos para todas las soluciones saturadas exceptuando la solución con punto de saturación a $40^{\circ} \mathrm{C}$ lo cual fue explicado con anterioridad. 


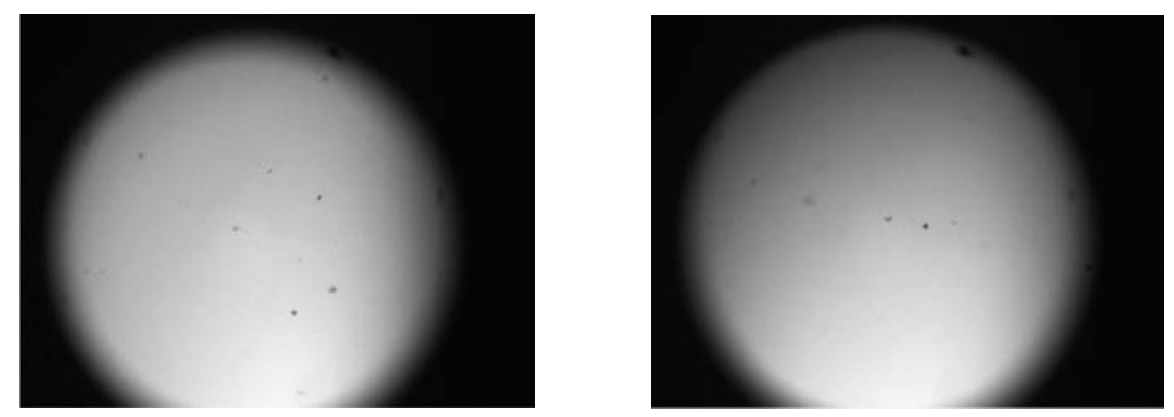

$$
\begin{array}{l|l|}
\mathrm{D}(4,3)=30.4 \mu \mathrm{m}-\mathrm{S}(4,3)=4.2 \mu \mathrm{m} & \mathrm{D}(4,3)=49.9 \mu \mathrm{m}-\mathrm{S}(4,3)=10.7 \mu \mathrm{m}
\end{array}
$$

a)
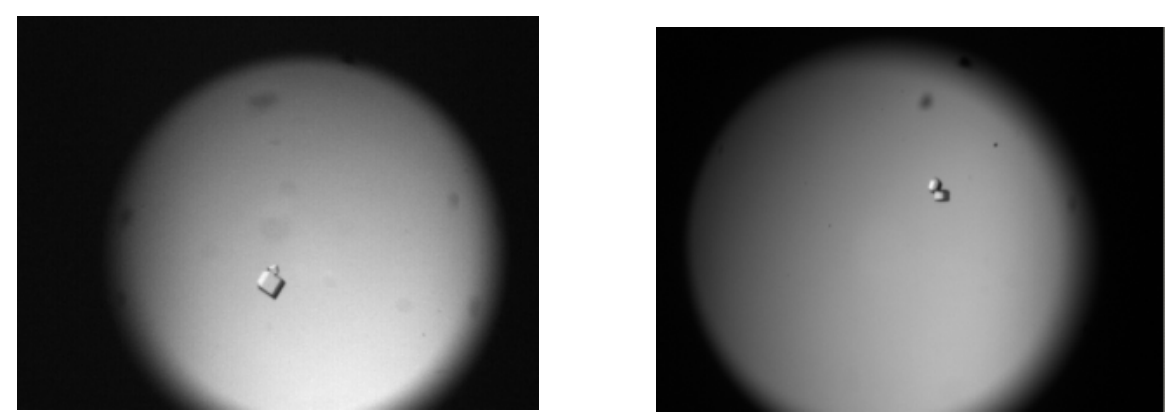

$$
\mathrm{D}(4,3)=50.9 \mu \mathrm{m}-\mathrm{S}(4,3)=4.5 \mu \mathrm{m} \quad \mathrm{D}(4,3)=130.2 \mu \mathrm{m}-\mathrm{S}(4,3)=1.3 \mu \mathrm{m}
$$

b)
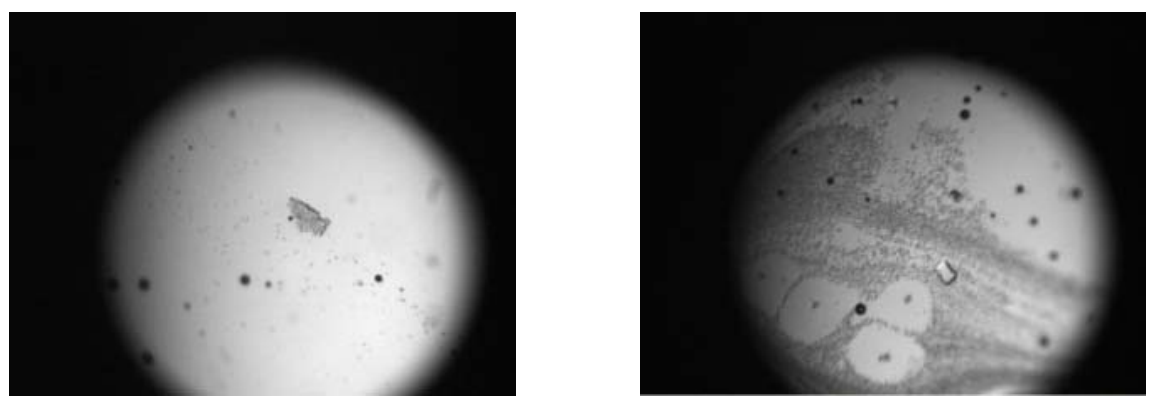

$\mathrm{D}(4,3)=83.1 \mu \mathrm{m}-\mathrm{S}(4,3)=23.1 \mu \mathrm{m}$ $\mathrm{D}(4,3)=57.1 \mu \mathrm{m}-\mathrm{S}(4,3)=21.6 \mu \mathrm{m}$

c)

Figura 2.5 Secuencia micrográfica de la producción y crecimiento de núcleos para una solución saturada a $40^{\circ} \mathrm{C}$. a) primera zona metaestable $\left(40-37^{\circ} \mathrm{C}\right)$, b) segunda zona metaestable $\left(36-33^{\circ} \mathrm{C}\right)$ y c) zona inestable $\left(32{ }^{\circ} \mathrm{C}\right.$ o menor $)$. 

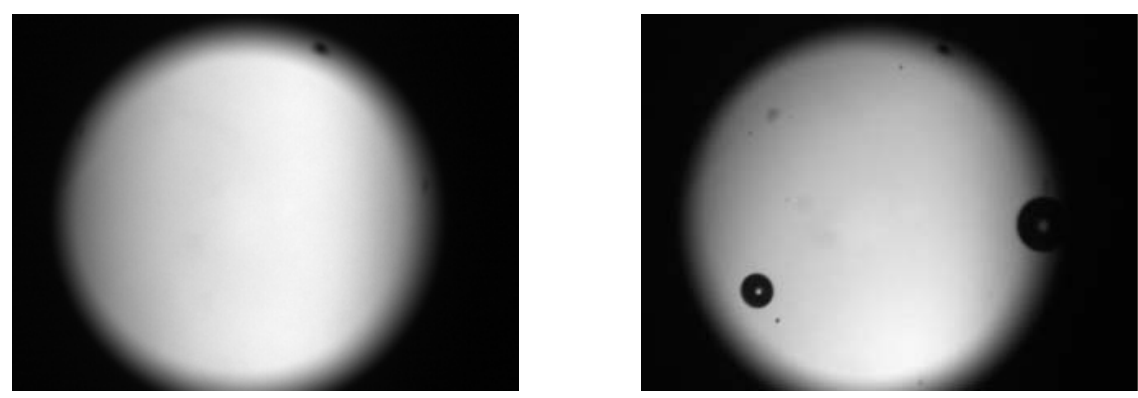

\begin{tabular}{|l|l|}
\hline $\mathrm{D}(4,3)=0 \mu \mathrm{m}-\mathrm{S}(4,3)=0 \mu \mathrm{m}$ & $\mathrm{D}(4,3)=0 \mu \mathrm{m}-\mathrm{S}(4,3)=0 \mu \mathrm{m}$ \\
\hline
\end{tabular}

a)
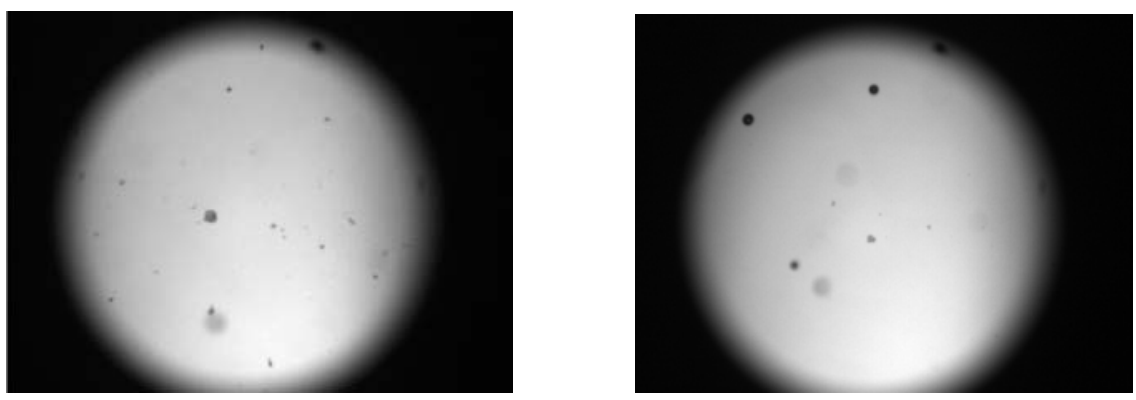

\begin{tabular}{|l|l|}
\hline$D(4,3)=51 \mu \mathrm{m}-\mathrm{S}(4,3)=2.6 \mu \mathrm{m}$ & $\mathrm{D}(4,3)=51.3 \mu \mathrm{m}-\mathrm{S}(4,3)=3.1 \mu \mathrm{m}$ \\
\hline
\end{tabular}

b)
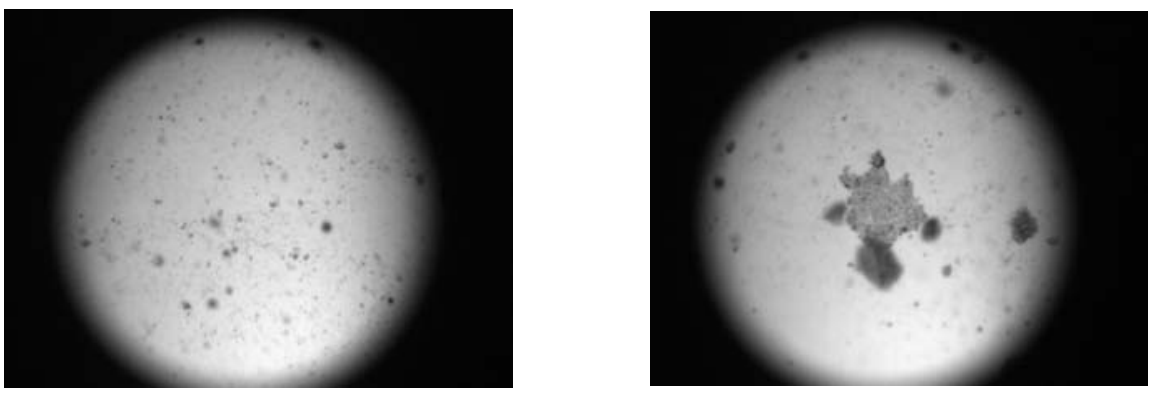

$$
\mathrm{D}(4,3)=34.6 \mu \mathrm{m}-\mathrm{S}(4,3)=5.4 \mu \mathrm{m}
$$

$\mathrm{D}(4,3)=54.5 \mu \mathrm{m}-\mathrm{S}(4,3)=10.1 \mu \mathrm{m}$

c)

Figura 2.6 Secuencia micrográfica de la producción y crecimiento de núcleos para una solución saturada a $50^{\circ} \mathrm{C}$. a) primera zona metaestable $\left(50-48{ }^{\circ} \mathrm{C}\right)$, b) segunda zona metaestable $\left(47-45^{\circ} \mathrm{C}\right)$ y c) zona inestable $\left(44^{\circ} \mathrm{C}\right.$ o menor). 


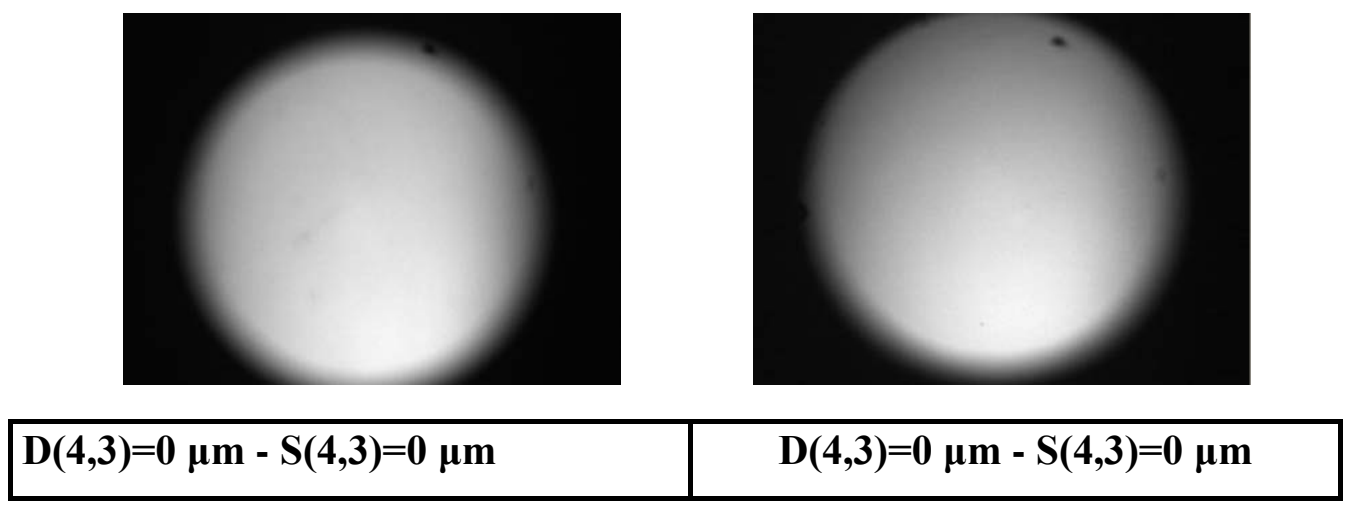

a)
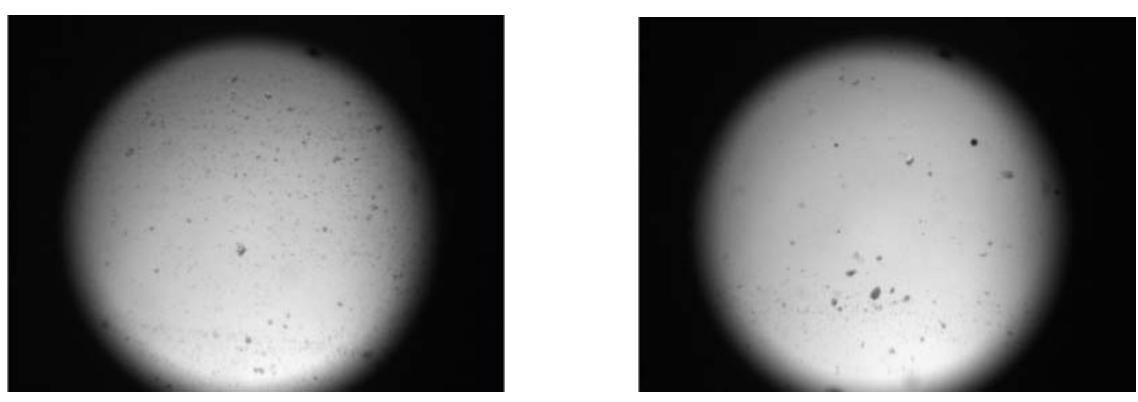

\begin{tabular}{|l|l|}
\hline $\mathrm{D}(4,3)=31.3 \mu \mathrm{m}-\mathrm{S}(4,3)=2.9 \mu \mathrm{m}$ & $\mathrm{D}(4,3)=44.6 \mu \mathrm{m}-\mathrm{S}(4,3)=8.6 \mu \mathrm{m}$ \\
\hline
\end{tabular}

b)
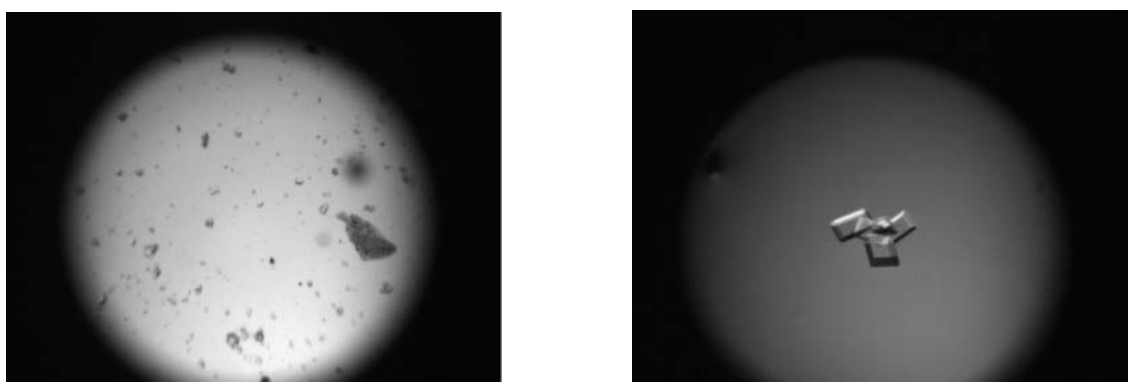

$$
\begin{array}{|l|l|}
\hline \mathrm{D}(4,3)=53.3 \mu \mathrm{m}-\mathrm{S}(4,3)=8.6 \mu \mathrm{m} & \mathrm{D}(4,3)=101.8 \mu \mathrm{m}-\mathrm{S}(4,3)=32.1 \mu \mathrm{m} \\
\hline
\end{array}
$$

c)

Figura 2.7 Secuencia micrográfica de la producción y crecimiento de núcleos para una solución saturada a $60^{\circ} \mathrm{C}$. a) primera zona metaestable $\left(60-59{ }^{\circ} \mathrm{C}\right)$, b) segunda zona metaestable $\left(58-56^{\circ} \mathrm{C}\right)$ y c) zona inestable $\left(55^{\circ} \mathrm{C}\right.$ o menor $)$. 


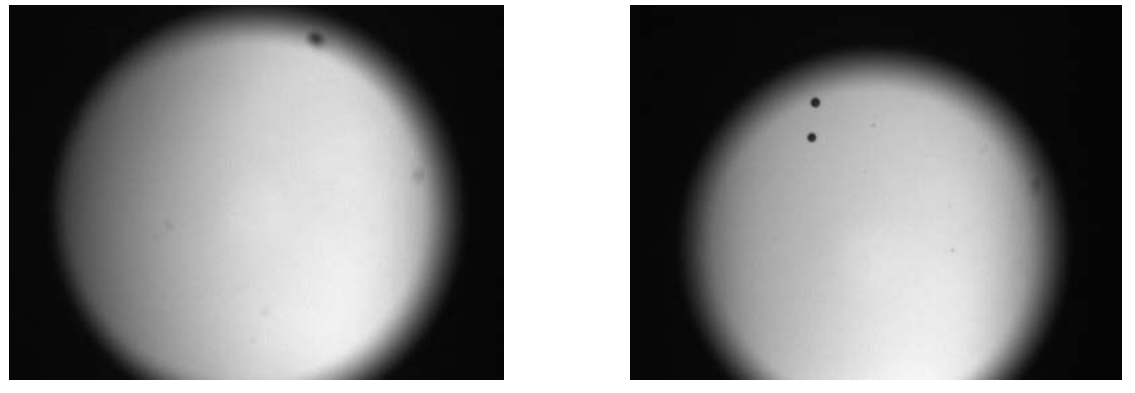

\begin{tabular}{|l|l|}
\hline$D(4,3)=0 \mu \mathrm{m}-\mathrm{S}(4,3)=0 \mu \mathrm{m}$ & $\mathrm{D}(4,3)=0 \mu \mathrm{m}-\mathrm{S}(4,3)=0 \mu \mathrm{m}$ \\
\hline
\end{tabular}

a)
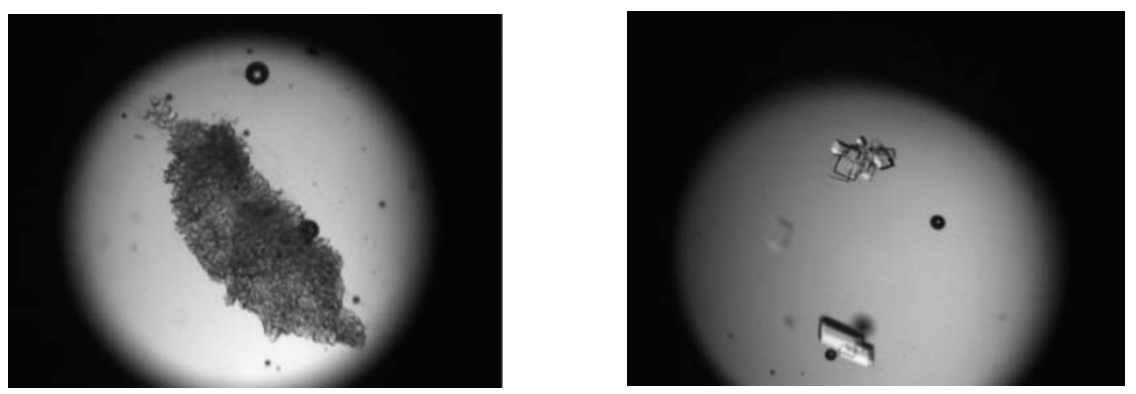

$$
\begin{array}{|l|l|}
\hline \mathrm{D}(4,3)=144 \mu \mathrm{m}-\mathrm{S}(4,3)=10.3 \mu \mathrm{m} & \mathrm{D}(4,3)=214.9 \mu \mathrm{m}-\mathrm{S}(4,3)=51.9 \mu \mathrm{m} \\
\hline
\end{array}
$$

b)
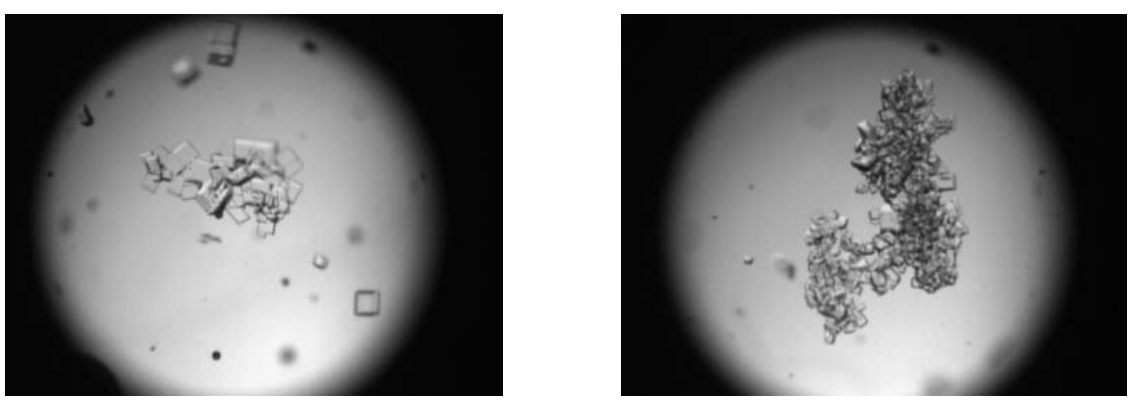

$$
\begin{array}{|l|l|}
\hline D(4,3)=160 \mu \mathrm{m}-\mathrm{S}(4,3)=46.5 \mu \mathrm{m} & D(4,3)=259 \mu \mathrm{m}-\mathrm{S}(4,3)=80.2 \mu \mathrm{m} \\
\hline
\end{array}
$$

c)

Figura 2.8 Secuencia micrográfica de la producción y crecimiento de núcleos para una solución saturada a $70^{\circ} \mathrm{C}$. a) primera zona metaestable $\left(70-67{ }^{\circ} \mathrm{C}\right)$, b) segunda zona metaestable $\left(66-65^{\circ} \mathrm{C}\right)$ y c) zona inestable $\left(64^{\circ} \mathrm{C}\right.$ o menor $)$. 


\subsubsection{Límites de las zonas metaestable y lábil}

La Tabla 2.5 presenta los puntos críticos de concentración en términos de densidad identificados por rangos de temperaturas y a la asignación de zonas (metaestable y lábil), según el análisis de la Sección 2.4.3, para las soluciones de saturación a 40, 50, 60 y $70{ }^{\circ} \mathrm{C}$.

Tabla 2.5. Identificación de los puntos críticos.

\begin{tabular}{|c|c|c|c|c|c|c|c|c|}
\hline \multirow[t]{2}{*}{ Zonas } & \multicolumn{2}{|c|}{$\begin{array}{c}\text { Solución } \\
\text { saturada } \\
70^{\circ} \mathrm{C}\end{array}$} & \multicolumn{2}{|c|}{$\begin{array}{c}\text { Solución } \\
\text { saturada } \\
60^{\circ} \mathrm{C}\end{array}$} & \multicolumn{2}{|c|}{$\begin{array}{c}\text { Solución } \\
\text { saturada } \\
50{ }^{\circ} \mathrm{C}\end{array}$} & \multicolumn{2}{|c|}{$\begin{array}{c}\text { Solución } \\
\text { saturada } \\
40^{\circ} \mathrm{C}\end{array}$} \\
\hline & $\begin{array}{c}\text { Temp. } \\
\left({ }^{\circ} \mathrm{C}\right)\end{array}$ & $\begin{array}{c}\text { Dens. } \\
\left(\mathrm{g} / \mathrm{cm}^{3}\right)\end{array}$ & $\begin{array}{c}\text { Temp. } \\
\left({ }^{\circ} \mathrm{C}\right)\end{array}$ & $\begin{array}{c}\text { Dens. } \\
\left(\mathrm{g} / \mathrm{cm}^{3}\right)\end{array}$ & $\begin{array}{c}\text { Temp. } \\
\left({ }^{\circ} \mathrm{C}\right)\end{array}$ & $\begin{array}{l}\text { Dens. } \\
\left(\mathrm{g} / \mathrm{cm}^{3}\right)\end{array}$ & $\begin{array}{c}\text { Temp. } \\
\left({ }^{\circ} \mathrm{C}\right)\end{array}$ & $\begin{array}{c}\text { Dens. } \\
\left(\mathrm{g} / \mathrm{cm}^{3}\right)\end{array}$ \\
\hline Primera & 70 & 1.3576 & 60 & 1.3542 & 50 & 1.3478 & 40 & 1.3409 \\
\hline zona & 67 & 1.3540 & 59 & 1.3537 & 48 & 1.3488 & 37 & 1.3407 \\
\hline Segunda & 66 & 1.3556 & 58 & 1.3551 & 47 & 1.3485 & 36 & 1.3429 \\
\hline zona & 65 & 1.3552 & 56 & 1.3535 & 45 & 1.3511 & 33 & 1.3439 \\
\hline $\begin{array}{c}\text { Zona } \\
\text { inestable }\end{array}$ & 64 & 1.3574 & 55 & 1.3560 & 44 & 1.3520 & 32 & 1.3453 \\
\hline
\end{tabular}

Temp. $=$ Temperatura; Dens. $=$ Densidad

La Figura 2.9 presenta el gráfico de densidad-temperatura donde se localizan los puntos críticos (límites de las zonas metaestable y lábil) considerando la temperatura menor de cada rango de temperatura presentado en la Tabla 2.5. La densidad correspondiente a cada temperatura de saturación $\left(40,50,60\right.$ y $\left.70{ }^{\circ} \mathrm{C}\right)$ fue localizada considerando la Figura 2.3 que presenta los promedios de densidad de las corridas experimentales.

De la Figura 2.9, se observa que el ancho de las zonas (metaestable y lábil) aumenta de forma no lineal conforme la temperatura de saturación (enfriamiento) disminuye en un rango de 70 a $40{ }^{\circ} \mathrm{C}$. Meade y Chen, (1977), reportaron que el ancho de cada una de estas zonas para una solución de azúcar de caña permanecen constantes (y lineales) a lo largo del mismo rango de temperatura de enfriamiento. 


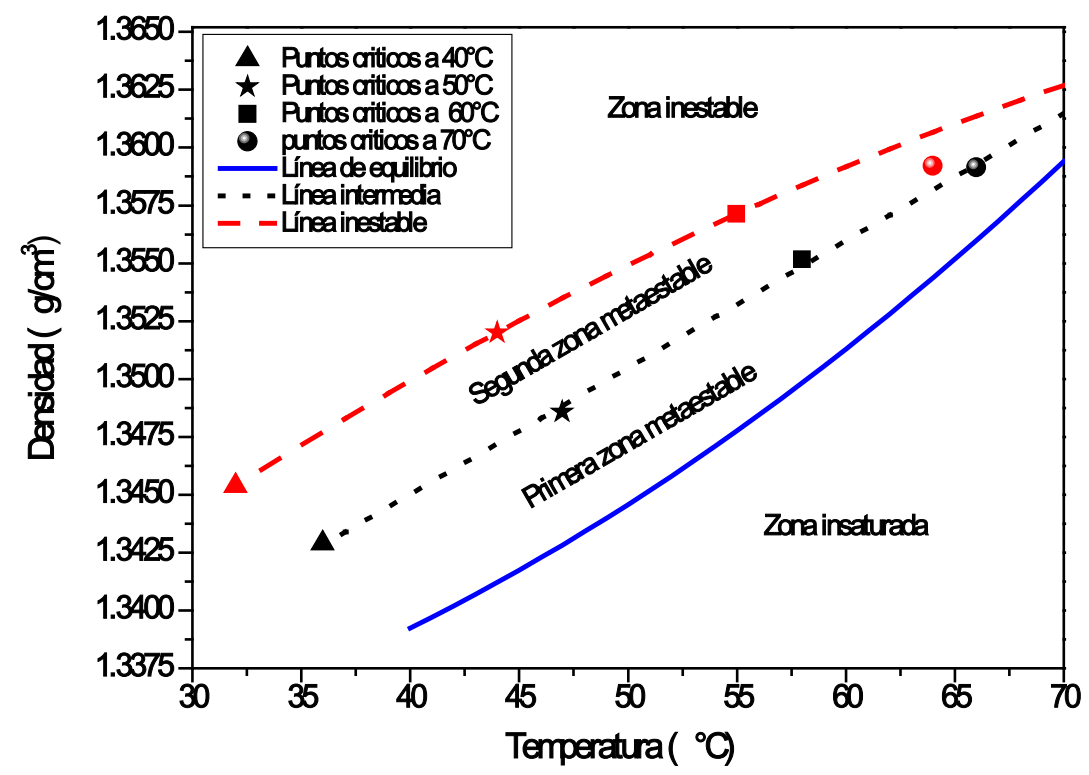

Figura 2.9 Identificación de los puntos críticos en un diagrama de concentración temperatura.

Con este trabajo se contribuye a tener un mejor conocimiento de la línea de saturación, zona metaestable (primera y segunda) y zona lábil; información que es requerida frecuentemente para tener un control adecuado de la sobresaturación en el proceso industrial de cristalización de azúcar de caña. Lo anterior conducirá a operar la cristalización de azúcar de caña en zonas aceptables y obtener una DTC específica al disminuir la dispersión por la inhibición de la nucleación homogénea y heterogénea. También permitirá desarrollar una estrategia confiable de control concentración - temperatura (C-Control).

\subsubsection{Modelado de los límites de concentración}

Una regresión no lineal de segundo orden fue aplicada a los datos experimentales presentados en la Figura 2.9 (software NCSS), obteniéndose la Ec. (2.6) y la Ec. (2.7) que describen el límite intermedio de la zona metaestable y el límite de inicio de la zona lábil o inestable. 
Línea intermedia con $\mathrm{R}^{2}=0.9988$ :
$\rho_{\text {intermedia }}=1.323293+5.397512 \mathrm{E}-04 * \mathrm{~T}+8.32078 \mathrm{E}-08 * \mathrm{~T}^{2}$

Donde $\rho_{\text {intermedia }}$ es la densidad en el límite intermedio de la zona metaestable en $\mathrm{g} / \mathrm{cm}^{3}$. El intervalo de densidad del modelo para un rango de temperatura de 70 a $40{ }^{\circ} \mathrm{C}$ es de 1.36148 a $1.34502 \mathrm{~g} / \mathrm{cm}^{3}$, respectivamente.

Línea lábil con $\mathrm{R}^{2}=0.9985$.

$\rho_{\text {labil }}=1.322541+8.325854 \mathrm{E}-04 * \mathrm{~T}-3.700576 \mathrm{E}-06 * \mathrm{~T}^{2}$

Donde $\rho_{\text {labil }}$ es la densidad del límite de inicio de la zona lábil en $\mathrm{g} / \mathrm{cm}^{3}$. El intervalo de densidad del modelo para un rango de temperatura de 70 a $40{ }^{\circ} \mathrm{C}$ es de 1.36269 a 1.34992 $\mathrm{g} / \mathrm{cm}^{3}$, respectivamente.

\subsubsection{Cinética de crecimiento}

La Figura 2.10 presenta las cinéticas de crecimiento a partir de datos experimentales de cada solución de saturación (70, 60, 50 y $\left.40^{\circ} \mathrm{C}\right)$, según el procedimiento de la Sección 2.3.6. De esta figura se observa que la pendiente inicial de la cinética de crecimiento es muy similar en todas las soluciones saturadas, pero con diferente magnitud en la velocidad de crecimiento debido a la sobresaturación disponible en cada sistema, ya que una solución a mayor temperatura de saturación $\left(70{ }^{\circ} \mathrm{C}\right)$, mayor será el soluto disponible para formación y crecimiento de cristales, como se presenta en la Tabla 2.4. Después de un cierto tiempo (de 20 a 30 minutos), la pendiente de la cinética de crecimiento se vuelve negativa indicando que la nucleación es el fenómeno dominante. Los coeficientes y valores de cada variable del modelo matemático empleado (Ec. 2.2) para las soluciones saturadas, se presentan en la Tabla 2.6. 


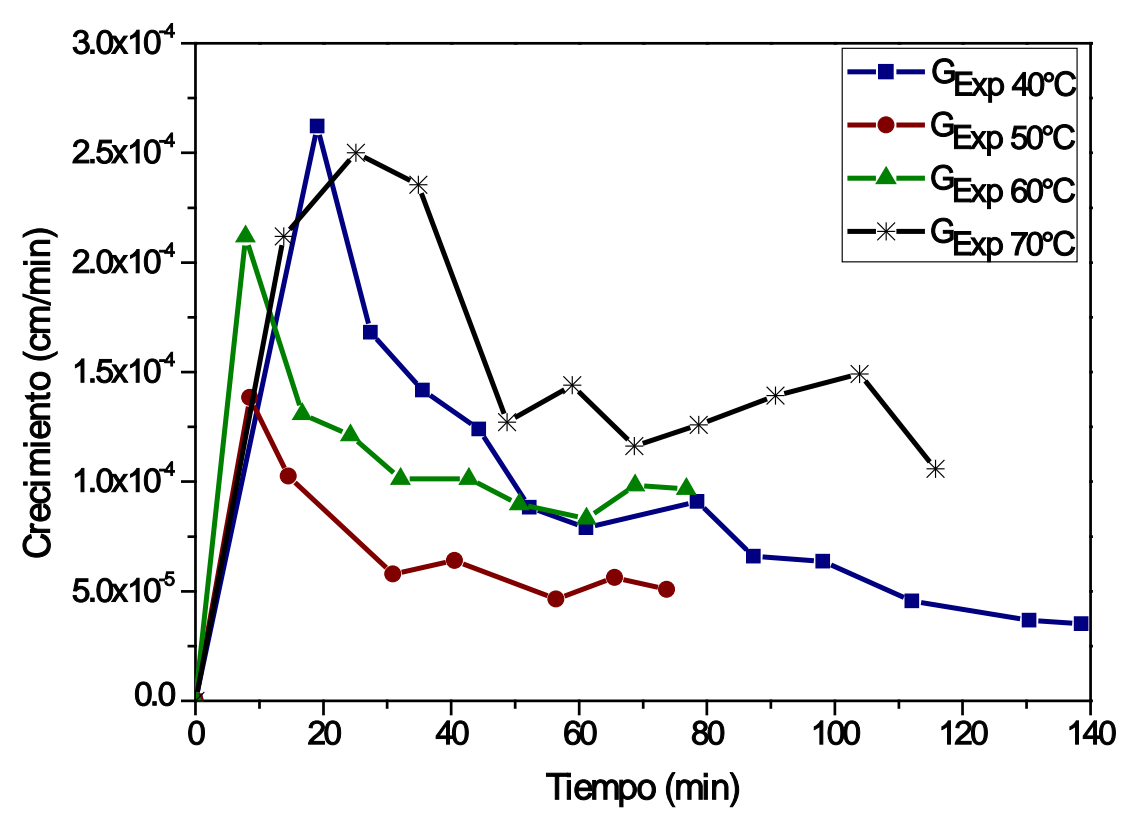

Figura 2.10 Cinética de crecimiento para cada solución saturada.

El parámetro $\mathrm{K}_{\mathrm{g}} \mathrm{y} \alpha$ identificado como la constante de velocidad y coeficiente exponencial de la densidad relativa, respectivamente, presentan un comportamiento descendente conforme la temperatura de saturación de las soluciones es menor. Esto excepto para la temperatura de saturación de $40{ }^{\circ} \mathrm{C}$, debido a que la solución saturada a esta temperatura ya contenía cristales pequeños de 30.4 a 49 ^m , esto también afectó en la obtención de $\mathrm{K}_{\mathrm{g}}$ para la $\mathrm{G}_{\rho \mathrm{\rho} a \mathrm{t}} 40^{\circ} \mathrm{C}$.

Tabla 2.6. Parámetros de los modelos cinéticos de crecimiento para las soluciones saturadas a $70,60,50$ and $40^{\circ} \mathrm{C}$.

\begin{tabular}{|c|c|c|c|c|c|}
\hline $\begin{array}{c}\text { Modelo } \\
(\mathrm{cm} / \mathrm{min})\end{array}$ & $\begin{array}{c}\mathrm{K}_{\mathrm{g}} \\
\left(\mathrm{cm}^{4} \cdot{ }^{\circ} \mathrm{C} / \mathrm{g} \cdot \mathrm{min}^{2}\right)\end{array}$ & $\begin{array}{c}\mathrm{t} \\
(\mathrm{min})\end{array}$ & $\begin{array}{c}\mathrm{T} \\
\left({ }^{\circ} \mathrm{C}\right)\end{array}$ & $\alpha$ & $\mathrm{R}^{2}$ \\
\hline $\mathrm{G}_{\rho_{\text {Sat } 70^{\circ} \mathrm{C}}}$ & $6.214943 \mathrm{E}-04$ & $0 \leq t \leq 115.7$ & $57 \leq T \leq 67$ & -.5367282 & 0.8351 \\
\hline $\mathrm{G}_{\rho_{\text {Sat } 60^{\circ} \mathrm{C}}}$ & $2.635383 \mathrm{E}-05$ & $0 \leq t \leq 76.7$ & $50 \leq T \leq 59$ & -1.087036 & 0.9149 \\
\hline $\mathrm{G}_{\rho_{\text {Sat } 50^{\circ} \mathrm{C}}}$ & $1.945965 \mathrm{E}-06$ & $0 \leq t \leq 73.7$ & $40 \leq T \leq 48$ & -1.489136 & 0.9617 \\
\hline $\mathrm{G}_{\rho_{\text {Sat } 40^{\circ} \mathrm{C}}}$ & $8.279054 \mathrm{E}-05$ & $0 \leq t \leq 138.5$ & $27 \leq T \leq 40$ & -.6492592 & 0.9026 \\
\hline
\end{tabular}


La Figura 2.11 presenta los datos experimentales de la cinética de crecimiento con respecto a la temperatura para la solución de saturación de $70{ }^{\circ} \mathrm{C}$ (ver Sección 2.4.3). En esta figura, se ilustra como ejemplo el bosquejo de los límites de densidad de las zonas (metaestable y lábil) de acuerdo a las temperaturas de la Tabla 2.5 (caso: $70{ }^{\circ} \mathrm{C}$ ). Se observa que en la primera zona metaestable no existen cristales o núcleos formados, ya que la sobresaturación del sistema no es lo suficientemente grande para formar núcleos, pero en el caso de ensemillado, el soluto disponible permitiría el crecimiento de éstos.

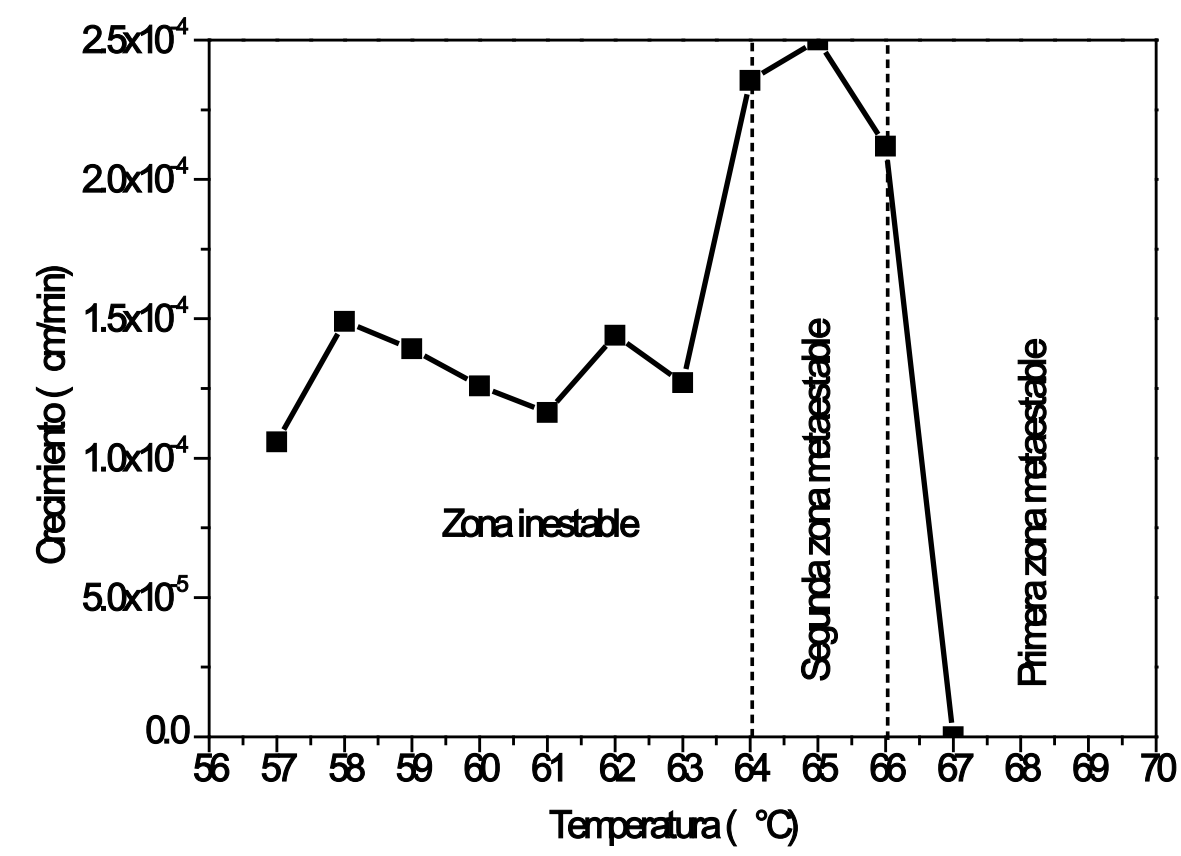

Figura 2.11 Cinética de crecimiento para una solución saturada a $70{ }^{\circ} \mathrm{C}$.

En la segunda zona metaestable se aprecia la formación de núcleos y crecimiento de cristales con una alta tasa de crecimiento. Finalmente, en la zona lábil o inestable se observa que la cinética de crecimiento disminuye, esto debido a que el soluto disponible en la fase continua emigra hacia la formación de nuevos núcleos y compite con la integración de soluto a la cara del cristal y su crecimiento, por lo que se considera que es el fenómeno de nucleación el que domina en esta zona. 


\subsection{Conclusiones}

Con la identificación de los puntos críticos de forma experimental y los modelos matemáticos que describen los limites de concentración de la línea de saturación o equilibrio, primera y segunda zona metaestable, y zona lábil en términos de densidad, sé encontró que el ancho de las zonas aumenta de forma no lineal conforme la temperatura de saturación (enfriamiento) disminuye en un rango de 70 a $40{ }^{\circ} \mathrm{C}$. Esta información es frecuentemente requerida en el proceso industrial de cristalización de azúcar de caña para tener un control adecuado de la sobresaturación, por lo que se contribuye a tener un mejor conocimiento de la línea de saturación, zona metaestable (primera y segunda) y zona lábil.

En la industria azucarera actualmente se cuenta con tres criterios de paró de forma generalizada: 1) La demanda de corriente eléctrica debido a la viscosidad de la templa, 2) medición de ${ }^{\circ}$ Brix y 3) la decisión del tachero en base a su experiencia. Sin embargo, ninguno de estos criterios de paró puede por sí solo dar información de que ruta de concentración y DTC se está llevando en la cristalización, es por ello que esta información puede contribuir como un criterio de paro más eficiente.

El método experimental desarrollado para la obtención de los límites de concentración para azúcar de caña refinada (comercial) es reproducible y puede también ser aplicado para otras sustancias cristalizables por enfriamiento. 


\section{Reconocimiento}

Parte del material presentado en este capítulo se utilizó para la elaboración del siguiente artículo:

O. Velazquez-Camilo, E. Bolaños-Reynoso*, L. Lopez-Zamora and J. Alvarez-Ramirez., Experimental Evaluation of the Concentration Zone Widths in Cane Sugar Crystallization using Data and Image Acquisition. ICSIE_49 (The 2010 International Conference of Signal and Image Engineering).

Oscar Velazquez-Camilo ${ }^{1}$, Eusebio Bolaños-Reynoso ${ }^{2}$, Eduardo Rodriguez ${ }^{1}$, Leticia LopezZamora $^{2}$ and Jose Alvarez-Ramirez ${ }^{1 *}$. Experimental Estimation of the Concentration Zone Widths in Cane Sugar Crystallization using Data and Image Acquisition. Journal of Crystal Growth. (Enviado; número de referencia: CRYS-S-10-01428). 
CAPÍTULO III

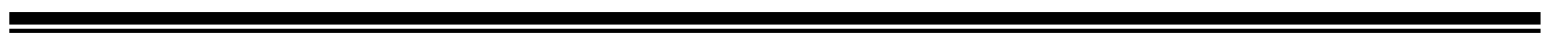




\section{Desarrollo de una Estrategia C-Control para la sobresaturación de azúcar de caña en un cristalizador por lotes a vacío}

\subsection{Resumen}

En este capítulo se diseñó e implementó una estrategia de control de la sobresaturación de azúcar de caña en un cristalizador por lotes a vacío a nivel planta piloto. En el capitulo anterior se especificó que la fuerza impulsora para la formación de partículas es la sobresaturación. Y ya que la industria azucarera en México actualmente no cuenta con sistemas de control eficientes en sus procesos para obtener productos con DTC específica, debido a la complejidad de determinar la sobresaturación en línea y a la falta de un control robusto, se propuso controlar esta variable, con el objetivo de obtener indirectamente una DTC específica y mayor Masa de Cristal Formado (MCF). El algoritmo de control fue de tipo C-control, obteniéndose un controlador PID retroalimentado servo-regulador para el control de la sobresaturación (densidad) en seudolínea, las variables manipulables fueron la presión de vacío (enfriamiento adiabático) y la temperatura en la chaqueta. Esta estrategia de control (C-control) generó un enfriamiento moderado por evaporación adiabática en el interior del cristalizador, beneficiándose el crecimiento de cristales de azúcar de caña. El incremento del tamaño de cristal, de la masa formada y el agotamiento de la sobresaturación disponible en el sistema, contribuyen a la reducción de mieles finales de proceso.

\subsection{Introducción}

Como el agua, la energía y el aire comprimido, el vacío es de gran utilidad en muchas plantas químicas (Vilbert, 2004). El vacío es usado para retirar gases o vapores que pueden interferir en una reacción, además de que refuerza la eficacia de la reacción, el rendimiento y la recuperación de compuestos esenciales. Con el vacío, el punto de ebullición de líquidos se reduce, lo cual es útil para procesos con compuestos sensibles a la temperatura como la 
cristalización de azúcar de caña (Tahal, 2000). La transferencia de calor a través de líquidos es más eficaz sin la presencia de burbujas de aire, así que los productos sólidos producidos de una fase líquida bajo vacío, son más homogéneos y están casi libres de burbujas de aire.

El ciclo tradicional de operación de la cristalización de azúcar se divide en varias fases secuénciales. Durante la primera fase el cristalizador es parcialmente lleno de un jugo que contiene sacarosa disuelta, llamado éste como licor. El licor es concentrado por evaporación hasta alcanzar un valor de sobresaturación definido. En esta fase se introducen semillas de cristal para inducir la producción de los cristales sembrados, reduciéndose el efecto de la nucleación espontánea (primaria) (Genk, 2000). Esto es el principio de la segunda fase. Posteriormente, se evapora agua con una presión de operación de vacío constante y la concentración del licor aumenta produciendo el crecimiento del cristal. En el proceso estándar de cristalización al vacío, la evaporación toma lugar y es necesario agregar más licor o agua para mantener el nivel medio de la sobresaturación y aumentar el volumen. La tercera fase consiste principalmente en controlar la capacidad de evaporación, por razones de economía en la fase final del proceso, se reemplaza el licor por otros jugos de menor pureza. Al final del proceso, el cristalizador está lleno de una suspensión de cristales de azúcar y mieles finales que se deja caer en un tanque de almacenamiento antes de ser centrifugado. El control del cristalizador involucra la manipulación de la velocidad de alimentación de licor de azúcar y jarabe, permaneciendo constante la presión de vacío en la mayoría de los lotes de proceso (Simoglou et al., 2005). Para controlar la temperatura, velocidad de agitación y presión de vacío entre otras variables de influencia en la DTC, así como para determinar la DTC mediante adquisición de imágenes y microscopia electrónica, se emplean nuevas herramientas tecnológicas. Éstas incluyen procesadores y sistemas operativos más poderosos, que han permitido el desarrollo de aplicaciones de sistemas de medición, control y automatización en laboratorios, mediante la interrelación de computadoras personales, herramientas de software y tecnologías de fácil implementación con bajo costo de mantenimiento. Tanto el desarrollo como la implementación de adquisición de datos computarizados tienen como objetivo lograr un control retroalimentado interactivo, así como mediciones más precisas (Kostic, 1998). En la actualidad, existen los sistemas llamados SCADA (Supervisory Control and Data Acquisition), los cuales son una aplicación de software diseñado para funcionar en computadoras sobre la producción, proporcionando comunicación con los 
dispositivos de campo (controladores autónomos, autómatas programables, etc.) y controlando el proceso de forma automática apoyándose, desde la pantalla de la computadora (Bolaños-Reynoso et al., 2008). El nivel de sobresaturación en cristalizadores por lotes a vacío (enfriamiento por evaporación adiabática) es determinada por el porcentaje de energía transferida, si la sobresaturación no es controlada adecuadamente para el crecimiento de los cristales existentes, ésta se dirigirá a un punto en el que se origina la nucleación espontánea provocando un incremento indeseable en el número de núcleos. Un modo deseable de operación es aquel que cambia el porcentaje de enfriamiento por evaporación adiabática para llevar a cabo un nivel de sobresaturación que apoye un adecuado porcentaje de crecimiento de los cristales sembrados y minimice o inhiba la nucleación. Trabajos anteriores utilizando regulación dinámica de la presión de vacío mediante la aplicación de un setpoint dinámico o perfiles de presión de vació (sistemas T-control) (Bolaños-Reynoso et al., 2008), han presentado un avance significativo en el control de la cristalización (favoreciendo el crecimiento de cristales y minimizando la nucleación). Sin embargo, por no conocerse la sobresaturación en línea/seudolinea se sigue operando en la zona lábil o inestable lo que conlleva a una producción súbita de núcleos los cuales compiten con los cristales existentes por el soluto disponible en la solución (fase continua).

El principal objetivo de este trabajo fue el diseño de un algoritmo de control de tipo Ccontrol (Fujiwara et al., 2005) para la sobresaturación (concentración en términos de densidad de la fase continua) dentro de la primera zona metaestable, obteniéndose un controlador PID retroalimentado servo-regulador en un cristalizador por lotes a vacío, las variables manipulables fueron: la presión de vacío (enfriamiento adiabático) y la temperatura en la chaqueta. Al controlar la sobresaturación dentro de la primera zona metaestable se busca asegurar que crezcan solamente los núcleos/cristales sembrados para obtener mayor MCF y uniformidad en la DTC.

\subsection{Metodología}

\subsubsection{Infraestructura}

El laboratorio de plantas piloto perteneciente a la División de Estudios de Postgrado e Investigación del I.T. de Orizaba, cuenta con una planta piloto con cristalizador por lotes a vacío 
de acero inoxidable con chaqueta de calentamiento - enfriamiento, un sistema de adquisición de datos e imágenes (LabView e IMAQ Vision Builder de National Instruments, Inc.), densímetro digital (DMA-4500 de Anton-Paar), caldera, motor de agitación variable y bomba de vacío como se ilustra en la Figura 3.1.

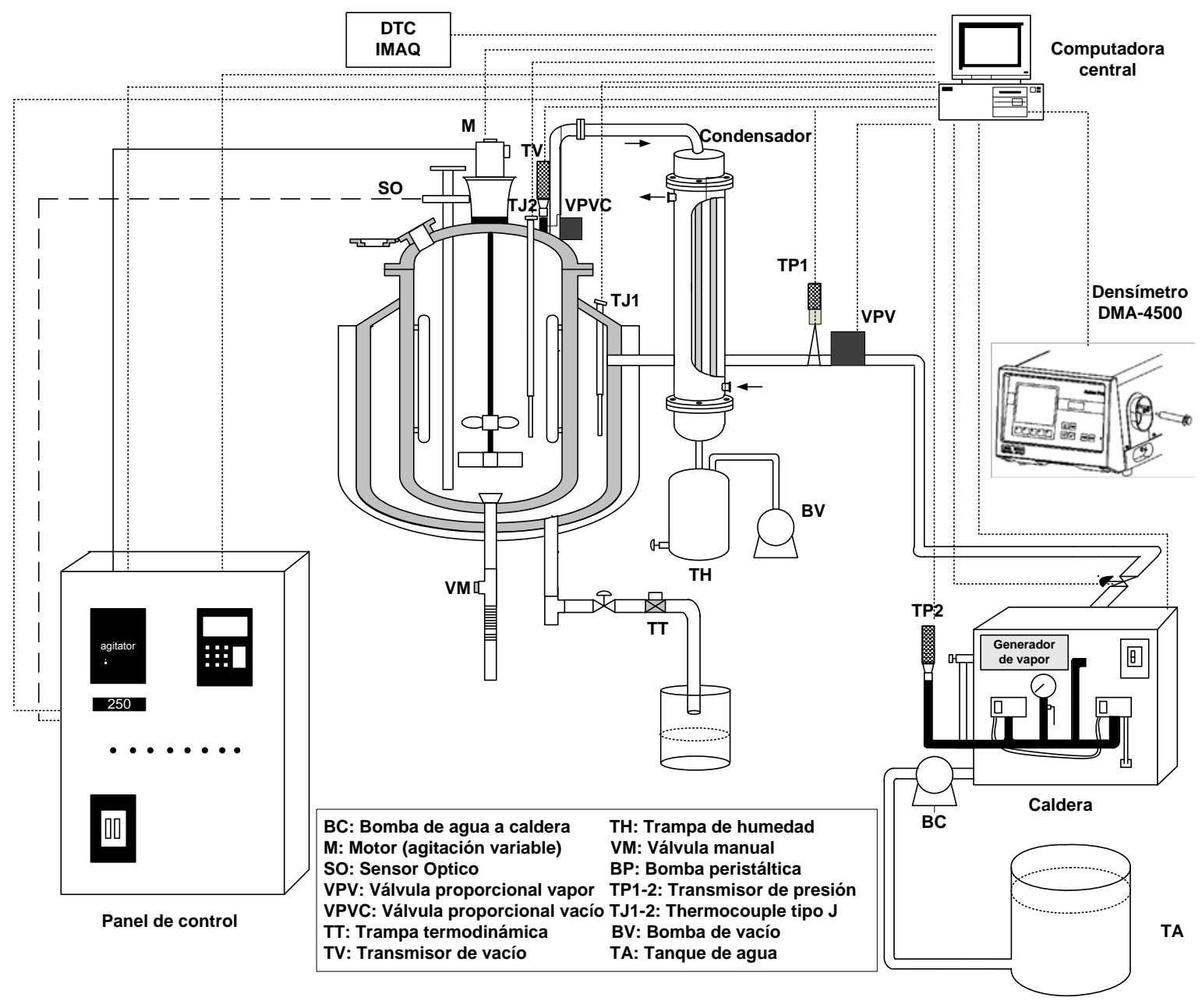

Figura 3.1 Cristalizador por lotes a vacío.

\subsubsection{Sistema de adquisición de datos e imágenes}

Los instrumentos y accesorios finales de control usados en la planta piloto se presentan en la Tabla 3.1. El sistema de adquisición de datos e imágenes consta de los dispositivos electrónicos presentados en la Tabla 3.2. 
Tabla 3.1. Instrumentos y dispositivos electrónicos del cristalizador por lotes a vacío.

\begin{tabular}{|c|c|}
\hline Cantidad & Dispositivos \\
\hline 1 & $\begin{array}{l}\text { Cristalizador de acero inoxidable de } 12.7779 \text { L., chaqueta de calentamiento- } \\
\text { enfriamiento de } 11.1019 \text { L., } 4 \text { deflectores de } 17 \mathrm{~cm} \text {. de ancho por } 3.5 \mathrm{~cm} \text {. de largo, } \\
\text { flecha de agitación de } 39 \mathrm{~cm} \text {. de largo. }\end{array}$ \\
\hline 1 & $\begin{array}{l}\text { Agitador para tanque cerrado modelo NSDB te HP, transmisión directa de } \\
\text { 1,750 rpm de } 1 \text { fase } 60 \text { ciclos, } 110 \text { VCA totalmente cerrado, sin ventilación, de } \\
\text { acero inoxidable } 316 \text { con brida de } 4 \text { in. de diámetro en acero inoxidable, con } \\
\text { flecha agitadora de } 26 \text { in. de longitud y } 1 \frac{1}{2} \text { in. de diámetro en acero inoxidable } 316 \text {. }\end{array}$ \\
\hline 1 & $\begin{array}{l}\text { Impulsor tipo propela marina de } 3 \text { in. de diámetro con tres hojas de acero } \\
\text { inoxidable } 316 \text {. }\end{array}$ \\
\hline 1 & Impulsor paletas planas en acero inoxidable 316, de 3 in. de diámetro. \\
\hline 2 & Termopar tipo J. Temperatura de 0 a $760{ }^{\circ} \mathrm{C}$, longitud de cable: $1 \mathrm{~m}$. \\
\hline 1 & $\begin{array}{l}\text { Bomba hidráulica QB60 marca Clean Water Puma. Potencia 1/2 HP para } 127 \\
\text { VCA monofásico, 3,450 rpm, } 35 \text { L/min de capacidad con } 1 \text { in. de entrada y salida. }\end{array}$ \\
\hline 2 & Termopozos de 1 in. de diámetro de entrada NPT en acero inoxidable. \\
\hline 1 & $\begin{array}{l}\text { Aislamiento térmico para alta temperatura a base de } 1 \frac{1}{2} \mathrm{in} \text {. de espesor de fibra de } \\
\text { vidrio de } 18 \mathrm{~kg} \text { de densidad con barrera de vapor de papel foil de aluminio, } \\
\text { acabado de lámina de aluminio calibre } 26 \text {, lisa, biselada y sujeta con alambre } \\
\text { galvanizado, capacidad de } 80-150^{\circ} \mathrm{C} \text {. }\end{array}$ \\
\hline 1 & Bomba de vacío Felisa modelo FE-1400, 0.33 HP y 0-60 Hz. \\
\hline 1 & $\begin{array}{l}\text { Variador de velocidad Allen-Bradley, modelo cat 1305-AA04A-ES-HA2 serie C, } \\
0.75 \mathrm{KW} / 1 \mathrm{Hp} \text {. }\end{array}$ \\
\hline 1 & $\begin{array}{l}\text { Generador de vapor SUSSMAN modelo MBA9. Presión máxima de trabajo } 100 \\
\text { Psi. Voltaje de trabajo } 240 \text { VAC. Voltaje de control } 120 \text { VAC. }\end{array}$ \\
\hline 1 & Trampa Termodinámica de 1/2 in. NPT. \\
\hline 1 & $\begin{array}{l}\text { Sistema de tubería galvanizada de } 1 / 2 \text { in. de diámetro para la circulación del agua } \\
\text { de calentamiento-enfriamiento. }\end{array}$ \\
\hline 1 & $\begin{array}{l}\text { Válvula reguladora de presión Norgren de } 1 / 2 \text { in., con entrada máxima de } 21 \\
\text { Kgcm-2 y descarga máxima de } 9 \mathrm{Kgcm}-2 \text {. }\end{array}$ \\
\hline 1 & $\begin{array}{l}\text { Condensador de acero inoxidable } 316 \text {, con entrada de } 1 / 2 \text { in. y salida de } 1 / 4 \text { de in. } \\
\text { con una longitud de } 27 \text { in. y } 4 \text { in. de diámetro. }\end{array}$ \\
\hline 1 & Tanque de plástico de capacidad de 1100 L., con tapa roscada. \\
\hline 1 & $\begin{array}{l}\text { Trampa húmeda de acero inoxidable } 316 \text { con una longitud de } 13 \text { in. y } 3 \text { in. de } \\
\text { diámetro, entrada, salida y purga de } 1 / 2 \text { in. }\end{array}$ \\
\hline
\end{tabular}


Tabla 3.2. Dispositivos electrónicos para el sistema de adquisición de datos e imágenes

\begin{tabular}{|c|l|}
\hline Cantidad & \multicolumn{1}{|c|}{ Dispositivos } \\
\hline 3 & $\begin{array}{l}\text { Tarjetas de adquisición de datos: PCI-6229M, PCI-6023E y PCI-6025E de } \\
\text { National Instruments Inc. }\end{array}$ \\
\hline 1 & $\begin{array}{l}\text { Tarjeta de adquisición de datos: PCI-232/485.2CH. National Instruments, } \\
\text { Inc. }\end{array}$ \\
\hline 1 & Tarjeta de adquisición de imágenes PCI-1407 de National Instruments, Inc. \\
\hline 1 & Portador de módulos blindado SC-2345 de National Instruments, Inc. \\
\hline 1 & Bloque conector blindado SCB-68 de National Instruments, Inc. \\
\hline 2 & $\begin{array}{l}\text { Módulos de acondicionamiento de señal: 2 SCC-TC02 y 2 SCC-CI20, de } \\
\text { National Instruments, Inc. }\end{array}$ \\
\hline 1 & Bloque conector SCB-100 de National Instruments, Inc. \\
\hline 1 & Transmisor de presión de vacío modelo 07356-02. Marca Cole-Parmer. \\
\hline 1 & Microscopio electrónico trinocular 48923-30. Marca Cole-palmer. \\
\hline 1 & $\begin{array}{l}\text { Cámara monocromática con video RS-170. Lente de 0.19 mm por píxel, de } \\
\text { National Instruments, Inc. }\end{array}$ \\
\hline
\end{tabular}

\subsubsection{Estrategia de control C-control (C-T)}

Las tendencias tecnológicas en el campo de la cristalización indican que los sistemas CControl son superiores a los sistemas tradicionales dependiente del tiempo (T-control) basados en funciones indexadas (Fujiwara et al., 2005), por ello se decidió implementar un sistema CControl. Para la implementación de la estrategia C-Control se obtuvieron las líneas de equilibrio a partir de experimentos basados en un diseño de enfoque directo para delimitar las zonas de concentración metaestables en términos de densidad (línea de saturación, zona metaestable (primera y segunda) y zona lábil) (Capítulo 2, Sección 2.4.5). De lo anterior se identificó la primera zona metaestable como la zona donde se favorece el crecimiento de cristales (sembrados) y se inhibe la nucleación espontánea, y en la segunda zona metaestable como la zona donde coexisten ambos fenómenos fisicoquímicos (crecimiento y nucleación) pero es el crecimiento del cristal la cinética dominante, por lo que aún se favorece el crecimiento de los cristales sembrados 
al inicio del proceso, por otro lado la zona lábil es la zona donde también coexisten ambos fenómenos fisicoquímicos. Sin embargo, la nucleación es la cinética dominante con respecto al crecimiento del cristal. Una vez obtenidas las líneas de equilibrio, se desarrollaron instrumentos virtuales mediante programación gráfica en LabView de National Instruments Inc. (Antonio y Romero, 2009) para la implementación de los límites de las zonas de concentración para azúcar de caña refinada en términos de densidad.

El desarrollo del panel de control central, permitió dar seguimiento a las variables más importantes del proceso (concentración, presión de vacío, presión de vapor de caldera, velocidad de agitación, temperatura del interior y chaqueta del cristalizador entre otras) (Ver Figura 3.2), información necesaria para tener un control adecuado de la sobresaturación en el proceso industrial de cristalización de azúcar de caña. El panel de control principal consta de pestañas secundarias en donde se puede dar seguimiento de forma específica a las variables más importantes del proceso, las pestañas son: Concentración, temperatura, presión de vacío, presión de vapor, agitación, enfriamiento directo y resultados. Todas las características y detalles de estas pestañas están presentadas en el Apéndice C, Sección C.1.

Como objetivo de control se pensó en mantener un gradiente adecuado de sobresaturación dentro de la primera zona metaestable y usar la segunda zona metaestable como una zona de amortiguamiento para compensar las perturbaciones al sistema provenientes principalmente por el retardo en la medición de la densidad. Las variables manipulables fueron: la presión de vacío y la temperatura en la chaqueta, para ello se emplearon válvulas proporcionales de vacío y vapor como elementos finales de control, ambas válvulas fueron programadas para responder a sistemas con dinámicas lentas (ver Apéndice C, Sección C.2). Dentro de las perturbaciones principales se encuentran el flujo de vapor en la chaqueta y el retardo en la medición de concentración (densidad). Una vez definido los elementos del lazo cerrado, se obtuvo una función de transferencia de primer orden, a partir de la curva de reacción experimental (respuesta concentración-temperatura). El controlador propuesto fue un servo-regulador PID retroalimentado, sintonizado con el método de razón de decaimiento de un cuarto de ZieglerNichols (Ogata, 2003; Smith y Corripio, 1991). 


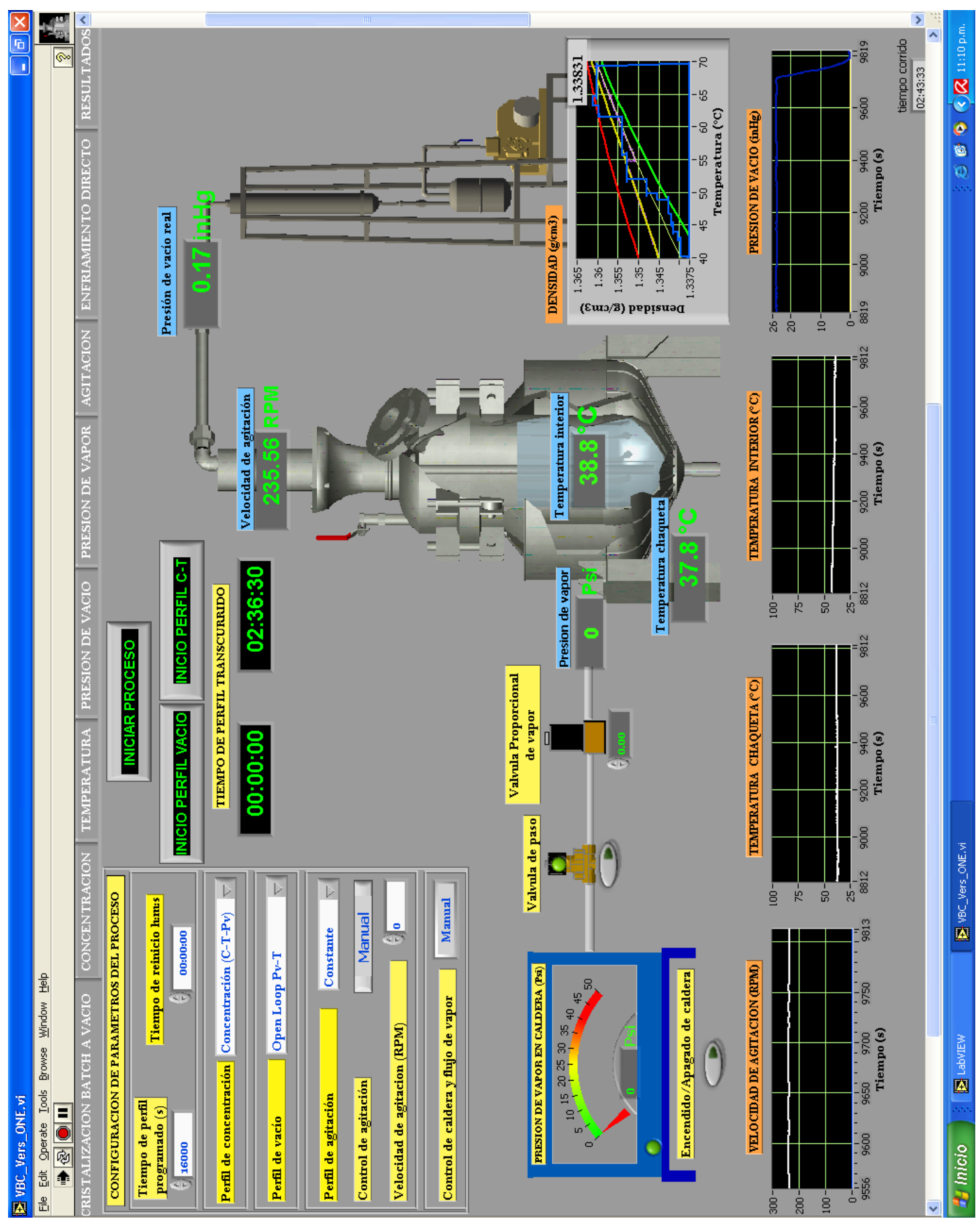

告 


\subsubsection{Condiciones iniciales del proceso}

El rango de enfriamiento adiabático fue de 70 a $40{ }^{\circ} \mathrm{C}$, debido a que a nivel industrial estas son las temperaturas de operación tradicionales y porque las líneas de equilibrio fueron obtenidas para este rango de temperaturas. La masa sembrada se fijó en 4.5 gr de

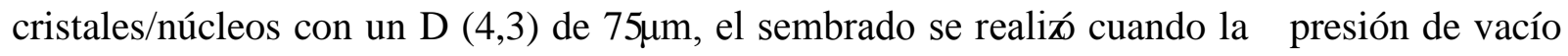
se estabilizaba entre 21 inHg y 21.5 inHg, correspondiente a los 2 minutos de arrancado el proceso. Se prepararon 12,158.67 gr de solución de azúcar de caña saturada a $70{ }^{\circ} \mathrm{C}$ de acuerdo a la metodología descrita por Bolaños-Reynoso et al., (2008) que consiste de 9,235.98 g de azúcar comercial y 2,922.68 g de agua (concentración de $75.962{ }^{\circ}$ Brix a la temperatura de saturación de $70{ }^{\circ} \mathrm{C}$ ) en el interior del cristalizador, la velocidad de agitación se mantuvo constante a 250 rpm durante todo el lote. La temperatura inicial de la chaqueta e interior del cristalizador fue de $70^{\circ} \mathrm{C}$, y la presión de vacío inicial fue de $0 \mathrm{inHg}$. La densidad inicial se obtiene 2 minutos antes de arrancar el proceso a partir del muestreo que sirve para verificar si la solución está en el punto de saturación.

\subsection{Resultados}

\subsubsection{Identificación de las variables del proceso}

En la Figura 3.3 se presentan esquemáticamente las variables del proceso más importantes a considerar para la implementación de un sistema de control en la cristalización de azúcar de caña refinada. Se observa un sistema multivariable con tres posibles entradas manipulables y tres variables de carga o de perturbación potencial, y tres posibles variables controlables como salida. Las variables manipulables son la temperatura de la chaqueta $\left(\mathrm{T}_{\mathrm{j}}\right)$, presión de vacío (Pvac) y las condiciones de la siembra (DTC y cantidad de masa sembrada). 


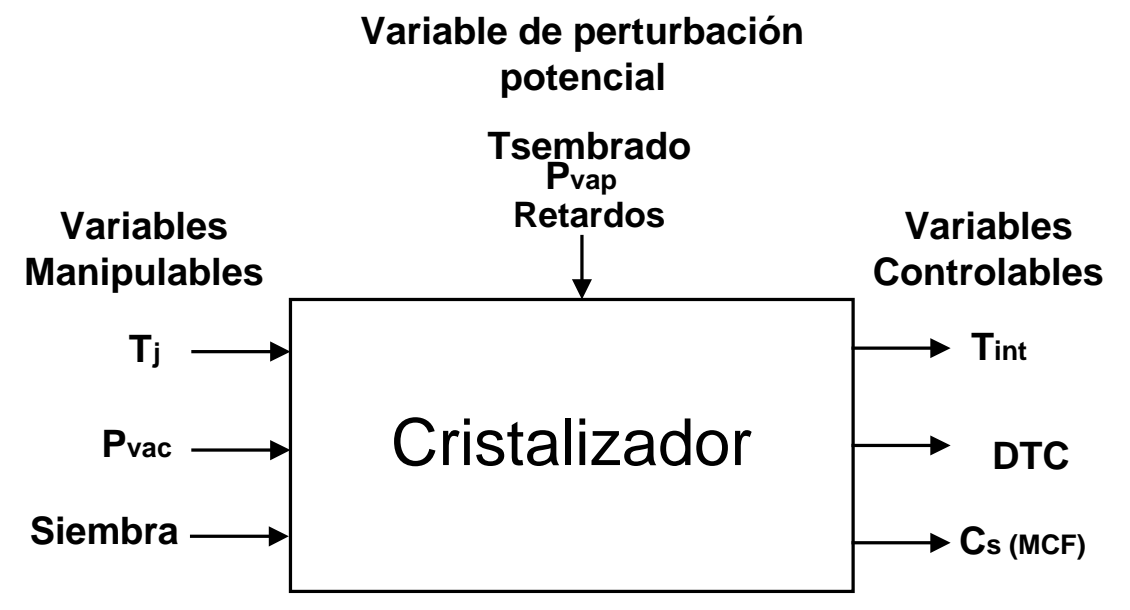

Figura 3.3 Variables relevantes del proceso de cristalización por lotes a vacío.

Las variables de perturbación potencial están conformadas por el tiempo de siembra (Tsembrado), presión de vapor (Pvap) y retardos de los equipos de medición. Las variables controlables están integradas por la temperatura del interior del cristalizador ( $\left.T_{\text {int }}\right)$, la DTC y la concentración de sobresaturación $\left(\mathrm{C}_{\mathrm{s}}\right)$. De lo anterior se optó por tomar como variables manipulables la temperatura en la chaqueta y la presión de vacío, para controlar la concentración de sobresaturación y la temperatura del interior del cristalizador, considerando como variables de perturbación la presión de vapor en la chaqueta y el retardo de los equipos de medición principalmente del densímetro DMA-4500 que puede variar entre 5 y 10 minutos.

Otra variable importante que se debe medir en línea es la temperatura de equilibrio ( $\mathrm{T}_{\mathrm{Eq}}$.) o también conocida como punto de elevación, la cual indica el punto (temperatura) en que la solución empieza a evaporarse para un valor de presión de vacío especifico, de tal forma que entre más aumenta la presión de vacío menor será la temperatura de equilibrio en el sistema y menor la temperatura para que el agua de la solución se evapore, ésta información es muy útil conocerse en línea ya que permite saber cuándo se está evaporando y con ello la sobresaturación del sistema. Para obtener la temperatura de equilibrio se realizó una corrida experimental con solución de azúcar de caña saturada a $70{ }^{\circ} \mathrm{C}$, la cual fue calentada hasta 80 ${ }^{\circ} \mathrm{C}$ y enfriada adiabáticamente hasta $49^{\circ} \mathrm{C}$ realizando cambios de tipo escalón positivos en la presión de vacío del sistema en un rango de 17.5 a 24 inHg, en total se realizaron 12 cambios tipo escalón alcanzándose un estado estacionario en el sistema entre cada cambio escalón, en 
la Figura 3.4 se presentan los datos experimentales y su ajuste polinomio descrita por la Ec. (3.1), con $\mathrm{R}^{2}=0.9967$.

$\mathrm{T}_{\mathrm{Eq} .}=9.7579+9.72314 \cdot \mathrm{Pvac}-0.33703 \cdot \mathrm{Pvac}^{2}$

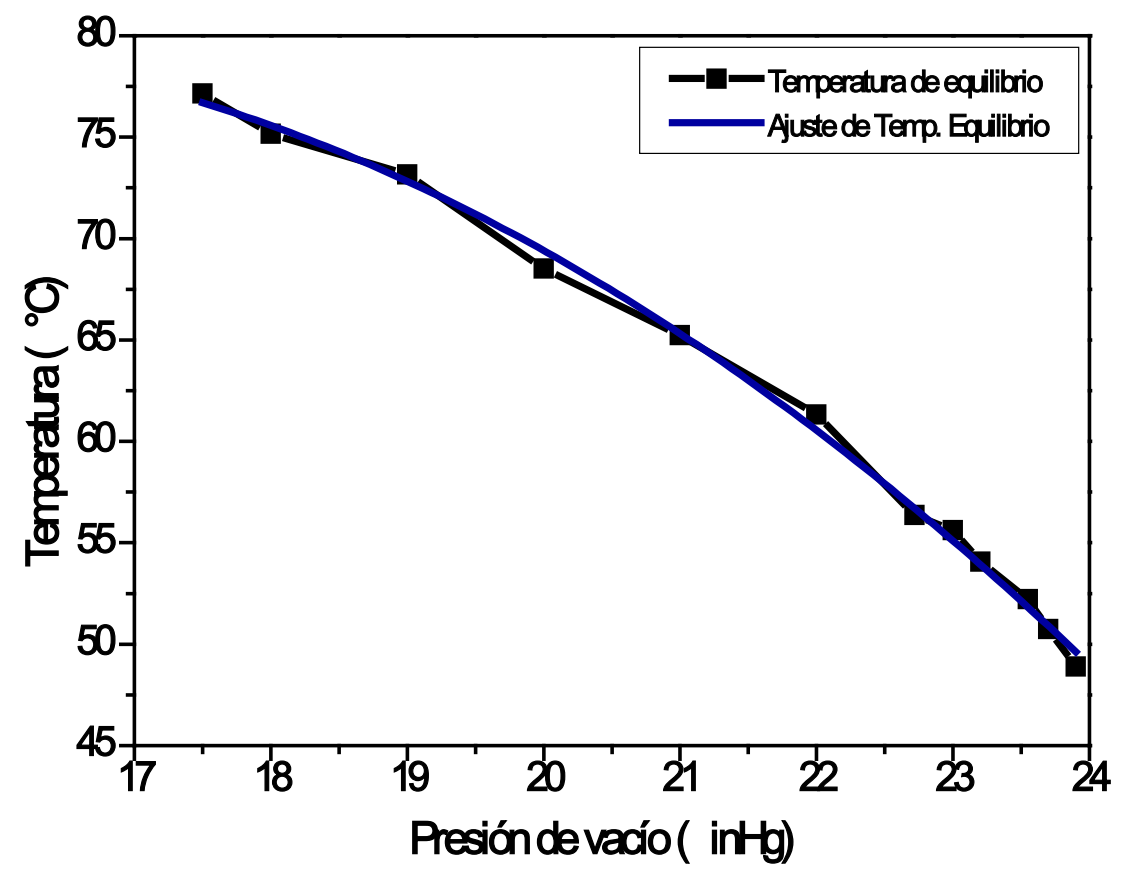

Figura 3.4 Temperatura de equilibrio con respecto a la presión de vacío.

\subsubsection{Análisis a lazo abierto}

En la Figura 3.5 se presenta la respuesta del proceso a lazo abierto para la concentración en términos de densidad, la presión de vacío y la temperatura del interior del cristalizador. Esta corrida experimental se realizó con el fin de observar la sensibilidad de las variables manipulables descritas en la Sección 3.3.3. Se observa que en los primeros 50 minutos la concentración del sistema tiende a aumentar y a disminuir después de este tiempo hasta alcanzar 168 minutos, así mismo la presión de vacío permanece con una tendencia constante los primeros 50 minutos con aproximadamente 20.5 inHg y posteriormente aumenta con una tendencia de tipo lineal de 20.5 a 24 inHg hasta alcanzar 168 minutos. 


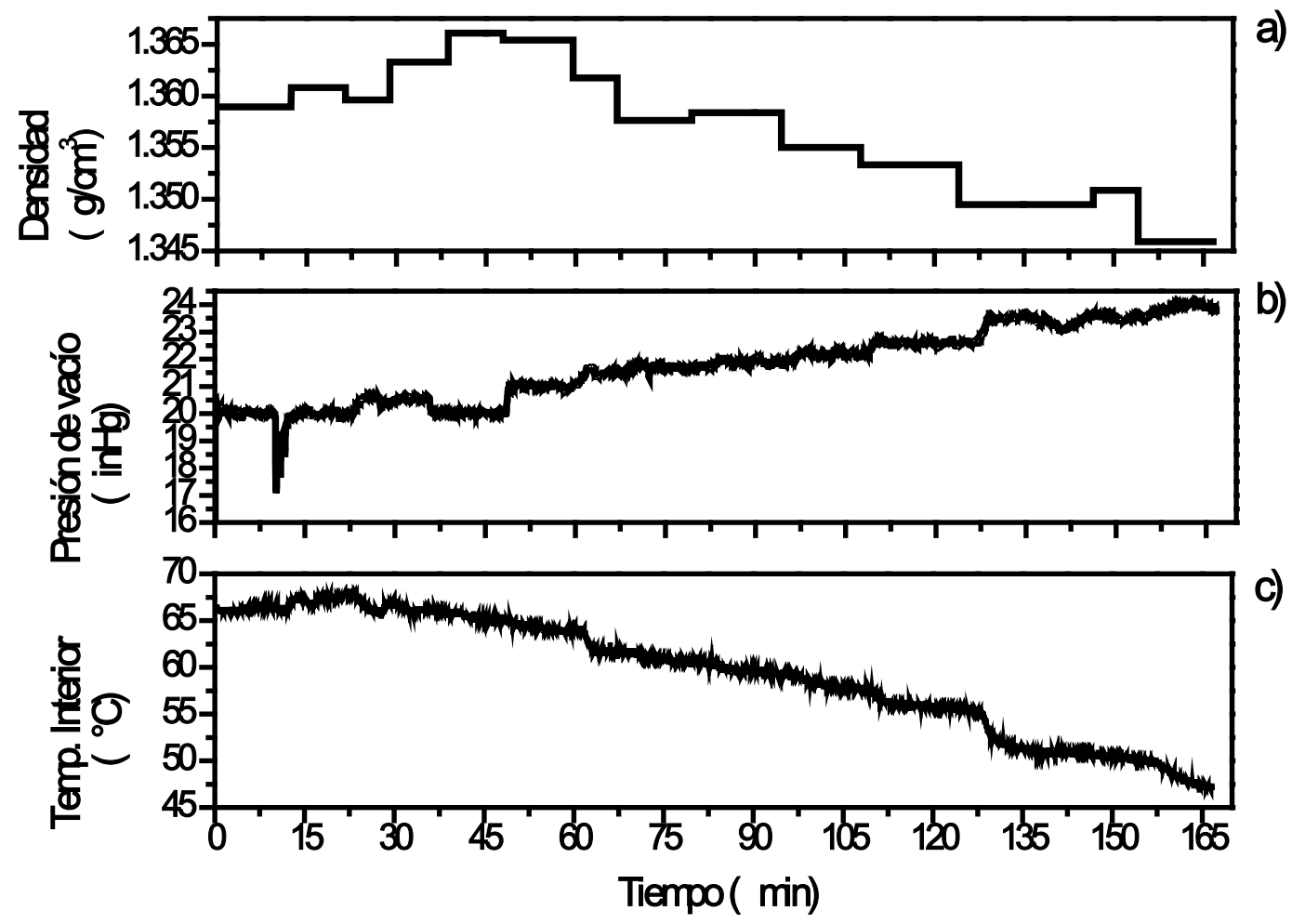

Figura 3.5 Respuesta del proceso a lazo abierto. a) densidad, b) presión de vacío y c) temperatura del interior del cristalizador.

La temperatura presenta la misma tendencia que la presentada por la presión de vació pero de forma inversa, permaneciendo constante los primeros 50 minutos y disminuyendo con una tendencia lineal los últimos 118 minutos del proceso.

En la Figura 3.6 se presenta un diagrama de concentración-temperatura en donde los primeros 50 minutos del proceso se observa una dinámica inestable en la densidad (fase continua), posteriormente en los últimos minutos la densidad se ubica dentro la primera zona metaestable, muy cerca de la línea intermedia. Es fácil de observar que el sistema por sí solo es difícil de ser controlado dentro de la primera zona metaestable (ver Figura 3.6). Aunque la densidad en todo el tiempo de lote es medida de la misma forma como se específico en la Sección 2.3.2 y 2.3.3, es posible que a tiempos tempranos la densidad de la solución aumente debido a la presencia de núcleos/cristales de tamaños que se ubicarían en la escala manométrica difíciles de ser filtrados por el papel azucarero estándar (19 $\mu$ m porosidad), lo cual es imposible de ser verificado con el sistema de adquisición de imágenes actual que 
realiza mediciones por arriba de $1 \mu \mathrm{m}$. Por lo anterior, sería recomendable utilizar un sistema de adquisición de imagen más potente en resolución microscópica y un mejor medio filtrante, o en su defecto implementar un sistema de muestreo diferente. Otra alternativa son las técnicas de difracción de rayo laser, que aún para cristales de $0.05 \mu \mathrm{m}$, estos núcleos son detectables debido a su capacidad de desviar el haz de rayo laser.

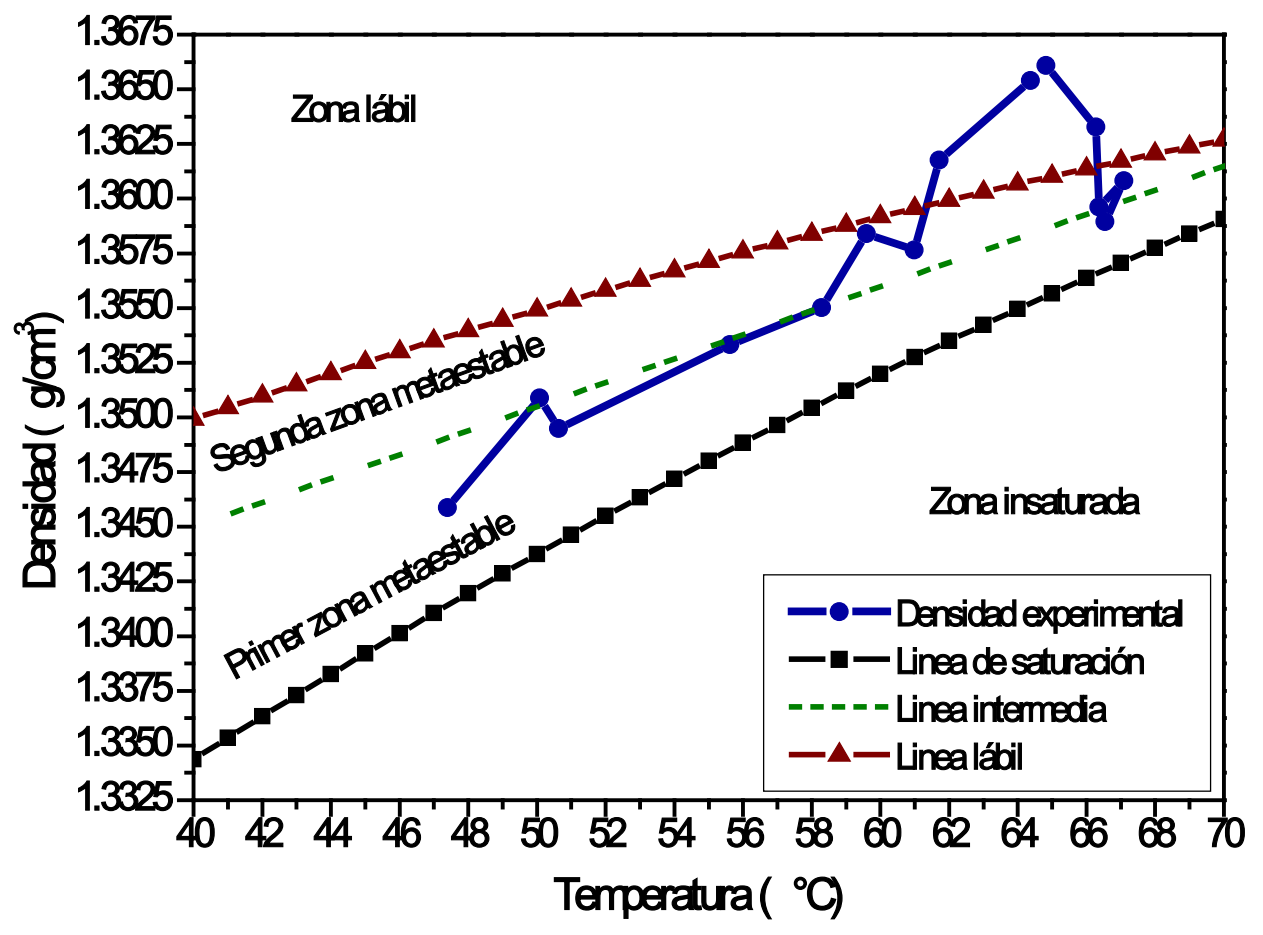

Figura 3.6 Diagrama concentración-temperatura a lazo abierto.

Lo anterior puede ser explicado mediante un análisis de las temperaturas del sistema (temperatura interior, temperatura chaqueta y temperatura de equilibrio) presentado en la Figura 3.7 y su interacción con la presión de vació. Se observa de la Figura 3.7 que la temperatura interior no sobrepasa a la temperatura de equilibrio y solo en algunos puntos llega a estar en el mismo valor, sin embargo la temperatura de la chaqueta si sobrepasa por muchos grados centígrados a la temperatura del interior y de equilibrio durante los primeros 45 minutos y esporádicamente a lo largo del proceso. Lo anterior proporciona una evaporación abrupta del disolvente (agua) provocan a su vez un gradiente de sobresaturación grande que repercute en la generación de nucleación espontánea e incluso aglomerados de cristales. 


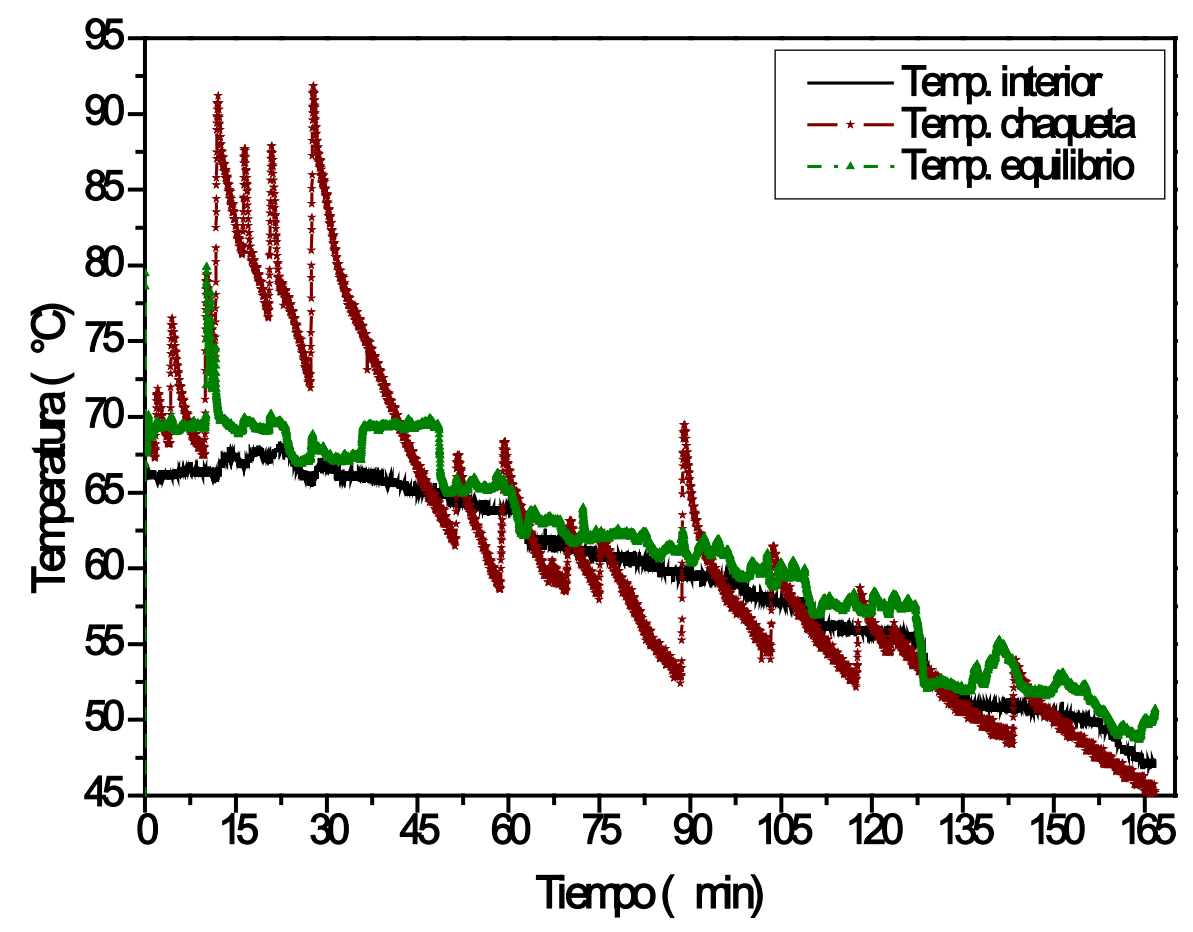

Figura 3.7 Temperaturas del sistema a lazo abierto.

Esto representa una cristalización en donde se alcanza la sobresaturación de manera poco eficiente por evaporación abrupta. Por lo tanto, si la temperatura en la chaqueta disminuye en un gradiente considerable con respecto a la temperatura de equilibrio, entonces se favorecerá la transferencia de energía del interior del cristalizador (seno de la solución) hacia la chaqueta (formándose cristales que requerirán un extenso tiempo de proceso). Esto representa una cristalización en donde se alcanza la sobresaturación por enfriamiento a presión atmosférica. No obstante, si la temperatura en la chaqueta sigue una tendencia muy estrecha con respecto a la temperatura de equilibrio, al aumentar la presión de vacío se estaría enfriando la solución para favorecer la cristalización (favoreciéndose el crecimiento de cristales sembrados y evitándose la nucleación espontánea). Esto representa una cristalización en donde se alcanza la sobresaturación de manera eficiente por enfriamiento adiabático teniendo como variable manipulable la presión de vacío.

En ninguno de los casos los perfiles de enfriamiento del interior del cristalizador y de la chaqueta de enfriamiento deberían de cruzarse, ya que esto significaría que en lugar de estarse enfriando el sistema la chaqueta estaría proporcionando calor al interior en lugar de 
retirarlo del equipo. Esta consideración física se ve reflejada en el balance de energía como una violación a la segunda ley de la termodinámica, la cual establece que la energía fluye de forma natural hasta alcanzar su equilibrio térmico de las zonas más calientes a las más frías, sin la presencia de un sistema que genere trabajo.

Así que se le atribuye a la temperatura de la chaqueta la razón por la cual la densidad es llevada por arriba de la línea lábil lo cual es indeseable en el proceso de cristalización. Lo anterior llevó a configurar un lazo de control para la temperatura de la chaqueta manipulando la presión de vapor proveniente de la caldera con una válvula proporcional, con el objetivo de mantener la temperatura de la chaqueta lo más cercana a la temperatura de equilibrio y que solamente fuese la presión de vacío la variable que influyera de manera directa en el control de la sobresaturación. Sin embargo, por no contarse con otra variable que liberará la presión de vapor dentro de la chaqueta cuando ésta por inercia tendía a subir la temperatura y aunado al calor de cristalización liberado después de los $55^{\circ} \mathrm{C}$ de enfriamiento, se decidió manejar esta variable a lazo abierto.

\subsubsection{Obtención del modelo matemático de la concentración en el cristalizador por lotes a vacío}

Para diseñar el controlador servo-regulador PID retroalimentado en el cristalizador por lotes a vacío se requiere del modelo matemático o función transferencia que describa la dinámica del sistema. La identificación de la función transferencia del sistema se llevó a cabo mediante el método experimental de la curva de reacción ante un cambio escalón positivo en la presión de vacío con lo que se obtuvieron los parámetros para un modelo de primer orden más tiempo muerto; el procedimiento de dicho método experimental aplicado al sistema de cristalización de azúcar de caña se presenta a continuación.

1.- Se aplicó un cambio escalón en la señal de control en forma manual. La magnitud del cambio escalón en la variable manipulable (presión de vacío ( $\Delta$ Pvac )) fue de 0.603 inHg lo cual representa una magnitud de cambio lo suficientemente grande como para que se pueda 
medir el cambio consecuente en la señal de salida o variable controlable (densidad), pero no tanto como para que las no linealidades del proceso ocasionen la distorsión de la respuesta (Smith y Corripio, 1991).

2.- Posteriormente se adquirieron los datos experimentales a través del sistema SCADA descrito en la Sección 3.3.3. Los datos experimentales se obtuvieron desde el momento en que se introduce al cambio escalón hasta que el sistema alcanza su nuevo estado estacionario. Es importante que durante la prueba de escalón no existan perturbaciones por lo que se procuro mantener la temperatura del interior y de la chaqueta muy cercanas a la temperatura de equilibrio pero sin sobrepasarla.

3.- A la gráfica obtenida en el paso anterior se le conoce como curva de reacción del proceso la cual se presenta en la Figura 3.8. Para calcular los valores de tiempo muerto $\left(\mathrm{t}_{\mathrm{d}}\right) \mathrm{y}$ tiempo del proceso $\left(\tau_{\mathrm{p}}\right)$, se ubicaron dos puntos sobre la gráfica de la curva de reacción del proceso que se encuentran en la región de alta tasa de cambio, los cuales están determinados por los tiempos $\mathrm{t}_{1} \mathrm{y}_{\mathrm{2}}$ (equivalentes al 28.3 y 63.2\% del cambio escalón total); los valores encontrados para $t_{1}$ y $_{2}$ se sustituyen en las ecuaciones presentadas a continuación.

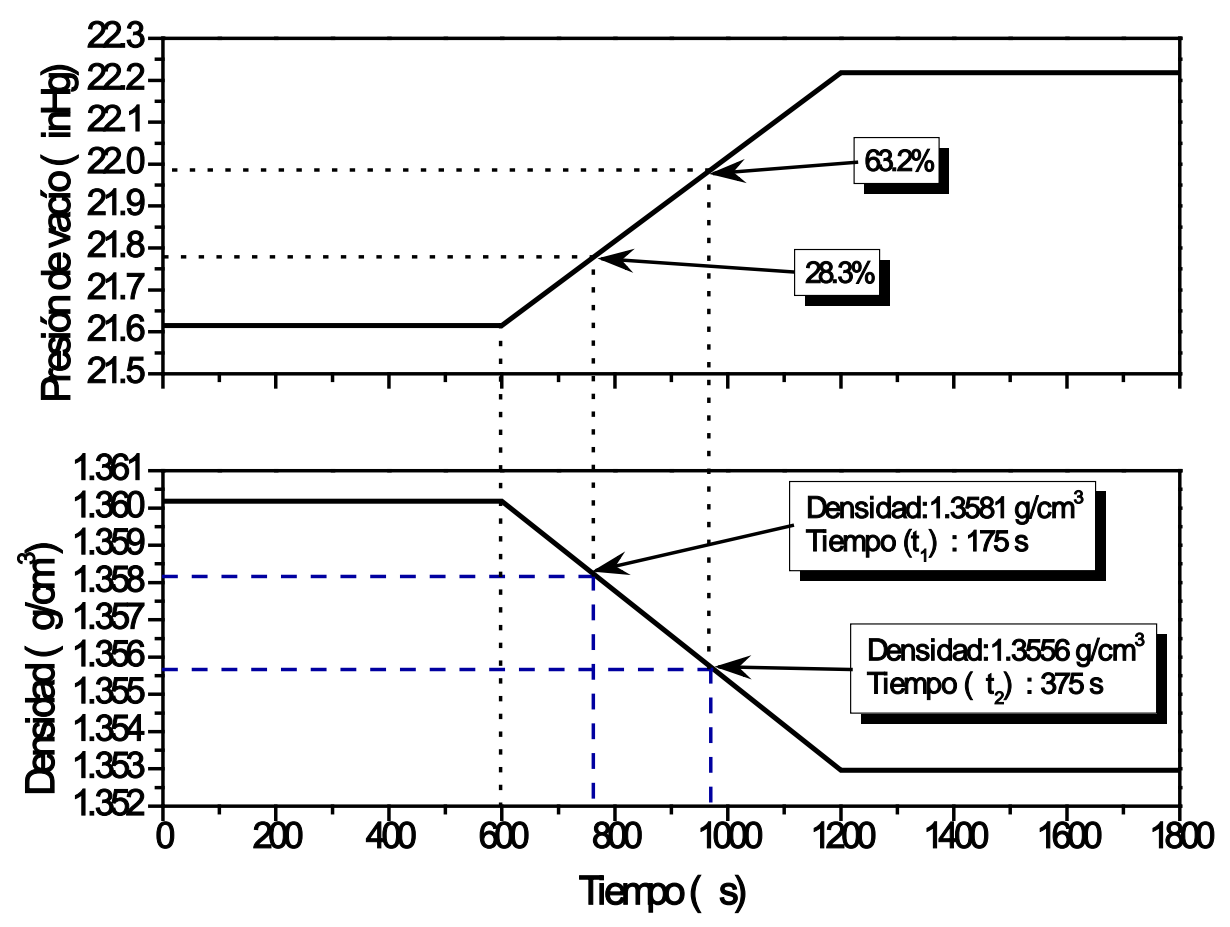

Figura 3.8 Curva de reacción de la concentración en el cristalizador por lotes a vacío. 


$$
\begin{aligned}
& \tau_{p}=\frac{3}{2}\left(t_{2}-t_{1}\right)=\frac{3}{2}(375-175)=300 \mathrm{seg} \\
& \tau_{d}=\left(t_{2}-\tau\right)=(375-300)=75 \mathrm{seg}
\end{aligned}
$$

La ganancia del proceso $\left(\mathrm{K}_{\mathrm{p}}\right)$, se calcula a partir de la razón de cambio en la variable de salida ( $\Delta \rho_{\text {exp }}$ ) entre el cambio en la variable de entrada ( $\Delta$ Pvac ), descrita por la Ec. (3.4).

$$
\mathrm{K}_{\mathrm{P}}=\frac{\Delta \rho_{\text {exp }}}{\Delta \mathrm{Pvac}}=\frac{-0.00722 \mathrm{~g} / \mathrm{cm}^{3}}{0.60297 \mathrm{inHg}}=-0.011974 \mathrm{~g} / \mathrm{cm}^{3} \cdot \mathrm{inHg}
$$

De esta forma se obtuvo la función transferencia en el dominio de Laplace considerando un modelo de primer orden más tiempo muerto, descrito por la Ec. (3.5).

$$
G(s)=\frac{K_{p} \cdot e^{\left(-\tau_{d} \cdot s\right)}}{\tau_{p} \cdot s+1}=\frac{-0.011974 \cdot e^{(-75 \cdot s)}}{300 \cdot s+1}
$$

Aunque la señal que describe el cambio en la presión de vacío se asemeja más a una rampa que aun escalón, el cambio especificado en la variable manipulable (entrada del sistema) fue de tipo escalón. Lo anterior es debido a las múltiples resistencias (transferencia de masa lenta, efectos viscosos, evaporación, desviaciones a la temperatura de equilibrio, etc.) que presenta el sistema, lo que ocasionó que la respuesta dinámica esperada tipo exponencial, se deforme y se observe como una rampa. Todas las resistencias mencionadas podrían considerarse como “capacidades interactuantes” que conducirían a una respuesta similar a la de un sistema de segundo orden tipo sobre amortiguado (respuestas lentas tipo rampa). Sin embargo, la función de transferencia obtenida (Ec. 3.5) representó satisfactoriamente el comportamiento del sistema con un tiempo muerto de 75 segundos. Cabe aclarar que los datos presentados del tiempo 0 al 600 segundos solamente se presentan para que se observe que ambas variables (Presión de vacío y densidad) vienen de un estado estacionario, pero la perturbación se realizó a los 600 segundos del proceso. 


\subsubsection{Análisis a lazo cerrado}

Anteriormente en la Sección 3.3.3, se planteo como objetivo de control el mantener un gradiente adecuado de sobresaturación dentro de la primera zona metaestable y usar la segunda zona metaestable como una zona de amortiguamiento para compensar las perturbaciones al sistema provenientes principalmente por el retardo en la medición de la densidad. Para lo anterior se estableció un setpoint o punto de ajuste de la concentración en función de la temperatura del proceso, el setpoint está definido por las ecuaciones y acotaciones siguientes:

Setpoint $=1.3043+0.001 \cdot \mathrm{T}-3 \times 10^{-6} \cdot \mathrm{T}^{2} \quad$ para $\quad 55^{\circ} \mathrm{C}<\mathrm{T} \leq 70^{\circ} \mathrm{C}$

$\mathrm{y}$

Setpoint $=1.323295+0.0005398 \cdot \mathrm{T}+8.320781 \times 10^{-08} \cdot \mathrm{T}^{2} \quad$ para $\quad 40^{\circ} \mathrm{C} \leq \mathrm{T} \leq 55^{\circ} \mathrm{C}$

Lo anterior se presenta esquemáticamente en un diagrama de concentracióntemperatura en la Figura 3.9.

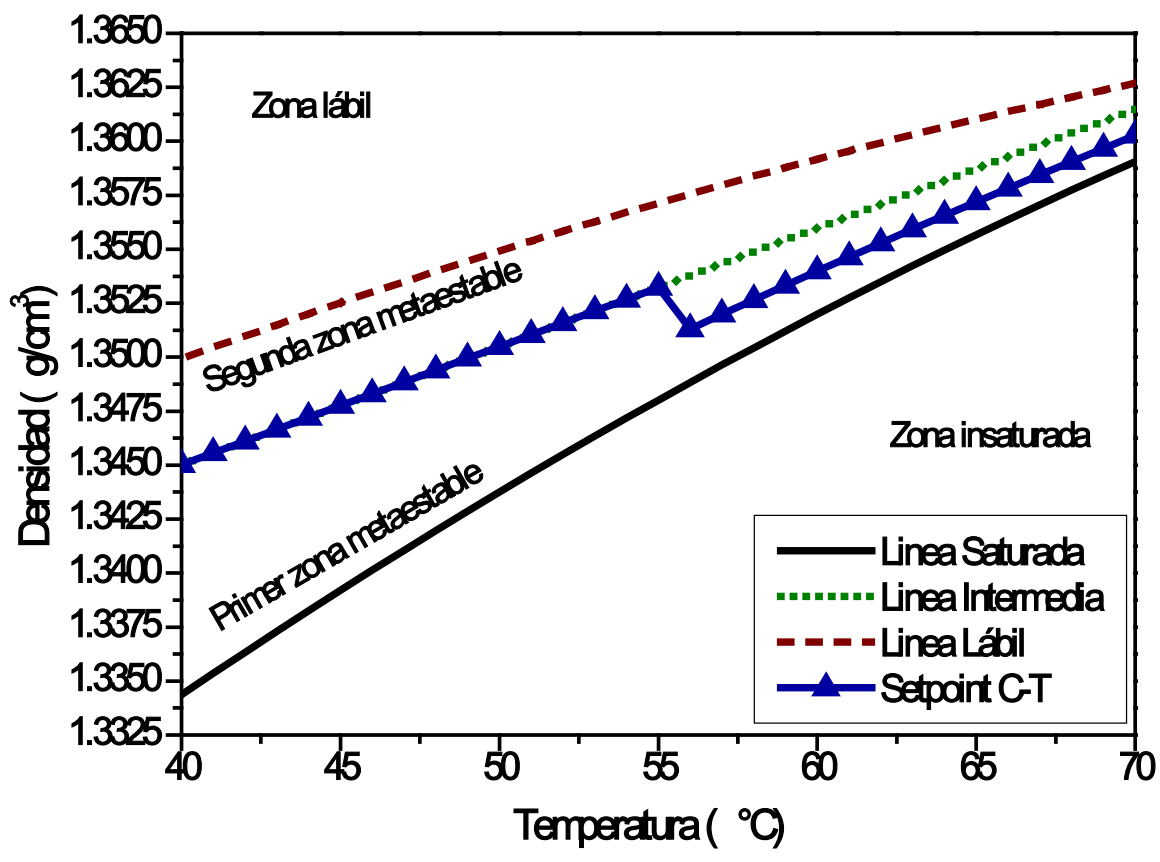

Figura 3.9 Setpoint de concentración-temperatura. 
El principal motivo de realizar un cambio en la tendencia del setpoint C-T a la temperatura de enfriamiento de $55^{\circ} \mathrm{C}$, es debido a que la cristalización de azúcar de caña es una reacción exotérmica por lo tanto entre más se acerca la temperatura de enfriamiento a los $40{ }^{\circ} \mathrm{C}$ mayor es el calor de cristalización liberado. Otra forma de compensar el calor de cristalización liberado pudo haber sido un cambio de parámetros en el controlador con una ganancia lo suficientemente grande para intensificar más la respuesta de control en este rango de temperatura. Sin embargo, teniendo caracterizado el proceso se decidió por modificar el setpoint obteniéndose buenos resultados. A partir de los parámetros obtenidos para la función de transferencia a lazo abierto (Ec. 3.5) y usando la Tabla 3.3 se sintonizaron los parámetros del controlador servo-regulador PID retroalimentado.

Tabla 3.3 Ajuste de parámetros de sintonía usando razón de asentamiento de un cuarto de Ziegler-Nichols.

\begin{tabular}{|c|c|c|c|}
\hline Tipo de controlador & $\begin{array}{c}\text { Ganancia } \\
\text { proporcional } \\
\left(\mathrm{K}_{\mathrm{C}}\right)\end{array}$ & $\begin{array}{c}\text { Tiempo } \\
\text { integral } \\
\left(\tau_{\mathrm{I}}\right)\end{array}$ & $\begin{array}{c}\text { Tiempo derivativo } \\
\left(\tau_{\mathrm{D}}\right)\end{array}$ \\
\hline Proporcional (P) & $\frac{1}{\mathrm{~K}_{\mathrm{p}}}\left(\frac{\tau_{\mathrm{d}}}{\tau_{\mathrm{p}}}\right)^{-1}$ & ------ \\
\hline $\begin{array}{c}\text { Proporcional-Integral (PI) } \\
\frac{0.9}{\mathrm{~K}_{\mathrm{p}}}\left(\frac{\tau_{\mathrm{d}}}{\tau_{\mathrm{p}}}\right)^{-1}\end{array}$ & $3.33 \cdot \tau_{\mathrm{d}}$ & ----- \\
\hline $\begin{array}{c}\text { Proporcional-Integral-Derivativo } \\
\text { (PID) }\end{array}$ & $\frac{1.2}{\mathrm{~K}_{\mathrm{p}}}\left(\frac{\tau_{\mathrm{d}}}{\tau_{\mathrm{p}}}\right)^{-1}$ & $2 \cdot \tau_{\mathrm{d}}$ & $\frac{1}{2} \tau_{\mathrm{d}}$ \\
\hline
\end{tabular}

Los parámetros de sintonía para el controlador PID fueron: $\mathrm{Kc}=-400.868476 ; \tau_{\mathrm{I}}=150$; $\tau_{\mathrm{D}}=37.5$. Se realizaron tres corridas experimentales para validar y analizar la estrategia CControl implementada en el cristalizador por lotes a vacío, los estados del sistema obtenidos para las tres corridas experimentales se presentan en las figuras (3.10-3.12).

En la Figura 3.10 se presentan las respuestas del sistema para la corrida 1, en la Figura 3.10b y 3.10d se observa como la presión de vacío aumenta para corregir las caídas en la densidad cuando ésta se encuentra muy cerca de la línea de saturación para las temperaturas de enfriamiento o de operación de $61.6{ }^{\circ} \mathrm{C}$ y $49{ }^{\circ} \mathrm{C}$, para estos mismos puntos de operación se 
observa en la Figura 3.10a que la temperatura de equilibrio la cual es función de la presión de vacío permanece por debajo de la temperatura del interior evaporándose de esta forma agua de la solución para sobresaturar el sistema y alejarse de la zona insaturada y permanecer dentro de la primera zona metaestable. También se observa que la presión de vacío permanece 44.5 minutos aproximadamente en un valor promedio de 21.5 inHg, este también fue el tiempo en el que la densidad permaneció dentro de la segunda zona metaestable. Es interesante ver que en las tres corridas experimentales se repite el mismo patrón de estabilización de la solución, lo anterior puede deberse a un gradiente alto de sobresaturación inicial en el sistema, lo que hace que la estrategia de control tarde en corregir y compensar el error. De lo anterior se tienen que la sobresaturación permanece dentro de la primera zona meaestable el mayor tiempo del lote.
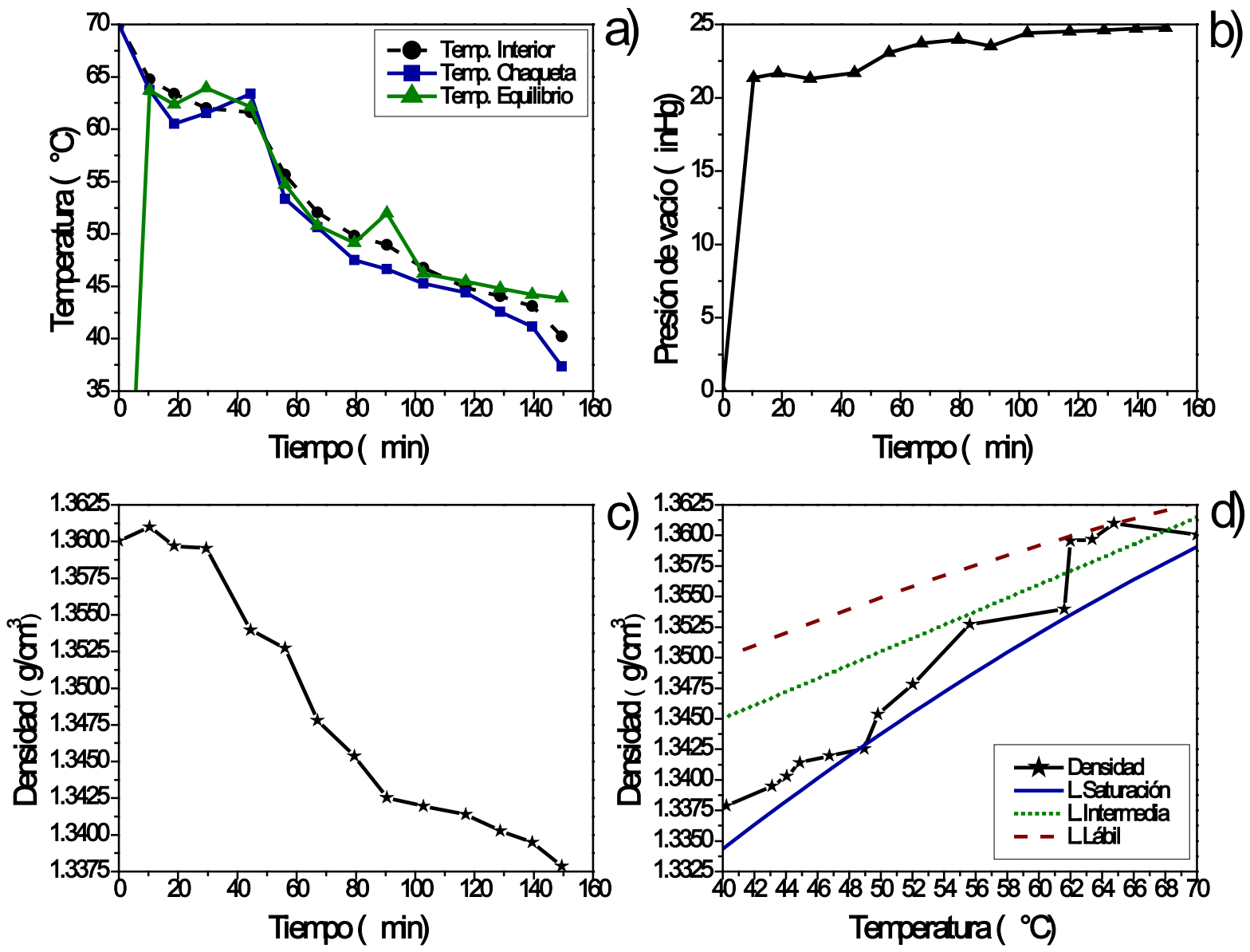

Figura 3.10 Respuestas del sistema (corrida 1). a) temperaturas, b) presión de vacío, c) densidad y d) diagrama concentración-temperatura. 
En la Figura 3.11 se presentan las respuestas del sistema para la corrida 2, del análisis entre la Figura 3.11b y 3.11d se observa que a diferencia de la corrida 1, en esta corrida el control de la densidad es más fino en cuanto a la anticipación y corrección de los errores, por ello se observan menos variaciones en la presión de vacío, la cual permanece por espacio de 80 minutos aproximadamente en un valor promedio de 21.5 inHg, este también fue el tiempo en el que la densidad permaneció oscilando dentro de la segunda zona metaestable y la línea intermedia. En la Figura 3.11a se observa con más claridad la forma en que el sistema de control regula la densidad del sistema para permanecer dentro de la primera zona metaestable, se observa que la temperatura de equilibrio permanece por arriba de la temperatura del interior el mismo tiempo que la presión de vació permanece en 21.5 inHg, disminuyendo así la sobresaturación del sistema y evitar que la densidad saliera hacia la zona lábil.
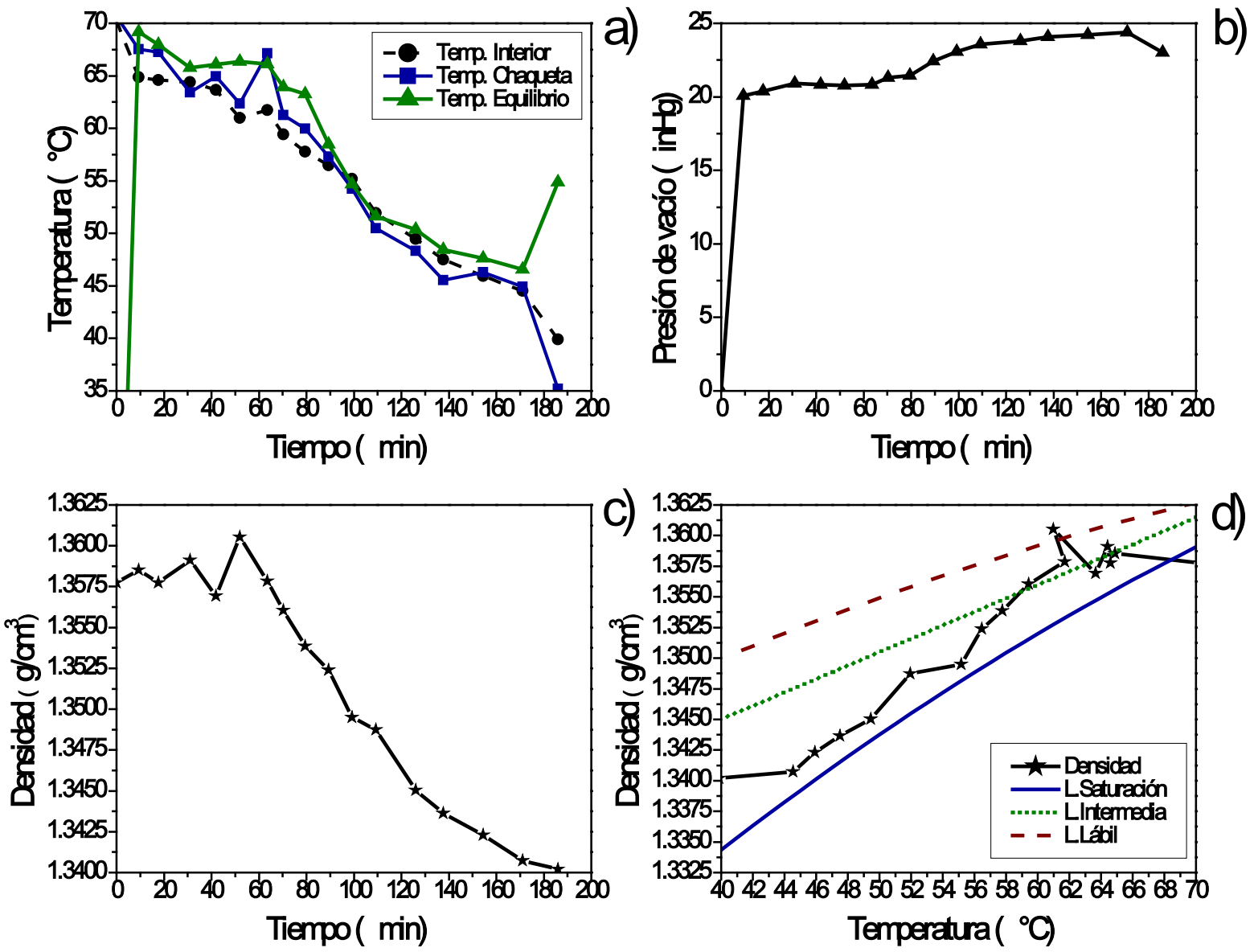

Figura 3.11 Respuestas del sistema (corrida 2). a) temperaturas, b) presión de vacío, c) densidad y d) diagrama concentración-temperatura. 
El valor de la densidad, la caída de la presión de vacío y respuesta de la temperatura en el último punto de muestreo (minuto 186) se debe a que se rompió el enfriamiento adiabático al hacer recircular agua a $35^{\circ} \mathrm{C}$ a través de la chaqueta, ya que el rendimiento de la bomba de vacío no fue suficiente para seguir enfriando por debajo de los $45{ }^{\circ} \mathrm{C}$. Sin embargo, el enfriamiento por contacto directo implementado en el último minuto del proceso no afectó la sobresaturación del sistema, permaneciendo dentro de la primera zona metaestable. Es recomendable implementar una bomba de vacío de mayor potencia al proceso para asegurar el enfriamiento adiabático hasta los $40^{\circ} \mathrm{C}$.

En la Figura 3.12 se presentan las respuestas del sistema para la corrida 3, en la Figura 3.12b y 3.12d se observa como la presión de vacío disminuye súbitamente de 23.9 inHg a 20 inHg a los 120 minutos del proceso debido a una perturbación introducida en la densidad por el mismo equipo de medición (DMA-4500) el cual envía la información por paquetes almacenándolas en el búfer de la computadora. Sin embargo, es común que cuando la computadora o el equipo de medición se encuentran trabajando por más de 24 horas seguidas tiende a mandar los paquetes de información de manera errónea de tal forma que en lugar de mandar un valor de $1.34496 \mathrm{~g} / \mathrm{cm}^{3}$ solamente manda el último digito de la cantidad total “6”, lo que hace que el sistema actué corrigiendo y regulando un error inexistente, la forma de solucionar este error en la medición es reiniciando el equipo (DMA-4500) con la misma muestra para obtener una nueva lectura pero correcta.

El tiempo que duró en corregirse la perturbación por el equipo de medición fue de aproximadamente 2 minutos lo que hizo que el sistema se recupere fácil y rápidamente. Esto debido a la dinámica lenta del proceso de cristalización de azúcar de caña. Sin embargo, si la dinámica de cristalización fuese rápida este tipo de perturbación sería de gran afectación sobre el proceso. Otro factor que ayudó en el control de la sobresaturación, fue que la temperatura de la chaqueta (presión de vapor), al no estar a lazo cerrado y ligada a la temperatura de equilibrio (Sección 3.4.2), está no se manipuló como se observa en la Figura 3.12a. De manera que si se hubiese operado a lazo cerrado la inercia y gradiente del error hubiese disuelto la mayoría de los cristales ya formados, llevando al proceso a un tiempo de lote muy largo y obteniéndose una DTC aleatoria. 

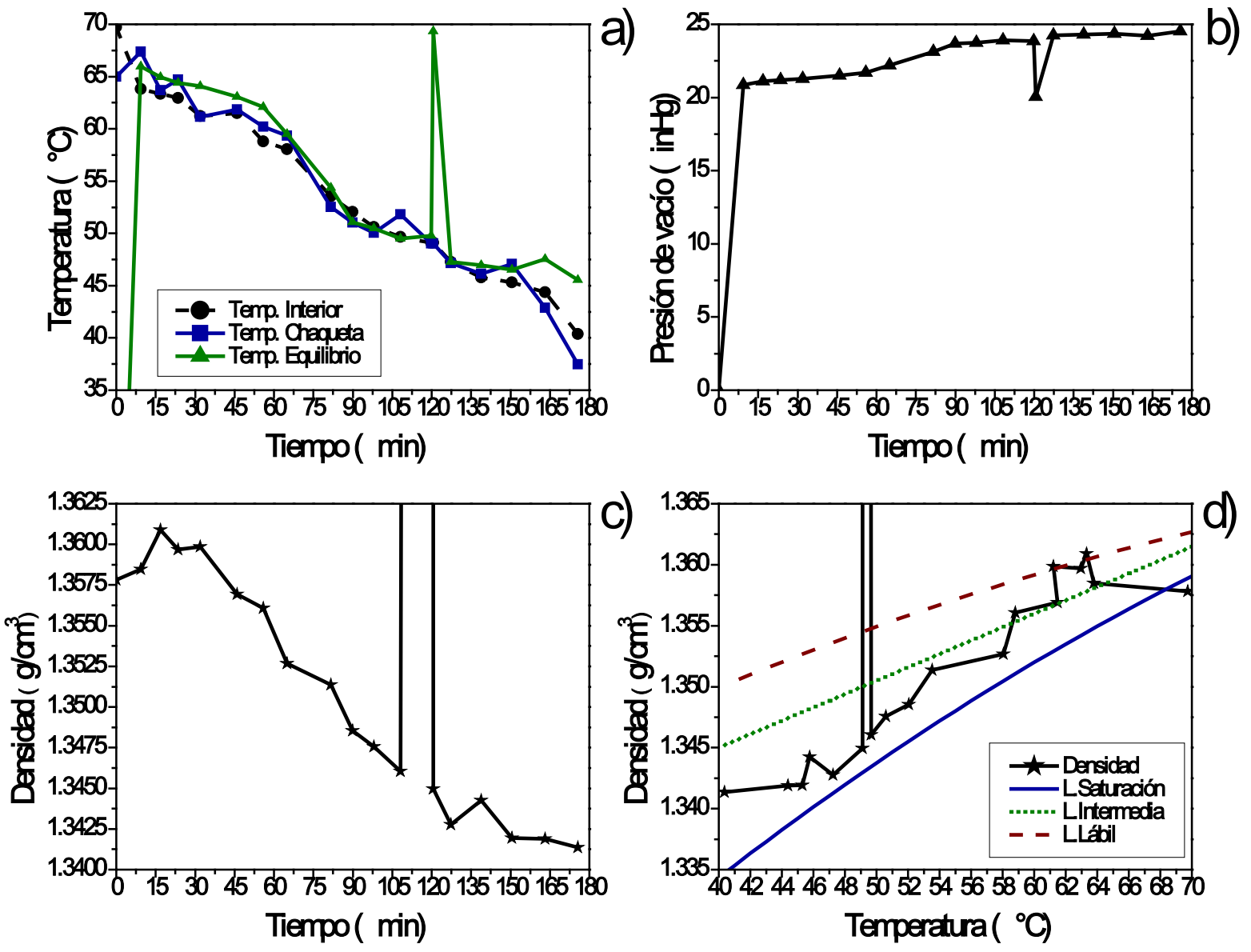

Figura 3.12 Respuestas del sistema (corrida 3). a) temperaturas, b) presión de vacío, c) densidad y d) diagrama concentración-temperatura.

Lo anterior resultó ser un buen ejemplo para probar el sistema de control ante perturbaciones potenciales de magnitud grande. Al igual que en la corrida 2, en el último punto de muestreo se rompió el enfriamiento adiabático al hacer recircular agua a $37.5{ }^{\circ} \mathrm{C}$ a través de la chaqueta y agotar la sobresaturación del sistema para obtener una mayor conversión de cristales de azúcar de caña. De la misma forma que en las otras corridas el enfriamiento por contacto directo implementado en el último minuto del proceso no afectó la sobresaturación del sistema.

En la Figura 3.13 se presenta un diagrama de concentración-temperatura en donde se comparan las densidades de las tres corridas experimentales, se observa que las tres corridas experimentales presentan el mismo patrón ó comportamiento lo que hace reproducible la 
experimentación con la estrategia de control implementada. Se observa al inicio del proceso (segunda muestra para todas las corridas) que existe un nivel alto de sobresaturación, esto puede deberse a que el gradiente de vacío al inicio del proceso (21.5 inHg en promedio) es también alto.

Lo anterior hizo que la acción de control presentara problemas para corregir la desviación del sistema al inicio de cada corrida para un rango de enfriamiento de $70{ }^{\circ} \mathrm{C}$ a 60 ${ }^{\circ} \mathrm{C}$, en donde la sobresaturación permanece dentro de la segunda zona metaestable hasta que tiende a agotarse y se mete a la primera zona metaestable, lo anterior puede corregirse modificando el setpoint para este rango de temperatura o modificando los parámetros de sintonía del controlador. Posteriormente a partir de la temperatura de enfriamiento de $60{ }^{\circ} \mathrm{C}$ a $44^{\circ} \mathrm{C}$, la sobresaturación del sistema presenta una tendencia de tipo lineal dentro de la primera zona metaestable, esto también es fácilmente observado en las figuras 3.10c, 3.11c y 3.12c.

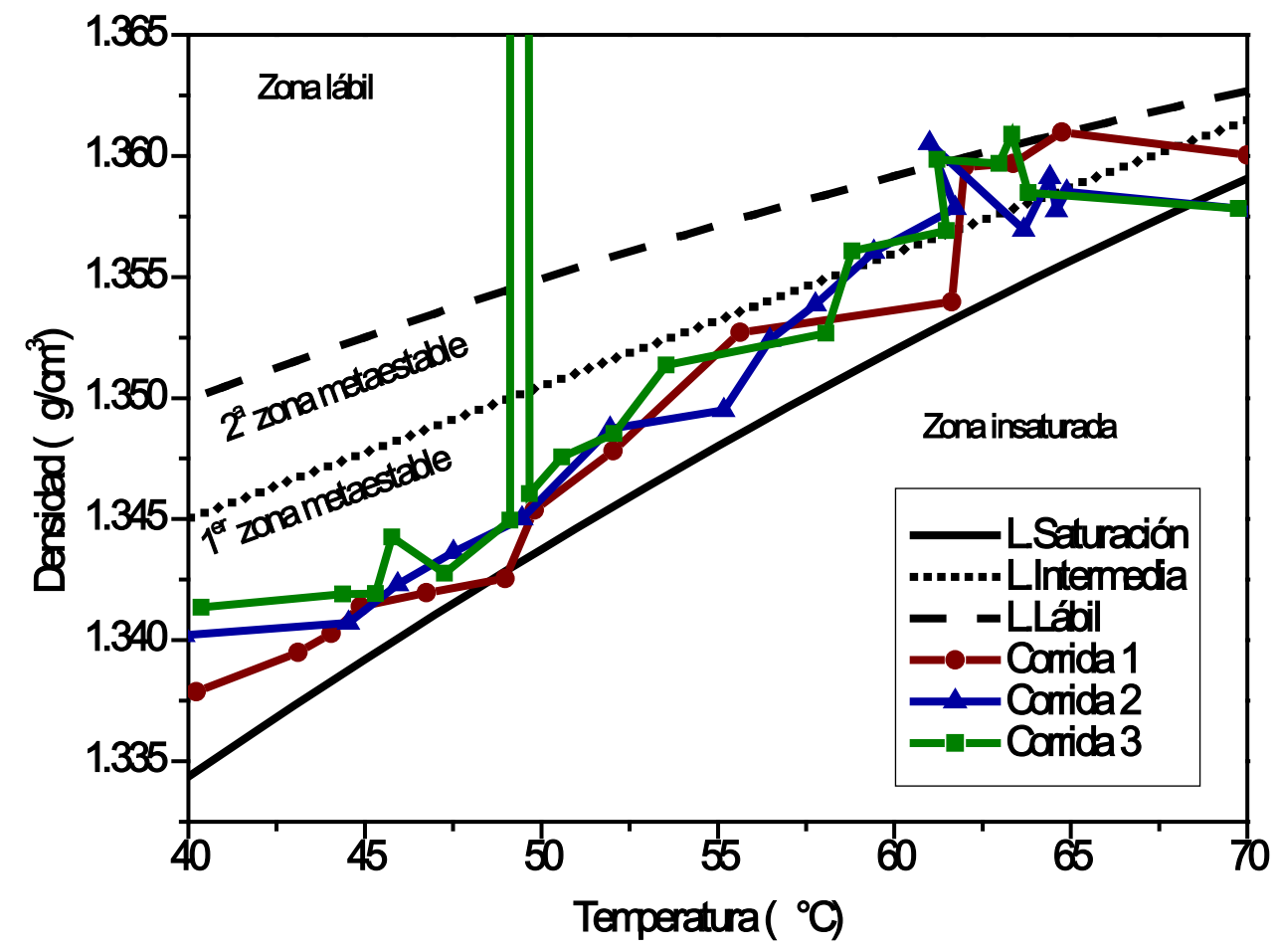

Figura 3.13 Comparativa de la densidad en un diagrama concentración-temperatura.

En la Figura 3.14 se presenta el diámetro promedio relativo al volumen $\mathrm{D}(4,3)$ (Figura 3.14a) y su desviación estándar S(4,3) (Figura 3.14b), se observa de la Figura 3.14a que el 
$\mathrm{D}(4,3)$ inicial es de $75 \mu \mathrm{m}$ con $\mathrm{S}(4,3)=28.95 \mu \mathrm{m}$ y una masa de siembra de $4.5 \mathrm{~g}$ para todas las corridas. El valor máximo de $\mathrm{D}(4,3)$ para la corrida 1 fue de $\mathrm{D}(4,3)=230 \mu \mathrm{m}$; para la corrida 2 fue de $\mathrm{D}(4,3)=305 \mu \mathrm{m}$ y para la corrida 3 fue de $\mathrm{D}(4,3)=283.5 \mu \mathrm{m}$. La corrida 1 presentó una diferencia notable en cuanto al tamaño máximo de cristal, esto debido a que la corrida 1 presenta un punto de operación que llega a estar por debajo de la línea de saturación y aunque fue corregido por la estrategia de control este punto afectó en el crecimiento de los cristales al final del lote, ya que en la zona de insaturación los cristales formados tienden a disolverse.
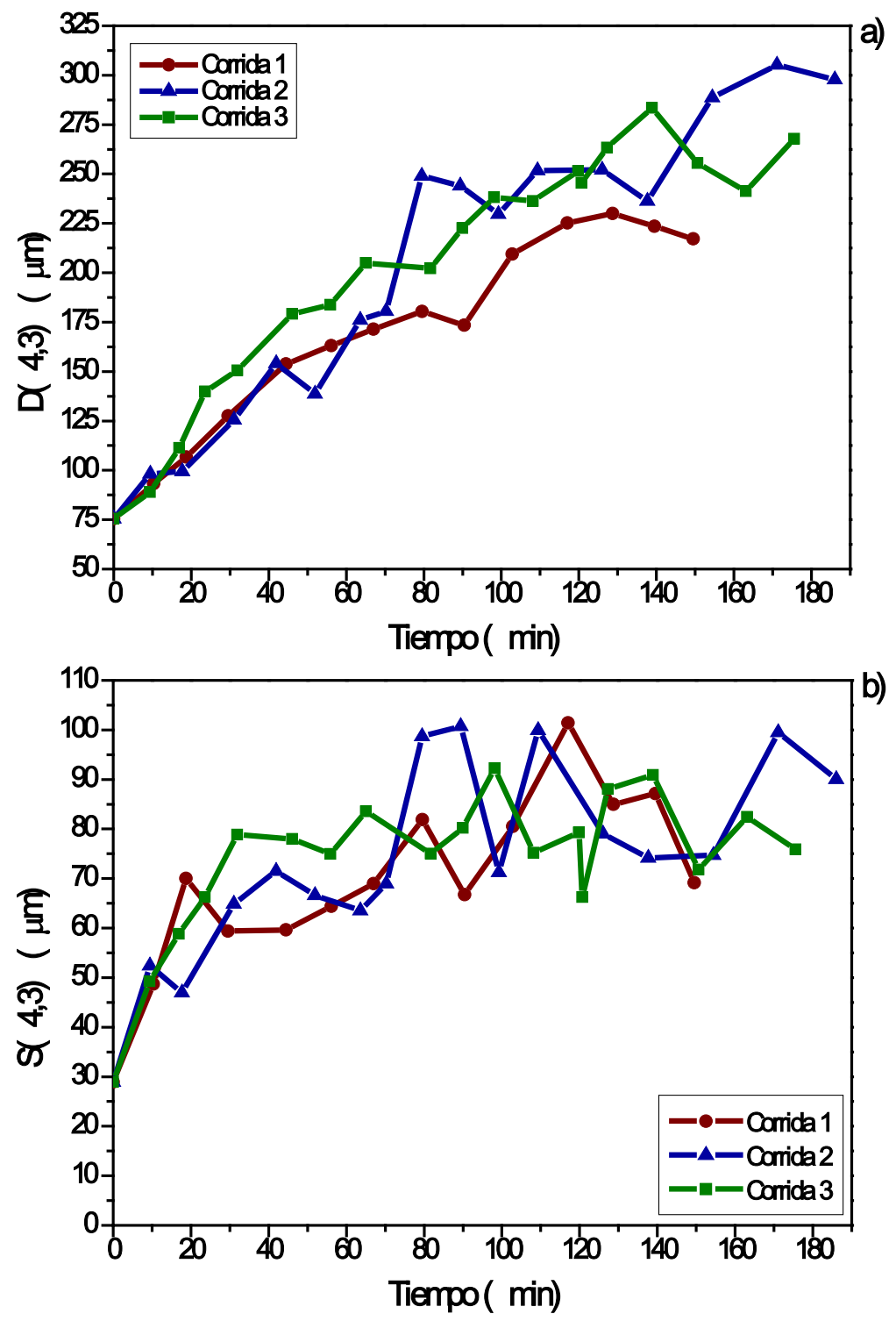

Figura 3.14 Comparativas de respuestas experimentales. a) $D(4,3)$ y b) $S(4,3)$. 
También si se promedian los valores máximos de $\mathrm{D}(4,3)$ de las tres corridas se tendría un valor promedio de $\mathrm{D}(4,3)=272.95 \mu \mathrm{m}$ y un valor promedio de $\mathrm{S}(4,3)=91.78 \mu \mathrm{m}$, lo que equivale a decir que el cristal sembrado creció 3.6 veces su tamaño inicial de $\mathrm{D}(4,3)=$ himm , este resultado no dista mucho con respecto a la mejor corrida de Bolaños-Reynoso et al., (2008) en donde el cristal sembrado creció 3.7 veces su taño inicial, pero con el doble de dispersión.

La Figura 3.15 presenta la DTC de tipo log-normal en \% volumen correspondiente a la corrida 1, se observa que el \% volumen inicia en $12.5 \%$ y termina en $19.5 \%$ aproximadamente, el \% volumen de esta corrida no fue muy alto comparado con la corrida 2 y 3 debido principalmente por existir un punto de operación por debajo de la línea de saturación. Estos datos son consistentes con el grafico de D(4,3) presentado en la Figura 3.14.

En la Figura 3.16 se presenta representativamente la serie micrográfica a diferentes tiempos del proceso correspondientes a la corrida 1, en ella se observa como la densidad de la fase dispersa aumenta conforme avanza el proceso obteniéndose experimentalmente una MCF de 4229.74 g de azúcar.

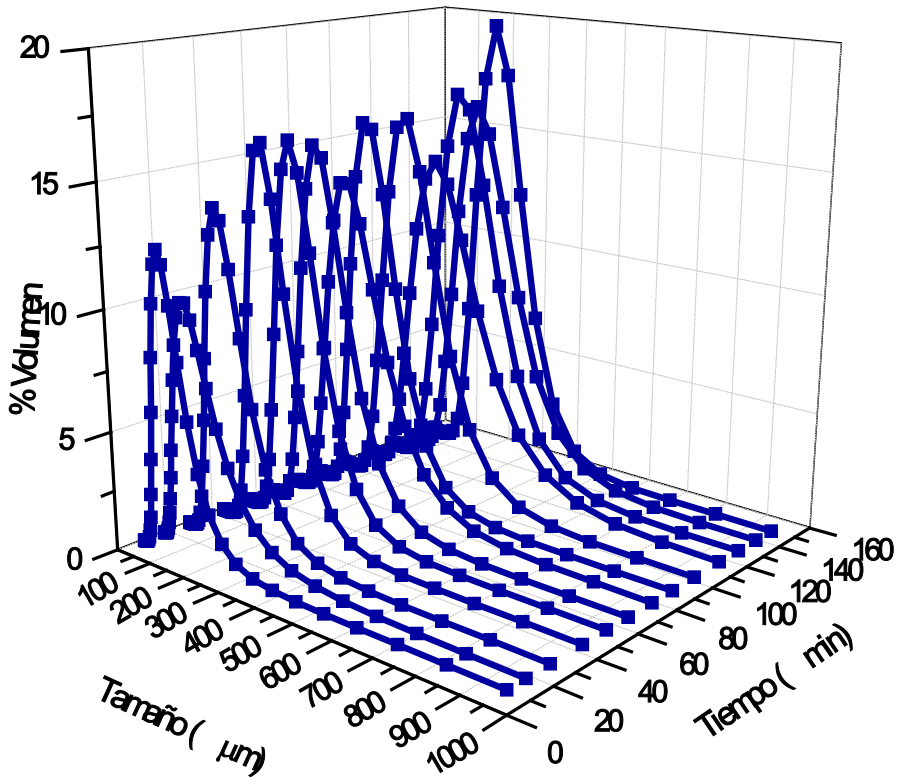

Figura 3.15 DTC tipo log-normal en \% volumen de la corrida 1. 


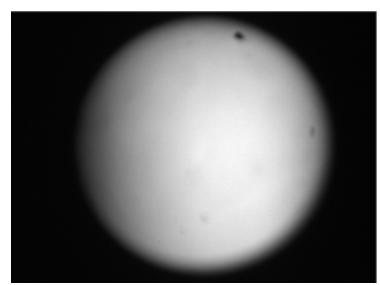

a)

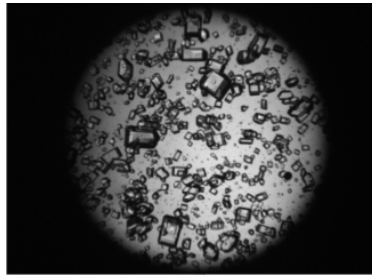

c)

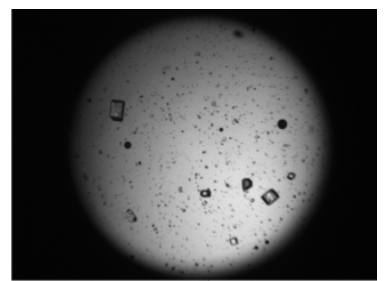

b)

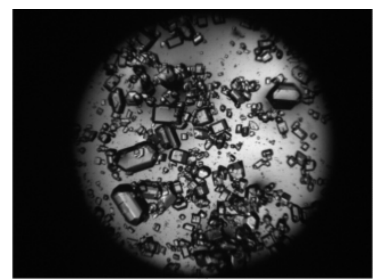

d)

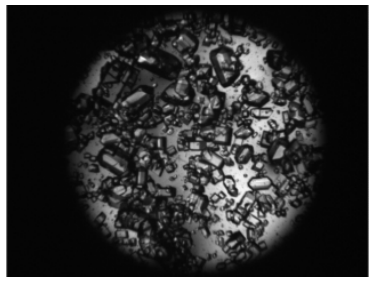

e)

Figura 3.16 Micrografías de la corrida 1. a) min 0, b) min 10.4, c) min 67, d) min 128.7 y e) $\min 149.5$

En la Figura 3.17 se presenta la DTC de tipo log-normal en \% volumen correspondiente a la corrida 2, se observa que él \% volumen inicia en $12.5 \%$ al igual que en la corrida 1 y 3, y termina en $21 \%$ aproximadamente, el \% volumen de esta corrida presenta un comportamiento creciente de tipo lineal en él \% volumen de la DTC a diferencia de la corrida 1, que permanece constante en 16 \% volumen casi todo el tiempo de lote. Otra característica de esta corrida es que él \% volumen presenta un comportamiento oscilatorio, esto puede deberse a la influencia que tienen los cambios en la sobresaturación sobre la DTC.

En la Figura 3.18 se presenta de forma representativa la serie micrográfica a diferentes tiempos del proceso correspondientes a la corrida 2, observándose de forma cualitativa como la densidad y el crecimiento de la fase dispersa aumenta conforme al avance del proceso, la MCF experimental obtenida para esta corrida fue de 4174.86 g de azúcar. 


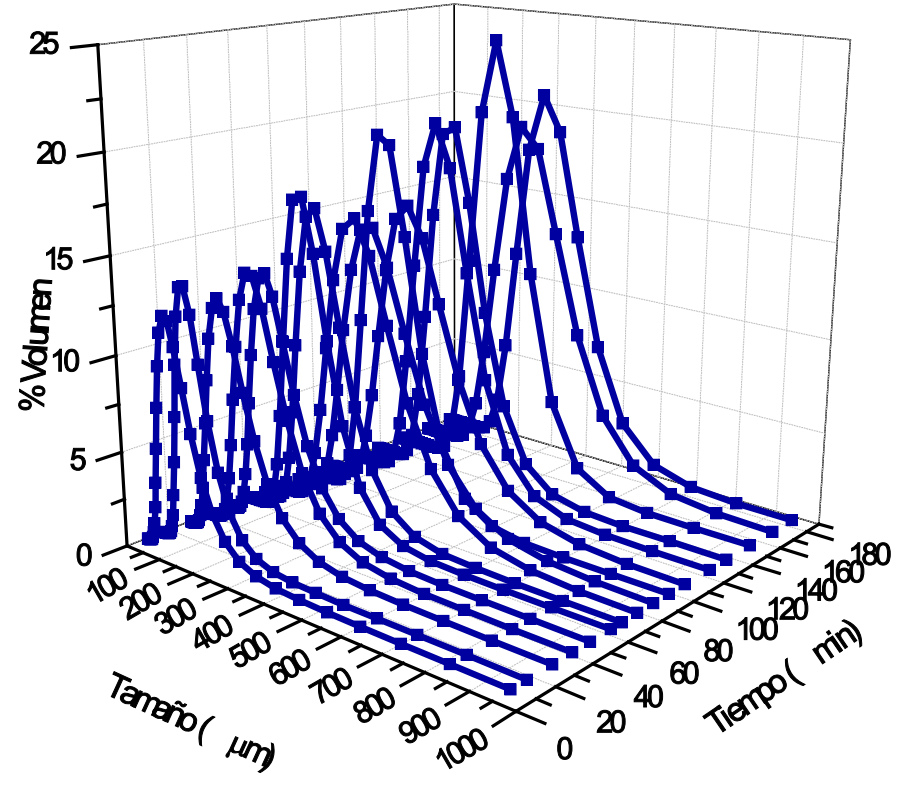

Figura 3.17 DTC tipo log-normal en \% volumen de la corrida 2.

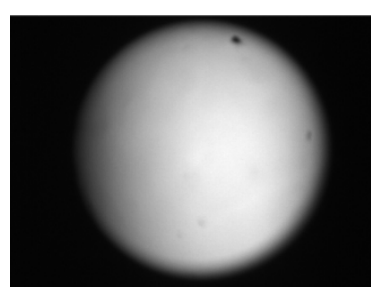

a)

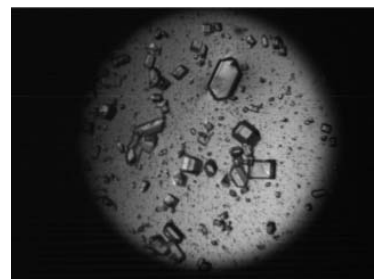

c)

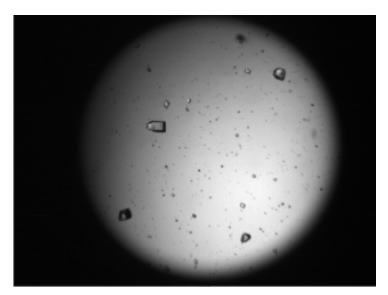

b)

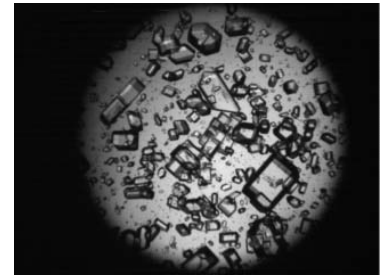

d)

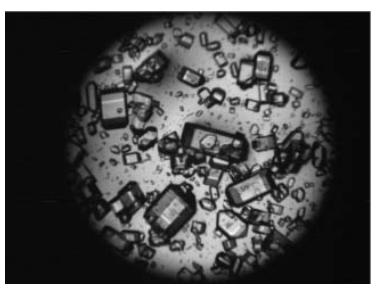

e)

Figura 3.18 Micrografías de la corrida 2. a) min 0, b) min 9.4, c) min 63.6, d) $\min 126$ y e) $\min 186$ 
En la Figura 3.19 se presenta la DTC de tipo log-normal en \% volumen correspondiente a la corrida 3, se observa que el \% volumen inicia en $12.5 \%$ y termina en 22 $\%$ aproximadamente.

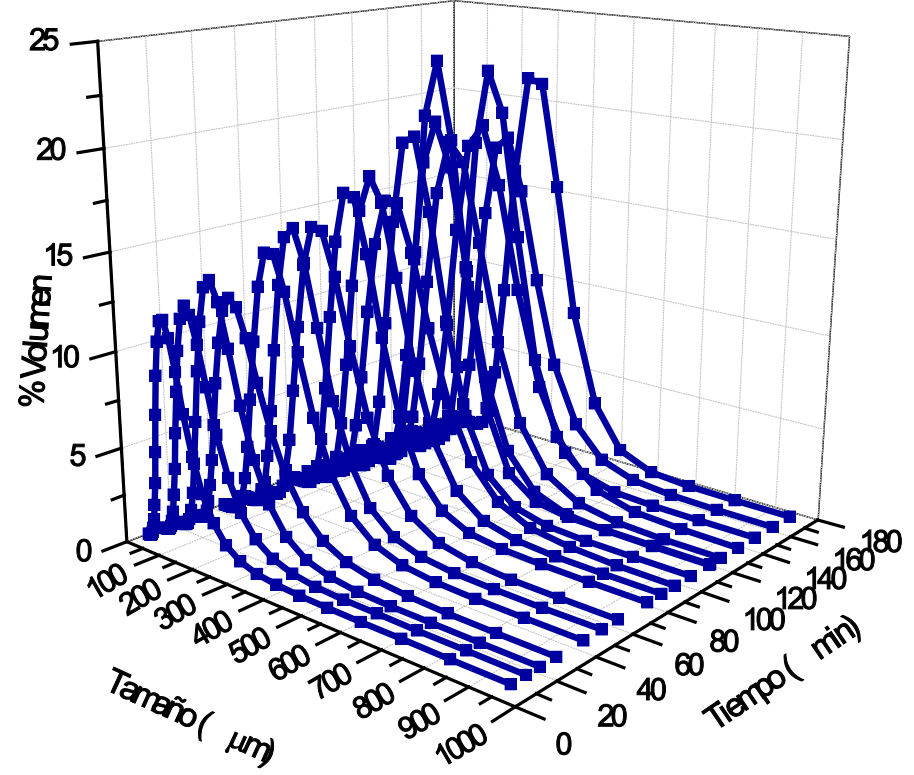

Figura 3.19 DTC tipo log-normal en \% volumen de la corrida 3.

El \% volumen de esta corrida presenta un comportamiento creciente de tipo lineal en él \% volumen de la DTC similar a la corrida 2, pero difiere en que no presenta un comportamiento oscilatorio, y es hasta el final del proceso que existe un decremento en él \% volumen, observable también en él grafico del $\mathrm{D}(4,3)$ presentado en la Figura 3.14a. Lo anterior puede deberse a efectos mecánicos por atrición causada por una masa alta de cristales formados al final del lote.

En la Figura 3.20 se presenta de forma representativa la serie micrográfica a diferentes tiempos del proceso correspondientes a la corrida 3, se observa cualitativamente al igual que en las dos corridas anteriores que la densidad y el crecimiento de la fase dispersa aumentan conforme avanza el proceso, obteniéndose de forma experimental una MCF de 4099.38 g de azúcar. 


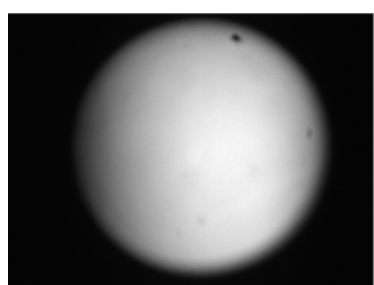

a)

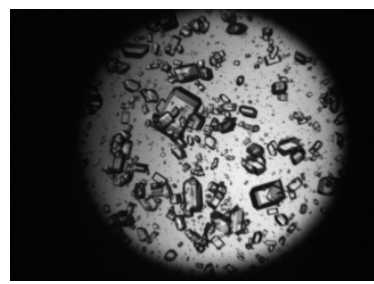

c)

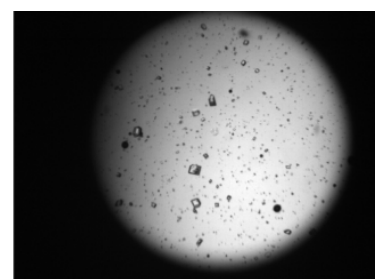

b)

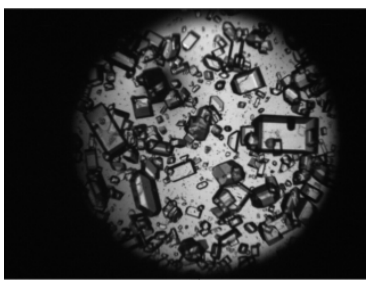

d)

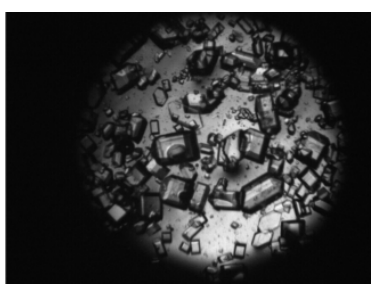

e)

Figura 3.20 Micrografías de la corrida 3. a) $\min 0$, b) $\min 9.4$, c) $\min 60$, d) $\min 120.7$ y e) $\min 175.6$

En la Figura 3.21 se contrasta la estrategia C-Control implementada para la sobresaturación con respecto a otras técnicas de enfriamiento implementadas por BolañosReynoso et al. (2008), y los resultados obtenidos en un ingenio del estado de Veracruz, Mex. Se observa que la implementación del sistema C-Control, es más eficiente en el control de la sobresaturación que con respecto a los sistemas tradicionales (T-Control). El tiempo del proceso (tiempo de lote) en Bolaños-Reynoso et al. (2008) fue de 90 min de los cuales los primeros 40 minutos del proceso permanece dentro de la zona inestable debido a un gradiente de sobresaturación alto provocado por una elevada tasa de evaporación durante 30 minutos que llaman tiempo de evaporación constante. El tiempo del proceso del ingenio fue de aproximadamente 240 minutos observándose que a nivel industrial se carece de sistemas robustos de control en la sobresaturación. 


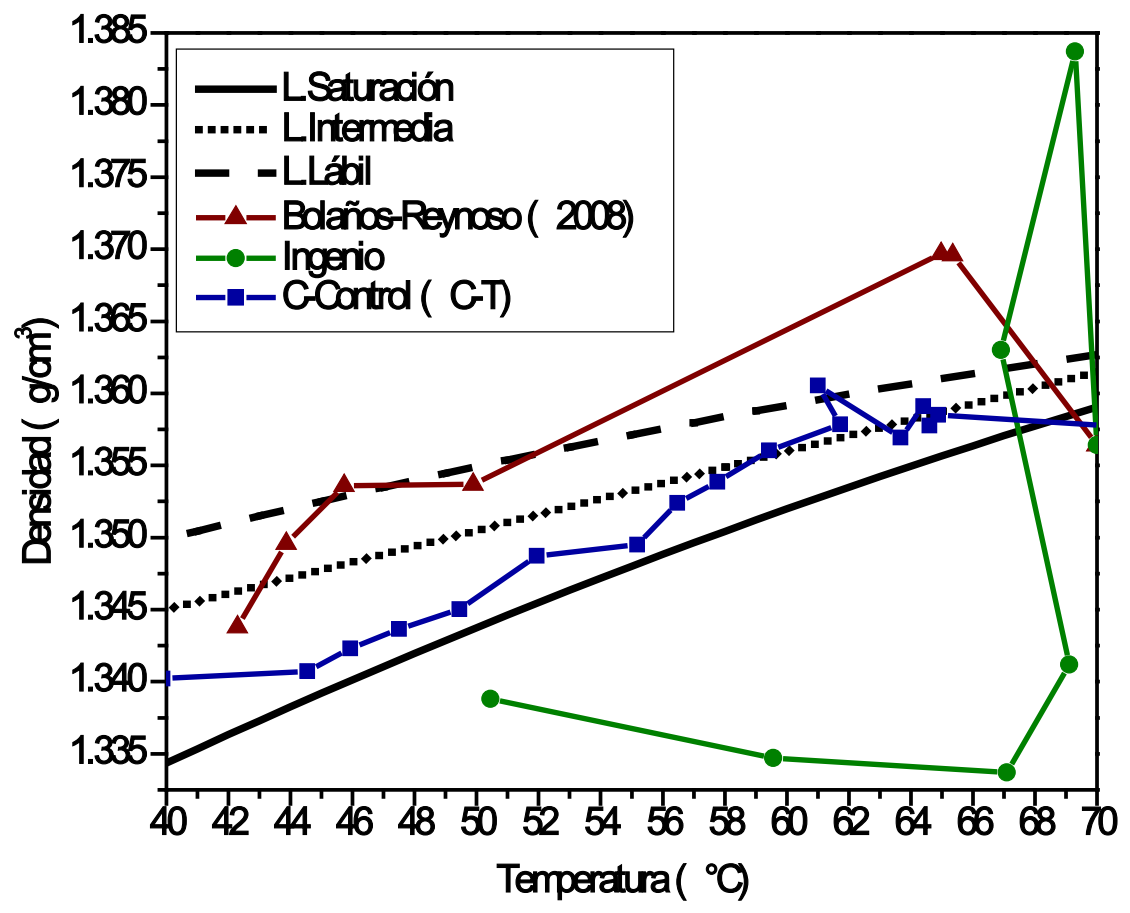

Figura 3.21 Comparativa de técnicas de enfriamiento y control de la sobresaturación en un diagrama de concentración-temperatura y limites metaestables.

Con la estrategia C-Control (C-T) el tiempo del proceso fue de 186 min (corrida 2), obteniéndose una MCF de 4200 gr en promedio y una $\mathrm{D}(4,3)=3 \varphi 5 \mathrm{~m}$. La perturbacón por retardo de medición de la concentración (densidad) fue un gran problema para el control del proceso obteniéndose retardos de hasta 8 minutos, sin embargo, la estrategia de control implementada corrigió satisfactoriamente las perturbaciones presentadas.

\subsection{Conclusiones}

La estrategia de control C-Control (C-T) permite obtener un control adecuado de la sobresaturación dentro de la primera zona metaestable, con un tiempo de lote fijado principalmente por la naturaleza del proceso de cristalización de azúcar de caña. El control de la sobresaturación dentro de la primera zona metaestable por sí sola no asegura una DTC uniforme, ya que él \% volumen tiende a incrementarse con el tiempo del proceso. Sin 
embargo, aparentemente la tasa de enfriamiento o nivel de sobresaturación incluso dentro de la primera zona metaestable pueden ser factores de influencia en la DTC final.

En comparación con otras técnicas de enfriamiento implementadas como BolañosReynoso et al., (2008) y la empleada en un ingenio del estado de Veracruz, Mex., la estrategia C-Control demostró ser más robusta en el control de la sobresaturación.

A partir de los datos experimentales de los estados del sistema es factible proponer un sistema T-Control (función indexada) como el propuesto por Bolaños-Reynoso et al. (2008) usando regulación dinámica de presión de vacío.

El sistema C-Control (C-T) para la cristalización de azúcar de caña presenta la desventaja de que en el mercado aún no existen equipos sofisticados que analicen la concentración en línea sin retardos, los cuales son de gran perturbación al sistema.

\section{Reconocimiento}

Parte del material presentado en este capítulo se utilizó para la elaboración del siguiente artículo:

O. Velazquez Camilo ${ }^{\text {a*}}$, E. Bolaños Reynoso ${ }^{\text {b }}$, J.J. Alvarez Ramirez ${ }^{\text {a }}$ y Y.S. Pliego-Bravo ${ }^{\text {b, }}$ “Control de la Sobresaturación de Azúcar de Caña en un Cristalizador Batch a Vacío" Presentado en el XXXI Encuentro Nacional de la AMIDIQ. Huatulco, Oax. Mex. del 4 al 7 de mayo de 2010. (SIM044). 
CAPÍTULO IV

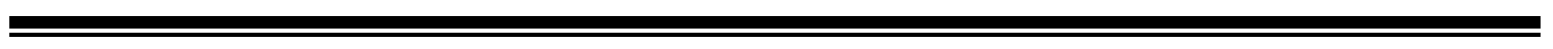




\section{Análisis comparativo de la dinámica de un cristalizador continuo tipo tanque agitado: casos isotérmico y por enfriamiento}

\subsection{Resumen}

En este trabajo se caracterizó dinámicamente vía simulación un cristalizador continuo tipo tanque agitado en estado isotérmico y por enfriamiento, y se estudiaron alternativas de operación y controlabilidad del proceso. El modelo matemático del proceso está basado en el método de momentos. El proceso metodológico consistió en la implementación de un servocontrol SISO (única entrada-única salida) retroalimentado con controlador PID (proporcional-integral-derivativo). Los parámetros de sintonía del controlador se obtuvieron con las estrategias de un modelo de control interno (IMC). La variable del proceso a controlar fue el diámetro promedio relativo en \% volumen $\mathrm{D}(4,3)=\mu_{4} / \mu_{3}$, ya que es una variable muy usada en el ámbito comercial e industrial; la variable manipulable en el caso isotérmico y por enfriamiento fue la concentración del soluto en la alimentación y la temperatura de enfriamiento, respectivamente. Del análisis estático se observan las zonas donde existe la presencia de ciclos límites y los valores de tiempos de residencia más favorables para operar y controlar la cristalización isotérmica y por enfriamiento. Se concluye que el controlador PID retroalimentado que se implementó en los dos casos fue satisfactorio eliminando las desviaciones entre el punto de ajuste y la respuesta de la variable controlable. A pesar de que la sustancia de trabajo en este estudio fue sulfato de amonio-agua (sistema polar con transferencia de masa rápida) y no azúcar de caña-agua (sistema no polar con transferencia de masa lenta), el ejercicio de simulación fue el primer acercamiento en el estudio de la cristalización, en donde a partir de los resultados obtenidos por simulación dinámica se pudo inferir que si se deseaba controlar la sobresaturación, era necesario obtener las curvas de concentración de equilibrio y/o metaestables. 


\subsection{Introducción}

La cristalización es ampliamente usada en la industria para producir sólidos cristalinos con una alta pureza. Las oscilaciones no lineales en los procesos de cristalización en operación continua es un fenómeno bien conocido representando en la práctica un problema para el diseño, operación y control de estos procesos (Pathath y Kienle, 2003).

Los modelos matemáticos en el proceso de cristalización o procesos particulados comúnmente son obtenidos a través de la aplicación de balances de población, materia y energía (MBP). Los balances de población consisten en un sistema de ecuaciones integrodiferenciales no lineales que describen la evolución de la DTC y se encuentran acopladas con un sistema de ecuaciones diferenciales ordinarias (ODEs) que describen la evolución de las variables de estado de la fase continua (Christofides et al., 2000; Shi et al., 2006).

La cristalización en operación continua presenta grandes ventajas de las cuales se enuncian: el bajo costo de operación, poca demanda de mano de obra, posibilidad de clasificar y obtener un producto de calidad constante. Y como desventajas están la tendencia a la formación de incrustaciones en las superficies de intercambio de calor, así como el diseño adecuado de la descarga del producto final, y la obtención de un tamaño de cristal pequeño. Además presenta una desventaja adicional para el diseñador ya que existen ciertas clases de sustancias donde la cristalización en continuo es difícil por lo que muchas veces es preferible la operación discontinua (Srinivasakannan et al., 2002). Como se ha mencionado con anterioridad la mayoría de las industrias que utilizan el proceso de cristalización, no tienen un control satisfactorio sobre la DTC especificada y en la operación en continuo representa un problema más, ya que es sabido que en este tipo de operación es común la presencia de puntos inestables y de ciclos limites. 


\subsection{Caso isotérmico}

\subsubsection{Modelo matemático para la operación isotérmica}

El modelo del proceso fue descrito primeramente a partir de un MBP considerando un cristalizador continuo tipo tanque agitado en estado isotérmico con trampa de finos (Lei et al., 1971). Posteriormente Jerault et al. (1983) a partir del MBP desarrollaron el modelo de momentos el cual fue reducido por el método de residuales ponderados por Chiu y Christofides (1999). El modelo de momentos tiene una solución numérica relativamente menos complicada que resolver el MBP ya que se evita resolver las ecuaciones diferenciales parciales del balance de población, además de que es un método ampliamente utilizado por la mayoría de los investigadores en cristalización (Doherty et al., 2006) y permite un mejor análisis de los parámetros de interés como los diámetros promedios relativos, específicamente al diámetro promedio relativo en $\%$ volumen $\mathrm{D}(4,3)=\mu_{4} / \mu_{3}$. (ya que es una variable muy usada en el ámbito comercial e industrial (Quintana-Hernández et al., 2008)).

Las principales condiciones de operación y características del modelo del proceso para un cristalizador continuo en estado isotérmico son las siguientes: el cristalizador opera bajo condiciones isotérmicas y volumen constante, la suspensión (magma) está perfectamente mezclada por lo que la toma de una muestra en cualquier punto del cristalizador es representativa del sistema, la transferencia de energía (calor) de la chaqueta al interior del cristalizador es muy rápida, la formación de cristales vía nucleación es de tamaño infinitesimal y el crecimiento de los cristales es independiente del tamaño, y la sustancia de trabajo es sulfato de amonio (Shi et al., 2006).

El sistema de ecuaciones es un sistema no lineal que consiste de ecuaciones diferenciales ordinarias; las cuales se resuelven mediante el método de integración numérica de Runge-Kutta de $4^{\circ}$ orden. El sistema de ecuaciones de momentos acoplado al balance de concentración del soluto en la fase continua se presenta de la Ec. (4.1) a la Ec. (4.4). En la Tabla 4.1 se presentan los parámetros del proceso: 


$$
\begin{aligned}
& \frac{\mathrm{d} \mu_{0}}{\mathrm{dt}}=-\frac{\mu_{0}}{\tau}+\left(1-\frac{4}{3} \pi \mu_{3}\right) \mathrm{k}_{2} \mathrm{e}^{-\left[\mathrm{k}_{3} /\left(\left(\mathrm{C} / \mathrm{C}_{\mathrm{S}}\right)-1\right)^{2}\right]} \\
& \frac{\mathrm{d} \mu_{\mathrm{j}}}{\mathrm{dt}}=-\frac{\mu_{\mathrm{j}}}{\tau}+\mathrm{jk} \mathrm{k}_{1}\left(\mathrm{C}-\mathrm{C}_{\mathrm{S}}\right) \mu_{\mathrm{j}-1} \\
& \frac{\mathrm{dC}}{\mathrm{dt}}=\frac{\mathrm{C}_{0}-\mathrm{C}-4 \pi \mathrm{k}_{1} \tau\left(\mathrm{C}-\mathrm{C}_{\mathrm{S}}\right) \mu_{2}(\rho-\mathrm{C})}{\tau\left[1-\left(\frac{4}{3} \pi \mu_{3}\right)\right]}
\end{aligned}
$$

donde: $\mathrm{k}_{2}=\mathrm{k}_{2, \text { nom }} \quad \mathrm{y} \quad \rho=\rho_{\text {nom }}+0.1 \rho_{\text {nom }} \quad$ nom $=$ valor nominal

Tabla 4.1. Parámetros del proceso (Christofides et al., 2000).

\begin{tabular}{|l|l|}
\hline Parámetros & \multicolumn{1}{|c|}{ Valor } \\
\hline $\mathrm{C}_{0}$ & $1000\left(\mathrm{~kg} / \mathrm{m}^{3}\right)$ \\
\hline $\mathrm{C}_{\mathrm{S}}$ & $980.2\left(\mathrm{~kg} / \mathrm{m}^{3}\right)$ \\
\hline$\rho_{\text {Crist }}$ & $1769\left(\mathrm{~kg} / \mathrm{m}^{3}\right)$ Perry \\
\hline$\rho_{\text {sol }}$ & $1243.5\left(\mathrm{~kg} / \mathrm{m}^{3}\right)$ Salcedo \\
\hline$\rho_{\text {sol }}$ & $3740.059\left(\mathrm{~kg} / \mathrm{m}^{3}\right)$ Perry \\
\hline $\mathrm{k}_{1}$ & $5.065 \times 10-2\left(\mathrm{~mm} \cdot \mathrm{m}^{3} / \mathrm{kg} \cdot \mathrm{hr}\right)$ \\
\hline $\mathrm{k}_{2, \text { nom }}$ & $7.958\left(\mathrm{~mm}^{-1} \cdot \mathrm{hr}{ }^{-1}\right)$ \\
\hline $\mathrm{k}_{3}$ & $1.217 \times 10-3(-----)$ \\
\hline$\tau$ & $1(\mathrm{hr})$ \\
\hline
\end{tabular}

\subsubsection{Análisis dinámico y estático del proceso a lazo abierto para la operación isotérmica}

Como un primer acercamiento al estudio de la sensibilidad de parámetros del proceso a lazo abierto, se manipulará el tiempo de residencia $(\tau)$. 
Las figuras (4.1-4.2) muestran las respuestas del proceso de importancia (estados del sistema) en estudio como la concentración del soluto y el diámetro promedio relativo al volumen $\mathrm{D}(4,3)$ a lazo abierto para diferentes tiempos de residencia.

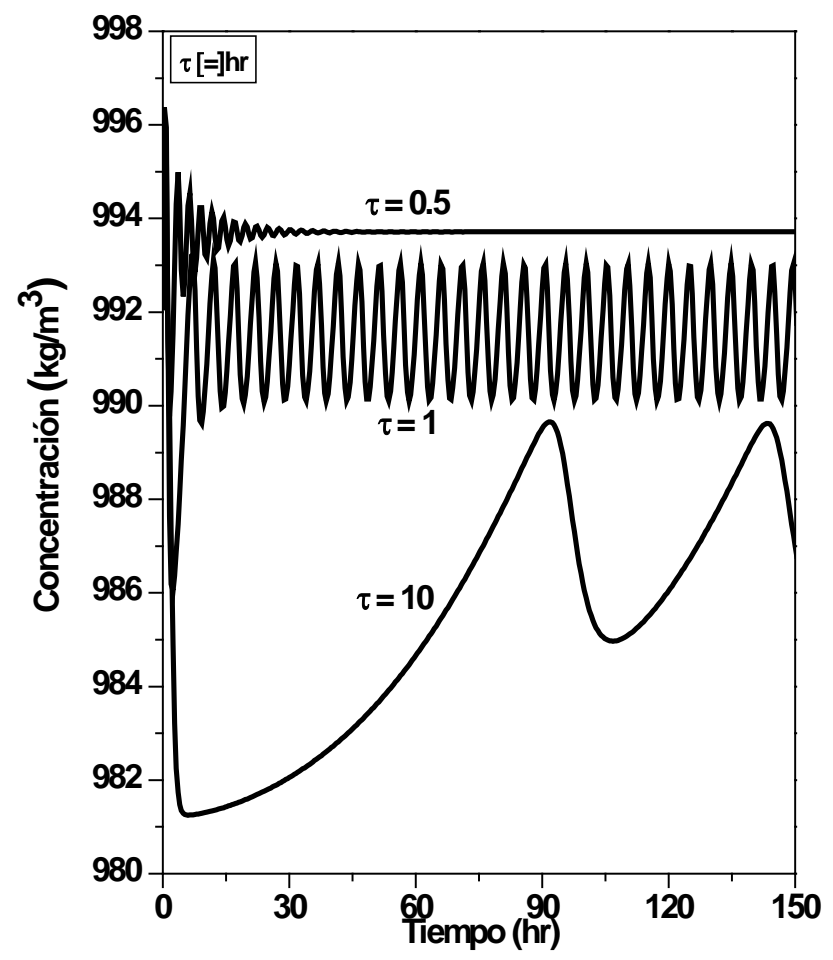

Figura 4.1 Respuesta del proceso (concentración del soluto) a lazo abierto para diferentes tiempos de residencia.

Se observa que para $\tau>0.5 \mathrm{hr}$ existen oscilaciones límites (oscilaciones sostenidas) lo cual es muy común en los cristalizadores continuos tipo tanque agitado. Sin embargo, las respuestas del proceso para $\tau \leq 0.5 \mathrm{hr}$ presentan oscilaciones que se amortiguan para alcanzar un estado estacionario estable (aproximadamente $70 \mathrm{hr}$ para un $\tau=0.5 \mathrm{hr}$ ). De las figuras (4.1-4.2) se deduce que es conveniente trabajar con $\tau \leq 0.5 \mathrm{hr}$, para una mayor estabilidad y fácil manejo del proceso.

Un análisis estático (estados estacionarios) de la variable a controlar y las posibles variables manipulables puede arrojar más información sobre la estabilidad o inestabilidad del proceso. 


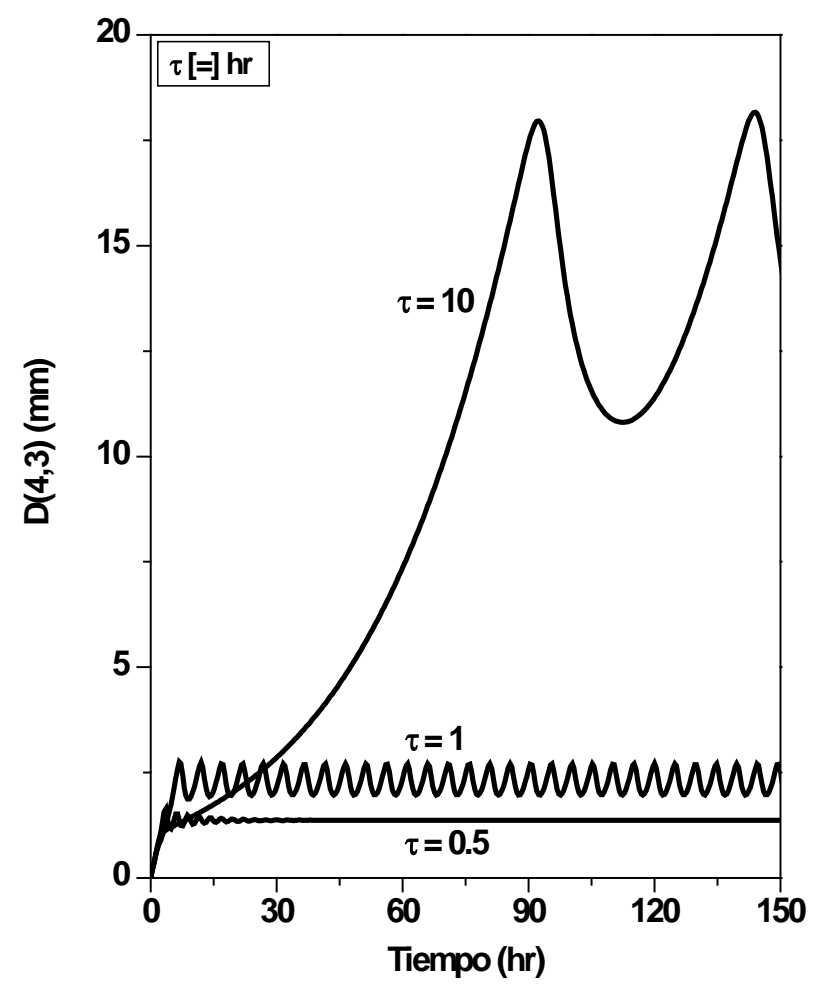

Figura 4.2 Respuesta del proceso $(D(4,3))$ a lazo abierto para diferentes tiempos de residencia.

En las figuras (4.3-4.4) se exhiben las respuestas estáticas para el $\mathrm{D}(4,3)$ a diferentes tiempos de residencias y concentración de alimentación. En la Figura 4.3 se observa que existe una zona de operación (franja oscura) donde aparecen los ciclos límites de acuerdo a los valores de concentración de alimentación y tiempo de residencia establecidos. Esta zona crece conforme aumenta el tiempo de residencia; corroborándose así que es más estable trabajar con $\tau \leq 0.5 \mathrm{hr}$, ya que las oscilaciones límites aparecen a partir de un $\tau \geq 0.6 \mathrm{hr}$. En la Figura 4.4 se observan dos puntos de inflexión no lineales, una ganancia del proceso poco sensible a las perturbaciones (entre los puntos de inflexión) y dos ganancias a los extremos muy sensibles a las perturbaciones, lo cual convierte al sistema en un proceso muy difícil de ser controlado globalmente.

Se observa que para cualquier respuesta, a partir del primer punto de inflexión hasta el segundo punto de inflexión es necesario un gradiente muy grande en la concentración de alimentación $\left(\mathrm{C}_{0}\right)$ para pasar de un valor de $\mathrm{D}(4,3)$ a otro de mayor o menor magnitud, según sea el objetivo de operación (cristalizar o solubilizar). 


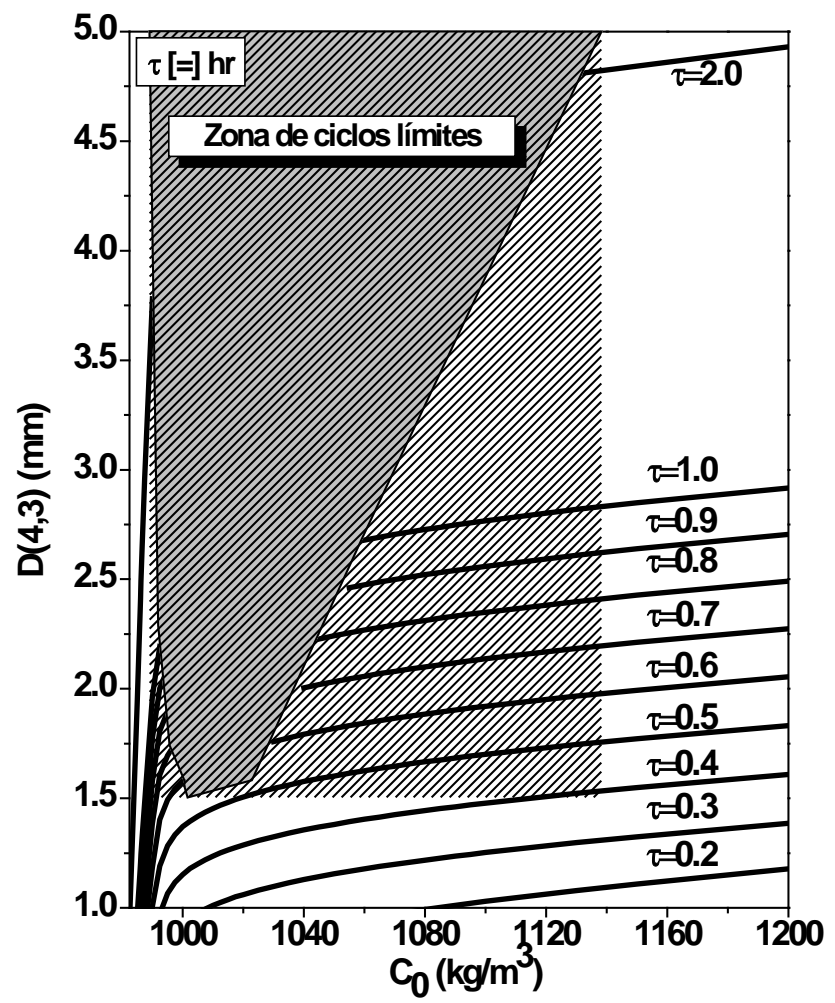

Figura 4.3 Respuesta estática de $D(4,3)$ sobre la zona de ciclos límites para la operación isotérmica.

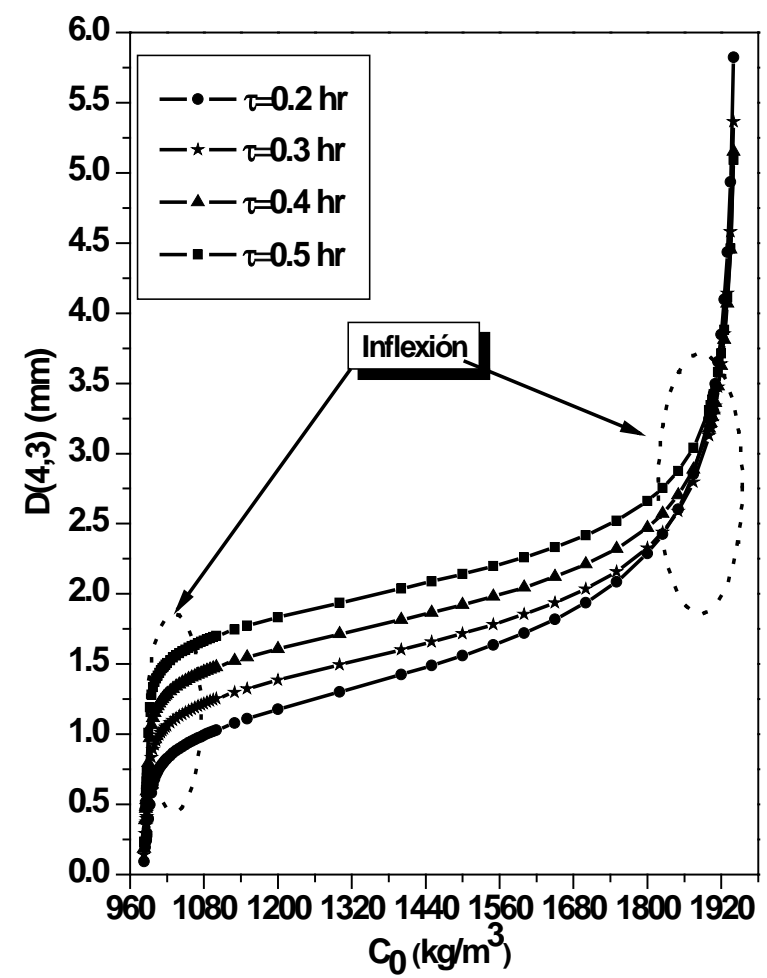

Figura 4.4 Estudio estático de $D(4,3)$ sobre las zonas de alta y baja sensibilidad. 


\subsubsection{Control bajo operación isotérmica}

En la Figura 4.5 se presenta la respuesta del proceso a lazo abierto con $\tau=0.3 \mathrm{hr}$, alcanzándose el estado estacionario en aproximadamente $10 \mathrm{hr}$, con un valor de $\mathrm{D}(4,3)=0.93$ mm. Esto indica que es factible usar técnicas de control retroalimentado para regular la operación del cristalizador.

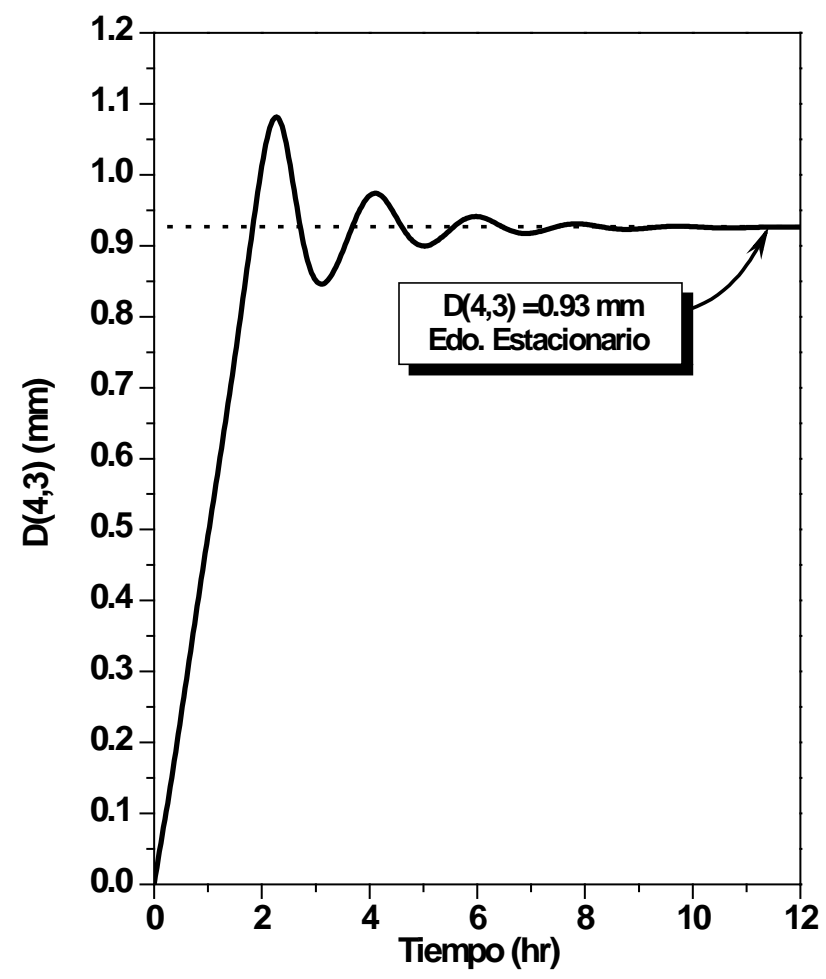

Figura 4.5 Respuesta del proceso a lazo abierto (operación isotérmica con $\tau=0.3 \mathrm{hr}$ ).

El objetivo de control fue establecer un valor de punto de ajuste de $D(4,3)=1 \mathrm{~mm}$ aplicando un servocontrol retroalimentado con controlador PID, el cual se sintonizo mediante las reglas IMC obtenidas por Skogestad (2003). Los parámetros de sintonía del controlador fueron $\mathrm{K}_{\mathrm{C}}=1938.0539 \mathrm{~kg} / \mathrm{m}^{3} \mathrm{~mm}, \tau_{\mathrm{I}}=0.5242189 \mathrm{hrs}$ y $\tau_{\mathrm{D}}=4.125 \times 10^{-6} \mathrm{hrs}$.

Se observa en la Figura 4.6 que la respuesta a lazo cerrado alcanza el valor del punto de ajuste en aproximadamente 2.5 hrs para posteriormente, una vez estabilizado el proceso, se aplica una perturbación de tipo escalón positivo y negativo a las 7 hr. 

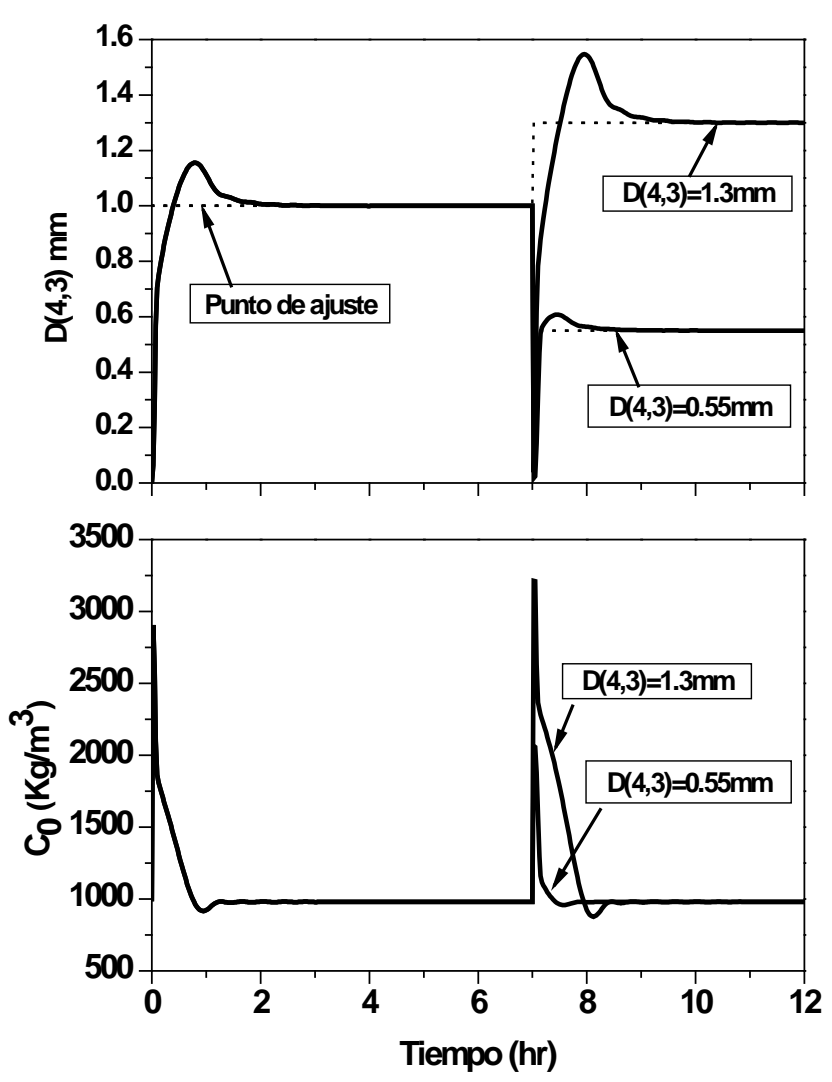

Figura 4.6 Respuesta del proceso a lazo cerrado (operación isotérmica con $\tau=0.3 \mathrm{hr}$ ).

Los valores de las perturbaciones se hicieron hasta el punto en que el controlador se desestabilizaba, fijando como valor máximo para el escalón positivo un $\mathrm{D}(4,3)=1.3 \mathrm{~mm}$ y para el escalón negativo un $\mathrm{D}(4,3)=0.55 \mathrm{~mm}$. También se observa que el tiempo en alcanzarse el valor del punto de ajuste negativo es mucho menor en comparación al cambio en escalón positivo ( 2 y $3 \mathrm{hr}$, respectivamente). Esto es debido a que el proceso de cristalización es más difícil de realizar que el proceso de disolución.

En otras palabras, el estudio presentado en la Figura 4.4 muestra que para alcanzar valores por arriba de un $\mathrm{D}(4,3)=1 \mathrm{~mm}$, el sistema necesitará una concentración de alimentación muy alta y por lo tanto mucho más tiempo de proceso. De lo anterior se observa que el proceso controlado por sí mismo es inoperable ya que a pesar de que por simulación se alcanza a estabilizar el proceso aun bajo cambios de escalones positivos y negativos, la exigencia del controlador de aumentar la concentración de alimentación de $1000 \mathrm{~kg} / \mathrm{m}^{3}$ a 3000 $\mathrm{Kg} / \mathrm{m}^{3}$ es inoperable, debido principalmente a la zona de operación la cual presenta trayectorias excesivamente rápidas. 


\subsection{Caso por enfriamiento}

\subsubsection{Modelo matemático para la operación por enfriamiento}

Debido a la dificultad de operar y controlar el cristalizador continuo tipo tanque agitado en operación isotérmica, se propone analizar el cristalizador en operación por enfriamiento. Se empleo el modelo matemático del caso isotérmico presentado en la Sección 2, con las siguientes suposiciones: el caso de operación por enfriamiento requeriría de la adición de una ecuación para el balance de energía, pero si se considera que se tiene un equipo altamente eficiente en la transferencia de energía en el sistema chaqueta-interior del cristalizador, se tendría que las temperaturas tanto en la chaqueta como en el interior serian casi idénticas. También la dinámica del proceso es cuasi-estacionaria, una suposición comúnmente tomada para sistemas continuos ya que la escala de tiempo de transferencia de calor es mucho más pequeña que la escala de tiempo de cristalización; por ejemplo para un cambio escalón en la temperatura de enfriamiento, la dinámica de la respuesta del sistema (temperatura del interior) es más rápida en comparación con la respuesta de la dinámica de concentración en la fase continua, ya que la transferencia de masa en el proceso de cristalización de sulfato de amonio es lenta debido a efectos difusivos-convectivos (Osorio, 2004). Por lo que es posible suponer que el tiempo que tarda en alcanzarse el estado estacionario de la temperatura del interior y que representa la parte dinámica del proceso y que el modelo no predice puede considerarse insignificante. Así que el modelo es aceptable a partir del estado estacionario para cada temperatura de saturación dada. En esta zona, los cambios en la concentración de la fase continua (soluto) son útiles para explicar el crecimiento de los cristales. Una de las variantes para el modelo en operación por enfriamiento es la de mantener constante la concentración de alimentación y tomar como variable manipulable la concentración de saturación ya que esta variable depende directamente de la temperatura de enfriamiento. De tal forma que si la temperatura de enfriamiento disminuye, la concentración de saturación también disminuirá de manera proporcional. Manipular la concentración de saturación de manera directa permite obtener un mejor control del proceso ya que esta variable representa la fuerza impulsora para que los fenómenos fisicoquímicos tales como el crecimiento y la nucleación de los cristales se lleven a cabo. 
Lugo (2005), citado por Quintana et al. (2007), determinó experimentalmente la curva de solubilidad para el sulfato de amonio en un intervalo de temperatura de 10 a $50{ }^{\circ} \mathrm{C}$, obteniendo una correlación polinomial de tercer orden para el cálculo de la concentración de saturación en función de la temperatura.

$$
\begin{aligned}
\mathrm{C}_{\mathrm{S}}= & -4.5555^{-8} \mathrm{~T}_{\mathrm{enf}}{ }^{3}+1.7244^{-5} \mathrm{~T}_{\mathrm{enf}}^{2} \\
& +1.9921^{-3} \mathrm{~T}_{\mathrm{enf}}+0.70691
\end{aligned}
$$

\subsubsection{Análisis estático del proceso a lazo abierto para la operación por enfriamiento}

En la Figura 4.7 se presenta la respuesta estática del cristalizador por enfriamiento en un intervalo de concentración de saturación de $998.6 \geq \mathrm{C}_{\mathrm{S}} \geq 707 \mathrm{~kg} / \mathrm{m}^{3}{ }^{\circ} \mathrm{C}$, correspondiente a una temperatura de enfriamiento de $91.5 \geq \mathrm{T}_{\text {enf }} \geq 0$.

Al igual que en la operación isotérmica existe una zona en donde aparecen los ciclos límites de acuerdo a los valores que se han fijado para la concentración de saturación y tiempo de residencia. También, se observa que existe un punto de inflexión en el que a concentraciones de saturación cercanas a la concentración de alimentación $\left(\mathrm{C}_{0}=1000 \mathrm{~kg} / \mathrm{m}^{3}\right)$ la variable a controlar tiene una respuesta muy sensible, la cual aumenta proporcionalmente con respecto al tiempo de residencia, por lo que implementar una estrategia de control en esa zona sería difícil debido a su alta sensibilidad. Se observa también que para todos los tiempos de residencia (excepto para $\tau<0.3 \mathrm{hr}$ ) hay un valor máximo de $\mathrm{D}(4,3)$ el cual le corresponde un valor de concentración de saturación ya que para $\tau<0.3 \mathrm{hr}$ la pendiente del proceso es negativa en todo momento tal que para todo valor de la concentración de saturación es inversamente proporcional al D(4,3). Por lo tanto, no por enfriar o disminuir más la concentración de saturación del sistema se obtendrán cristales de mayor tamaño, lo anterior puede deberse a las limitaciones del modelo matemático empleado más que fenómenos físicoquímicos e hidrodinámicos del proceso. 


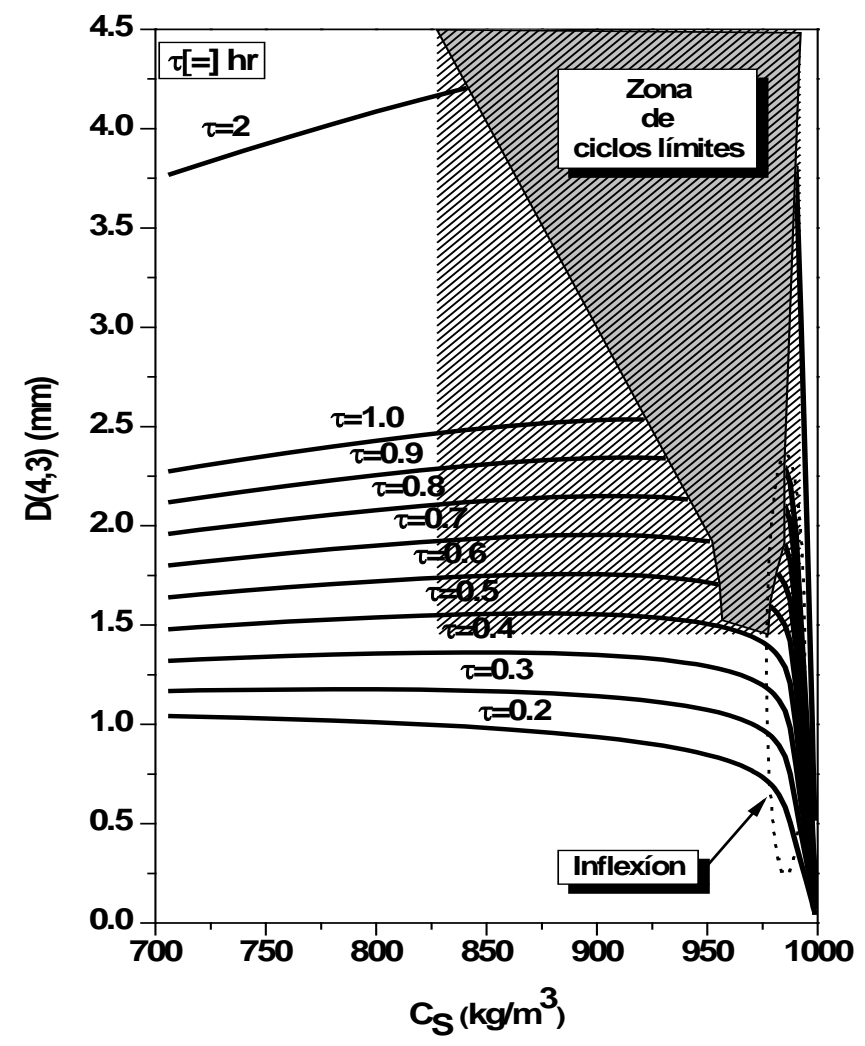

Figura 4.7 Estudio estático de $\mathrm{D}(4,3)$ sobre la zona de ciclos límites para la operación por enfriamiento.

En la Tabla 4.2 se presentan los valores máximos de $\mathrm{D}(4,3)$ para cada tiempo de residencia y concentración de saturación y su correspondiente temperatura de enfriamiento. Cabe señalar que los valores máximos de $\mathrm{D}(4,3)$ se obtienen despreciando los valores en la zona de ciclos límites.

Tabla 4.2 Valores máximos de $\mathrm{D}(4,3)$ para diferentes tiempos de residencia.

\begin{tabular}{|c|c|c|c|}
\hline $\begin{array}{c}\tau \\
(\mathrm{hr})\end{array}$ & $\begin{array}{c}\mathrm{T}_{\text {enf }} \\
\left({ }^{\circ} \mathrm{C}\right)\end{array}$ & $\begin{array}{c}\mathrm{C}_{\mathrm{S}} \\
\left(\mathrm{Kg} / \mathrm{m}^{3}\right)\end{array}$ & $\begin{array}{c}\mathrm{D}(4,3) \\
(\mathrm{mm})\end{array}$ \\
\hline 0.2 & 0 & 707 & 1.04233 \\
\hline 0.3 & 29.7 & 780 & 1.17671 \\
\hline 0.4 & 48.8 & 840 & 1.36215 \\
\hline 0.5 & 60.4 & 880 & 1.55866 \\
\hline 0.6 & 60.4 & 880 & 1.75665 \\
\hline 0.7 & 65.9 & 900 & 1.95458 \\
\hline 0.8 & 68.6 & 910 & 2.15025 \\
\hline 0.9 & 68.6 & 910 & 2.34421 \\
\hline 1.0 & 71.3 & 920 & 2.53625 \\
\hline 2.0 & 48.8 & 840 & 4.20214 \\
\hline
\end{tabular}




\subsubsection{Control bajo operación por enfriamiento}

En la Figura 4.8 se presenta la respuesta del proceso a lazo abierto considerando los valores del punto máximo para un $\tau=0.2 \mathrm{hr}$ con $\mathrm{C}_{\mathrm{S}}=707 \mathrm{~kg} / \mathrm{m}^{3}$ y $\mathrm{T}_{\text {enf }}=0{ }^{\circ} \mathrm{C}$. Se observa en la respuesta que el tiempo en alcanzarse el estado estacionario es de aproximadamente 2.2 hr. El objetivo de control será básicamente el mismo que se planteó para la operación isotérmica, establecer un valor de punto de ajuste de $\mathrm{D}(4,3)=1 \mathrm{~mm}$ aplicando un servocontrol retroalimentado con controlador PID sintonizado mediante las reglas IMC obtenidas por Skogestad (2003). Los parámetros de sintonía del controlador fueron: $\mathrm{K}_{\mathrm{C}}=-0.06375 \mathrm{~kg} / \mathrm{m}^{3} \mathrm{~mm}$, $\tau_{\mathrm{I}}=1.2102 \times 10^{-4}$ hrs. y $\tau_{\mathrm{D}}=0.014$ hrs.

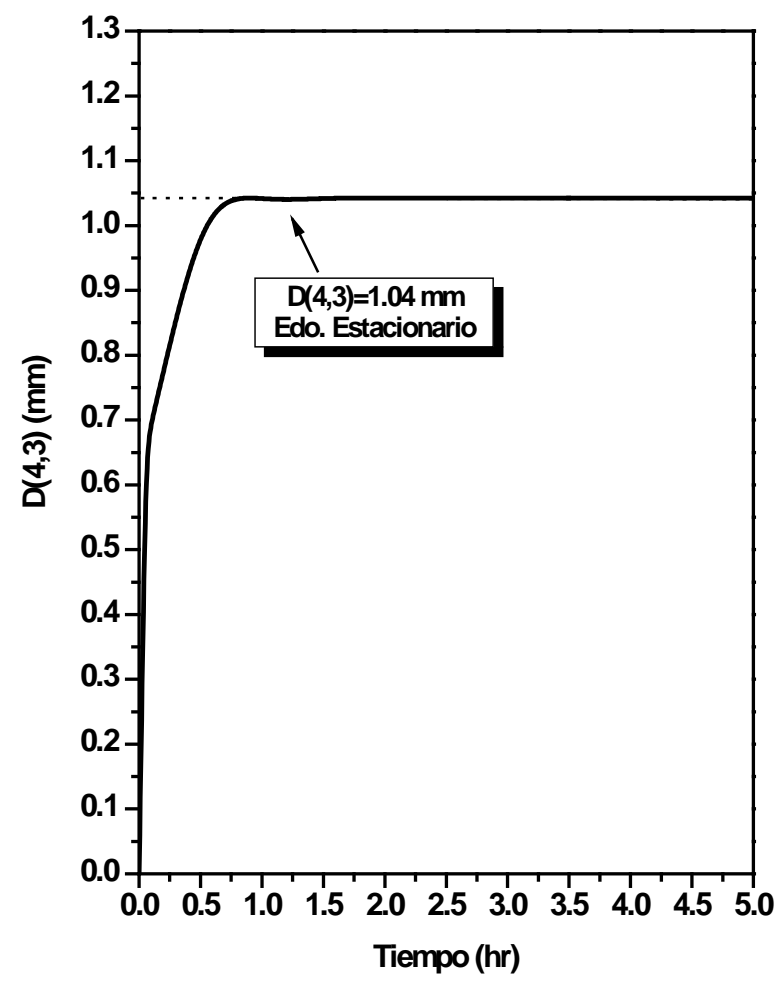

Figura 4.8 Respuesta del proceso a lazo abierto (operación por enfriamiento con

$$
\tau=0.2 \mathrm{hr}) \text {. }
$$

Se observa en la Figura 4.9 que la respuesta a lazo cerrado alcanza el valor del punto de ajuste en aproximadamente $1 \mathrm{hr}$ y posteriormente una vez estabilizado el proceso se le aplica al sistema una perturbación de tipo escalón positivo y negativo a las 3 horas del proceso. 

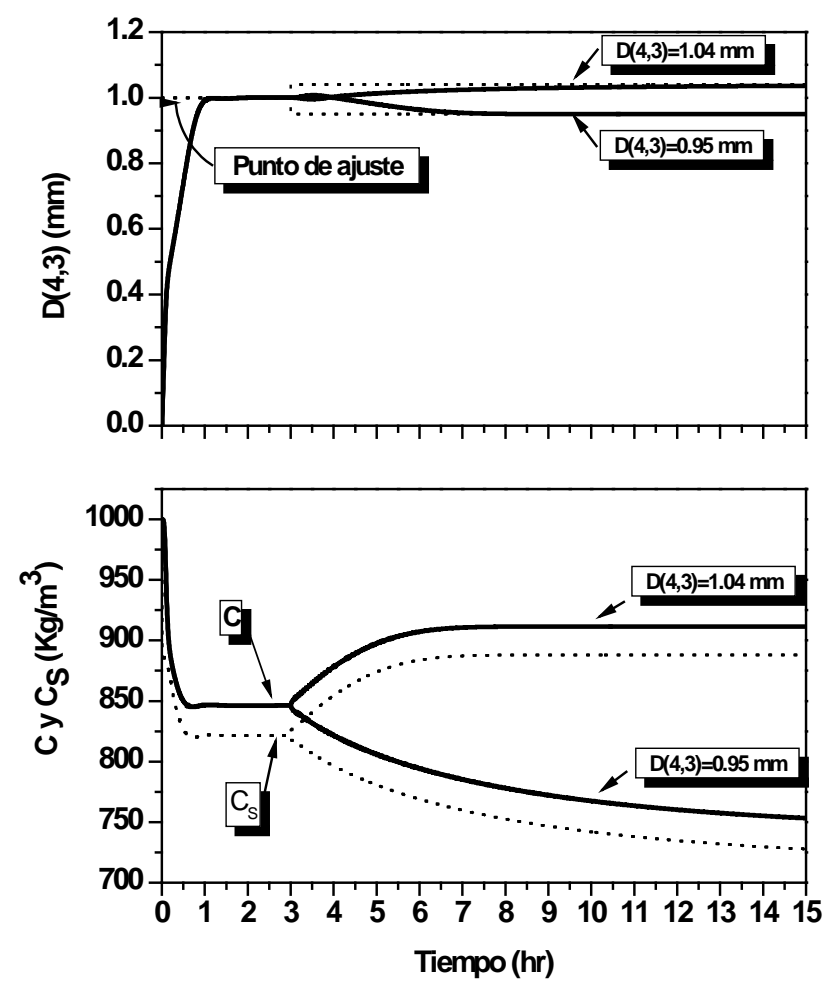

Figura 4.9 Respuesta del proceso a lazo cerrado (operación por enfriamiento con $\tau=0.2 \mathrm{hr})$.

Los valores de las perturbaciones se hicieron hasta el punto en que el controlador se desestabilizaba, fijando como valor máximo para el escalón positivo un $\mathrm{D}(4,3)=1.04 \mathrm{~mm}$ y para el escalón negativo un $\mathrm{D}(4,3)=0.95 \mathrm{~mm}$.

\subsection{Conclusiones}

El esquema de control implementado es funcional bajo las condiciones de operación elegidas. No obstante, el sistema isotérmico presenta dos puntos de inflexión y uno en la operación por enfriamiento, y en ambos casos se presentaron zonas de ciclos límites, que lo hacen muy inestable para la mayoría de las condiciones del proceso. Sin embargo, para cambios tipo escalón positivo y negativo en el punto de ajuste de magnitudes relativamente pequeñas y a tiempos de residencias menores de $6 \mathrm{hr}$ en el caso isotérmico, y menores de $3 \mathrm{hr}$ en la operación por enfriamiento, el controlador PID retroalimentado eliminó las desviaciones 
y las oscilaciones iníciales; alcanzándose en poco tiempo el punto de ajuste $(\mathrm{D}(3,4)=1 \mathrm{~mm})$ (2.5 y $1 \mathrm{hr}$, respectivamente) con respecto al proceso a lazo abierto (aproximadamente 10 y 2.2 hr, respectivamente). El tiempo de residencia es muy importante en la estabilidad del proceso, por lo que es mejor trabajar con $\tau \leq 5 \mathrm{hr}$ en la operación isotérmica y $\tau<3 \mathrm{hr}$ para la operación por enfriamiento. El sistema vía simulación es controlable bajo las restricciones antes mencionadas, es claro que en la realidad esto no sería posible debido a las exigencias del controlador al proceso para manipular flujos y temperaturas a lo largo de las zonas de baja sensibilidad.

Los sistemas de cristalización en continuo en donde su respuesta transiente se ha estabilizado, no presentan variaciones significativas en la sobresaturación del sistema, lo que origina cristales homogéneos de tamaño aceptable. Sin embargo, la operación en continuo bajo ciertas condiciones de operación (concentración de alimentación, temperatura) y tiempo de residencia mayores a $0.5 \mathrm{hr}$ es altamente inestable y difícil de ser controlada. Esto se asemeja a un sistema de cristalización por lotes, el cual es una operación unitaria sin mucha complejidad operativa, pero su estudio fenomenológico (control de la sobresaturación) y modelación resultan altamente complejos.

\section{Reconocimiento}

Parte del material presentado en este capítulo se utilizó para la elaboración del siguiente artículo:

O. Velázquez-Camilo, J.J. Álvarez-Ramírez y E. Bolaños-Reynoso, (2009). Comparative Analysis of the Crystallizer Dynamics Type Stirred Tank Continuous. Isothermic and Cooling Case. Revista Mexicana de Ingeniería Química (RMIQ), Vol. 8 (1), 127-133. 
CAPÍTULO V

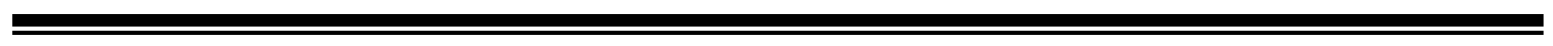




\section{Análisis Fractal de imágenes adquiridas de la cristalización de azúcar de caña}

\subsection{Resumen}

Debido a que a nivel industrial y científico se ha incrementado el uso y análisis de imágenes en línea/seudolinea para monitorear la evolución de la cristalización, se desarrolló un estudio basado en análisis fractal para cuantificar el grado de complejidad de la cristalización de azúcar de caña a diferentes tiempos del proceso. El principal objetivo de esta técnica es dar seguimiento al crecimiento del cristal a través de la cuantificación de los cambios de forma de acuerdo a la complejidad de las estructuras y/o al grado de irregularidad en los patrones de los cristales. Sin embargo, para las imágenes micrográficas obtenidas directamente de la solución (slurry) muestran que los cristales no se encuentran aislados, sino que presentan un patrón complejo de cristales de diferentes tamaños (pequeños y grandes) superpuestos de manera irregular. Para este fin, se usó el método de análisis de fluctuación con remoción de la tendencia (DFA) para un arreglo bidimensional, el cual provee un índice de exponente de escalamiento, para cuantificar el grado de complejidad de un patrón bidimensional irregular. Los resultados muestran que el exponente de escalamiento y la dimensión fractal másica de las imágenes proporcionan una visión o tendencia de la evolución del proceso de la cristalización.

\subsection{Introducción}

El proceso de la cristalización industrial involucra muchos pasos para obtener un producto con calidad comercial. El principal paso del proceso de la cristalización es dónde el licor es enfriado y evaporado por medio del vacío. Muchas variables pueden tener efectos determinantes en la calidad de los cristales, incluso la temperatura, presión de vacío, agitación y contenido de impurezas entre otros (Sangwal, 2007). Como consecuencia, la demanda de 
más y mejores productos ha motivado el uso de tecnologías modernas para el diseño de políticas de operación y supervisión de la evolución del crecimiento de cristales (Sutradhar, 2004). Estas tecnologías incluyen el uso de estrategias de control retroalimentado en línea y medición virtual (Bolaños-Reynoso et al., 2008). Recientemente, la adquisición de imágenes con cámara de alta velocidad y microscopio electrónico (Calderon-De-Anda et al., 2005; Wang et al., 2007) ha sido considerada como una mejora en el desarrollo de control retroalimentado y supervisión en línea del proceso de cristalización. Las imágenes proporcionan un análisis de la evolución de la cristalización en el seno de la solución estimando las formas de cristales, DTC y posibles nucleaciones secundarias y fenómenos de atrición. En la actualidad se han probado varias aplicaciones de análisis de imagen en línea para la supervisión y control de diferentes procesos de cristalización. Calderón-de-Anda et al., (2005) demostraron que con la técnica de segmentación multi-escala se pueden analizar las imágenes en línea de diferentes cristales con varias formas y diferentes cualidades de manera eficaz. Wang et al., (2007) estimaron la tasa de crecimiento de cristales individuales en tiempo real. Dharmayat et al., (2006) combinaron microscopía y difracción de rayos-x para monitorear la transformación polimórfica del acido L-glutámico. Qu et al., (2006) evaluaron mediante análisis de imagen los efectos de aditivos en un cristalizador por lotes por enfriamiento. Larsen y Rawlings (2009) evaluaron la viabilidad de una video cámara de alta resolución, para medir la DTC aplicando análisis de imagen y herramientas de estimación estadística de imágenes de una cristalización por lote simulada de un proceso fotoquímico industrial, mostrando que la técnica puede usarse para supervisar la razón de crecimiento de núcleos sembrados. La cual no puede monitorearse por las tecnologías convencionales. Los trabajos mencionados muestran que el uso de análisis de imagen tiene un potencial importante en el monitoreo de la evolución de la cristalización a nivel investigación e industrial.

La DTC es una de las variables más importantes del proceso que pueden ser medidas para monitorear el proceso de cristalización, también puede ser usada para estimar los momentos de la distribución, el $\mathrm{D}(4,3)$ y su desviación estándar $\mathrm{S}(4,3)$. Estas son variables muy usadas en el ramo industrial y que pueden ser usadas para el diseño de un lazo de control para corregir la variabilidad en la DTC y mejorar la calidad del producto. Sin embargo, como se presento en el Capítulo 2 y 3, es posible estimar la DTC según el procedimiento 
desarrollado por Bolaños-Reynoso et al., (2008) pero este procedimiento tiene el inconveniente de realizarse fuera de línea y se requiere de un tiempo largo para obtener la DTC, D(4,3) y S(4,3) (entre otras variables estadísticas de gran valor en el análisis y estudio de la evolución de la cristalización). Para resolver esta situación se ha propuesto un método de análisis de imagen en línea que pueda incorporar la información obtenida dentro de procedimientos de control retroalimentado. Los análisis de imágenes reportados con anterioridad se enfocan en el seguimiento de forma y dinámica de crecimiento de cristales aislados; para lo anterior se podrían tomar muestras desde el seno de la solución y ser diluidas o dispersadas para obtener cristales aislados uno de otro. En esta forma, se podría aplicar también la técnica de segmentación para dar información sobre los procesos de conformación de cristales. Sin embargo, imágenes tomadas de muestras obtenidas desde el seno de la solución (slurry) muestran un acomodo de los cristales de forma compleja e irregular como se muestra en la Figura 5.1 donde se presentan imágenes de cristales de azúcar de caña para cuatro diferentes tiempos de cristalización (10, 20, 55 y 83 minutos) (las imágenes fueron tomadas de acuerdo a técnica especificada en el Capitulo 2 Sección 2.3.2).
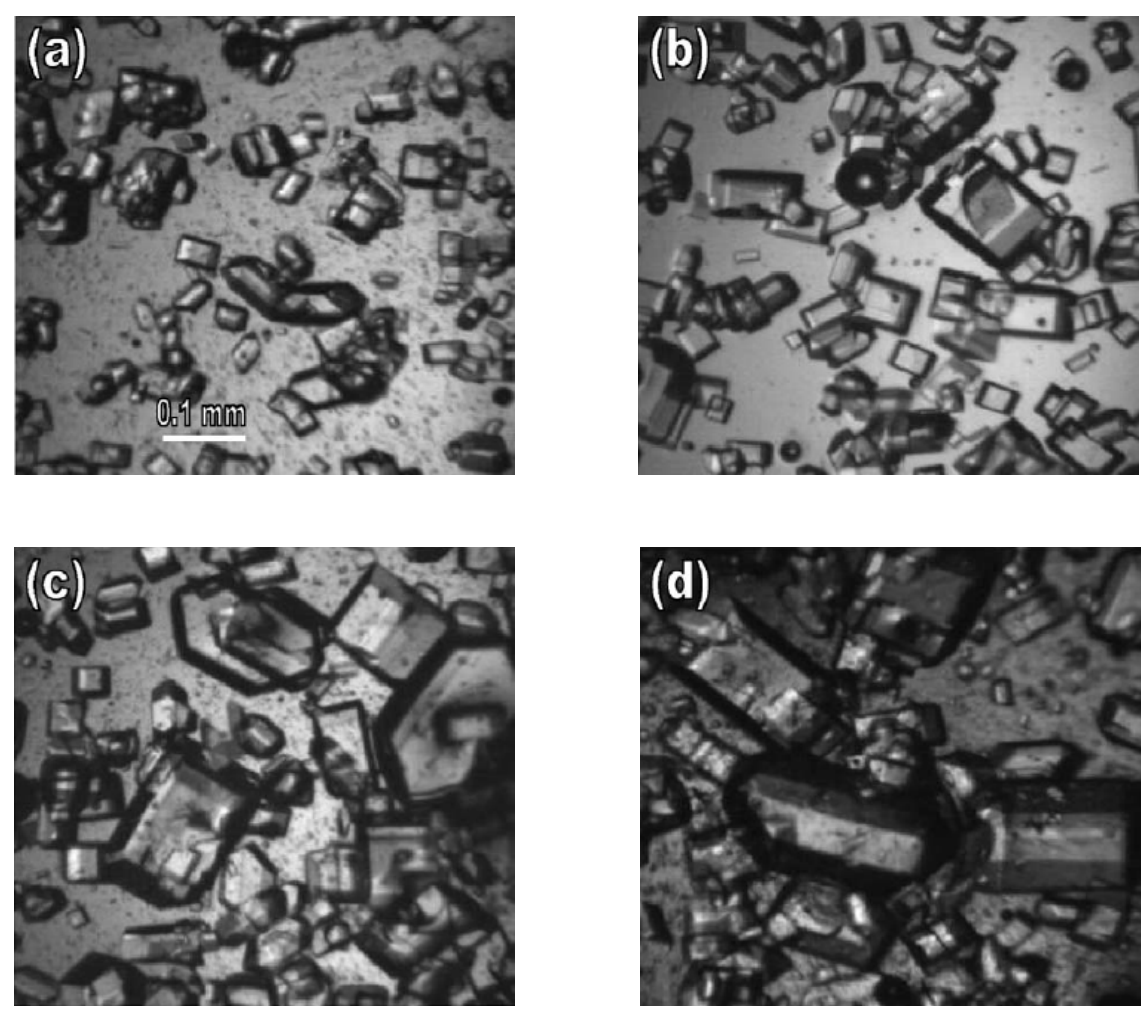

Figura 5.1 Secuencia de imágenes tomadas a diferentes tiempos del proceso. a) 10 min, b) $20 \mathrm{~min}$, c) $55 \mathrm{~min} \mathrm{y} \mathrm{d)} 83 \mathrm{~min}$. 
Para tiempos relativamente cortos (10 minutos) aún se pueden observar los contornos de los cristales. Sin embargo la densidad de la masa cristalizada aumenta con el tiempo, tanto que los cristales no se encuentran aislados, presentando un empaquetamiento de forma irregular y superposiciones de cristales de diferentes tamaños. Este patrón complejo refleja algunos aspectos de lo avanzado que se encuentra la cristalización, tales como la cantidad y diversidad de la masa cristalizada.

En este trabajo se exploró el análisis de imágenes tomadas de muestras obtenidas del seno de la solución, para monitorear la evolución del proceso de cristalización. Dado la complejidad del patrón de la cristalización de azúcar de caña presentada en la Figura 5.1, se ha pensado en utilizar algún método de análisis fractal para extraer información relativa a la evolución de la cristalización de azúcar de caña. Para este fin, se aplico el método de análisis de fluctuación con remoción de la tendencia (DFA) por sus siglas en ingles, el cual es un método desarrollado recientemente para obtener información sobre la complejidad de las imágenes presentadas en la Figura 5.1 (Gu y Zhou, 2006). Los resultados presentaron una correlación entre la fractalidad medida en términos de un exponente de escalamiento y dimensión fractal másica, y el $(\mathrm{D}(4,3))$. Estos resultados sugieren que el $\mathrm{D}(4,3)$ guarda información sobre la fractalidad geométrica de la cristalización, por ello el análisis fractal de imágenes de la cristalización de azúcar de caña puede ser usada como una herramienta complementaria para el monitoreo de la evolución de la cristalización.

\subsection{Metodología}

\subsubsection{Infraestructura}

Para la cristalización de azúcar de caña se utilizó la planta piloto perteneciente a la División de Estudios de Postgrado e Investigación del I.T. de Orizaba, la cual se describió en el Capitulo 3, Sección 3.3.1. 


\subsubsection{Sistema de adquisición de imagen}

Para la captura y análisis de imágenes se tomaron diversas muestras para diferentes tiempos del proceso de cristalización, cada muestra consistió de $7 \mathrm{ml}$ del slurry tomados desde el seno de la solución, para ello se usó el software IMAQ Vision Builder de National Instruments, Inc. Y una cámara monocromática RS-170, 60 Hz (8 bits de resolución). Con manipulación del haz de luz de un microscopio trinocular. La muestra es transportada desde el cristalizador hasta el sistema de adquisición de imagen por medio de una bomba peristáltica a 1500 rpm. La cámara captura una imagen que es procesada y limpiada, evitando variaciones indeseables de la luminosidad de la imagen, esto último se logra por medio de la técnica del umbral que permite obtener una imagen en escala de grises.

\subsubsection{Condiciones de operación}

Se preparó una solución de azúcar de caña para representar la meladura a nivel industrial (solución azucarada o jugo de caña concentrado) con 9235.9 g de azúcar refinada (comercial) y 2922.7 g de agua (75.962 ํㅏix correspondiente a una temperatura de saturación de $70{ }^{\circ} \mathrm{C}$ ) dentro del cristalizador, el sembrado de cristales o núcleos se realizó durante los primeros 4 minutos del proceso $\left(69^{\circ} \mathrm{C}\right.$ de temperatura interior y 21.5 inHg de presión de vacío) , con tamaños de núcleos de $\mathrm{D}(4,3)$ de $195.3 \mu \mathrm{m}$ en \% volumen y $\mathrm{S}(4,3)$ de $19.52 \mu \mathrm{m}$. La velocidad de la agitación fue mantenida constante en $250 \mathrm{rpm}$ durante todo el lote (90 minutos). Durante los primeros 30 minutos del proceso consiste en evaporarse la mayor cantidad de agua a $65^{\circ} \mathrm{C}$ y 21.5 inHg de presión de vacío (tiempo de evaporación constante) para estabilizar el lote y beneficiar el crecimiento de los cristales sembrados y minimizar la nucleación espontánea. Posteriormente a la etapa de evaporación constante, se aplica un perfil dinámico de regulación de presión de vacío por 60 minutos, causando una trayectoria por evaporación adiabática de $65^{\circ} \mathrm{C}$ a $41^{\circ} \mathrm{C}$. El perfil de enfriamiento adiabático implementado es conocido como perfil de frecuencia máxima o perfil natural que consiste en cambiar el setpoint de 21.5 inHg a 25 inHg de presión de vacío (Bolaños-Reynoso et al., 2008). 


\subsubsection{Concepto de geometría fractal}

La geometría fractal se basa en los trabajos de finales del siglo IX de matemáticos que descubrían y generaban estructuras geométricas complejas a partir de un objeto simple como: una línea, un triangula, un cuadrado o un cubo (llamado iniciador) al que se le aplicaba una simple regla de transformación (llamado generador) en un número infinito de pasos iterativos. El resultado de generar de manera infinita estos pasos iterativos, proveía una riqueza en detalles a diferentes escalas de observación, sin embargo, cuando estas eran comparadas con las piezas más grandes o con los conjuntos formados podían observarse similitudes entre sí (Peitgen et al., 1992; Eke et al., 2002). Esto es fácilmente observable en la Figura 5.2.

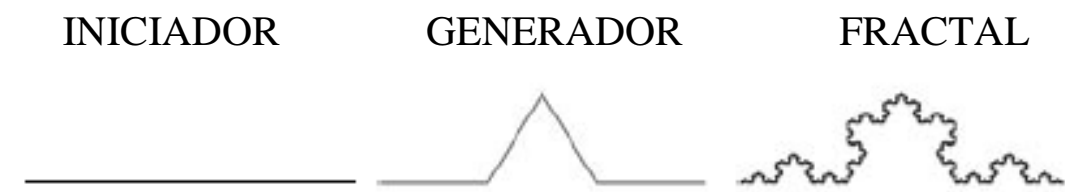

Curva de Von-Koch - 1D
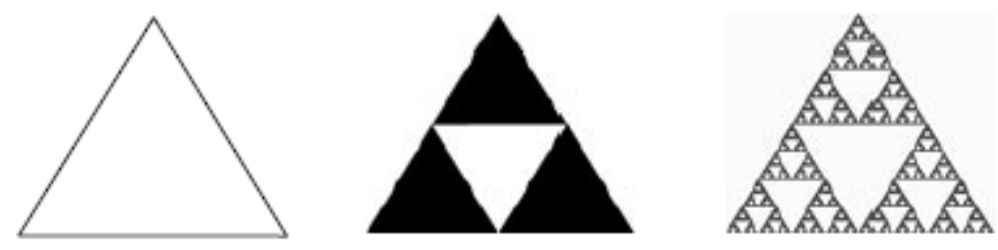

Triangulo de Sierpinski - 2D
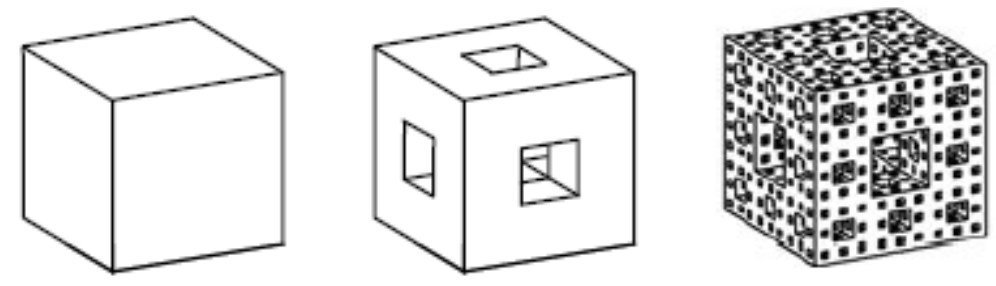

Esponja de Menger - 3D

Figura 5.2 Concepto matemático fractal.

De manera clásicamente las formas de la naturaleza siempre han sido descritas mediante figuras geométricas sencillas como las descritas en la Figura 5.2, como pueden ser rectas, círculos, cuadrados, cilindros, esferas y cubos entre otros. Sin embargo estas figuras 
sencillas no son del todo válidas para describir la esencia de la naturaleza. La geometría de la naturaleza depende de la escala de observación. Todas ellas invariantes a cualquier escala de observación. Por tanto, para describir la geometría de la naturaleza necesitamos figuras geométricas que también varíen con la escala de observación. Si estas figuras tienen autosimilitud entre sus diferentes escalas de observación, se les denomina fractales.

\subsubsection{Método de análisis fractal: Análisis de fluctuación con remoción de la tendencia (DFA)}

La Figura 5.1 se presentan cuatro micrografías tomadas en diferentes tiempos del proceso, mostrando un conjunto de cristales pequeños y grandes generados por los efectos de nucleación y crecimiento desde la solución sobresaturada. La distribución estocástica de los cristales sobre la superficie es evidente, sugiriendo una estructura de tipo fractal. También se observó que conforme el tiempo del lote aumentaba, el número y tamaño de los cristales también aumentaba con un aumento significativo en la complejidad de los cristales, lo que a su vez sugiere que las propiedades estructurales de los cristales es una función del tiempo de lote y/o del grado de enfriamiento de la solución sobresaturada. En este sentido es interesante considerar, si la fractalidad de los cristales puede ser relacionada con la evolución del proceso de cristalización; para ello se propuesto un método de análisis aplicado para un arreglo bidimensional y que cuantifica la fractalidad de las imágenes. Para lo anterior se propuso el método de análisis de fluctuación con remoción de la tendencia (DFA) para un arreglo bidimensional no estacionario de Gu y Zhou, (2006) para aplicarlo a las microscopías obtenidas del slurry del proceso. El método DFA para un espacio bidimensional consiste de los siguientes pasos:

\section{$\underline{\text { Paso } 1 .}$}

Considere una superficie la cual es denotado por un arreglo bidimensional X(i,j), donde $i=1,2, \ldots, M$ y $j=1,2, \ldots, N$, la superficie es particionada dentro de $M_{s} \times N_{s}$ segmentos cuadros separados del mismo tamaño $s \times s$ (cajas de tamaños iguales), donde $M_{s}=[M / s]$ 
y $\quad N_{s}=[N / S]$. Cada segmento puede ser denotado por $X_{V, w}$ tal que $X_{V, w}(i, j)=X\left(I_{1}+i, I_{2}+j\right)$ para $1 \leq i, j \leq s$, donde $I_{1}=(v-1) s$ y $I_{2}=(w-1) s$.

Paso 2.

Para cada segmento $X_{V, w}$ identificado por $v$ y $W$, se calcula la sumatoria acumulativa $u_{V, w}(i, j)$, como sigue:

$u_{V, W}(i, j)=\sum_{k_{1}=1}^{i} \sum_{k_{2}=1}^{j} X_{V, W}\left(k_{1}, k_{2}\right)$

donde $1 \leq i, j \leq s$, note que $u_{V, W}$ por sí mismo es una superficie.

$\underline{\text { Paso } 3 .}$

La tendencia de la superficie construida $u_{V, W}$ puede ser determinada por un ajuste polinomial con función bivariante preseleccionada $\tilde{u}_{v, w}(i, j)$. La función más simple podría ser un plano. En este trabajo la función polinomial bivariante seleccionada es la presentada en la Ec. (5.2).

$\tilde{u}_{v, w}(i, j)=a i+b j+c$

donde $1 \leq i, j \leq s$, con a, b y c como parámetros libres para ser determinados. Estos parámetros pueden ser determinados a través de operación matricial derivado del método de mínimos cuadrados. Puede obtenerse entonces la matriz residual $\varepsilon_{V, W}(i, j)$.

$\varepsilon_{V, W}(i, j)=u_{V, W}(i, j)-\tilde{u}_{V, W}(i, j)$ 
La función de fluctuación con remoción de la tendencia $F(V, W, s)$ del segmento $X_{V, w}$ es definida a través del muestreo de la varianza de la matriz residual $\varepsilon_{V, W}(i, j)$ como sigue:

$$
F(v, W, s)=\sqrt{\frac{1}{s^{2}} \sum_{i=1}^{s} \sum_{j=1}^{s} \varepsilon_{v, w}(i, j)^{2}}
$$

Note que la media del residual es cero debido al procedimiento de remoción de la tendencia.

\section{Paso 4.}

La función de fluctuación con remoción de la tendencia global es calculada mediante el promedio de todos los segmentos, como sigue:

$$
F(s)=\sqrt{\frac{1}{M_{s} N_{s}} \sum_{V=1}^{M_{s}} \sum_{w=1}^{N_{s}} F^{2}(V, W, s)}
$$

\section{Paso 5.}

Para determinar la relación de escalamiento entre la función de fluctuación con remoción de la tendencia $F(s)$ y el tamaño de escala $s$ (numero de cajas de tamaños s sobre la superficie), se varía el valor de $s$ en el rango de $s_{\min } \approx 10$ y $s_{\max } \approx \min (M, N) / 5$, obteniéndose una función de tipo ley de potencia:

$F(s) \sim s^{2 \alpha}$

donde $\alpha$ es el exponente de escalamiento, el cual es un indicador de la rugosidad o aspereza del arreglo bidimensional. Si $\alpha=0.5$ indica que no existe correlaciones y la rugosidad o aspereza es máxima, por el contrario si $\alpha>0.5$ indica la presencia de correlaciones en la conformación del arreglo, y si $\alpha<0.5$ la correlación en la señal es antipersistente es decir que un incremento es muy probable que este seguido de un decremento y viceversa. Los valores 
grandes de $\alpha$ son asociados con superficies lisas o parejas, es decir superficies más ordenadas y predecibles. El coeficiente constante 2 antes del exponente de escalamiento $\alpha$ está ligado a la técnica DFA con arreglo bidimensional.

\subsection{Resultados}

En la Figura 5.3 se presentan los estados del sistema, en la Figura 5.3a se presentan la temperatura del interior y la presión de vacío como una función del tiempo, se observa que tanto la temperatura y la presión de vacío mantienen un perfil constante con pequeñas variaciones los primeros 30 minutos del proceso (tiempo de evaporación constante) alrededor de $65{ }^{\circ} \mathrm{C}$ y 21.5 inHg respectivamente, sin embargo también es el tiempo en que la densidad permanece dentro de la zona inestable (Figura 5.3b), posteriormente al aplicarle el cambio escalón de $21.5 \mathrm{inHg}$ a $25 \mathrm{inHg}$ en la presión de vacío y dejar enfriar de $65{ }^{\circ} \mathrm{C}$ a $40{ }^{\circ} \mathrm{C}$ aproximadamente (temperatura de la chaqueta por debajo de la temperatura del interior), la densidad se ubica dentro de las zonas metaestables con un reducido efecto por la nucleación secundaria. En la Figura 5.3c se observa que la masa de cristal formado mantiene un incremento sostenido conforme el proceso avanza hasta alcanzar una MCF=3900 gr de azúcar aproximadamente y en la Figura 5.3d se observa que el D(4,3) máximo alcanzado fue de $\mathrm{D}(4,3)=350 \mu \mathrm{m}$ con su respectiva $\mathrm{S}(4,3)=160 \mu \mathrm{m}$. El decremento ligero presentado a los 70 minutos del proceso puede deberse a la atrición de cristales inducidos por una gran cantidad de masa de cristales formados y posiblemente a formas fractales irregulares.

En la Figura 5.1 se presentaron las imágenes microscópicas que fueron obtenidas para el monitoreo de la evolución de la cristalización a diferentes tiempos (10, 20, 55 y 83 minutos), se observó que la densidad de cristales aumenta con respecto al tiempo cubriendo la superficie de la imagen. Para tiempos cortos como se mostro en las figuras 5.1a y 5.1b los cristales se muestran aislados. Sin embargo, para tiempos largos (Figura 5.1c y 5.1d), la densidad y tamaños de cristales es mayor, tal que no se observan espacios libres para desplegar cristales de forma individual, mostrando superposición entre cristales pequeños y grandes. 

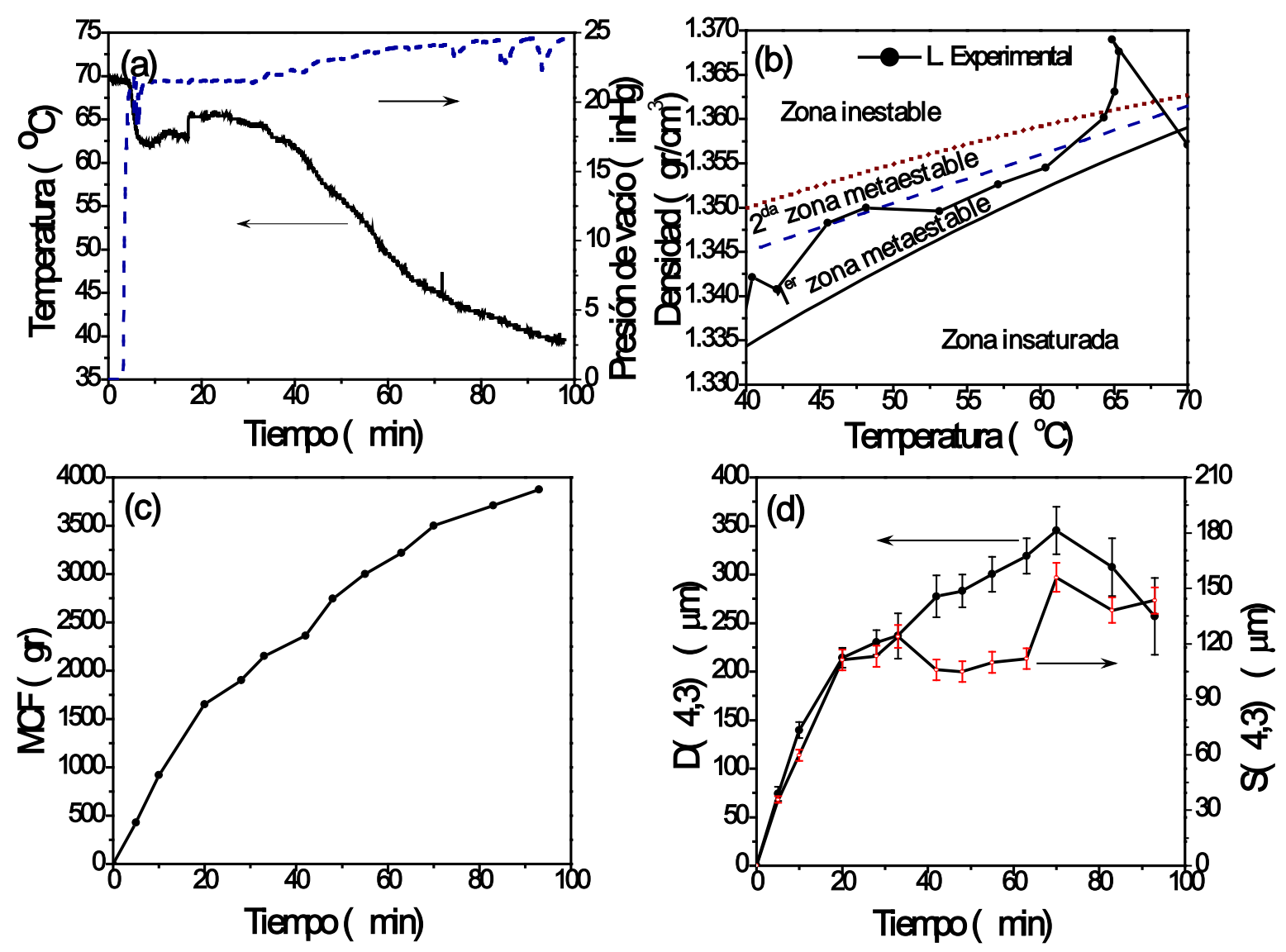

Figura 5.3 Variables del proceso. a) temperatura interior y presión de vacío, b) densidad experimental en un diagrama concentración-temperatura, c) masa de cristal formado

(MCF) y d) D(4,3) y S(4,3) obtenida de la DTC de tipo log-normal en \% volumen.

La diferencia en el patrón para cada tiempo es claro y dado la naturaleza irregular de la conformación de los cristales, se consideró satisfactorio el uso del DFA para la cuantificación de la fractalidad de la imagen. Primeramente se obtuvo el exponente de escalamiento de las imágenes en escala de grises de la Figura 5.1. Sin embargo, los valores estimados son estadísticamente constantes después del segundo muestreo del proceso de cristalización (10 minutos) estabilizándose en un valor para el exponente de escalamiento de 0.866 (Figura 5.4). Lo anterior puede deberse a la estructura afectada por la baja luminiscencia (imágenes oscuras) este patrón domina la función de fluctuación fractal, por lo que la estructura fractal para tiempos largos podría no ser discriminada. En este sentido, se decidió usar imágenes binarizadas que en principio guardarían la estructura fractal de la cristalización. La Figura 5.5 muestra las imágenes de la Figura 5.1 con un valor del umbral de $\gamma=75$. 


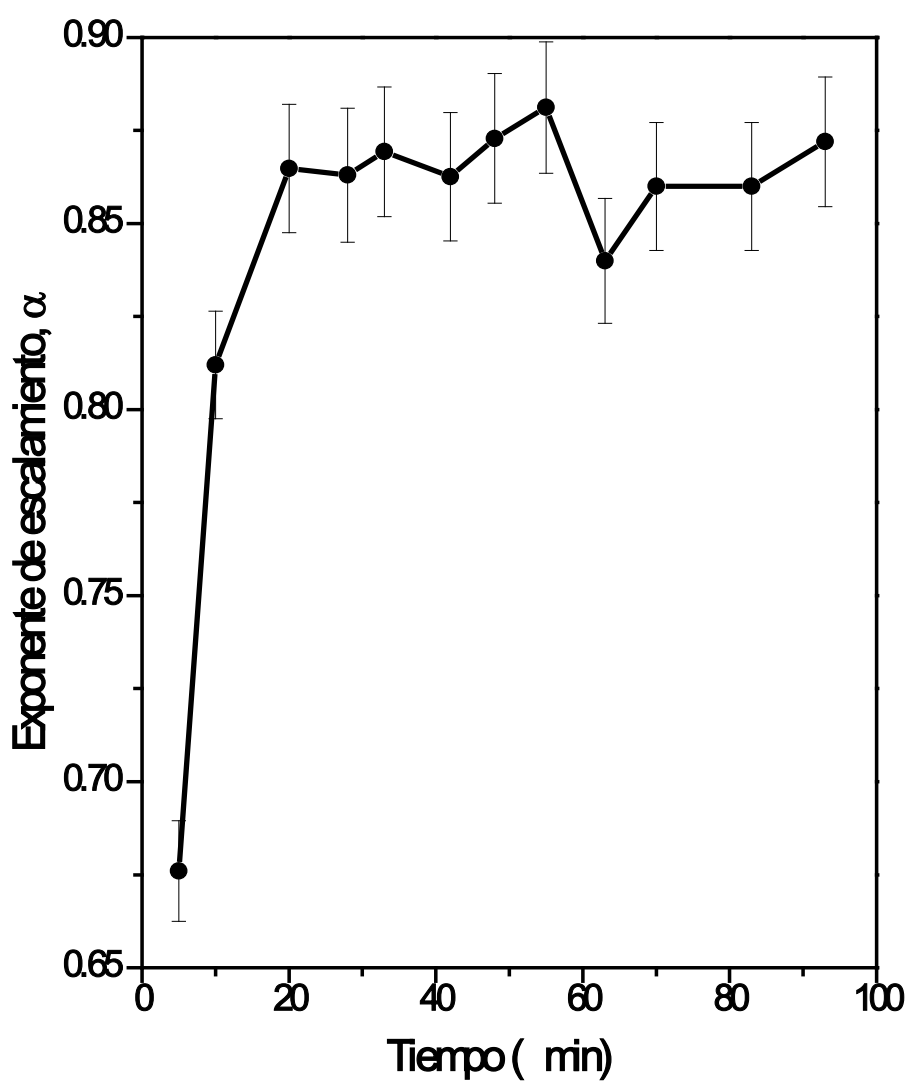

Figura 5.4 Exponente de escalamiento $\alpha$ para las imágenes en escala de grises en la Figura 5.1.

La geometría fractal es evidente sobretodo en las figura 5.5c y 5.5d, con una distribución irregular de cristales en el plano. Esta geometría fractal es inducida por los contornos de los cristales, que recuperan las sombras de las imágenes en escala de grises. Para tiempos de cristalización pequeños (5.5a y 5.5b) es fácil de observar los contornos de los cristales individuales, pero para tiempos largos (5.5c y 5.5d) los contornos de los cristales pequeños y grandes no se encuentran separados. Para una adecuada selección del valor del umbral en la binarización de las imágenes, se puede asumir en primera instancia que los valores de la densidad en la escala de grises tiene un valor binario conocido con distribución normal o log-normal, tal que el valor del umbral se toma como el valor medio de la escala de grises (Davila et al., 2007). Sin embargo, las imágenes presentadas en la Figura 5.5 no están distribuidas normalmente en la escala de grises, por lo que este criterio no es aplicable. 


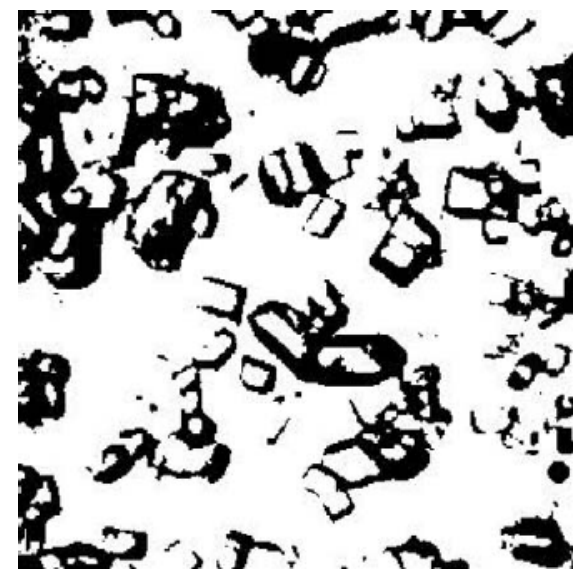

(a)

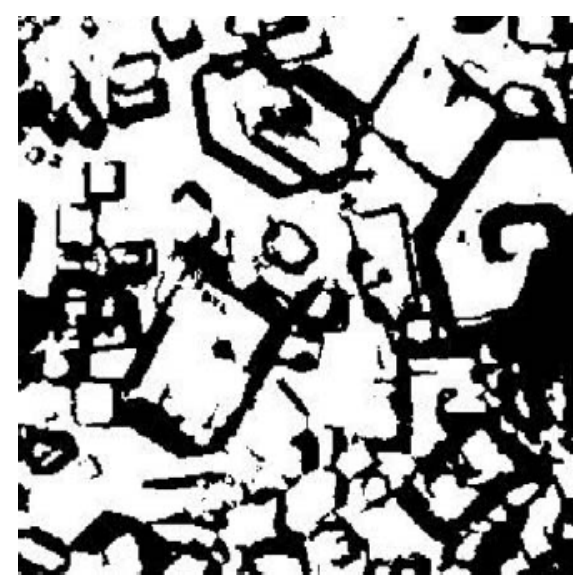

(c)

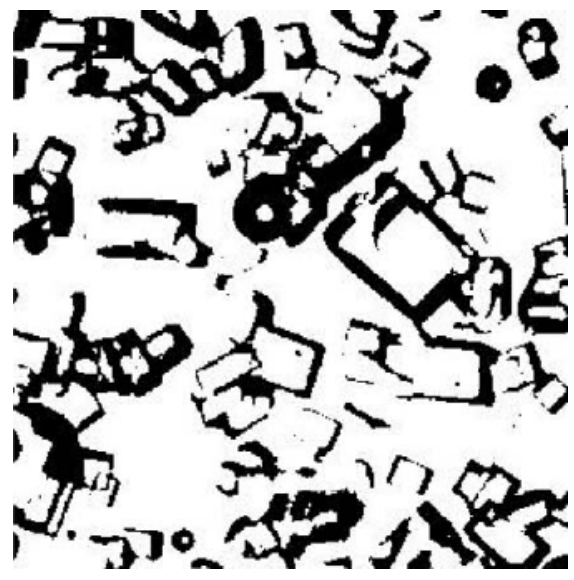

(b)

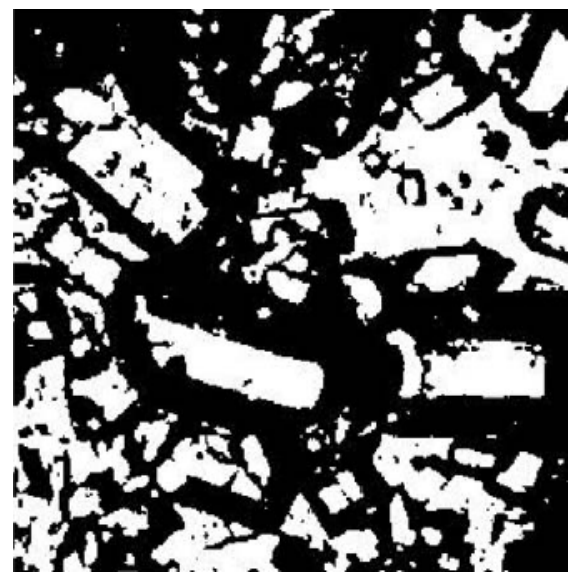

(d)

Figura 5.5 Imágenes binarizadas con valor del umbral de $\gamma=75$ correspondientes a la Figura 5.1.

En lugar del criterio anterior se aplicó otro enfoque para la selección del valor del umbral encontrándose así el máximo exponente de escalamiento. Este enfoque se basa en que los exponentes de escalamientos altos son relacionados con correlaciones de imagen altas mayores a 0.5 (Gu y Zhou, 2006). La Figura 5.6 presenta el exponente de escalamiento como una función del valor del umbral para tres imágenes seleccionadas (10, 42 y 83 minutos), demostrando que las correlaciones máximas están desplegadas en un rango $50 \leq \gamma \leq 125$, en este sentido, la extracción de información de la imagen de alta calidad es garantizada seleccionando un valor del umbral dentro de este rango. Estos resultados (Figura 5.6) corroboran la interpretación realizada sobre las figuras 5.5c y 5.5d. 


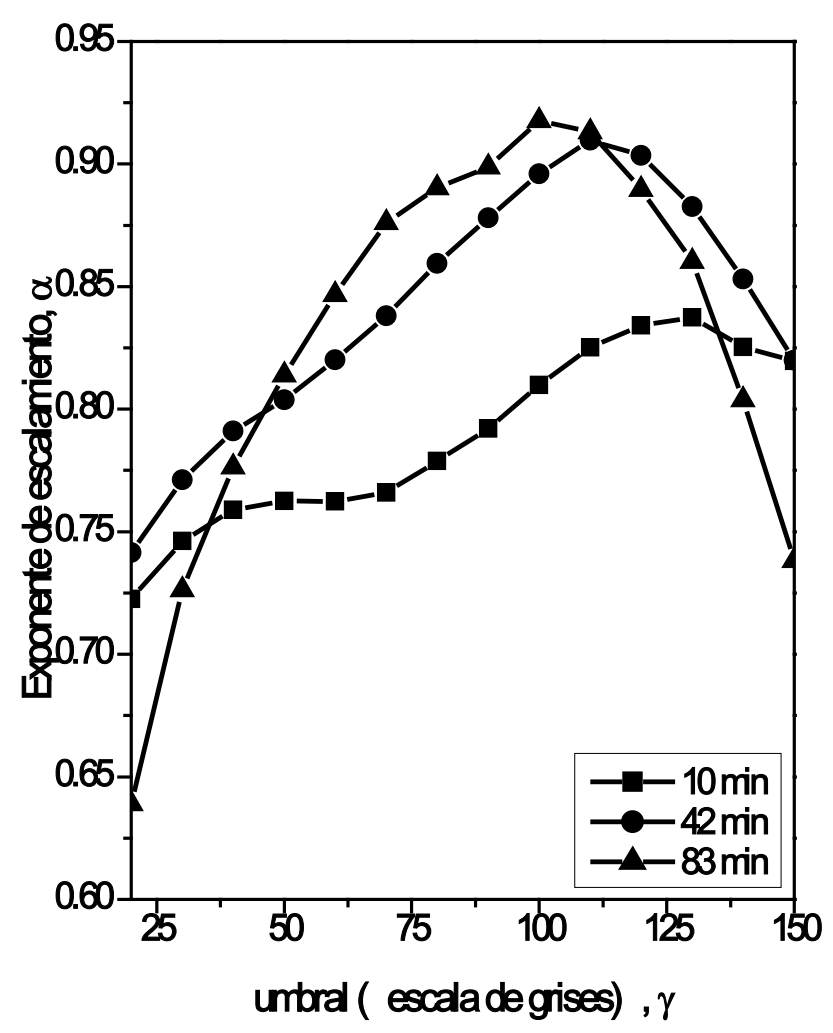

Figura 5.6 Exponente de escalamiento como una función del valor del umbral.

La Figura 5.7 muestra los resultados para las imágenes binarizadas en la Figura 5.5, para un valor del umbral de $\gamma=70$. La Figura 5.7 muestra que el exponente de escalamiento no es constante ya que cambia con el tiempo del proceso de cristalización.

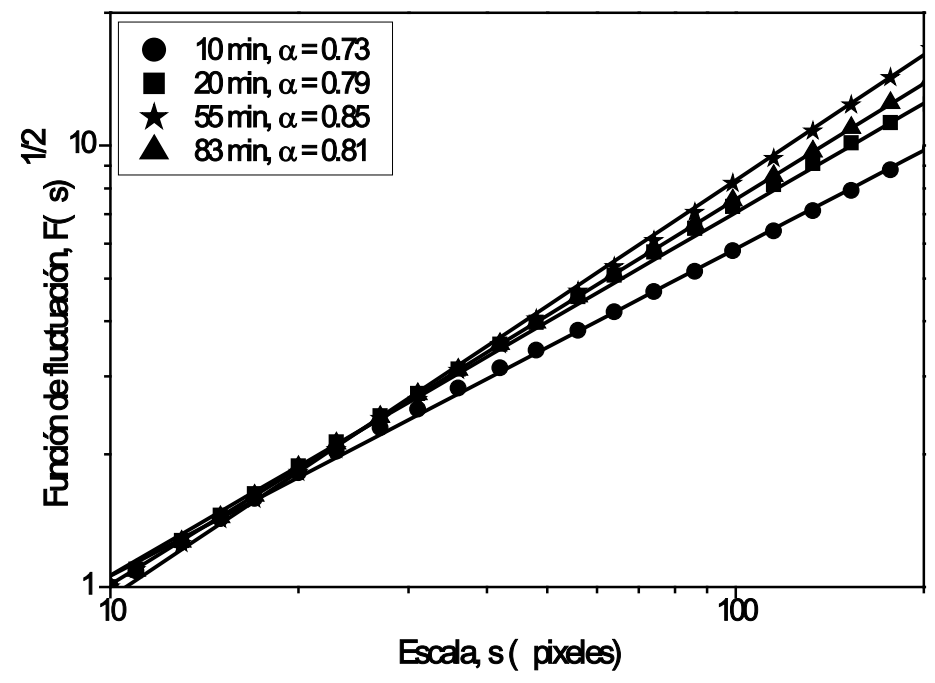

Figura 5.7 Resultados del DFA para las imágenes de la Figura 5.4. 
Una pregunta interesante es, si los cambios en el exponente de escalamiento pueden relacionarse con el avance del proceso de cristalización.

La Figura 5.8 despliega el exponente de escalamiento como una función del tiempo de cristalización para tres diferentes valores del umbral (50, 70 y 90). Se puede observar que para valores del umbral grandes se magnifican los efectos de partículas de tamaños pequeños en la imagen. La presencia de la caída en el exponente de escalamiento alrededor de los 30 minutos del proceso, puede deberse al cambio de operación realizada en el cristalizador (cambio escalón de 21.5 inHg a 25 inHg de presión de vacío). La Figura 5.8a muestra que el exponente de escalamiento con un valor de $\gamma=50$ incrementa con el tiempo del proceso. Para tiempos cortos, el exponente de escalamiento es de $\alpha=0.6$ aproximadamente, lo que refleja un ordenado pobre más aleatorio de cristales agregados, y conforme el tiempo del proceso se incrementa, el exponente de escalamiento alcanza valores de $\alpha=0.86$ para el tiempo de 48 minutos, indicando mayor orden y estructuras predecibles (estructuras de tipo fractal).

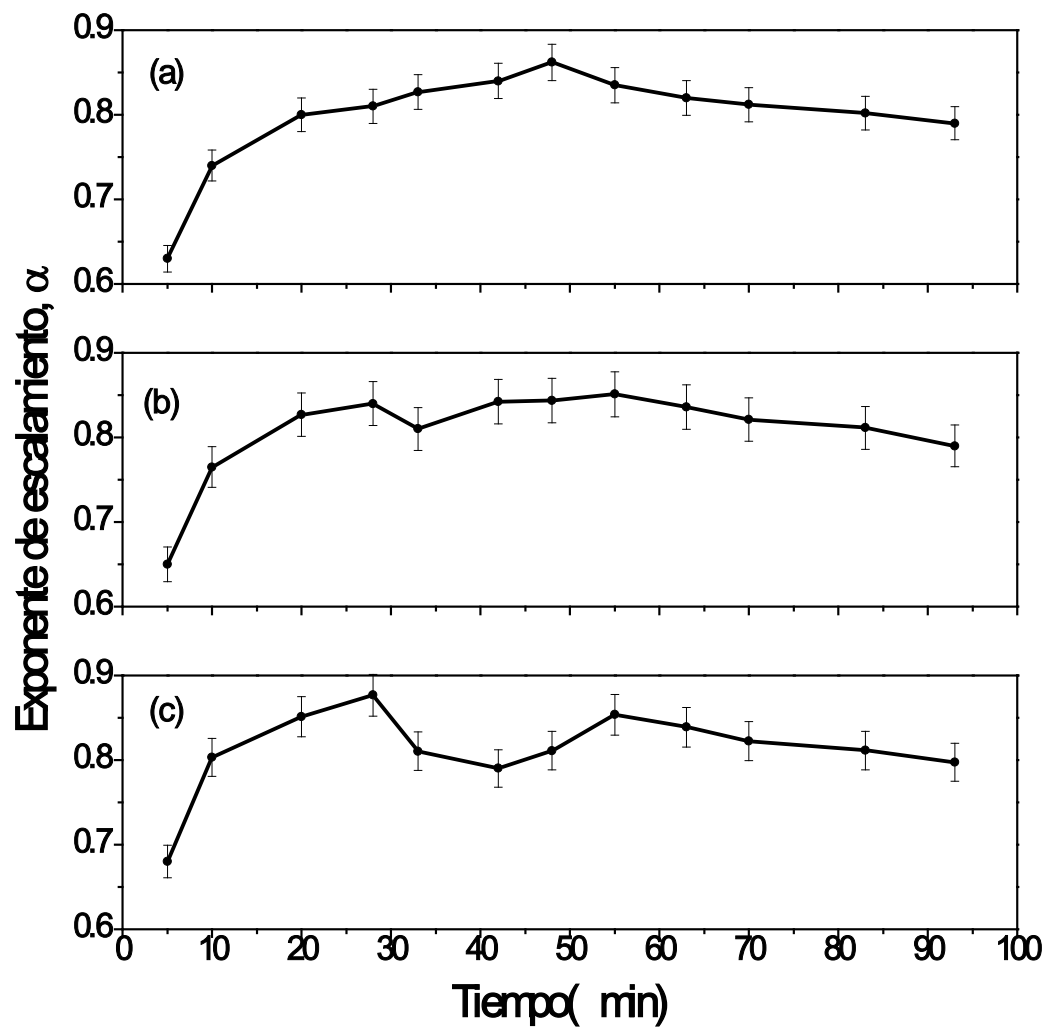

Figura 5.8 Exponente de escalamiento en función del tiempo de cristalización. a) $\gamma=50$, b) $\gamma=70$ y c) $\gamma=90$ 
Este incremento en la correlación de la imagen es debido a la distribución de cristales donde dominan los de tamaños grandes producidos por la dinámica de cristalización dentro de la primera zona metaestable, sin dejar de incluirse los más pequeños. También es interesante como el exponente de escalamiento decrece para tiempos largos, sugiriendo una reducción en la regularidad de los cristales agregados.

Como se mostró en la Figura 5.3c, la masa de cristal formada se incrementa de forma continua con el tiempo del proceso y la remoción del soluto del slurry. La cristalización y forma de cristales pueden ser afectadas por las limitaciones difusivas y efectos de atrición (Solomatov 1995; Miyashita et al., 2005). Lo anterior se puede contrastar con la Figura 5.1c y 5.1d (tiempos largos de operación) en donde se muestran pequeños cristales irregulares los cuales pueden resultar por efecto de la atrición mecánica inducida por una alta concentración de cristales formados y a una tasa de agitación alta. Aparentemente el decremento en la correlación de la imagen refleja estos efectos en el último periodo del proceso de cristalización. Otra característica similar es la que ocurre entre la dinámica del exponente de escalamiento con el D(4,3) presentado en la Figura 5.3d. En este sentido, se puede observar de manera general que la dinámica del exponente de escalamiento con un valor de umbral relativamente pequeño recupera o reconstruye la evolución de la variable $\mathrm{D}(4,3)$.

La Figura 5.8b muestra la dinámica del exponente de escalamiento para $\gamma=70$. Como en los casos previos, el exponente de escalamiento se incrementa hasta alcanzar un valor de $\alpha=0.85$, los cuales son asociados con arreglos de cristales de forma regular y más orden de cristales agregados. Es interesante como para el tiempo de 30 minutos del proceso, la dinámica del exponente de escalamiento decrece ligeramente coincidiendo con el cambio de las condiciones operación de 21.5 inHg y $65{ }^{\circ} \mathrm{C}$ (tiempo de evaporación constante) a 25 inHg y 41 ${ }^{\circ} \mathrm{C}$ (implementación del perfil de regulación dinámica de presión de vacío). Aparentemente este cambio en las condiciones de operación induce también un cambio en la dinámica de la formación de cristales, introduciendo más cristales agregados de forma irregular. El análisis de la imagen original (Figura 5.1) muestra la presencia de pequeños arreglos de cristales regulares. Dado que la densidad de cristales formados en el slurry es relativamente pequeña para los primeros 30 minutos, es evidente que estos pequeños cristales no son generados por 
efectos mecánicos, pero si al tiempo del proceso en que la concentración (densidad) permanece en la zona inestable produciendo nucleación secundaria. Esto se evidencia o magnifica aún más en la dinámica del exponente de escalamiento con $\gamma=90$ presentada en la Figura 5.8c. En este caso el decremento en la dinámica del exponente de escalamiento sobre los 30 minutos es más evidente, mostrando que el decremento en la correlación de la imagen no es producida por el valor del umbral de la imagen. Este resultado proporciona una visión adicional de los efectos del cambio en el modo de operación dentro del cristalizador desde un periodo de evaporación constante a un enfriamiento gradual. De hecho, el efecto del umbral aumentado magnifica los efectos de partículas de tamaños pequeños en la imagen.

La Figura 5.9 muestra la Figura 5.1b (imagen para el tiempo de proceso a los 20 minutos) para dos valores del umbral, indicando con una flecha la aparición de estructuras de tamaños pequeños en la imagen. En este sentido, se ve que el decremento en la correlación de la imagen indica efectos de nucleación secundaria debido posiblemente a efectos transientes en la trayectoria de enfriamiento y sobresaturación.

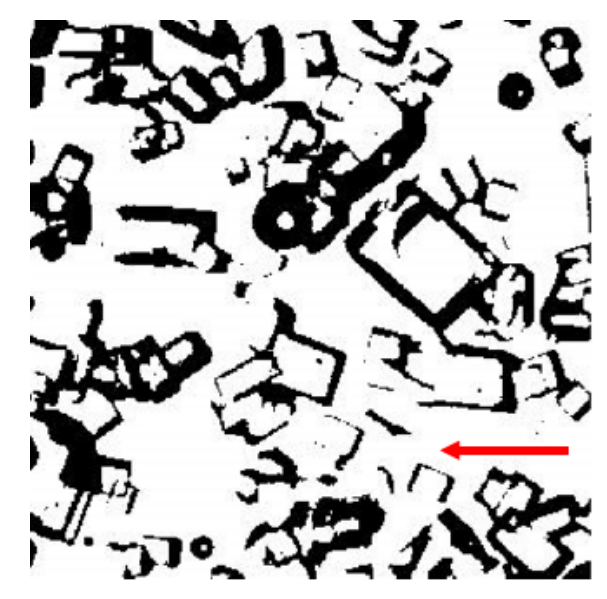

(a)

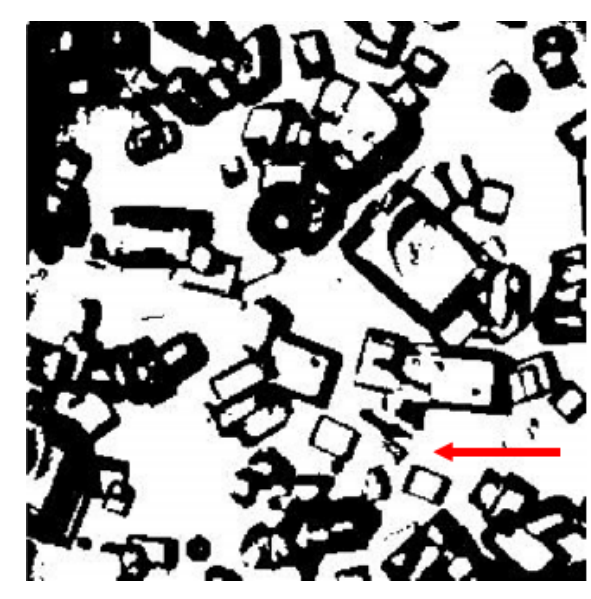

(b)

Figura 5.9 Imagen binarizada para el minuto 20. a) $\gamma=50$ y b) $\gamma=70$

Eventualmente al minuto 55, el exponente de escalamiento es restaurado para tiempos largos, indicando el rol dominante de cristales grandes en la estructura de cristales agregados. El exponente de escalamiento obtenido es relacionado con la presencia de correlaciones y 
menor rugosidad en la geometría aparentemente irregular de la imagen. La dimensión fractal es otro índice de la fractalidad de una imagen comúnmente usada en el análisis imágenes irregulares. La dimensión fractal puede ser considerada como una medida topológica de la cobertura del plano (2D). Un resultado con dimensión cercana 2 indica mayor fractalidad y mejor cobertura del plano. Esta no es la única dimensión fractal medida, pero su definición depende de los rasgos específicos de la imagen a ser caracterizados. En este caso, se eligió la dimensión fractal másica $\left(\mathrm{D}_{\mathrm{m}}\right)$, la cual relaciona la masa de un objeto fractal, $(\mathrm{M})$, para su tamaño lineal (s), como se presenta en la Ec. (5.7), donde “c” es una constante (Tang et al., 2006); Tang et al., 2008).

$M=C S^{D_{m}}$

En la Figura 5.10 se presenta la variación temporal de la dimensión fractal másica para los tres valores del umbral presentados en la Figura 5.8. Como se esperaba, la dimensión fractal másica se incrementa y se aproxima al valor de dimensión 2, así como la masa y tamaño de cristales formados se incrementan con el tiempo.

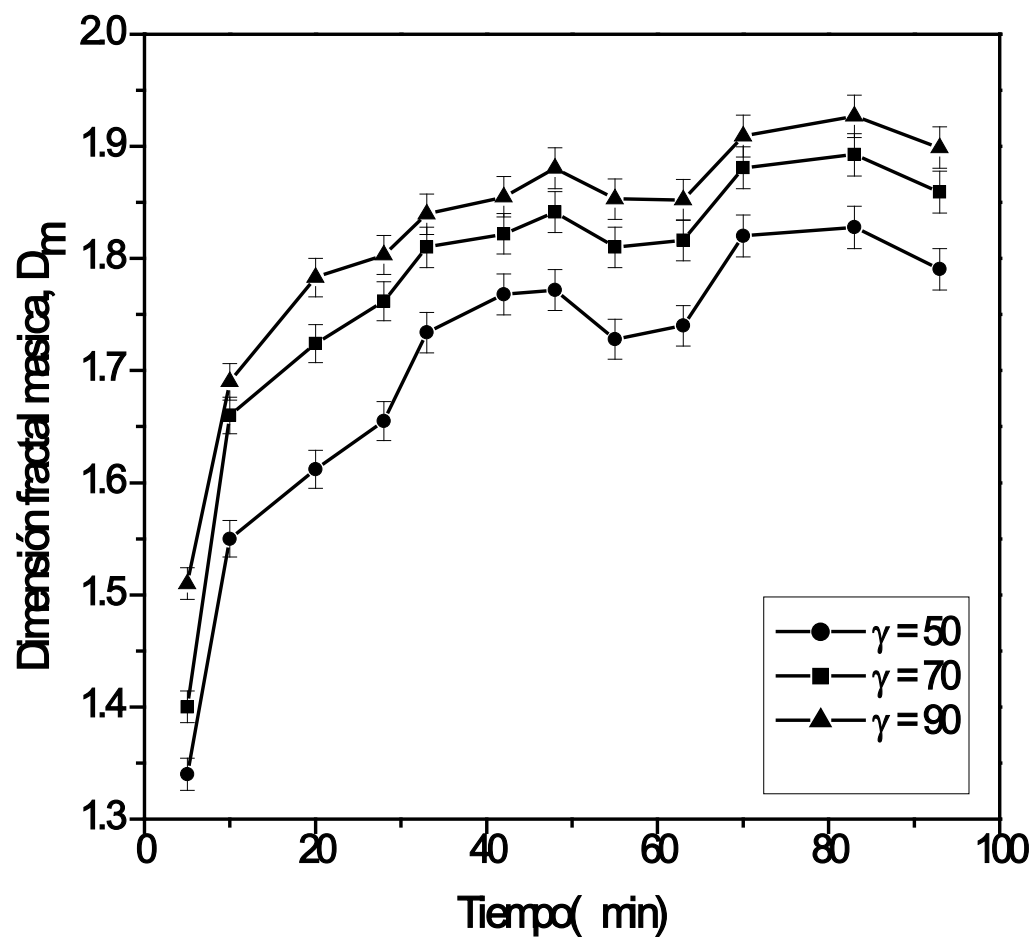

Figura 5.10 Dimensión fractal másica para los tres valores de umbral presentados en la

Figura 5.8. 
Se observa un decaimiento para los tiempos 45 minutos y 65 minutos, los cuales reflejan la caída de la desviación estándar mostrada en la Figura 5.3d. Este decaimiento es mayor para valores decrecientes de $\gamma$, lo que sugiere a su vez una mayor disṕiersin los datos experimentales tratados. A su vez, la reducción de la desviación estándar es una consecuencia del cambio en el modo de operación cuando la temperatura de la cristalización es sometida a una reducción gradual y continua de $65{ }^{\circ} \mathrm{C}$ a $41{ }^{\circ} \mathrm{C}$. Se observa también que existe un efecto de retardo entre la reducción del exponente de escalamiento (Figura 5.8c) y la reducción fractal másica (Figura 5.10). Ambos análisis y mediciones fractales fueron viables para detectar los efectos de los cambios de operación y/o evolución de la cristalización en las variables del $\mathrm{D}(4,3)$ y $\mathrm{S}(4,3)$.

Finalmente la Figura 5.11a y y 5.11b muestran el exponente de escalamiento y la dimensión fractal másica como una función del $\mathrm{D}(4,3)$. Regresiones polinomiales de tercer orden son presentadas con el objeto de ser ilustrativo en los datos experimentales, mostrando que el exponente de escalamiento es incrementado monótonamente para $\mathrm{D}(4,3)<250 \mu \mathrm{m}$.
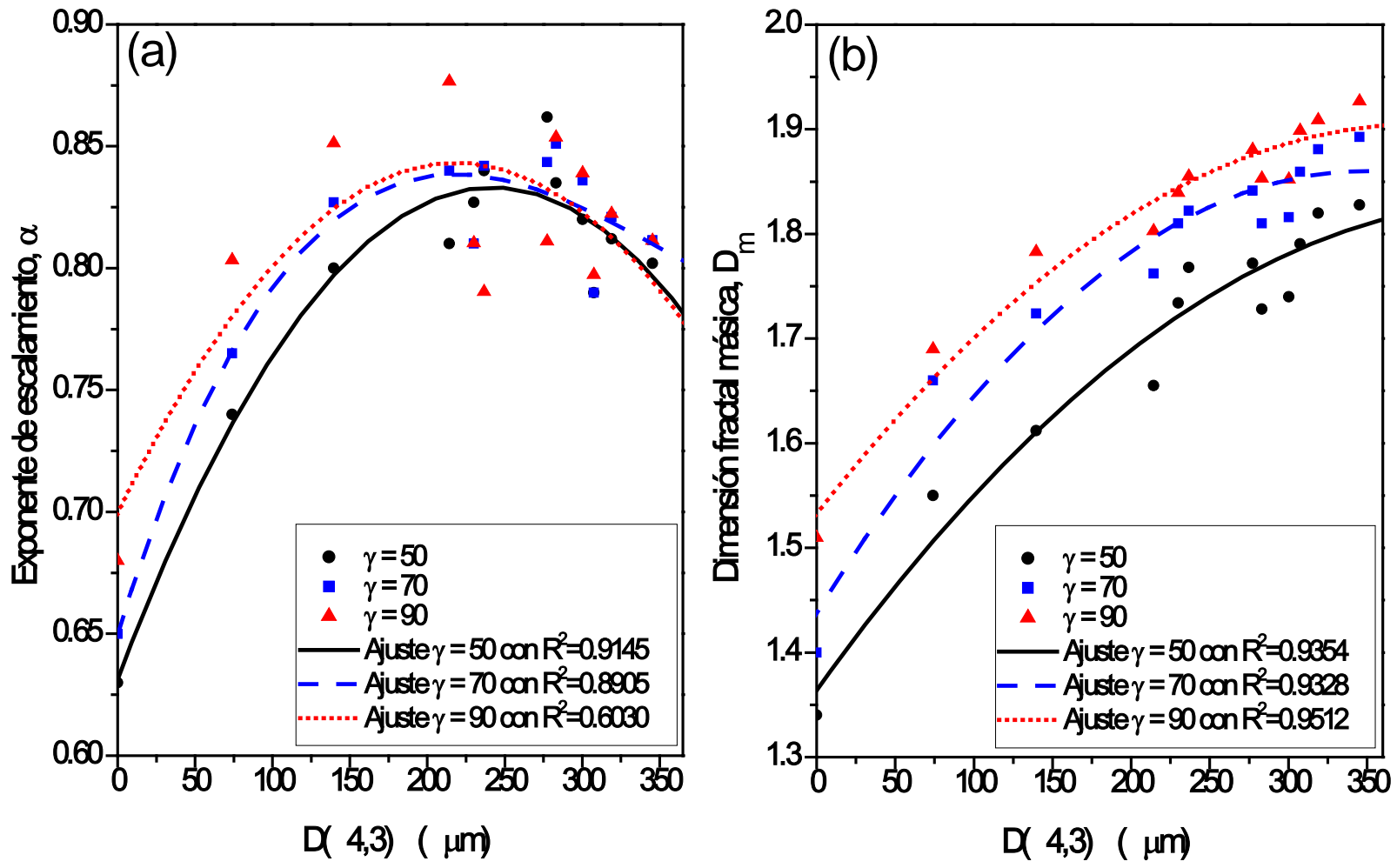

Figura 5.11 Exponente de escalamiento (a) y dimensión fractal másica (b), en función del diámetro promedio relativo al volumen $\mathrm{D}(4,3)$. 
Para valores mayores de $\mathrm{D}(4,3)=250 \mu \mathrm{m}$, la función de regresión muestra que el exponente de escalamiento decrece con el $\mathrm{D}(4,3)$. En contraste, las regresiones polinomiales indican que la dimensión fractal másica incrementa monótonamente para todo el rangos del $\mathrm{D}(4,3)$. De lo anterior parece ser que la dimensión fractal másica es más apropiada para monitorear el avance del tamaño de cristal, mientras que el exponente de escalamiento puede ser usado para identificar cambios en las condiciones de operación.

\subsection{Conclusiones}

En este trabajo se exploro la aplicación del método de análisis fractal DFA, para micrografías tomadas de la solución en el cristalizador (slurry), del cual se desprenden las siguientes conclusiones:

Los resultados mostraron que imágenes binarizadas extraídas de la escala de grises pueden proporcionar una visión de la evolución de la cristalización, incluso los efectos del crecimiento de orden durante el periodo inicial y la posible ocurrencia de nucleación secundaria y mecanismos de atrición debido a cambios en el modo de operación y densidad alta de cristales formados.

El presente estudio puede usarse como una herramienta complementaria para dar seguimiento a la evolución de la cristalización de azúcar de caña y cristales que presenten patrones fractales similares. El estudio se enfocó en el exponente de escalamiento y la dimensión fractal másica para dar seguimiento a la cristalización, encontrándose que existe una relación entre el D(4,3) y la dimensión fractal másica.

Finalmente, dada la complejidad de tamaños y formas de cristales en los procesos reales, el análisis de imagen en línea sólo debe usarse como un indicativo rápido de la dinámica de la cristalización y los resultados de las mediciones fractales deben complementarse con determinaciones de DTC fuera de línea. 


\section{Reconocimiento}

Parte del material presentado en este capítulo se utilizó para la elaboración del siguiente artículo:

Oscar Velazquez-Camilo, Eusebio Bolaños-Reynoso, Eduardo Rodriguez y Jose Alvarez-

Ramirez, (2010). Fractal Analysis of Crystallization Slurry Images. Journal of Crystal Growth. $312,842-850$. 


\section{CONCLUSIONES Y PERSPECTIVAS}




\section{CONCLUSIONES Y PERSPECTIVAS}

Se identificaron los puntos críticos de concentración de forma experimental en términos de densidad, y se obtuvieron los modelos matemáticos que definen los límites de concentración metaestables y lábil. También se desarrolló un panel de control virtual del proceso para dar seguimiento a la sobresaturación y la temperatura del sistema, en donde se implementaron los limites de concentración obtenidos.

El ancho de las zonas de concentración metaestables para un rango de temperatura de 70 a $40{ }^{\circ} \mathrm{C}$ tiene un comportamiento no lineal ya que conforme la temperatura de enfriamiento disminuye, el ancho de las zonas se incrementa, lo cual es discordante con respecto a lo reportado en la literatura sobre cristalización de azúcar de caña en donde se indica que el ancho de las zonas de concentración se mantiene constante a lo largo de un rango de temperatura similar. La medición (monitoreo) de la concentración respecto a la temperatura en el programa SCADA.Vi sólo es aplicable para un rango de temperatura de 70 a $40{ }^{\circ} \mathrm{C}$, y densidad de 1.335 a $1.402 \mathrm{~g} / \mathrm{cm}^{3}$ respectivamente. Esto debido a que las ecuaciones que establecen los límites de las líneas de equilibrio, intermedia y lábil fueron obtenidas de manera experimental a partir de soluciones saturadas a las temperaturas de 40, 50, 60 y $70{ }^{\circ} \mathrm{C}$.

La estrategia de control C-Control (C-T) permitió obtener un control adecuado de la sobresaturación dentro de la primera zona metaestable, con un tiempo de lote condicionado principalmente por la naturaleza del proceso de cristalización de azúcar de caña. El control de la sobresaturación dentro de la primera zona metaestable por sí sola no asegura una DTC uniforme, ya que él \% volumen tiende a incrementarse con el tiempo del proceso. Sin embargo, aparentemente la tasa de enfriamiento o nivel de sobresaturación incluso dentro de la primera zona metaestable pueden ser factores de influencia en la DTC final.

Con este trabajo se contribuye a tener un mejor conocimiento de la línea de saturación, zonas metaestables (primera y segunda) y zona lábil; información que frecuentemente es requerida para tener un control adecuado de la sobresaturación en el proceso industrial de cristalización de azúcar de caña. 
La aplicación del método de análisis fractal DFA puede usarse como una herramienta complementaria para dar seguimiento a la evolución de la cristalización de azúcar de caña. El estudio se enfocó en el exponente de escalamiento y la dimensión fractal másico para dar seguimiento a la cristalización, encontrándose que existe una relación que en mayor medida se incrementa monótonamente entre la $\mathrm{D}(4,3)$ y la dimensión fractal másica.

Dentro de las perspectivas actuales se encuentran:

- Desarrollo e implementación de una estrategia de control basado en análisis de imágenes en línea usando un sistema SCADA.

- Desarrollar una estrategia de control basado en estimación de propiedades termodinámicas.

- Evaluar la factibilidad de implementar los resultados obtenidos como un criterio de paró del proceso más confiable (límites de concentración metaestables y estrategia C-Control) a nivel industrial.

- Desarrollar un sistema de C-Control, para abatir la nucleación a tiempos tempranos (periodo de estabilización de los cristales sembrados).

- Evaluar alternativas para mejorar u obtener un sistema de adquisición de imagen más potente en resolución microscópica y un mejor medio filtrante, o en su defecto implementar un sistema de muestreo diferente.

- Extrapolar las técnicas y métodos usados en este trabajo para explorar otros sistemas particulados con parámetros distribuidos.

- Seguir explorando las técnicas fractales que han dado resultados favorables en el estudio de la evolución de la cristalización y desarrollar un simulador dinámico (software) para la cristalización de azúcar de caña que incluya estos métodos de análisis estadísticos. 
REFERENCIAS

BIBLIOGRÁFICAS 


\section{BIBLIOGRAFÍA}

1. Antonio y Romero. (2009). Desarrollo de Instrumentos Virtuales para la Implementación de Perfiles de Concentración-Temperatura en un Cristalizador por Lotes a Vacío. Trabajo de residencias profesionales I.T.Orizaba.

2. Bolaños R. E. (2000). Control y optimización de las condiciones de operación de cristalizadores batch por enfriamiento. Tesis de Doctorado en Ciencias en Ingeniería Química. I.T. de Celaya.

3. Cordova-Pestaña, N. M., Bolaños-Reynoso, E., Quintana-Hernandez, P.A. and Briseño-Montiel, V.M. (2004). Developing of CSD Analysis Software from Electronic Microscopy Measurement. XXV AMIDIQ’s Memories: Mexico.

4. Chiu, T. y Christofides, P. D. (1999). Nonlinear control of particulate processes. American Institute of Chemical Engineers Journal (AIChE) 45(6), 1279-1297.

5. Christofides, P. D. y Chiu, T. Y. (2000). Robust control of particulate processes using uncertain population balance. American Institute of Chemical Engineers Journal (AIChE) 46 (2), 266-280.

6. D. Tang, A.G. Marangoni. (2006). 3D fractal dimension of fat crystal networks, Chem. Phys. Lett. 433, 248-252.

7. D. Tang, A.G. Marangoni. (2008). Fractal dimensions of simulated and real fat crystal networks in 3D space, J. Am. Oil Chem. Soc. 85, 495-499.

8. Doherty, M. F., Jeffrey, D. W. y Duncan, A. M. (2006). Choosing an operating policy for seeded batch crystallization. American Institute of Chemical Engineers Journal (AIChE) 52(6), 2046-2054.

9. Eke A., Herman P., Kocsis L. y Kozak L R. (2002). Fractal characterization of complexity in temporal physiological signals. Physiol. Meas. 23, R1-R38.

10. Eusebio Bolaños-Reynoso, Omar Xaca-Xaca, Jose Alvarez-Ramirez, y Leticia LopezZamora. (2008). Effect Analysis from Dynamic Regulation of Vacuum Pressure in an Adiabatic Batch Crystallizer Using Data and Image Acquisition. Ind. Eng. Chem. Res. 47 (23), 9426-9436. 
11. E. Davila, D. Pares. (2007). Structure of heat-induced plasma protein gels studied by fractal and lacunarity analysis, Food Hydrocolloids 21, 147-153.

12. Fujiwara Mitsuko, Nagy Zoltan K., Chew Jie W. and Braatz Richard D. (2005). Firstprinciples and direct design approaches for the control of pharmaceutical crystallization. Journal of Process Control. 15, 493-504.

13. Geankoplis, C. J. (1999). Procesos de transporte y operaciones unitarias. C.E.C.S.A. Segunda Edición. México.

14. Genck W. J. (2000). Better growth in batch crystallizers. Chemical Engineering. 90-95. USA.

15. G.F. Gu, W.X. Zhou, (2006). Detrended fluctuation analysis for fractals and multifractals in higher dimensions, Phys. Rev. E 74, 061104.

16. George X. Zhou, Mitsuko Fujiwara, Xing Yi Woo,Effendi Rusli, Hsien-Hsin Tung, Cindy Starbuck, Omar Davidson, Zhihong Ge, y Richard D. Braatz. (2006). Direct Design of Pharmaceutical Antisolvent Crystallization through Concentration Control. Crystal Growth \& Design. 6 (4). 892-898.

17. H. Qu, M. Louhi-Kultanen, J. Kallas. (2006). In-line image analysis on the effects of additives in batch cooling crystallization, J. Cryst. Growth 289, 286-294.

18. Hugot, E. (1963). Manual para Ingenieros Azucareros, Editorial C. E. C. S. A. México.

19. J. Calderon-De-Anda, X.Z. Wang, K.J. Roberts. (2005). Multi-scale segmentation image analysis for the in-process monitoring of particles shape with batch crystallizers, Chem. Eng. Sci. 60, 1053-1065.

20. Jerauld, G. R., Vasatis, Y. y Doherty, M. F. (1983). Simple Conditions for the Appearance of Sustained Oscillations in Continuous Crystallizers. Chemical Engineering Science. 38(10), 1675-1681.

21. Jones A. G. (2002). Crystallization process systems, Butterworth- Heinemann.

22. K. Sangwal, (2007). Additives and Crystallization Processes: From Fundamentals to Applications, Wiley, NewYork.

23. Kostic, C. (1998). Data Acquisition and Control for an Innovative Thermal Conductivity Apparatus Using LabVIEW Virtual Instruments. Lab. Robot. Automat. J. 10, 107. 
24. Lei S. J., Shinnar R. y Katz S. (1971). The stability and dynamic behavior of a continuous crystallizer with a fines trap. American Institute of Chemical Engineers Journal (AIChE). 17(6), 1459-1470.

25. Lugo, J. R. (2005). Estudio para la determinación de la zona metaestable a través del análisis del proceso de nucleación para el sulfato de amonio. Tesis de Maestría en Ciencias en Ingeniería Química, Instituto Tecnológico de Celaya, México.

26. Meade, G. P. y Chen, J. C. (1977). Cane Sugar Handbook: A Manual for Cane Sugar Manufacturers and their Chemists. Wiley Publisher.

27. Mersmann, A. (1995). Crystallization Technology Handbook; Marcel Dekker: New York.

28. Mitsuko Fujiwara, Zoltan K. Nagy, Jie W. Chew y Richard D. Braatz. (2005). Firstprinciples and direct design approaches for the control of pharmaceutical crystallization. Journal of Process Control. 15. 493-504.

29. Ogata Katsuhiko. (2003). Ingeniería de Control Moderna, cuarta edición, Pearson, Prentice Hall.

30. Oscar Velazquez-Camilo, Eusebio Bolaños-Reynoso, Eduardo Rodriguez y Jose Alvarez-Ramirez. (2010A). Fractal Analysis of Crystallization Slurry Images. Journal of Crystal Growth. (312), 842-850.

31. O. Velázquez-Camilo, E. Bolaños-Reynoso, L. Lopez-Zamora y J. J. ÁlvarezRamírez. (2010B). Experimental Evaluation of the Concentration Zone Widths in Cane Sugar Crystallization using Data and Image Acquisition, World Congress on Engineering. Paper number: ICSIE_49 (The 2010 International Conference of Signal and Image Engineering), 30 June - 2 July, 2010. London, U.K.

32. O. Velázquez-Camilo, J.J. Álvarez-Ramírez y E. Bolaños-Reynoso. (2009). Comparative Analysis of the Crystallizer Dynamics Type Continuous Stirred Tank: Isothermic and Cooling Case. Revista Mexicana de Ingeniería Química (RMIQ). 8 (1). 127-133.

33. Osorio, R. R. (2004). Determinación de coeficientes de transferencia de masa aplicados a la cinética de crecimiento en cristalización de azúcar de caña. Tesis de Maestría en Ciencias en Ingeniería Química, Instituto Tecnológico de Orizaba, México. 
34. Pathath, P. K. y Kienle, A. (2003). Nonlinear Oscillations in Ammonium Sulfate Crystallization: A Comparison of Different Model Predictions. Industrial \& Engineering Chemistry Research. 42(26), 6949-6955.

35. P.A. Larsen, J.B. Rawlings. (2009). The potential of current high-resolution imagingbased particle size distribution measurements for crystallization monitoring, A.I.Ch.E. J. 55, 896-905.

36. Peitgen H-O, J"urgens H y Saupe D. (1992). Chaos and Fractals. New Frontiers of Science (New York: Springer)

37. Perry R. H. y D. W. Green. (2003). Manual del ingeniero químico. Perry, McGraw-Hill. $7^{\mathrm{a}}$ edición.

38. Quintana-Hernández, P., Bolaños-Reynoso, E., Salcedo-Estrada, L. I. y MoncadaAbaunza, D. A. (2001). Properties Determination for Saturated Solutions of Sugar. Avances en Ingenieria Quimica-AMIDIQ. 9 (1), 43-46.

39. Quintana, H. P., Bolaños, R. E., Miranda, C. B. y Salcedo, E. L. (2004). Mathematical Modeling and Kinetic Parameter Estimation in Batch Crystallization. AIChE Journal. 50 (7). 1407-1417.

40. Quintana Hernández, P. A., Tututi Avila, S., Bolaños Reynoso, E., Salcedo Estrada, L. I. y Fierro González, J. (2007). Desarrollo de un algoritmo de control para el proceso de cristalización por enfriamiento usando lógica difusa. XXVIII AMIDIQ. SIM-11.

41. Rawlings J. B. and Miller S.M. (1994). Model identification and control strategies for batch cooling crystallizers. AIChe Journal. 40 (8). 1312-1327.

42. S. Miyashita, Y. Saito, M. Uwaha. (2005). Fractal aggregation growth and the surrounding diffusion field, J. Cryst. Growth 283, 533-539.

43. S. Dharmayat, J. Calderon-De-Anda, R.B. Hammond, X. Lai, K.J. Roberts, X.Z. Wang. (2006). Polymorphic transformation of L-glutamic acid monitored using combined on-line video microscopy and X-ray diffraction, J. Cryst. Growth 294 (2006) 35-40.

44. Salcedo-Estrada L. I., Quintana-Hernandez, P. A. y Bolaños-Reynoso E. (2002). Mathematical Modeling in Batch Crystallization. Chem. Eng. Assoc. Chem. Eng. Uruguay 3. 21. 3-11. 
45. Simoglou A., Georgieva P., Martin E.B., Morris A. J., Feyo de Azevedo S. (2005). On line monitoring of a sugar crystallization process. Computer \& Chemical Engineering. 29, 1411-1422. USA.

46. Solís G. Y. y Villa V. A. G., (2008). Determinación experimental de la zona metaestable para la cristalización de azúcar de caña. Trabajo de residencias profesionales I. T. Orizaba, México.

47. Shi D., El-Farra N. H., Li M., Mhaskar P. y Christofides P. D. (2006). Predictive control of particle size distribution in particulate processes. Chemical Engineering Science. 61. 266-280.

48. Skogestad, S. (2003). Simple analytic rules for model reduction and PID controller tuning. Journal of Process Control. 13, 291-309.

49. Smith C.A. y Corripio B. A. (1991). Control automático de procesos teoría y práctica, Limusa.

50. Srinivasakannan C., Vasanthakumar R., Iyappan K. y Rao, P. G. (2002). A study on crystallization of oxalic acid in batch cooling crystallizer. Chem. Biochem Eng. Q 16 (3). 125-129. USA.

51. Stabinger, H., Leopold, H. and Kratky, O. (1967). A New Precision Method for Determination of Density of Liquids (Short Communication). Monatshefte Fur Chemie/Chemical Monthly. 98 (2). 436-438.

52. Stephanopoulos G. (1984). Chemical Process Control. An Introduction to Theory and Practice. Prentice Hall International, USA.

53. Sutradhar, B. C. (2004). Coping with Crystallization Problems. Chemical Engineering. 46-52.

54. Tahal, T. V. (2000). New Models for Sugar Vacuum Pans. Ph.D. Dissertation. Department of Chemical Engineering, St. Lucia, Queensland, Australia, (http://www.cheque.uq.edu.au/ugrad/theses/2000/iitheses/T_Tahal.pdf).

55. Ulrich J. (2003). Solution Crystallization-Developments and New Trends, Chem. Eng. Technol. 7, 921-927.

56. V.S. Solomatov. (1995). Batch crystallization under continuous cooling: analytical solution for diffusion limited crystal growth, J. Cryst. Growth 148, 421-431.

57. Vilbert, Phil. (2004). Mechanical Pumps for Vacuum Processing. Chem. Eng. 111, 44-51. 
58. X.Z. Wang, J. Calderon-De-Anda, K.J. Roberts. (2007). Real-time measurement of the growth rates of individual crystal facets using imaging and image analysis. A feasibility study on needle-shaped crystals of L-Glutamic acid, Trans. IChemE Part A 85 921-927.

59. Yi-dong Lang, Arturo M. C., y Lorenz T. B. (1999). Dynamic Optimization of a Batch Cooling Crystallization Process. Ind. Eng. Chem. Res., 38, 1469-1477.

\section{Manuales}

60. Manual of DMA-4500 Density meter of Anton Paar. www.anton-paar.com

61. Manual de usuario de NCSS and PASS 2004.

62. LabVIEW ${ }^{\mathrm{TM}}$ User Manual. (2003). National Instruments Corporation. USA. 
APÉNDICE A ב. 


\section{A.1 Ejecución del programa IMAQ visión builder}

Para realizar el análisis de partículas utilizando la técnica de microscopia electrónica con el sistema de adquisición de imágenes (IMAQ Visión Builder) se deben de realizar los siguientes pasos:

1.- Se enciende el equipo utilizado: microscopio electrónico trinocular 48923-30 (Cole Palmer), y cámara monocromática con video RS-170, 60 Hz entrelazado.

2.- Se coloca el porta objetos en el microscopio electrónico. Se selecciona el lente objetivo (10X) y el lente ocular (PL4) del microscopio con el cual se tomará la muestra.

3.- Se adquieren las imágenes, enfocando la cámara monocromática y regulando el haz de luz del microscopio trinocular, mover el porta objetos para captar diferentes tamaños de partículas de la muestra.

Se deben capturar como mínimo 3 imágenes para tener una población de partículas representativas en el tiempo del proceso específico, para garantizar la reproducción de la distribución de tamaño de cristal obtenida. Dependiendo de la calidad y de que tan representativas sean las imágenes capturadas se deberán seleccionar como mínimo 2 imágenes, para generar los datos de inicio en píxeles para el análisis de partículas de forma manual.

Para adquirir una imagen, en el software de IMAQ Vision Builder de National Instruments, se requiere efectuar el siguiente procedimiento:

En la ventana de inicio (ver Figura A.1), activar la instrucción Acquire Image. Para guardar una imagen (ver Figura A.2) activar Save Image, en File Name dar el nombre del archivo y en File Format seleccionar la extensión con la que se guardará dicho archivo, para este tipo de análisis se recomienda utilizar la extensión "BMP”, debido a que es un mapa de bit y en este los píxeles se encuentran más definidos. Además, conservan sus propiedades originales (color y tamaño); enseguida seleccionar la instrucción Save. 


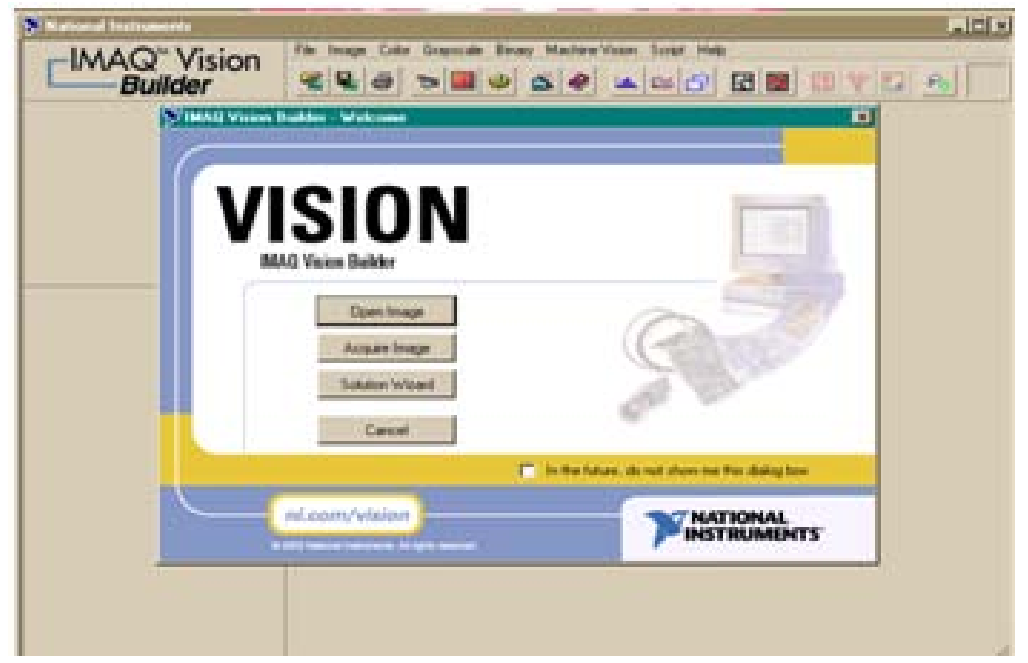

Figura A.1 Ventana de inicio del sistema de adquisición de imágenes (IMAQ).

Figura A.2 Ventana para guardar una imagen mediante el sistema de adquisición de imágenes (IMAQ).

Posteriormente se efectúan los cálculos del análisis en las muestras (imágenes), en este caso \% volumen. Para esto se lleva los datos de las mediciones en pixeles de las muestras al programa DTC-Aqd-Im (Córdova, 2004), que deben ser exportados a una hoja de Excel por medio de el programa IMAQ.

\section{A.2 Ejecución del programa DTC aqd-im para el cálculo de la DTC}

El programa DTC Adq-Im se creó para optimizar el análisis de partículas. Para ejecutar el software DTC Adq-Im versión 1.0, debe seguirse la siguiente metodología: 
1. Se debe abrir el programa DTC Adq-Im.exe dependiendo el sistema operativo que se está utilizando (Windows, Linux, MS-DOS). En la Figura A.3 se presenta la ventana inicio del programa, donde aparece el nombre del programa y la versión del mismo. La ventana principal aparecerá siempre al inicio del programa.

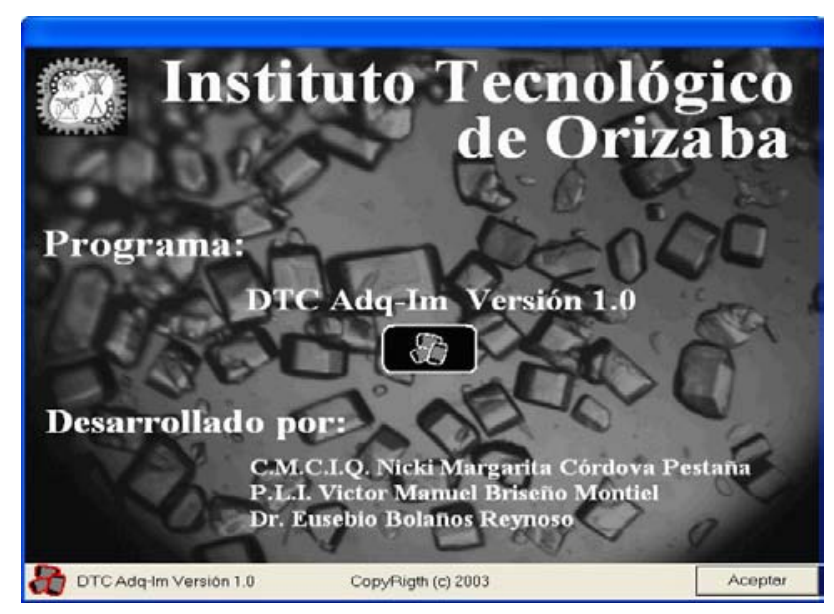

Figura A.3 Ventana principal del programa DTC Adq-im (Córdova 2004).

2. Se ingresan datos, pulsando el botón Nueva Corrida / Ingresar datos, Figura A.4; el programa responde abriendo 22 ventanas del editor de texto estándar de Windows (block de notas) con los nombres minuto10.dat, minuto20.dat ... minuto220.dat, en los cuales se deben ingresar los diámetros de los cristales obtenidos por el IMAQ en píxeles, guardar los cambios y cerrar los archivos.

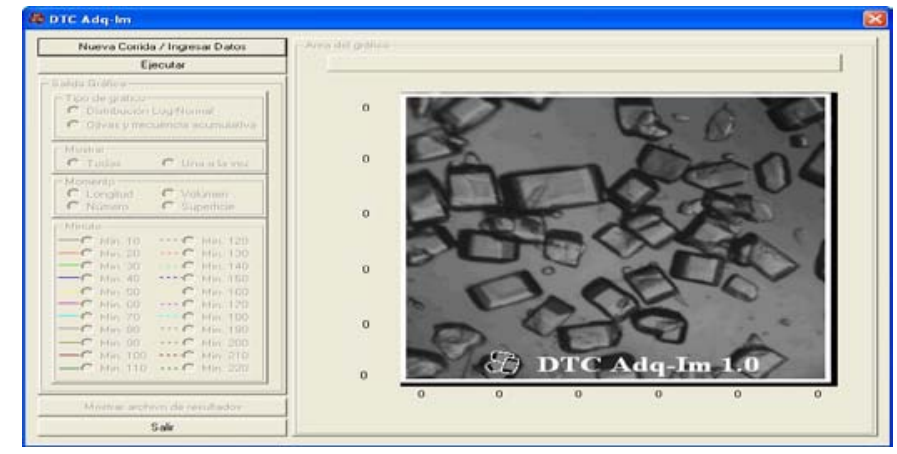

Figura A.4 Ventana de ingreso de datos en el programa DTC Adq-im (Córdova, 2004).

Se elige el gráfico de distribución log-normal, se debe elegir la opción una a la vez, lo que permitirá seleccionar el minuto que se desea analizar. Seleccionar el momento de distribución (en este caso volumen), de lo contrario no se visualizará nada en el área del 
gráfico; una vez realizado esto, se mostrarán en pantalla las gráficas de distribución lognormal de acuerdo a las opciones seleccionadas.

3. Si se pulsa sobre el botón Mostrar archivo de resultados, se abre en una ventana del navegador de Internet predeterminado. El archivo Index.htm está dividido por tres marcos; el marco superior (banner.htm) muestra un vínculo con la página principal del Instituto Tecnológico de Orizaba (ITO) y otro con la página principal de la Maestría en Ciencias en Ingeniería Química del ITO; el marco central o principal (DTCAdqIm.htm) muestra una imagen de presentación del programa y los autores del mismo y; el marco izquierdo (menu.htm) muestra un menú que sirve para abrir las tablas generales (minuto1.htm minuto22.htm) y las tablas finales (resfin1.htm - resfin22.htm) de resultados en dos modalidades, la primera abre las tablas en el marco central de la página y la segunda abre dichas tablas en una ventana nueva.

Como se puede observar en la Figura A.5, en el marco izquierdo se muestra el menú tablas e ilustra los minutos a los que se puede acceder y los botones para las tablas generales y finales; si se pulsa sobre alguna de las flechas, la tabla correspondiente se abrirá en el marco central de la ventana, pero si se pulsa en alguna de las impresoras que se encuentran al lado derecho de las flechas se abrirá la tabla correspondiente en una ventana nueva del navegador, para imprimir dicha tabla.

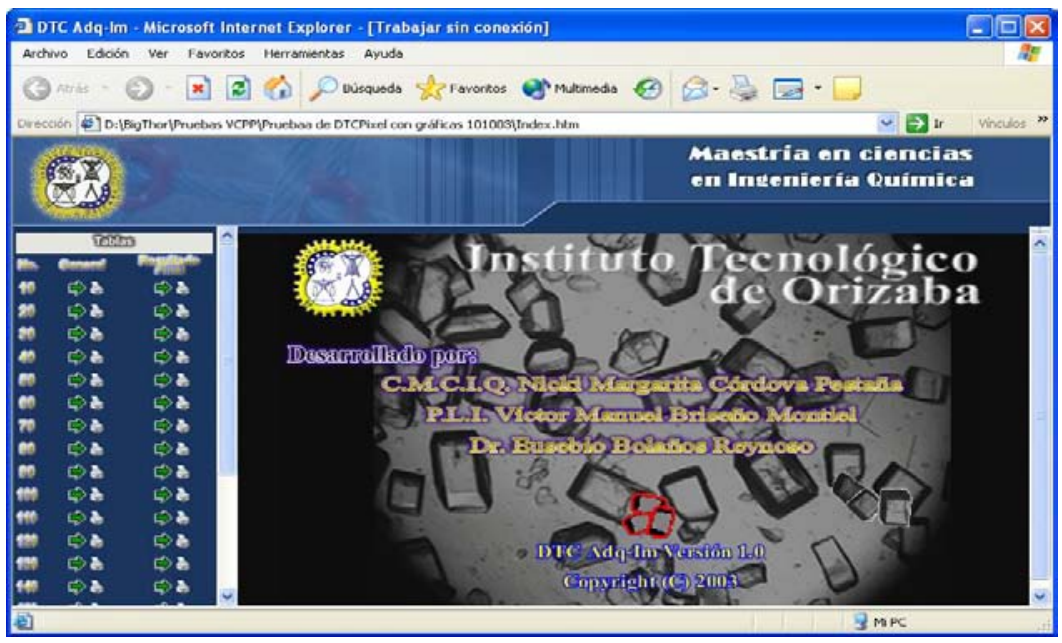

Figura A.5 Ventana de resultados del programa DTC Adq-Im (Córdova, 2004).

El programa DTC Adq-Im 1.0 recibe como datos de entrada los diámetros de los cristales obtenidos mediante el sistema IMAQ en píxeles, a través de veintidós archivos 
nombrados min10.dat - min220.dat que corresponden a cada uno de los minutos que se van a analizar; específicamente DTC Adq-Im 1.0 está diseñado para trabajar utilizando los datos únicamente de 22 archivos que corresponden a un tiempo de proceso de 220 minutos con un intervalo de 10 minutos.

Una vez abierta la ventana principal del programa, al pulsar el botón “Nueva Corrida / Ingresar Datos”, se abrirán dichos archivos. Cabe mencionar que se debe tener cuidado al momento de dar de alta los diámetros de los cristales en píxeles, procurando que el fin de archivo se encuentre inmediatamente después del último dato ingresado, ya que si se deja al menos una línea en blanco al final del archivo, ésta será tomada en cuenta como un elemento más de entrada y provocará errores el momento de realizar los cálculos. También, es importante aclarar que los datos deben ser almacenados en forma de lista. 
APÉNDICE B

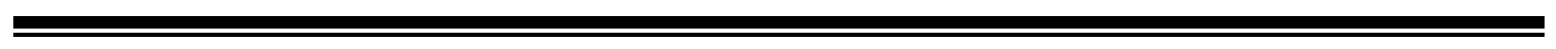




\section{B.1 Verificación de la ecuación de Moncada y Rodríguez para la línea de saturación en términos de densidad}

En el Capitulo 2, Sección 2.4.1., se discutió acerca de una inconsistencia de la ecuación de Moncada y Rodríguez (Quintana-Hernandez et al., 2001) específicamente para la temperatura de saturación a $40{ }^{\circ} \mathrm{C}$. Solís y Villa, (2008) obtuvieron la línea de saturación en términos de densidad a partir de soluciones preparadas de azúcar de caña refinada considerando la ecuación de Moncada y Rodríguez en términos de ${ }^{\circ}$ Brix, sin embargo debido a experimentos realizados para la obtención de los limites metaestables (Capitulo 2, Sección 2.4.3), se observo en repetidos experimentos que la temperatura de saturación a $40{ }^{\circ} \mathrm{C}$ se encontraba en un punto de sobresaturación alto, ya que ésta presentaba formación de cristales desde el inicio del enfriamiento (Figura 2.4a). Por lo anterior se procedió a obtener una nueva línea de saturación independiente de la ecuación de Moncada y Rodriguez para el punto de saturación a $40^{\circ} \mathrm{C}$. Se prepararon varias soluciones de azúcar de caña refinada (comercial) como se muestra en la Tabla B.1, cada prueba se evaluó por triplicado. El experimento consistió en calentar a baño maría las soluciones a una temperatura de $80{ }^{\circ} \mathrm{C}$ por 3 horas aproximadamente (tan pronto se observará que se había disuelto todo el azúcar) y posteriormente se dejó enfriar hasta $40{ }^{\circ} \mathrm{C}$ por 30 minutos, para confirmar si las soluciones se encontraban saturadas se observó a simple vista si habían precipitado de cristales y si no había se tomaba una alícuota de $3 \mathrm{ml}$ para observar al microscopio y verificar si efectivamente habían o no núcleos presentes; las soluciones en donde no se observaban cristales se les realizó una prueba adicional que consistió en agregar 0.1 gr de azúcar en la solución con agitación vigorosa por un periodo de 45 minutos aproximadamente, para observar si éste se disolvía o precipitaba, si el soluto agregado se disolvía significaba que la solución se encontraba insaturada, sin embargo si el soluto agregado precipitaba indicaba que la solución se encontraba en el punto de saturación. Todas las variables como la temperatura y volumen fueron asumidas y controladas constantes.

En la Figura B.1 se presentan los puntos de saturación experimentales (40, 50, 60 y 70 ${ }^{\circ} \mathrm{C}$ ) y su ajuste de tipo no lineal con la ecuación que la describe (Ec. B.1). 
Tabla B.1 Preparación de las soluciones en la obtención del punto de saturación a $40{ }^{\circ} \mathrm{C}$.

\begin{tabular}{|c|c|c|c|c|}
\hline Prueba & $\begin{array}{c}\text { Solución } \\
\text { gazúcar/ml }_{\text {agua }}\end{array}$ & $\begin{array}{c}\text { Densidad promedio } \\
\left(\mathrm{g} / \mathrm{cm}^{3}\right)\end{array}$ & $\begin{array}{c}\text { Núcleos } \\
\text { observados }\end{array}$ & $\begin{array}{c}\text { Prueba de } \\
\text { agregado }\end{array}$ \\
\hline 1 & 239 & 1.33939 & $\mathrm{Si}$ & No aplica \\
\hline 2 & 237 & 1.33898 & $\mathrm{Si}$ & No aplica \\
\hline 3 & 235 & 1.33741 & $\mathrm{Si}$ & No aplica \\
\hline 4 & 233 & 1.33495 & $\mathrm{Si}$ & No aplica \\
\hline 5 & 231 & 1.33497 & $\mathrm{Si}$ & No aplica \\
\hline 6 & 229 & 1.33416 & No & Precipito \\
\hline 7 & 227 & 1.33333 & No & Se disolvió \\
\hline 8 & 228 & 1.33255 & No & Se disolvió \\
\hline 9 & 230 & 1.33461 & $\mathrm{Si}$ & No aplica \\
\hline 10 & 229.5 & 1.33554 & $\mathrm{Si}$ & No aplica \\
\hline
\end{tabular}

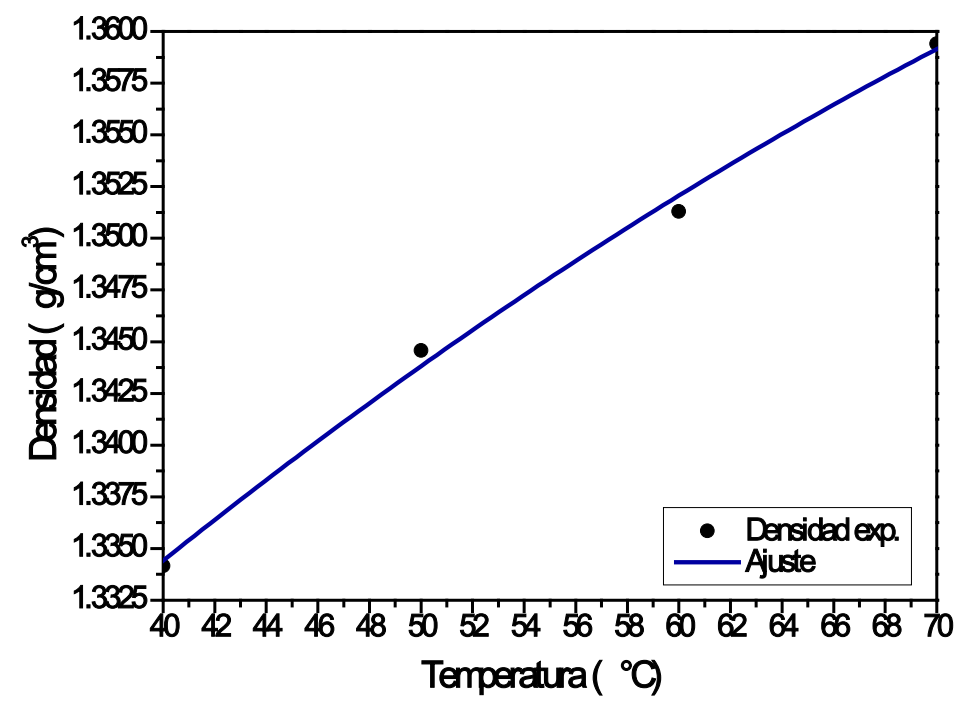

Figura B.1 Línea de saturación corregida en el punto de saturación a $40{ }^{\circ} \mathrm{C}$.

En la Figura B.2 se presenta la comparación de las líneas de saturación en términos de densidad obtenidas por Solís y Villa, (2008) y la línea de saturación con corrección en el punto de saturación a $40^{\circ} \mathrm{C}$. 


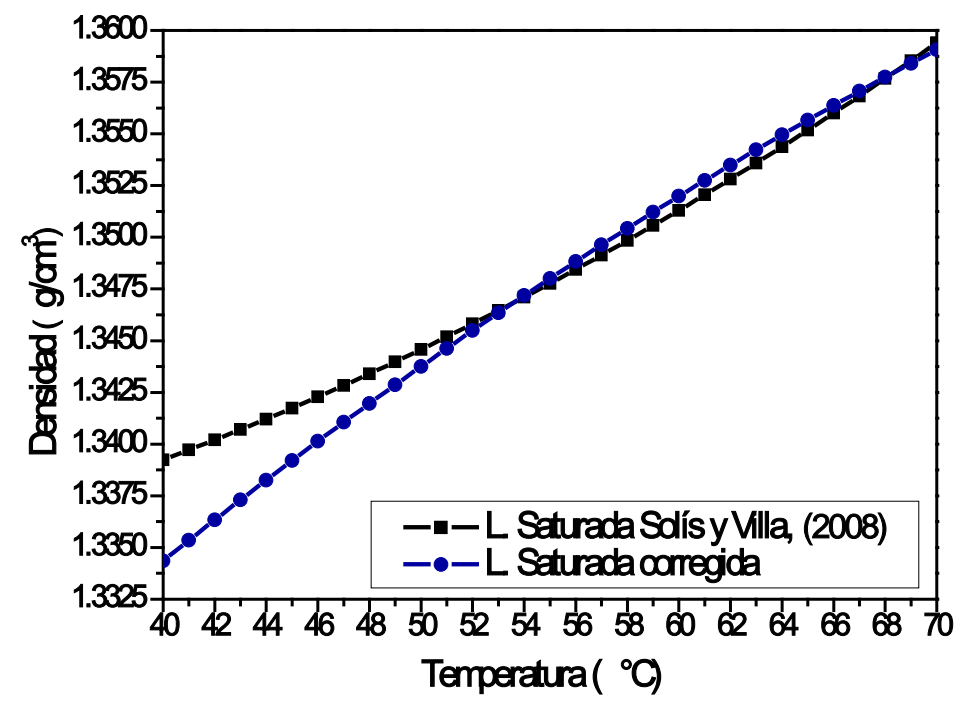

Figura B.2 Comparación entre las líneas de saturación corregida en el punto de saturación a $40{ }^{\circ} \mathrm{C}$ y la línea de saturación obtenida por Solís y Villa (2008).

$\rho_{\text {sat_corregida }}=1.28522+0.00146 * \mathrm{~T}-5.7875 \mathrm{E}-06 * \mathrm{~T}^{2}$

Donde $\rho_{\text {sat_corregida }}$ es la línea de saturación en términos de densidad corregida, con $\mathrm{R}^{2}=0.9887$

\section{B.2 Datos experimentales para la obtención de las densidades promedios}

Para la determinación de los puntos críticos (limites de las zonas de concentración) se parte de la curva de equilibrio (saturación) en términos de densidad (Ecuación 2.3). Se prepararon tres pruebas (1 corrida experimental con 2 replicas) a volumen constante para cada temperatura de saturación $\left(40,50,60,70^{\circ} \mathrm{C}\right)$ como se describió en la Tabla 2.4. En la Figura B.3 se presentan los resultados experimentales de concentración (densidad) con respecto a la temperatura. De las tres pruebas presentadas para cada temperatura de saturación se obtuvieron las densidades promedios tal como se presenta en la Figura 2.3. 


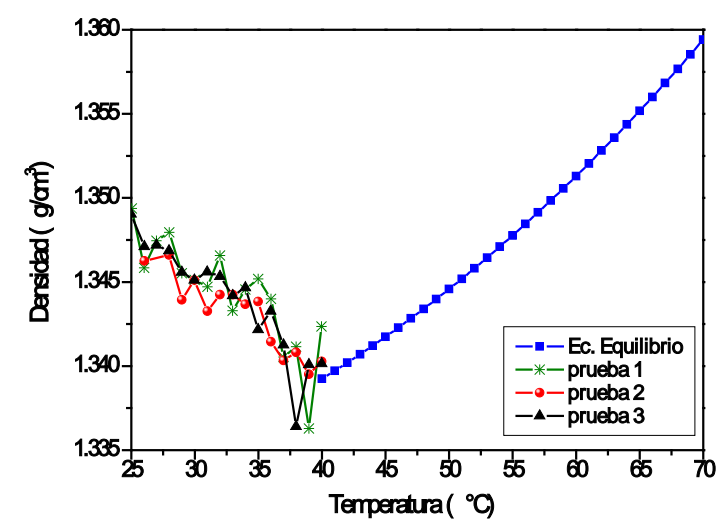

a)

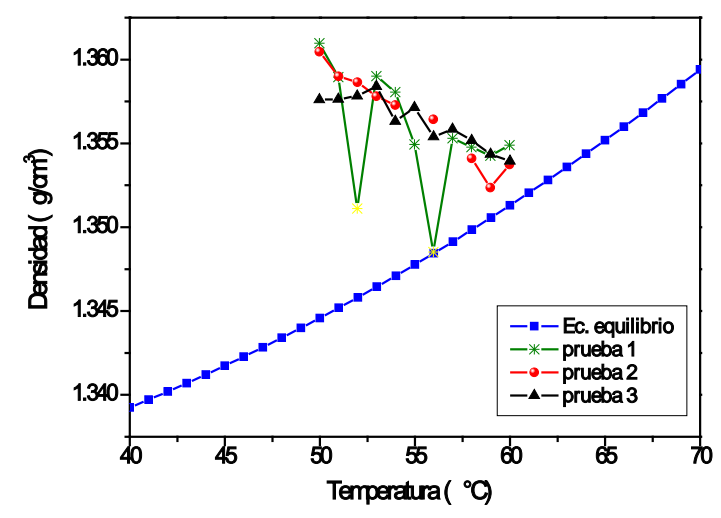

c)

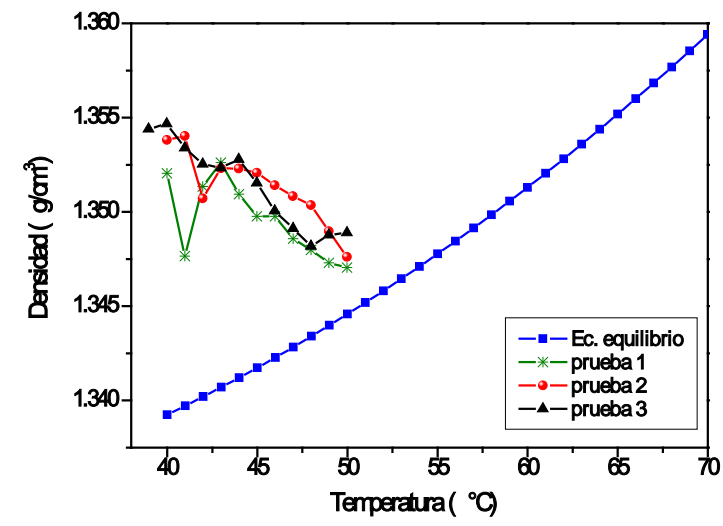

b)

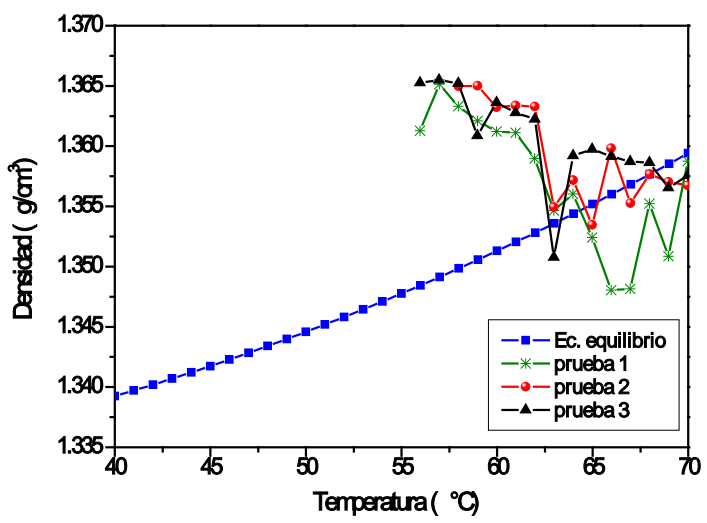

d)

Figura B.3 Resultados experimentales de la densidad con respecto a la temperatura. a) solución saturada a $40^{\circ} \mathrm{C}$, b) solución saturada a $50^{\circ} \mathrm{C}$, c) solución saturada $60^{\circ} \mathrm{C}$ y d) solución saturada a $70^{\circ} \mathrm{C}$.

\section{B.3 Resultados experimentales para la obtención de la DTC promedio y DTC más representativa}

En la Figura B.4 se muestra la DTC de los datos experimentales en \% volumen con una distribución de tipo log-normal para la muestra saturada a $70^{\circ} \mathrm{C}$. 


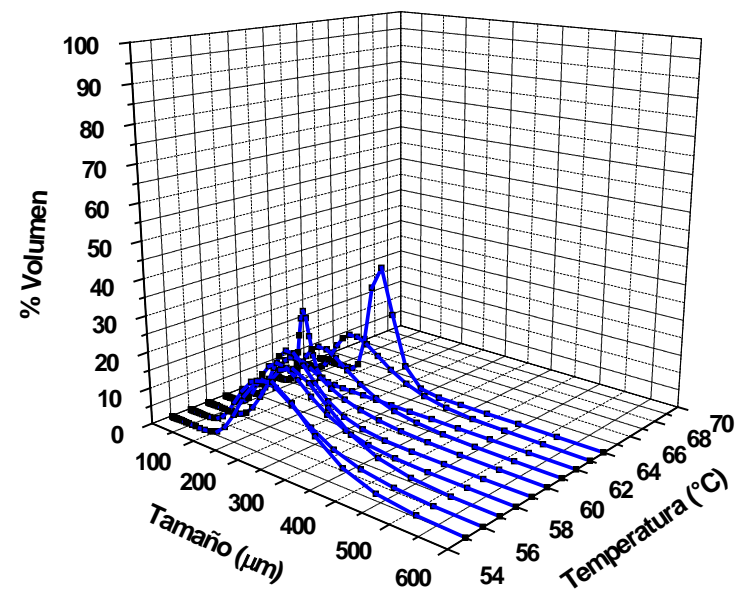

a)

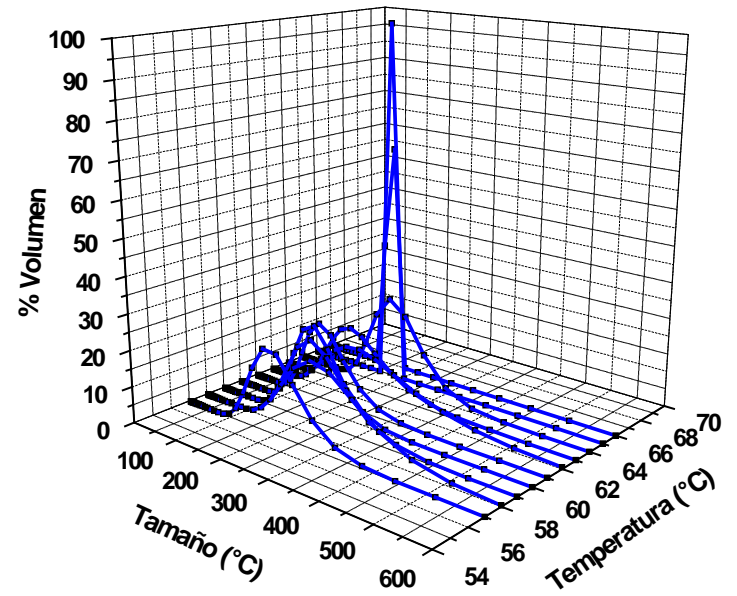

c)

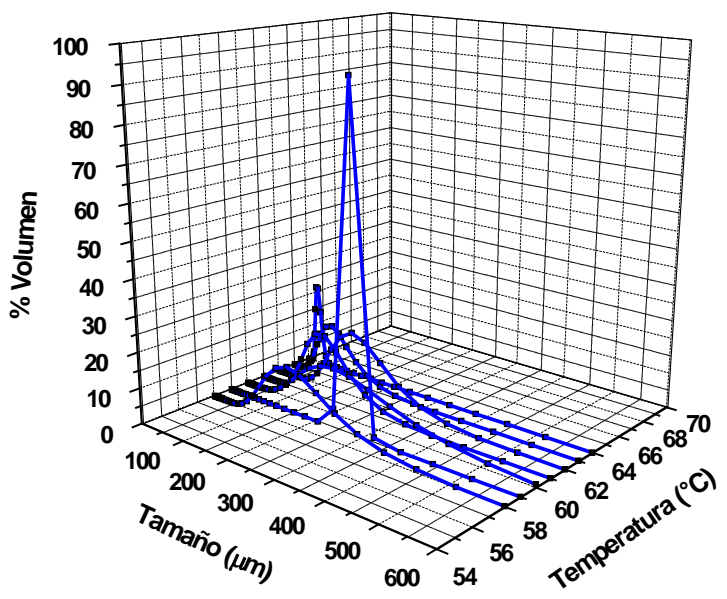

b)

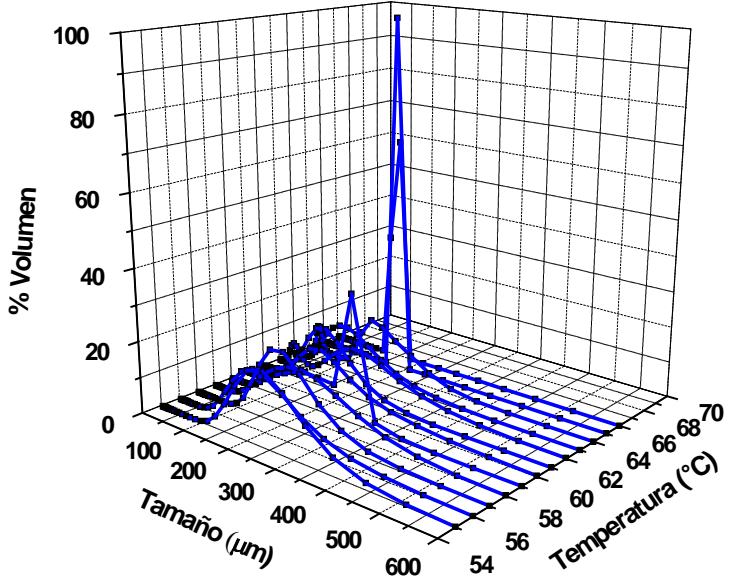

d)

Figura B.4 DTC en \% Volumen para una solución saturada a $70^{\circ} \mathrm{C}$. a) prueba 1 , b) replica 1, c) replica 2 y d) Promedios de las DTC.

La Figura B.4d es el promedio de las DTC de las tres corridas experimentales (Figura B.4a, B.4b y B.4c), se observa de la comparación entre el promedio y las corridas experimentales que la Figura B.4c (replica 2) es la que mejor denota un patrón en el crecimiento de cristales por lo que el análisis de la DTC y la localización de puntos críticos se referirá a esta corrida (Figura 2.4d del Capítulo 2). 
En la Figura B.5 se muestra la DTC de los datos experimentales en \% volumen con una distribución de tipo log-normal para la muestra saturada a $60{ }^{\circ} \mathrm{C}$. La Figura B.5d es el promedio de las DTC de las tres corridas experimentales (Figura B.5a, B.5b y B.5c), comparando la DTC promedio con las corridas experimentales se observa que la Figura B.5c (replica 2) es la que presenta un patrón similar en el crecimiento de cristales con respecto a la DTC promedio por lo que el análisis de la DTC y la localización de puntos críticos se referirá a esta corrida (Figura 2.4c del Capítulo 2).

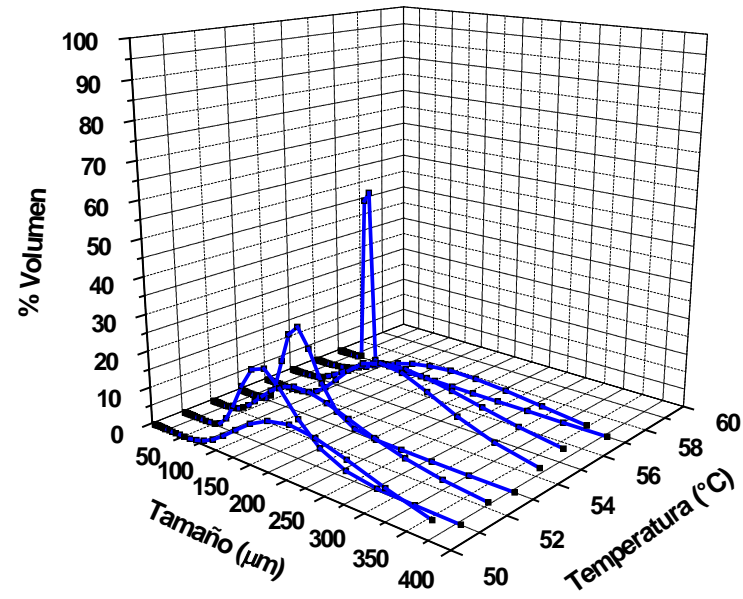

a)

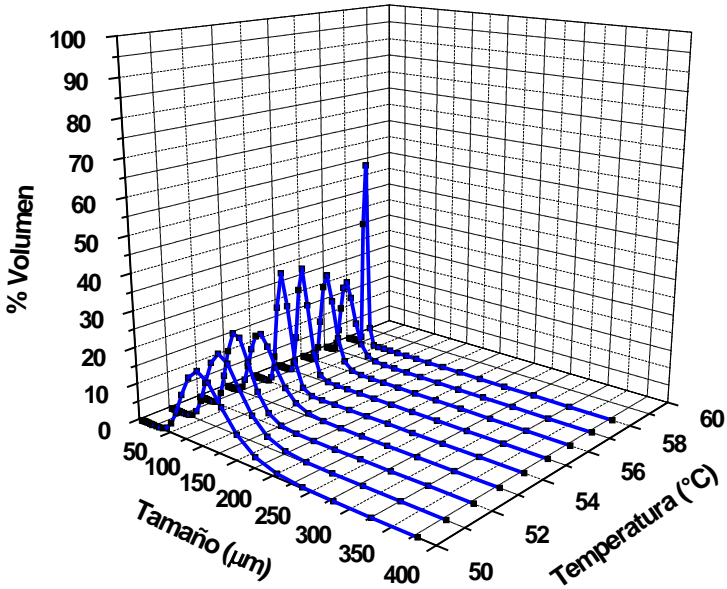

C)

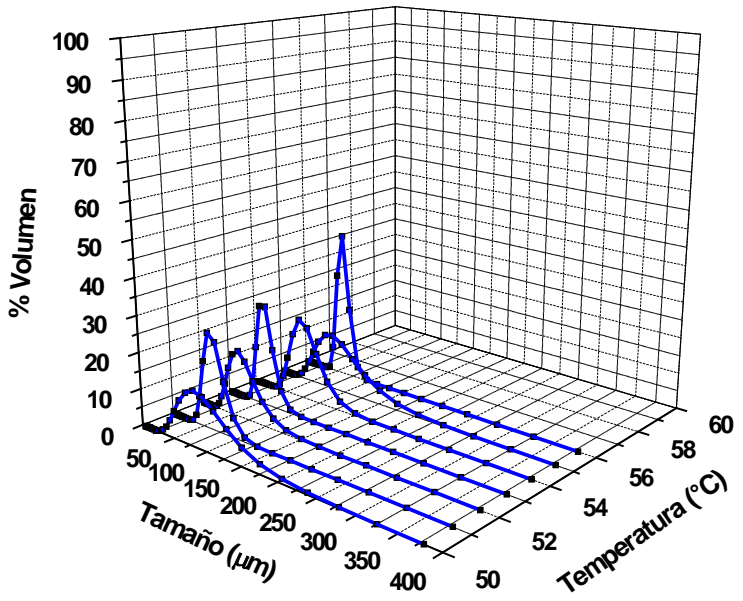

b)

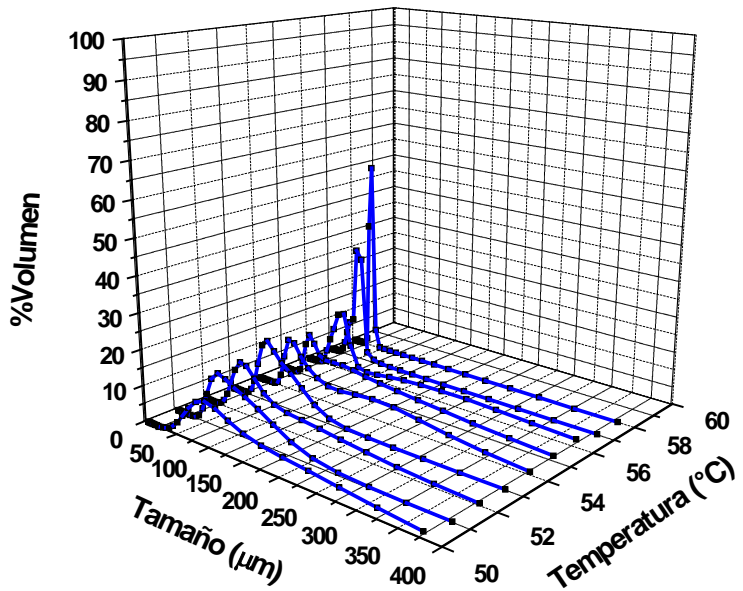

d)

Figura B.5 DTC en \% Volumen para una solución saturada a $60^{\circ} \mathrm{C}$. a) prueba 1 , b) replica 1, c) replica 2 y d) promedios de las DTC. 
En la Figura B.6 se muestra la DTC de los datos experimentales en \% volumen con una distribución de tipo log-normal para la muestra saturada a $50{ }^{\circ} \mathrm{C}$. La Figura B.6d es el promedio de las DTC de las tres corridas experimentales (Figura B.6a, B.6b y B.6c), comparando la DTC promedio con las corridas experimentales se observa que la Figura B.6a (prueba 1) es la que presenta un patrón similar en el crecimiento de cristales con respecto a la DTC promedio por lo que el análisis de la DTC y la localización de puntos críticos se referirá a esta corrida (Figura 2.4b del Capítulo 2).

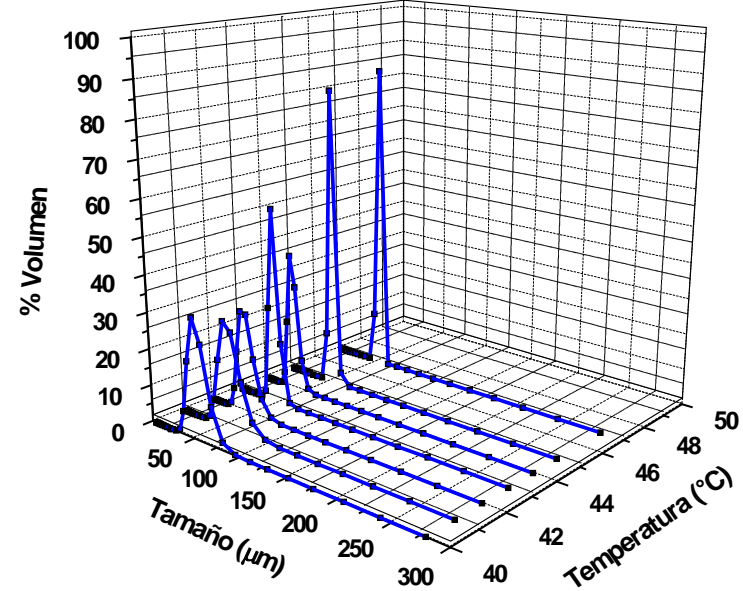

a)

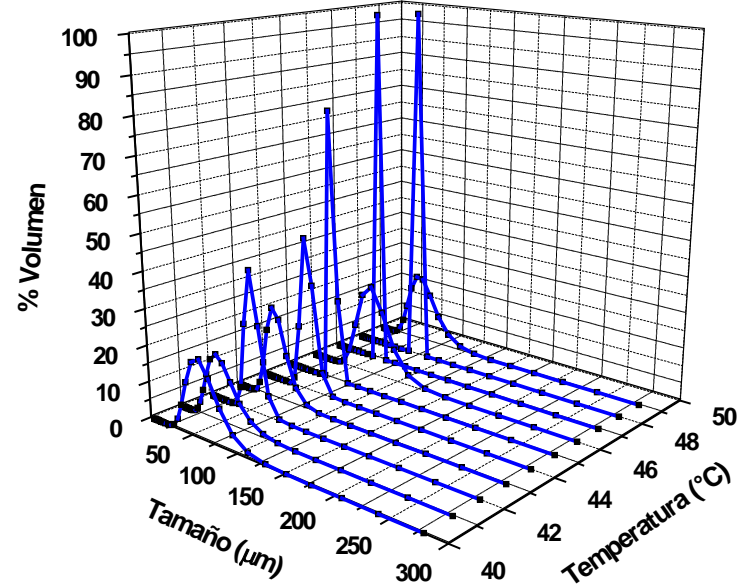

c)

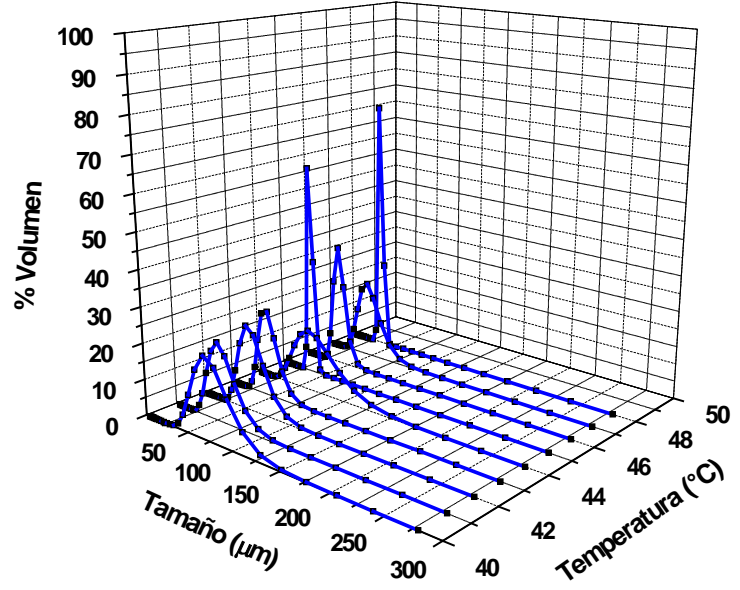

b)

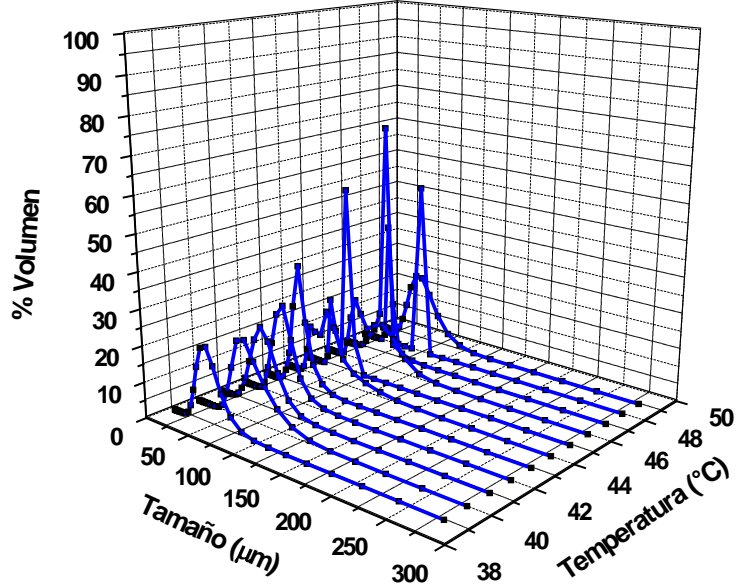

d)

Figura B.6 DTC en \% Volumen para una solución saturada a $50^{\circ} \mathrm{C}$. a) prueba 1, replica 1, c) replica 2 y d) promedios de las DTC. 
En la Figura B.7 se muestra la DTC de los datos experimentales en \% volumen con una distribución de tipo log-normal para la muestra saturada a $40{ }^{\circ} \mathrm{C}$. La Figura B.7d es el promedio de las DTC de las tres corridas experimentales (Figura B.7a, B.7b y B.7c), se observa de la comparación entre el promedio y las corridas experimentales que la Figura B.7b (replica 1) es la que mejor denota un patrón en el crecimiento de cristales por lo que el análisis de la DTC y la localización de puntos críticos se referirá a esta corrida (Figura 2.4a del Capítulo 2).
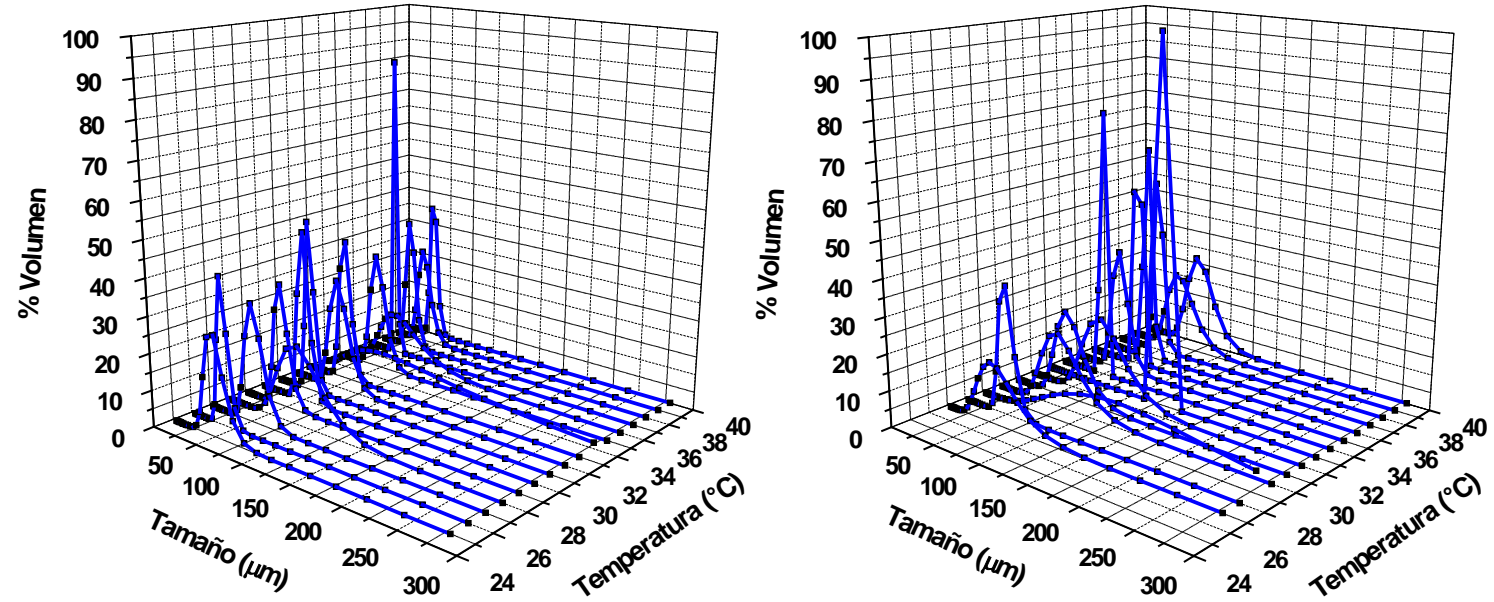

a)

b)
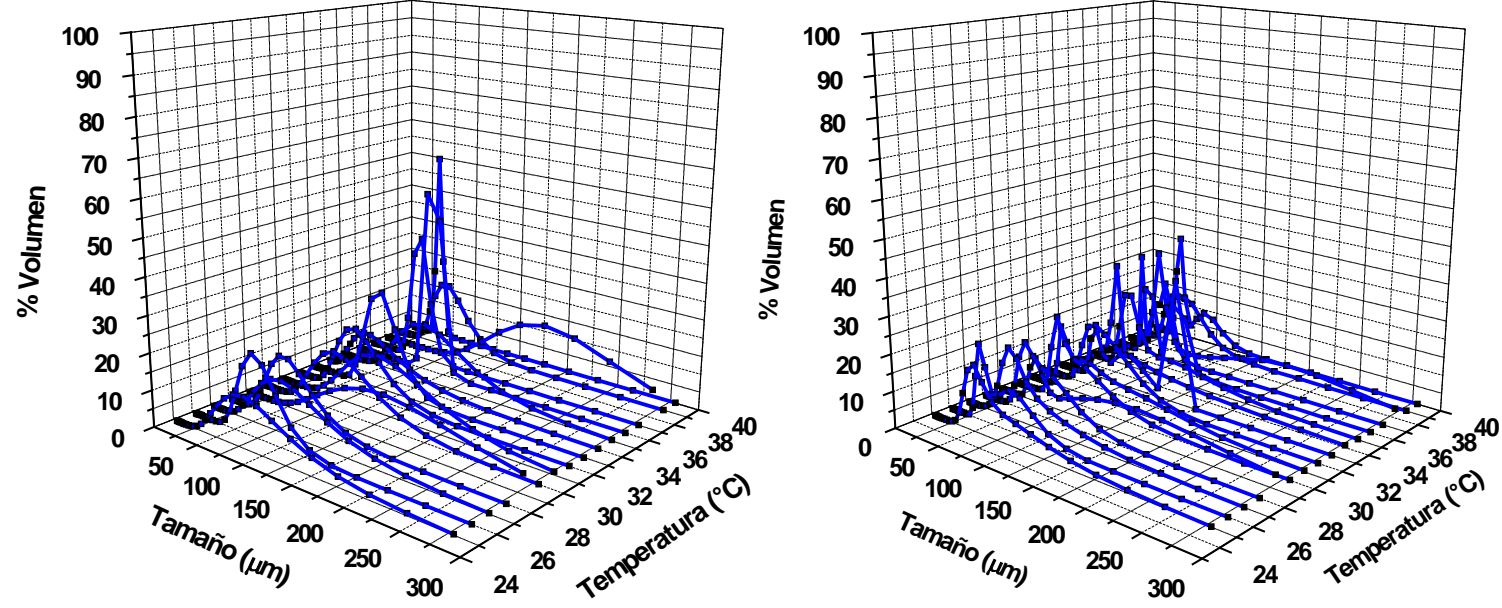

C)

d)

Figura B.7 DTC en \% Volumen para una solución saturada a $40^{\circ} \mathrm{C}$. a) prueba 1 , b) replica 1, c) replica 2 y d) promedios de las DTC. 
APÉNDICE C

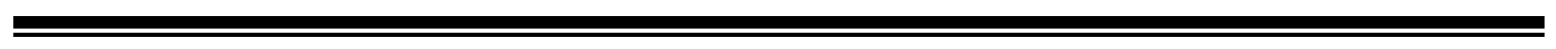




\section{C.1 Panel de control principal, pestañas secundarias y diagramas de bloques}

En la Figura C.1 se presenta el panel frontal o principal, en este panel se pueden observar de forma concisa todas las variables del proceso de mayor importancia. Si se desea tener un seguimiento más fino de la evolución de cierta variable se selecciona la pestaña correspondiente, para dar seguimiento a la evolución de la cristalización de forma detallada, dentro de las más importantes se encuentran: Concentración (Figura C.2), presión de vacío (Figura C.3) y resultados (Figura C.4).

En la Figura C.2 se presenta la pestaña donde se registran la temperatura interior y la concentración con respecto al tiempo, y un diagrama concentración-temperatura con los limites metaestables implementados para observa en todo tiempo la evolución de la sobresaturación.

En la Figura C.3 se presenta la pestaña donde se registra la presión de vacío con respecto al tiempo y la respuesta del controlador que abre o cierra la válvula proporcional indicada en porcentaje o voltaje. Las primeras dos primeras graficas de arriba abajo (columna izquierda) corresponden para la estrategia T-control y las últimas dos de arriba abajo (columna derecha) corresponden para la estrategia C-control.

En la Figura C.4 se presenta la pestaña para impresión de los datos experimentales (estados o variables) del sistema.

Otros estados o variables del sistema que se siguieron fueron: la presión de vapor en la caldera y la chaqueta, velocidad de agitación, recirculación de agua para enfriamiento de contacto directo para agotar sobresaturación, temperaturas del proceso (chaqueta, interior y equilibrio). De las figuras C.5-C.10 se presentan los códigos en el diagrama de bloques para los diferentes lazos de supervisión y control del proceso.

En la Figura C.5 se presenta el diagrama de bloques para la implementación de los perfiles de concentración y adquisición de la variable de concentración con respecto a la temperatura del sistema.

En la Figura C.6 se presenta el diagrama de bloques para la adquisición de datos del DMA-4500 vía puerto serial RS-232 (Basic Serial Write and Read.vi). 
En la Figura C.7 se presenta el diagrama de bloques para la manipulación y control de la velocidad de agitación, temperatura de equilibrio y setpoint de concentración-temperatura.

En la Figura C.8 se presenta el diagrama de bloques para la implementación de la estrategia C-Control retroalimentado PID.

En la Figura C.9 se presenta el diagrama de bloques para el control de la caldera y operación por enfriamiento.

En la Figura C.10 se presenta el diagrama de bloques para la impresión de datos experimentales en un archivo de hoja de cálculo para el análisis de los estados del sistema. 


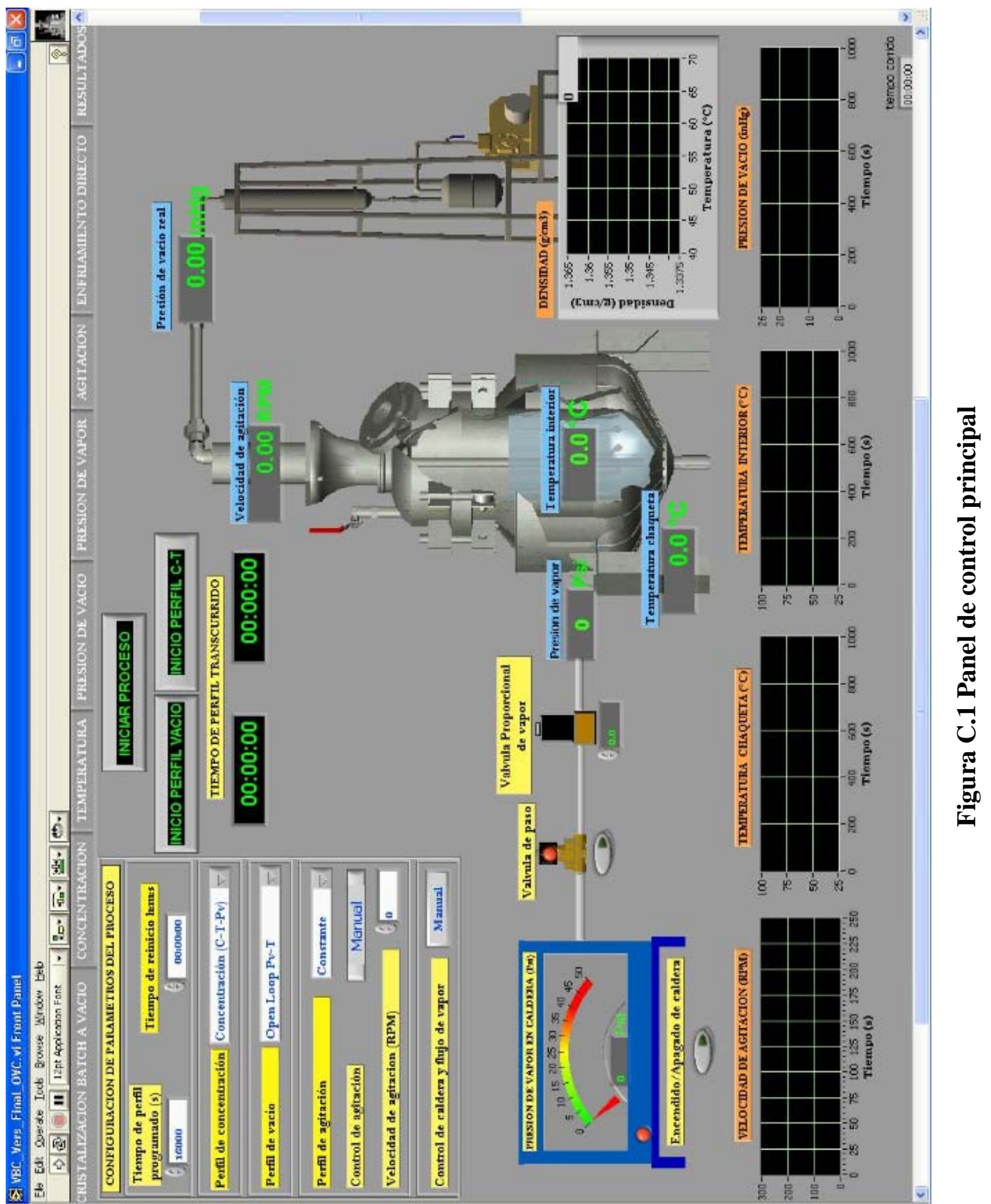




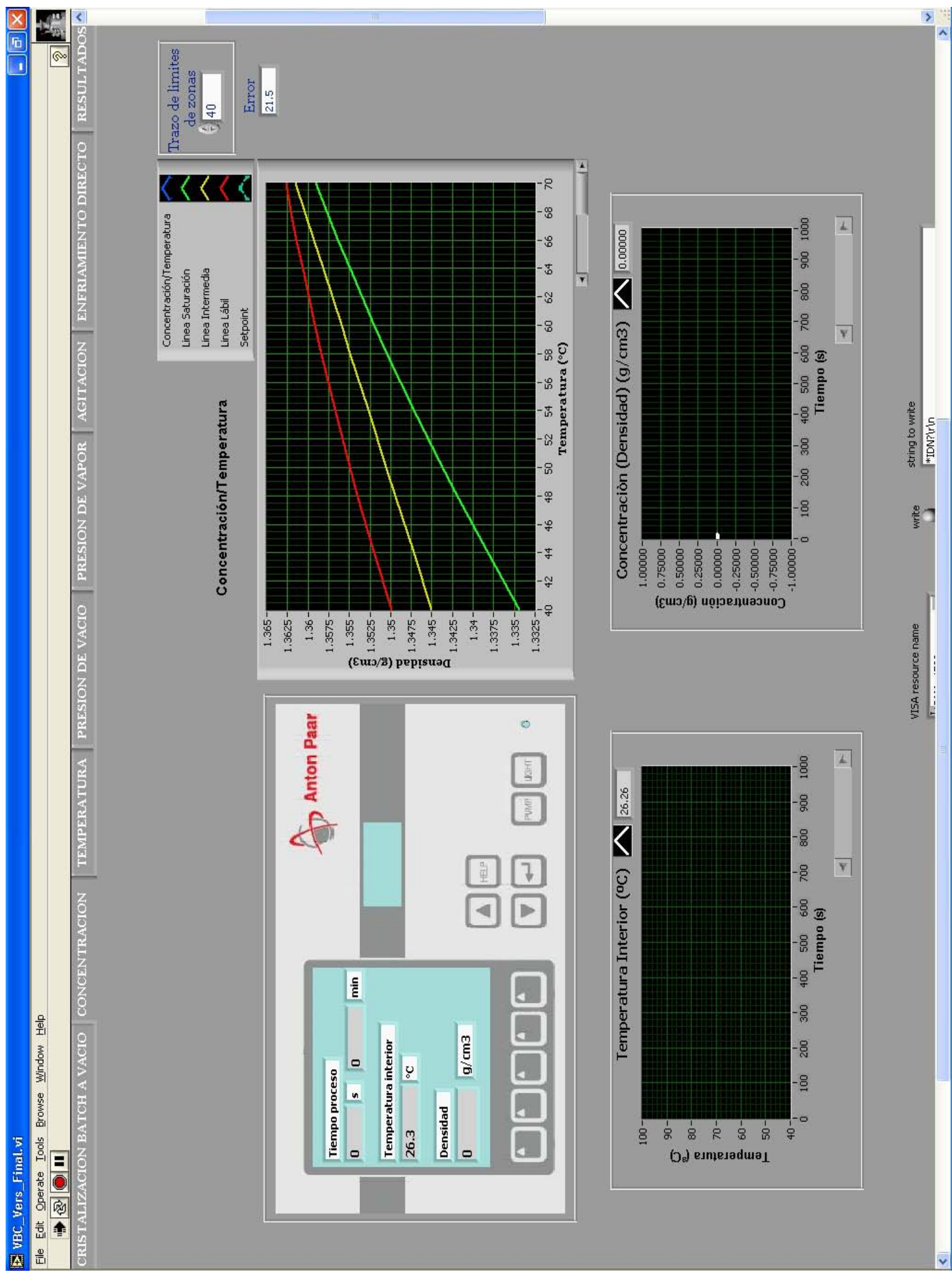

نี่ 


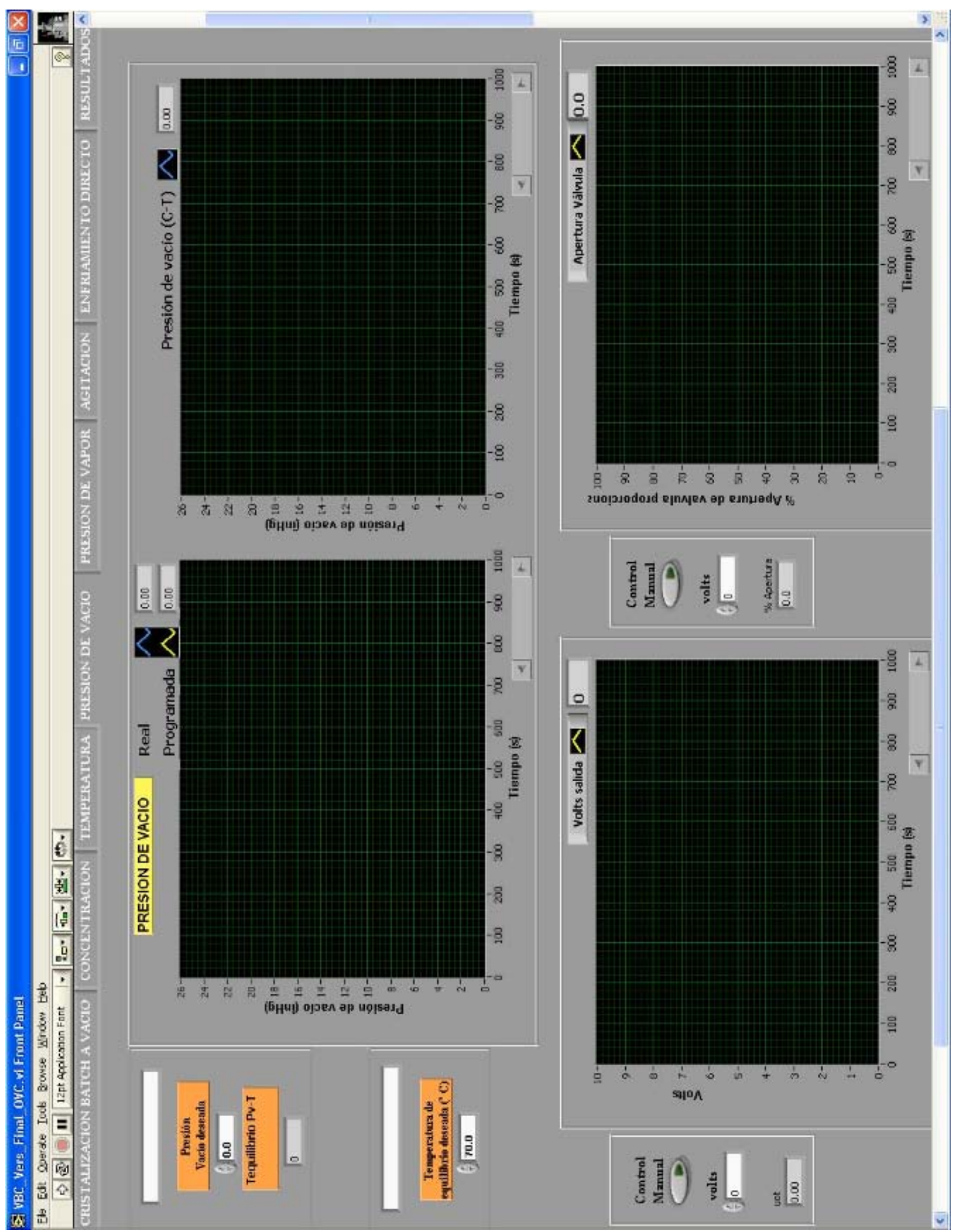

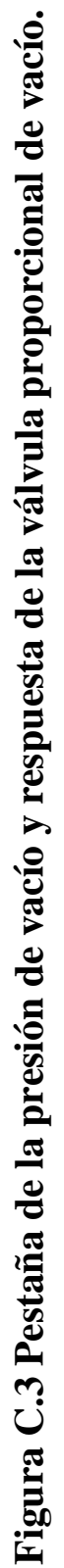




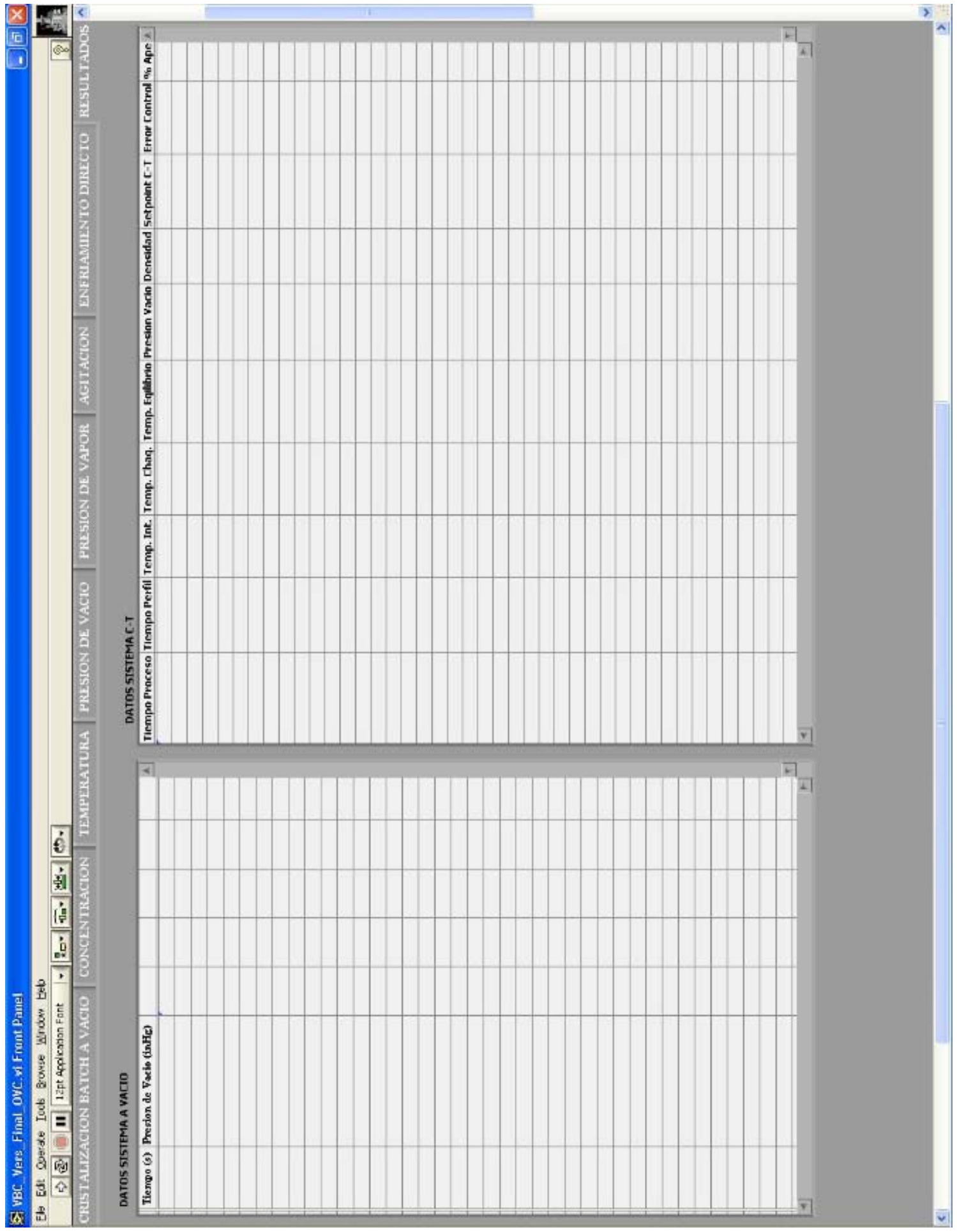

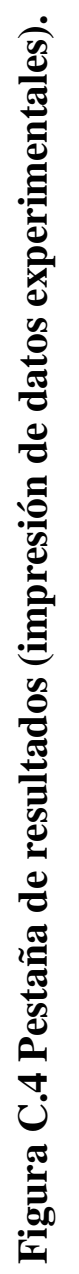




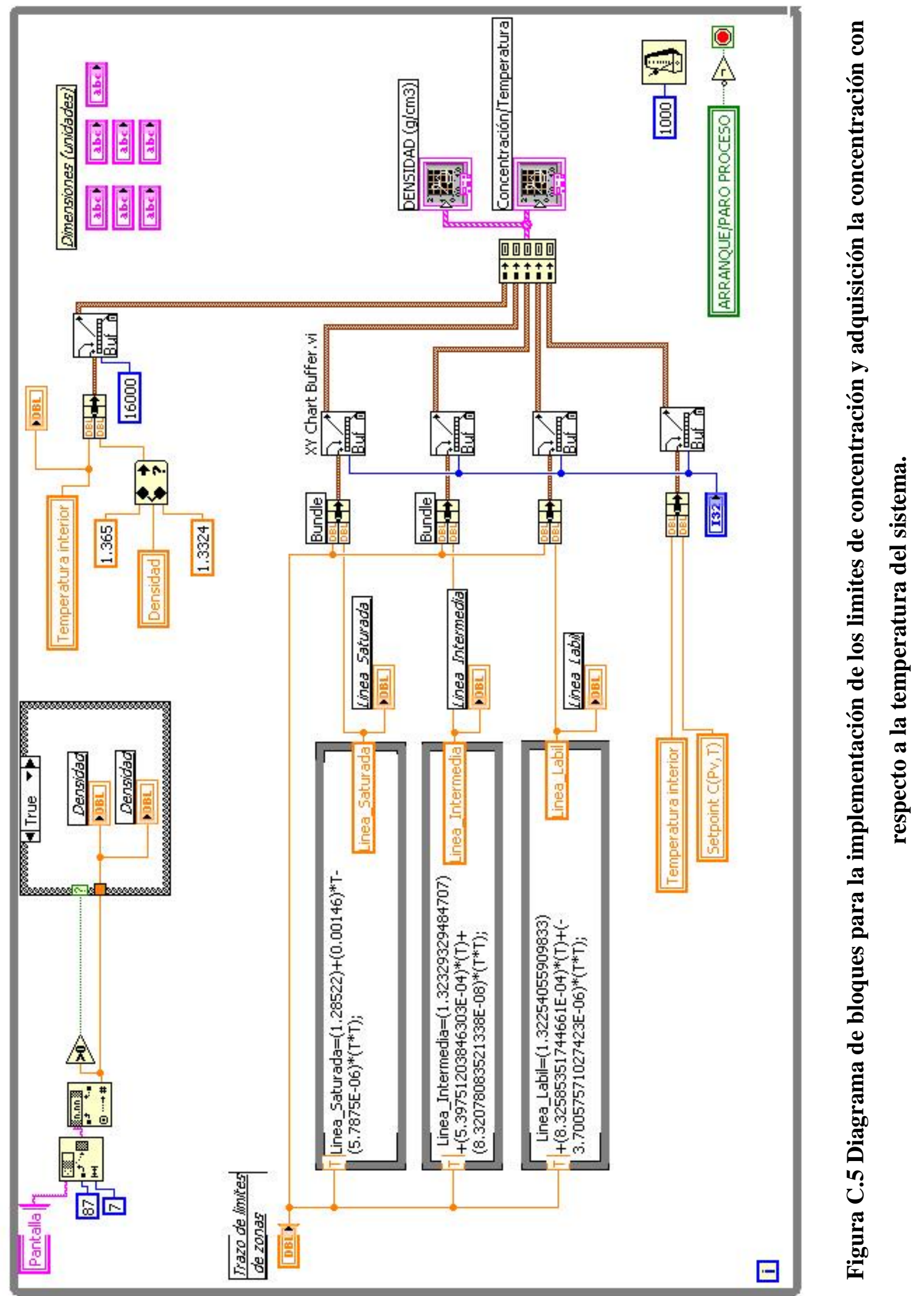




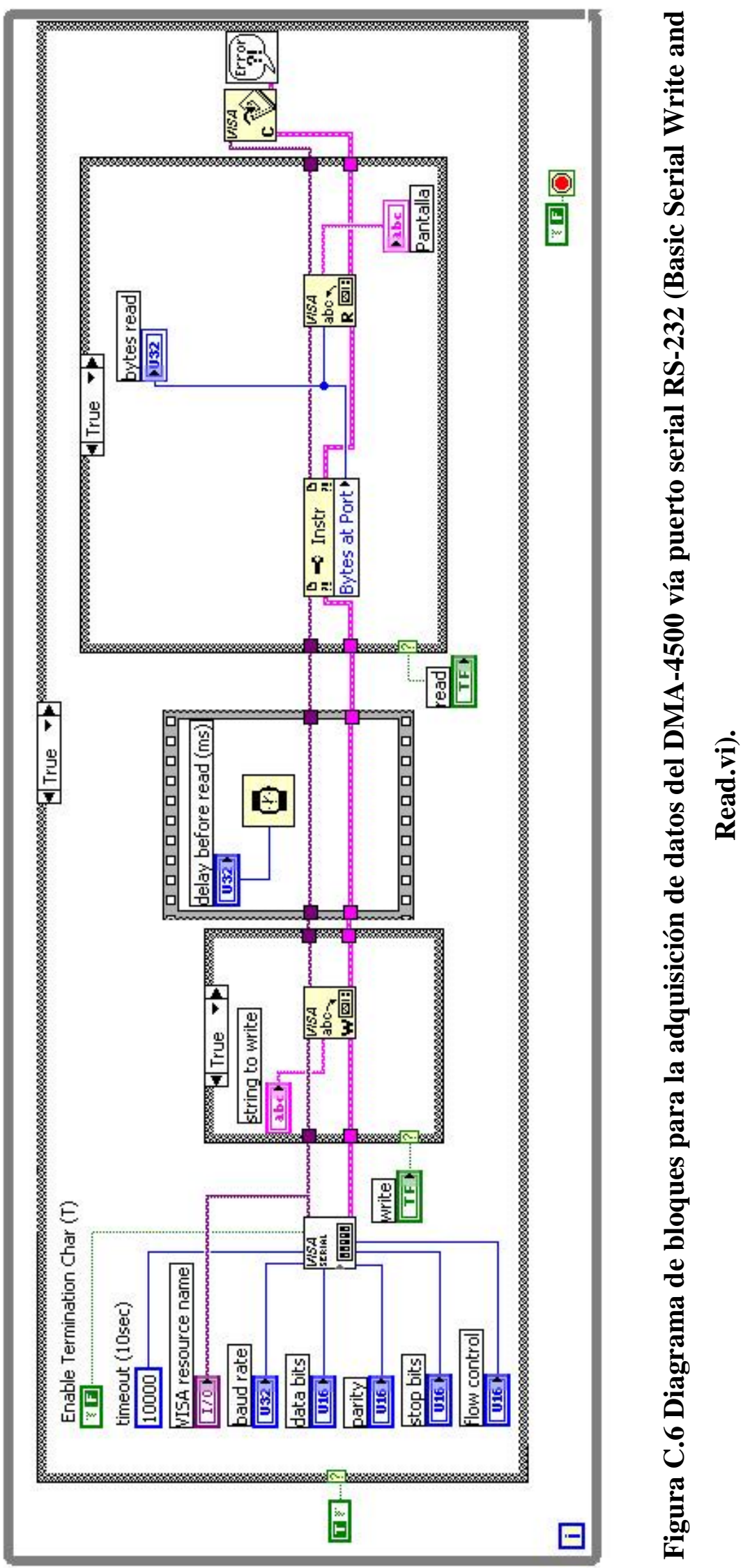




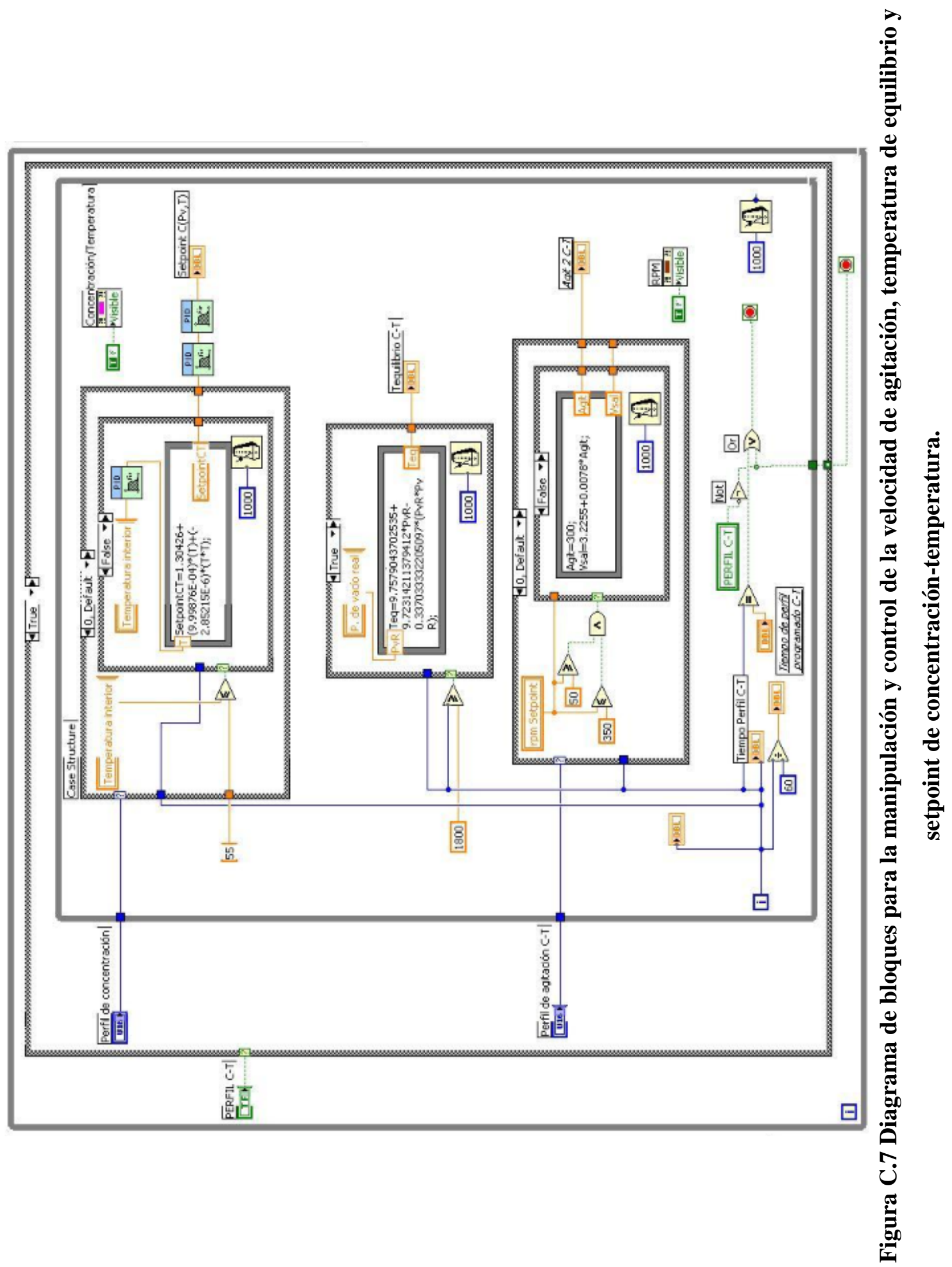




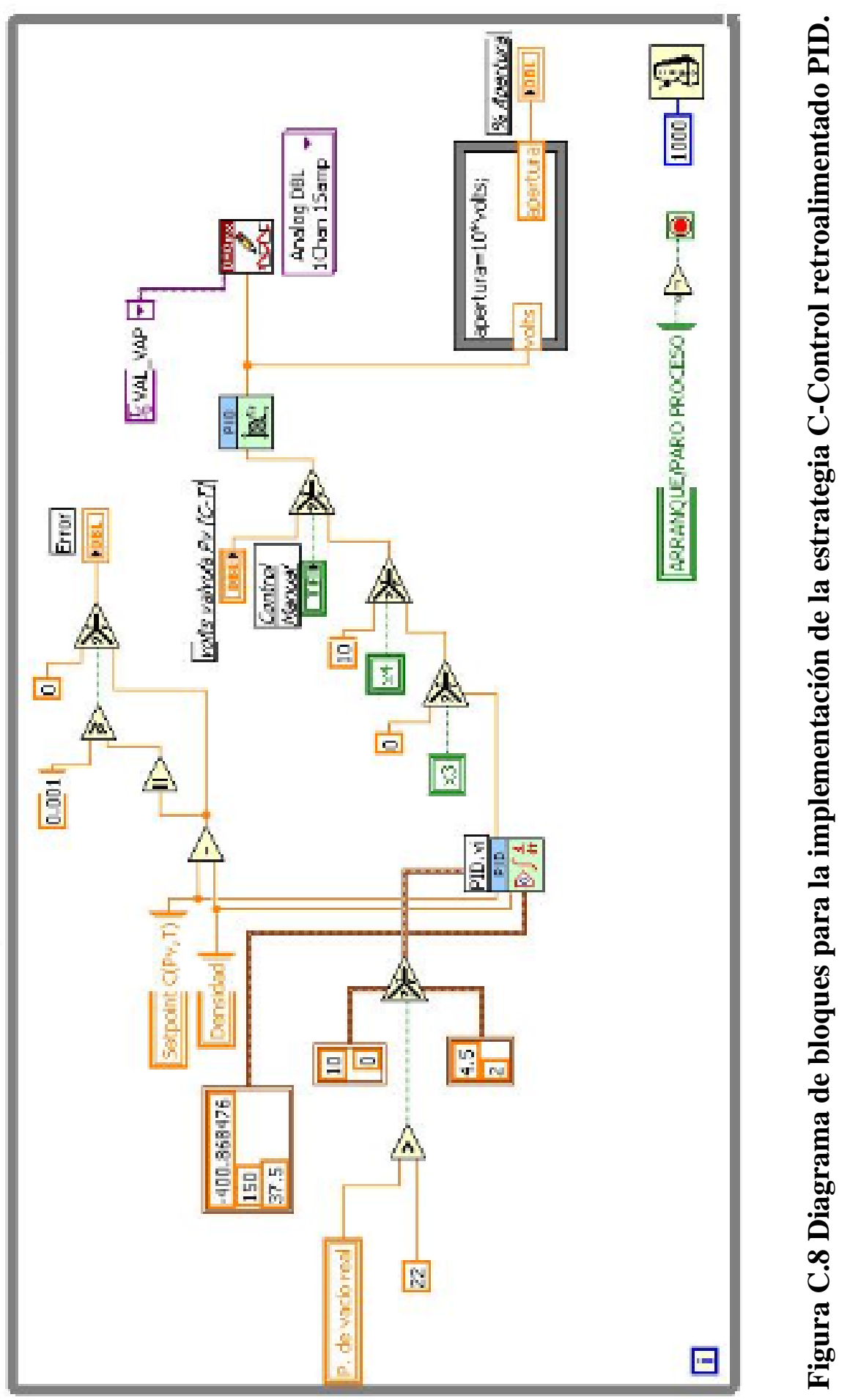




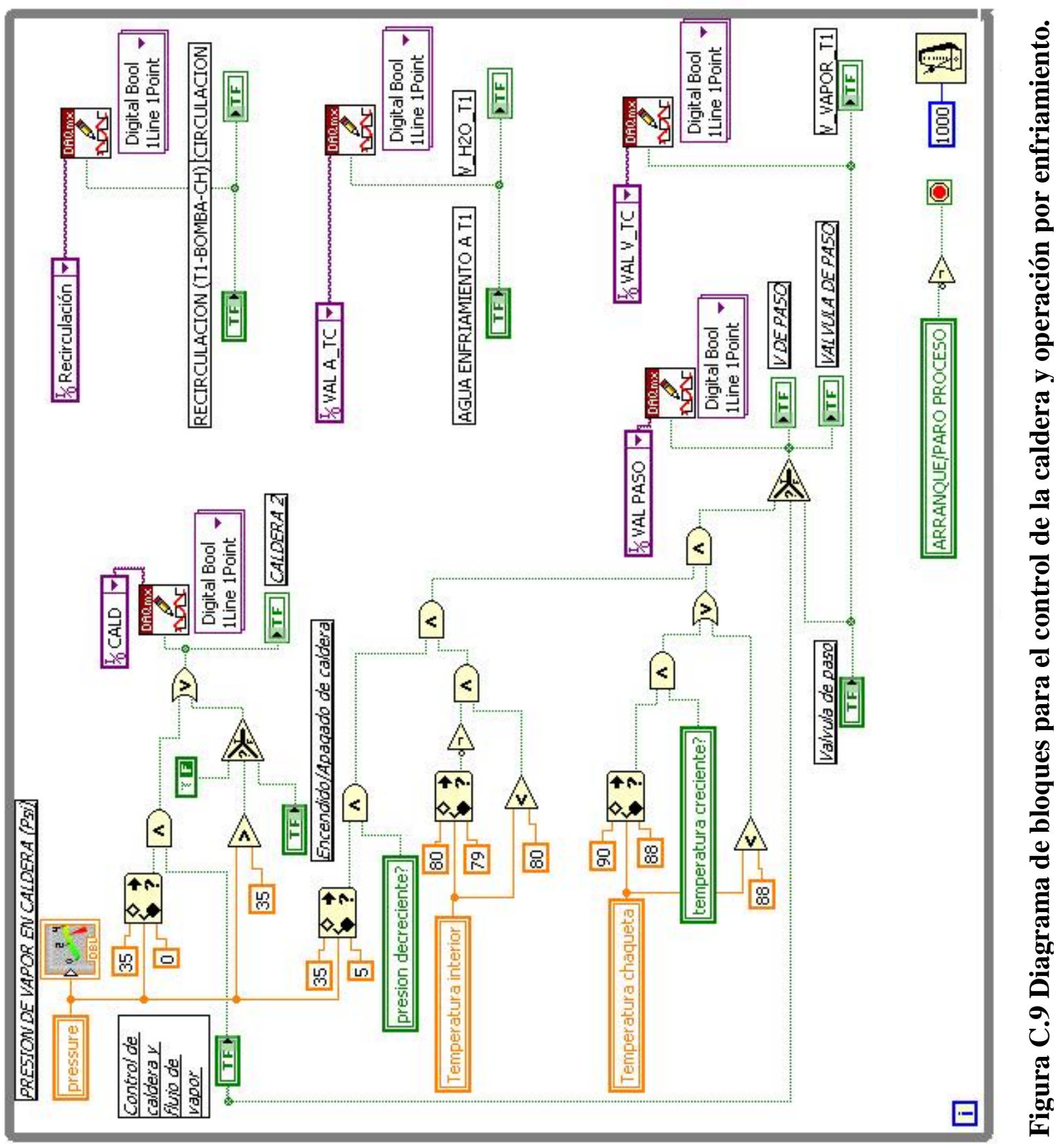




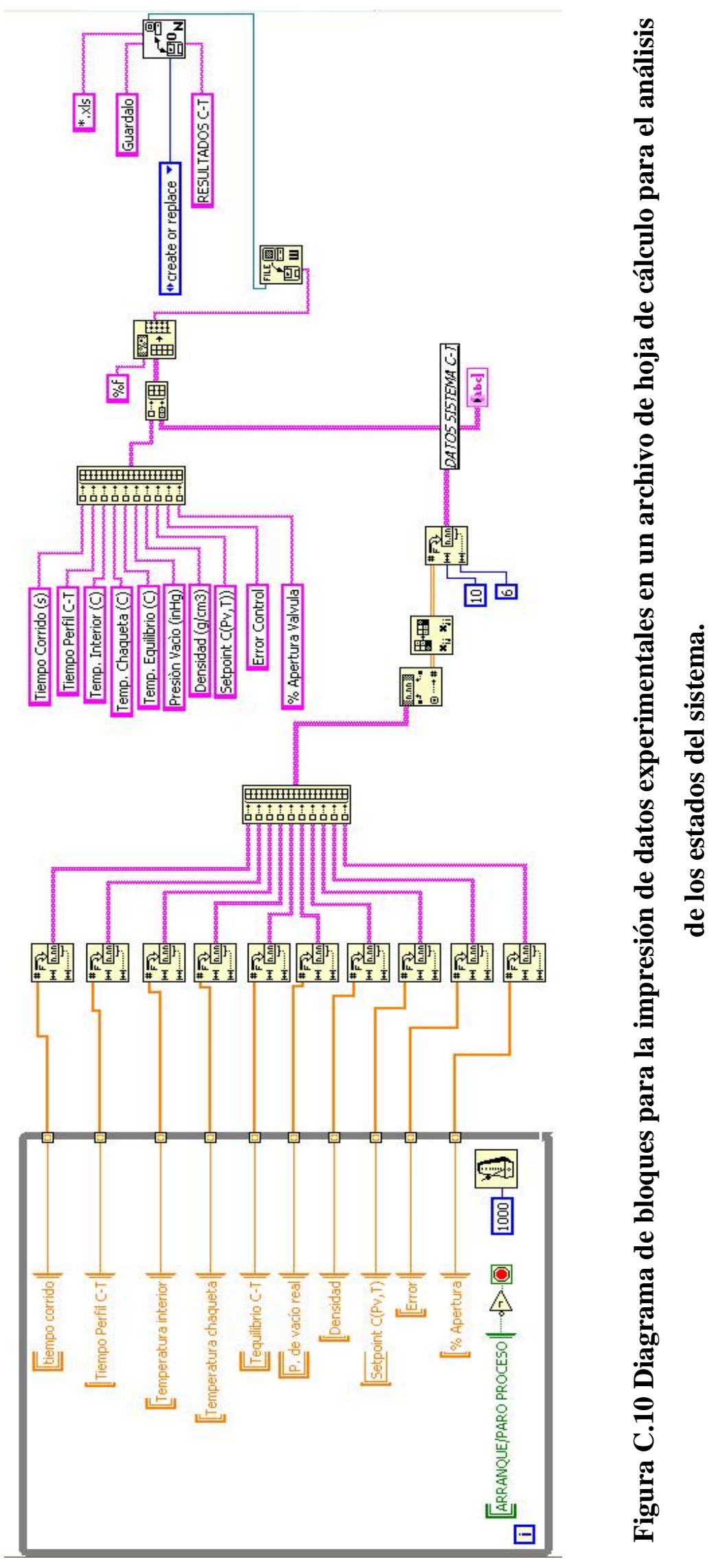




\section{C.2 Programación de válvulas proporcionales para un proceso con dinámica lenta}

La estrategia C-Control para el proceso de la cristalización de azúcar de caña requiere de manipular la presión de vacío en el interior y la presión de vapor en la chaqueta, para ello se cuenta con válvulas proporcionales para vacío y vapor de agua. La válvula proporcional para vacío de la marca Burkert, junto con su controlador electrónico digital de la misma compañía, tiene un cuerpo compuesto de acero inoxidable, posee un diámetro interno de $2 \mathrm{~mm}$ y la conexión es de 1/4" NPT, la corriente de operación es de 24 VCD, la temperatura de operación es de -10 a $90{ }^{\circ} \mathrm{C}$, en la Figura C.11a se presenta una imagen de la válvula proporcional de vacío instalada. La válvula proporcional para vapor de la marca Bürkert junto con su controlador electrónico digital de la misma compañía, tienen un cuerpo compuesto de latón y acero inoxidable, posee un diámetro interno de $8 \mathrm{~mm}$ y la conexión de sus puertos es de 1/2” NPT, la corriente de operación es de 24 VCD, la temperatura de operación es de -10 a $140{ }^{\circ} \mathrm{C}$, en la Figura C.11b se presenta una imagen de la válvula proporcional de vapor instalada.

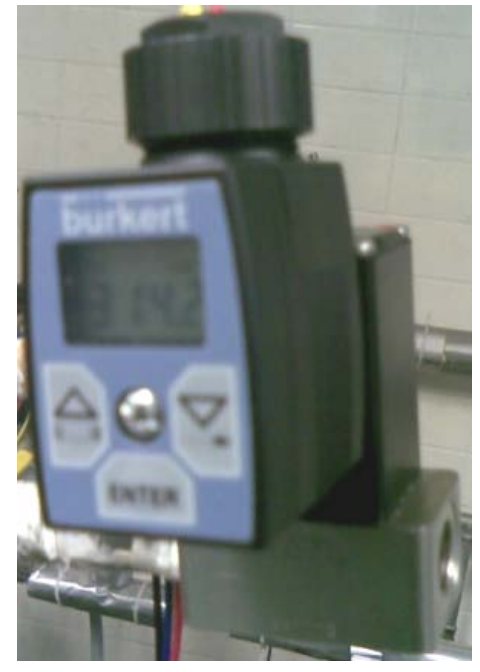

a)

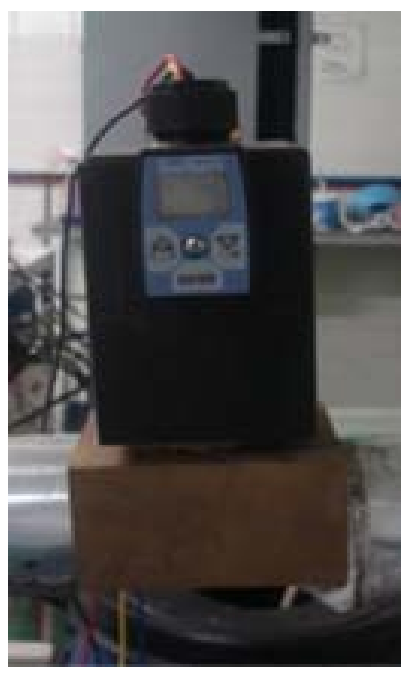

b)

Figura C.11 Válvulas proporcionales con controlador digital electrónico. a) para vacío y b) para vapor. 
Antes de realizar cualquier operación con las válvulas proporcionales, se configuraron los controladores electrónicos, siguiendo cada uno de los pasos que a continuación se mencionan (MA8605 operating instructions) considerando que la dinámica del proceso es lenta. Para llevar a cabo la selección y ajuste del tipo de válvula, tipo de señal de control, corriente de bobina mínima y máxima, entre otros a través del modo de configuración del controlador electrónico digital Burkert 8605 para ambos casos, se accede presionando la tecla enter por tres segundos (ver Figura C.12). El modo de configuración presenta nueve menús, los cuales se describen a continuación.

- En el menú input existen cuatro configuraciones seleccionables para el tipo de señal de entrada a utilizar que son de 0-5 VCD o 0-10 VCD, o bien de 0-20 mA o de 4-20 mA; la opción habilitada fue la de 0-10 VCD.

- El menú output contiene tres submenús.

- Uno de ellos es VALV que es donde se selecciona el tipo de válvula proporcional a utilizar.

- En el submenú VADJ se realiza la sintonía fina del rango de frecuencia aplicado por el controlador y sólo se modifica si la aplicación así lo requiere, ya que cuando se selecciona el tipo de válvula automáticamente se ajusta el valor de frecuencia asignado por el fabricante.

- En el submenú Adj es donde se ajusta la corriente de bobina mínima y máxima que soporta la válvula, y aunque ya existen valores por default, se debe asegurar que la corriente de bobina máxima sea menor ó igual a 400 mA y en el caso de la corriente mínima se debe ajustar a un valor en el que la válvula sometida a presión cierre por completo. Los valores introducidos fueros de 360 y 300 mA.

- El menú delay sirve para indicar el tiempo de la función rampa para atenuar cambios repentinos de la señal de entrada tanto creciente como decreciente, teniendo un intervalo de 0.1 a 10 s para el rango completo de 0 a $100 \%$ o 100 a $0 \%$ de la señal. Los valores elegidos fueron de 4.5 segundo para ambos rangos.

- El menú cut-off o de corte por punto cero se indica un porcentaje de 0 a $5 \%$ de la señal de entrada, el cual hace que se corte la alimentación a la válvula para que se asegure su cierre definitivo. El porcentaje elegido fue de $5 \%$. 


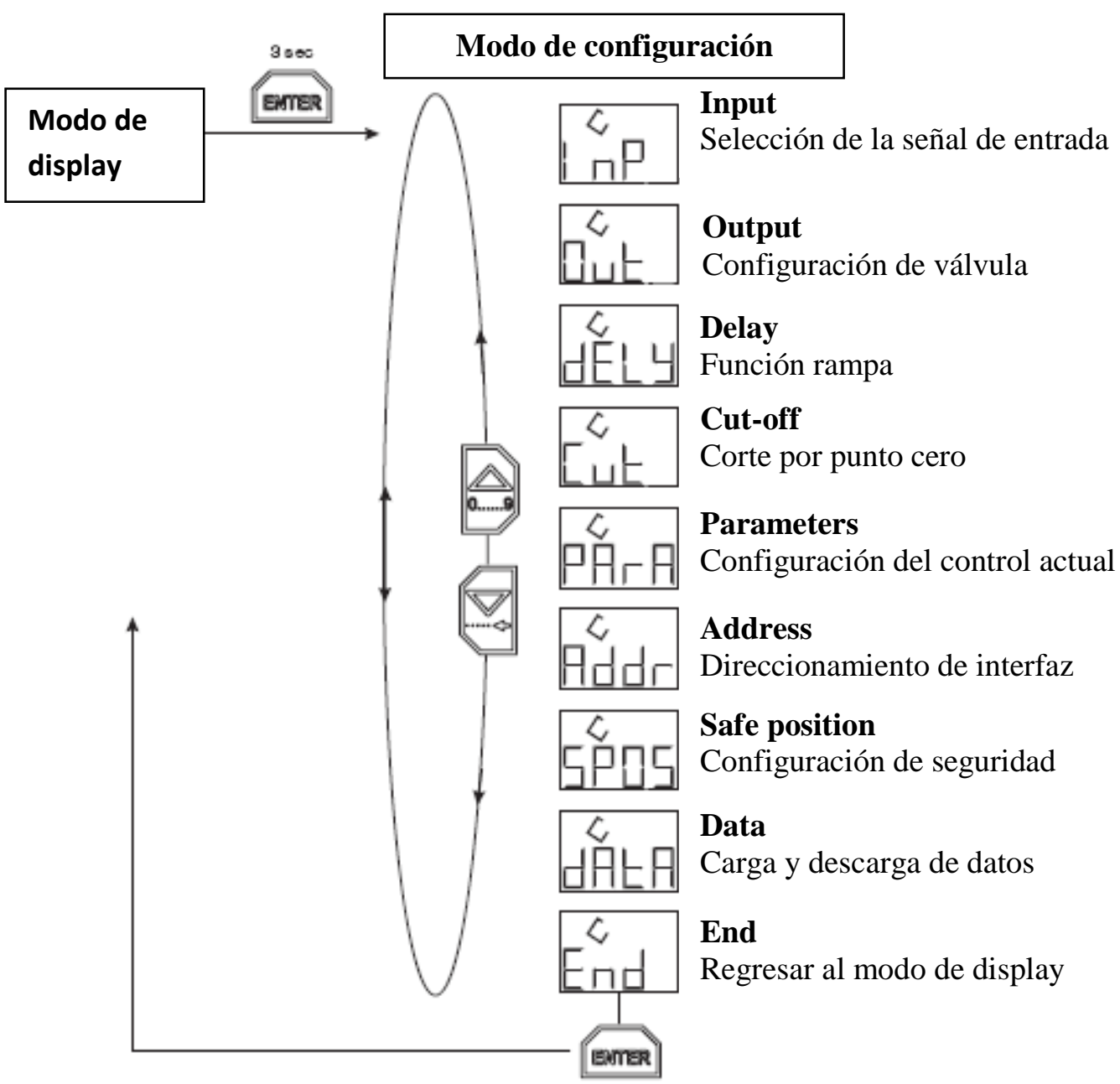

Figura C.12 Modo de configuración del controlador electrónico digital Burkert tipo 8605.

- La configuración de velocidad de respuesta del controlador se realiza en el menú parameters por medio de tres valores: SEt1 de respuesta lenta, SEt2 de respuesta intermedia y SEt3 de rápida respuesta. El valor seleccionado fue SEt1 para respuesta lenta.

- Los menús restantes data, safe position y address no son significativos para la correcta operación del controlador. 